\title{
Essays on migration and occupational choice
}

Citation for published version (APA):

Mahé, C. (2018). Essays on migration and occupational choice. [Doctoral Thesis, Maastricht University]. Datawyse / Universitaire Pers Maastricht. https://doi.org/10.26481/dis.20180622cm

Document status and date:

Published: 01/01/2018

DOI:

$10.26481 /$ dis. $20180622 \mathrm{~cm}$

Document Version:

Publisher's PDF, also known as Version of record

\section{Please check the document version of this publication:}

- A submitted manuscript is the version of the article upon submission and before peer-review. There can be important differences between the submitted version and the official published version of record.

People interested in the research are advised to contact the author for the final version of the publication, or visit the DOI to the publisher's website.

- The final author version and the galley proof are versions of the publication after peer review.

- The final published version features the final layout of the paper including the volume, issue and page numbers.

Link to publication

\footnotetext{
General rights rights.

- You may freely distribute the URL identifying the publication in the public portal. please follow below link for the End User Agreement:

www.umlib.nl/taverne-license

Take down policy

If you believe that this document breaches copyright please contact us at:

repository@maastrichtuniversity.nl

providing details and we will investigate your claim.
}

Copyright and moral rights for the publications made accessible in the public portal are retained by the authors and/or other copyright owners and it is a condition of accessing publications that users recognise and abide by the legal requirements associated with these

- Users may download and print one copy of any publication from the public portal for the purpose of private study or research.

- You may not further distribute the material or use it for any profit-making activity or commercial gain

If the publication is distributed under the terms of Article $25 \mathrm{fa}$ of the Dutch Copyright Act, indicated by the "Taverne" license above, 


\section{ESSAYS ON MigRATION and Occupational Choice}

Clotilde Mahé 
(C) Clotilde Mahé 2018

All rights reserved. No part of this publication may be reproduced, stored in a retrieval system, or transmitted in any form, or by any means, electronic, mechanical, photocopying, recording or otherwise, without the prior permission in writing, from the author.

Published by Datawyse / Universitaire Pers Maastricht

Florijnruwe 111-06

6218 CA Maastricht

Netherlands

ISBN 978-94-6295-930-9

Cover picture: M.C. Escher's "Day and Night" (C) 2018 The Escher Company-The Netherlands. All rights reserved. www.mcescher.com 


\section{Essays on Migration and Occupational Choice}

\section{DISSERTATION}

to obtain the degree of Doctor at the Maastricht University, on the authority of the Rector Magnificus Prof.dr. Rianne M. Letschert in accordance with the decision of the Board of Deans, to be defended in public on Friday, June 22, 2018, at 10.00 hours

by

Clotilde Mahé 


\section{Supervisors}

Prof.dr. Wim Naudé

Prof.dr. Melissa Siegel

\section{Assessment Committee}

Prof.dr. Andries de Grip (chair)

Prof.dr. Arnaud Dupuy, University of Luxembourg

Prof.dr. Didier Fouarge

Dr. Tobias Stöhr, Kiel Institute for the World Economy

Dr. Carlos Vargas-Silva, University of Oxford

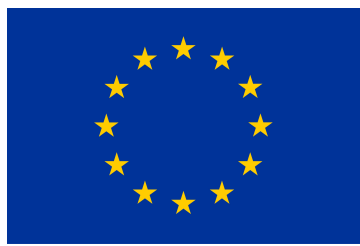

This research was funded by the European Union under the Marie Curie Initial Training Network (ITN) 'Transnational Migration, Citizenship and the Circulation of Rights and Responsibilities' (TRANSMIC) (FP7-PEOPLE-2013-ITN, Grant Agreement No. 608417). 
'Writing the truth being so difficult, I have in the interests of it allowed myself to go sometimes slightly beyond and slightly this side of it. All events and persons in this book are accidental and have something to do with the truth.'

—Robert Capa, Slightly Out of Focus 



\section{Acknowledgements}

Robert Capa wrote this disclaimer on the front jacket flap of the original edition of his memoirs of the Second World War as photojournalist. His words are a legacy of his sense of humour and humility. Putting into perspective his own courage, he did not claim reporting the truth about the front: he told the war through his lens.

Some more than 60 years later, and albeit in a very different context, his words convey well my feelings about completing this doctoral thesis. I initially thought pursuing doctoral studies would lead me to the truth. I have now come to realise that reaching - attempting to reach the truth is a long journey that requires self-deprecation.

First, I would like to acknowledge the financial support of the Europen Union under the Marie Curie Initial Training Network (ITN) 'Transnational Migration, Citizenship and the Circulation of Rights and Responsibilities' (TRANSMIC) (FP7-PEOPLE-2013-ITN, Grant Agreement No. 608417 ) in allowing me to conduct this research in ideal conditions.

This process has been shaped by multiple encouters. I would like to thank my supervisors, Wim Naudé and Melissa Siegel. Wim, I would like to thank you for your open-mindedness, your support and trusting my abilities. Each one of our meetings helped me stand back and move forwards at the same time. Melissa, I would like to thank you for your flexibility, your easy reach and your (communicable) willpower. You do make things happen!

I would like to thank the members of the assessment committee: Andries de Grip, Arnaud Dupuy, Didier Fouarge, Tobias Stöhr and Carlos Silva-Vargas. You pointed out inconsistencies in the first version of this manuscript, and helped me reflect on my work. Your comments substantially improved it.

Many others have contributed to this book, from Dauphine to Maastricht, passing by Nottingham and Bangkok, by giving some of their time to discuss ideas, and often taking the role of 'shadow' supervisors: Carlo Alcaraz, Daniel Alon, Simon Appleton, José Ernesto Amorós, Ragui Assaad, Elvis Avenyo, Britta Augsburg, Louis Boakye-Yiadom, Cheng Boon Ong, Tilman Brück, Raymundo Miguel Campos-Vázquez, Juan Carlos Castillo, Alison Cathles, Ali Chaudhary, Carmen Contreras, Neil Foster-McGregor, Caroline Krafft, Anda David, Amandine Desille, Markus Erberhadt, Damir Esenaliev, Maria Ferreira Sequeida, Tommaso Frattini, Hillel Fuld, Franziska Gassmann, Micheline Goedhuys, Pawel Kaczmarczyk, Mary Kaltenberg, Ayal Kimhi, Maty Konté, Edward Lazear, Maxime Legrand, Julien Loiseau, Katrin Marchand, Francesca Marchetta, Valentina Mazzucato, Aline Meysonnat, Pierre Mohnen, Janyl Moldalieva, Paula Nagler, Joanna Nestorowicz, Eleonora Nillesen, Nkechi Owoo, Zina Nimeh, Davina Osei, Merve Özer, Mueid Al Raee, Hillel Rapoport, Rebeca Raijman, Eran Razin, Joop 
de Ree, Alejandro Riaño, Isabel Ruiz Olaya, Clémentine Sadania, Simone Sasso, Shammai, Ronald Skeldon, Biagio Speciale, Nora Stel, Tamer Taha, Nyasha Tirivayi, Neda Trifkovic, Raquel Tsukada, Judit Vall Castello, Fernando Vargas Cuevas, Nardo de Vries, Jennifer Waidler and Elise Soazic Wang Sonne.

I would like to thank the participants of various events at which I presented my work: seminars of the MGSoG Migration and Development Research Group and of the UNU-MERIT Research Group I 'Economics of Innovation and Knowledge'; the 1st IZA/World Bank/NJD Conference on Jobs and Development (Colombia); the Workshop on Migration and the Labour Markets (Scotland); the AASLE Inaugural Conference (Australia); the 3rd IZA/DFID GLM-LIC Research Conference (USA); the Life in Kyrgyzstan Conference (Kyrgyzstan); the UNU-WIDER Development Conference on Migration and Mobility (Ghana); the 29th EALE Conference (Switzerland); the 1st UNU-MERIT Internal Conference (Netherlands); the TRANSMIC Final Conference (Italy); and the 2nd International Conference on Sustainable Development in Africa (Senegal).

Doing a $\mathrm{PhD}$ is said to be a lonely process; I was fortunate to do so at Maastricht University, in particular at UNU-MERIT/MGSoG, where its international community was of major support. Although only 'hosted', I have built friendships in each cohort. I had great office mates, always available to share ideas, doubts and frustrations, and who never complained of my sometimes smelly lunches: Shivani Achrekar, Bruhan Konda, Halefom Nigus, Pui Hang Wong (Hampton) and Yip Ching Yu (Annie). My paranymphen, Ester Serra Mingot and Elisa Calza. You have listened to me (and my never-ending ranting), and brought me comfort in many instances... Thank you! I would also like to thank Eveline in de Braek, Sueli Brodin, Mieke Drossaert, Mindel van de Laar, Herman Pijpers and Susan Roggen who helped me more than once in better understanding the MU and Dutch systems. I hope my never ending questions were not too much of a burden...

Last, I would like to thank my very closed ones. Maman, Mamie, Loïc et Hugo, merci d'avoir été à mes côtés pour discuter aussi bien recherche qu'angoisses... Merci de m'avoir toujours encouragée. Sergio... ¡Aquí estamos! Albeit how dissatisfied, 'French', I might be, I have enjoyed this process from beginning to end thanks to you. You have taught me that the comparison was within, not between; that I should do what makes me happy (even if I was bad at it); and that true grit and resilience, not inherent talent, were the road to success. You have developed my mind as a researcher as you have influenced my life. Gracias por todo lo que habemos vivido juntos hasta hoy.

Clotilde Mahé Maastricht, June 2018 


\section{Summary}

Motivated by the growing interest in migration as an economic and social phenomenon, this doctoral thesis explores several aspects of the relationship between migration and occupational choice. It consists of four self-contained essays, studying the effects of migration on occupational choice (Chapters 2-3), on the time allocation of those who stay behind (4) as well as the determinants of migration (5). Together, these Essays refine existing thinking on labour, migration and social health protection, by suggesting that, in low- and middle-income countries, migration contributes to a dynamic, lifetime continuum of occupations, and that publicly provided healthcare condition migration, directly or indirectly, through effects on the labour force.

Chapter 2 uses data from Egypt to show that migration influences the formation of a balanced skill profile conducive to entrepreneurship by facilitating the accumulation of skills across sectors and occupations. With data from Kyrgyzstan, findings of Chapter 3 suggest that, while return migration increases the probability to enter into self-employment, returnees' motives to do so are based on necessity rather than opportunity, when market-supporting institutions are lacking. As a result, self-employment tends to be more of a temporary choice, akin to a 'parking lot' - they are more likely to exit from self-employment in subsequent periods than non-migrants, and to move to employed occupations. Turning to those who stay behind, Chapter 4 reveals that the return of migrant household members alters the time allocation of non-migrating household members, spouses, even once migration is complete. Last, Chapter 5 uses a natural experiment in Mexico, the introduction of publicly provided healthcare, to stress that financial and care constraints prevent households from sending migrants. By freeing up working-age household members' time and strengthening household (economic) resilience in the face of health shocks, non-contributory health insurance alleviates financial and time constraints, and increases internal migration.

The findings of this thesis thus contribute to the academic and policy debates by suggesting that (i) migrating can be seen as a process shaping entrepreneurial abilities; (ii) the potential for return migration to stimulate entrepreneurship in origin communities should not be overestimated, as it might not lead to sustaining a career in self-employment in the absence of market-supporting institutions; (iii) the necessity to account for (possibly) time depriving effects on women induced by their husbands temporarily migrating, even once migration is complete; and that (iv) social health protection can have multiplier effects on economic development through migration by enabling labour force detachment of working-age members in affiliated households. 



\section{Contents}

$\begin{array}{ll}\text { Acknowledgements } & \text { vii }\end{array}$

Summary $\quad$ ix

1 Introduction 1

1.1 Migration and occupational choice upon return . . . . . . . . . . . . . 2

1.2 Migration and female spouses who stay behind $\ldots \ldots \ldots \ldots$

1.3 Migration and publicly provided healthcare . . . . . . . . . . . 8

2 Can migrating develop entrepreneurial abilities? 13

2.1 Introduction . . . . . . . . . . . . . . . . . . . . . 13

2.2 Conceptual background . . . . . . . . . . . . . . . . 15

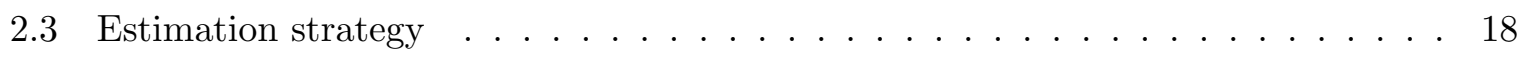

2.4 Data . . . . . . . . . . . . . . . . . . . . . 23

2.4 .1 Data source . . . . . . . . . . . . . . . . . 23

2.4 .2 Descriptive statistics . . . . . . . . . . . . . . . . 23

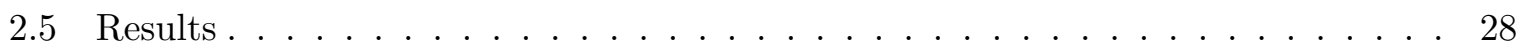

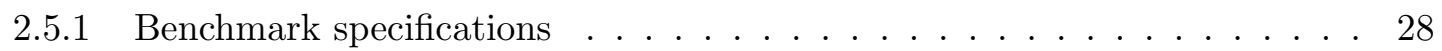

2.5.2 Robustness checks . . . . . . . . . . . . . . . . 31

2.5.3 Heterogeneity . . . . . . . . . . . . . . . . . . . . 32

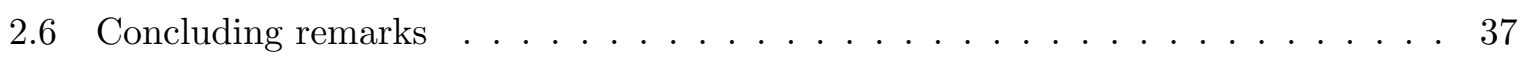

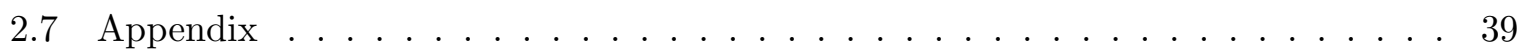

3 Does migration disrupt self-employment trajectories?

3.1 Introduction . . . . . . . . . . . . . . . . . . . . 45

3.2 Relevant literature . . . . . . . . . . . . . . . . . . 47

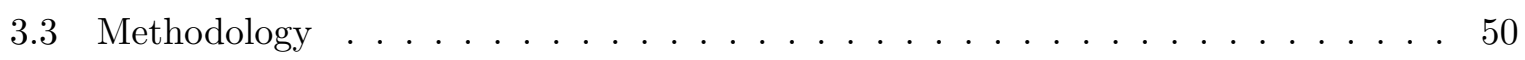

3.3 .1 Estimation strategy $\ldots \ldots \ldots \ldots \ldots \ldots$

3.3 .2 Data source . . . . . . . . . . . . . . . . . . . . 54

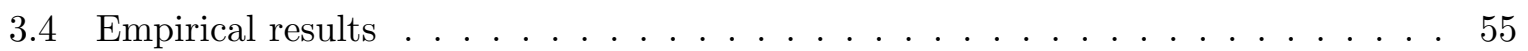

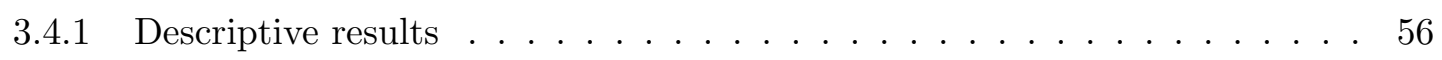

3.4.2 Benchmark regression results . . . . . . . . . . . . . . 60

3.4 .3 Robustness checks . . . . . . . . . . . . . . . 61

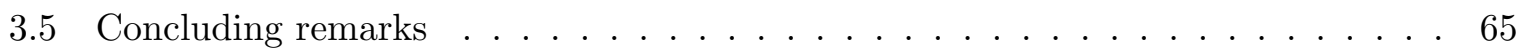

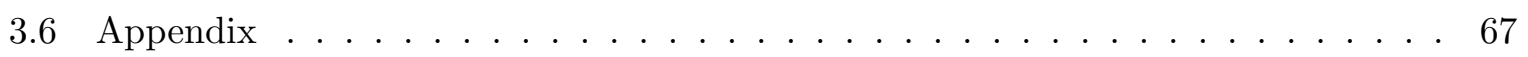


4 Does living with return migrants affect time use? $\quad 89$

4.1 Introduction . . . . . . . . . . . . . . . . . . . . . . 89

4.2 Conceptual background . . . . . . . . . . . . . . . . . 91

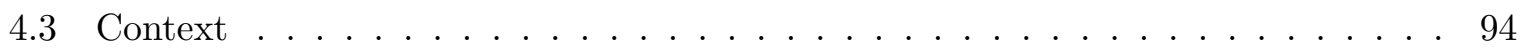

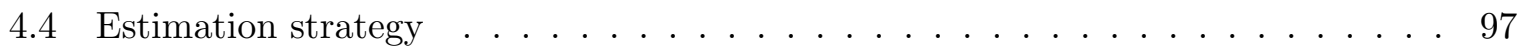

4.4 .1 Data source . . . . . . . . . . . . . . . . . . . . . 102

4.4 Descriptive statistics . . . . . . . . . . . . . . . . . 103

4.5 Results . . . . . . . . . . . . . . . . . . 106

4.5.1 Benchmark specifications . . . . . . . . . . . . . . 106

4.5.2 Heterogenous effects . . . . . . . . . . . . . . . . . . 108

4.6 Concluding remarks . . . . . . . . . . . . . . . . . . . . . . . . 114

4.7 Appendix . . . . . . . . . . . . . . . . . . . 118

5 Does publicly provided healthcare affect migration? $\quad 121$

5.1 Introduction . . . . . . . . . . . . . . . . . . . . . 121

5.2 Publicly provided healthcare and migration . . . . . . . . . . . . 123

5.3 Mexico's health insurance system . . . . . . . . . . . . . . . . 126

5.4 Data and empirical strategy . . . . . . . . . . . . . . . . . . 128

5.4 .1 Empirical strategy . . . . . . . . . . . . . . . . . . . 128

$5.4 .2 \quad$ Data . . . . . . . . . . . . . . . . . . . . . . 129

5.5 Results . . . . . . . . . . . . . . . . . . . 138

5.5 .1 Benchmark results . . . . . . . . . . . . . . . . 138

5.5 .2 Robustness checks . . . . . . . . . . . . . . . . . . . . . 140

5.5 .3 Heterogenous effects . . . . . . . . . . . . . . . . . . . 141

5.5 .4 Investigating potential mechanisms . . . . . . . . . . . . . . . 144

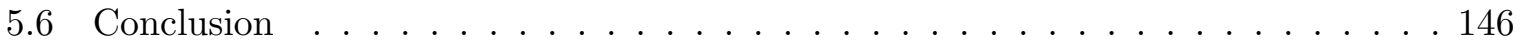

6 Conclusion $\quad 149$

6.1 Main findings . . . . . . . . . . . . . . . . . . . . . . . 149

6.2 Policy implications . . . . . . . . . . . . . . . . . . . . . 150

6.3 Suggestions for future research . . . . . . . . . . . . . . 152

$\begin{array}{ll}\text { Bibliography } & 155\end{array}$

$\begin{array}{ll}\text { Addendum on valorization } & 165\end{array}$

$\begin{array}{ll}\text { About the author } & 169\end{array}$

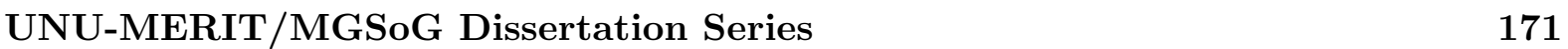




\section{List of Tables}

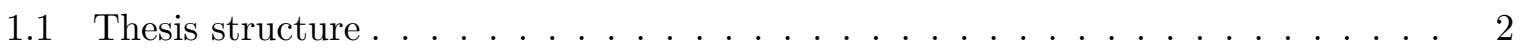

2.1 Descriptive statistics of estimation sample . . . . . . . . . . . . 25

2.2 Benchmark coefficient estimates . . . . . . . . . . . . . . . . . . 29

2.3 Robustness checks . . . . . . . . . . . . . . . . . . . 33

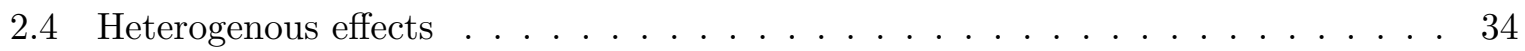

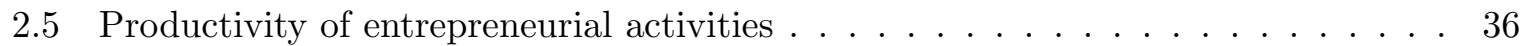

A1 Sensitivity to exclusion restriction definition in equation (1) . . . . . . . . 39

A2 Average marginal effects of oil price on the probability of return migration, holding migration distance constant at different values . . . . . . . . . . . . . . 40

A3 Occupational transition of returnees, before and after migration (\%) . . . . . 41

A4 Sectoral transition of returnees, before and after migration $(\%) \ldots \ldots \ldots$

A5 Occupational transition of returnees self-employed at the time of the survey, before and after migration $(\%) \ldots \ldots \ldots \ldots$. . . . . . . . . . . . . 42

A6 Sectoral transition of returnees self-employed at the time of the survey, before and after migration $(\%) \ldots \ldots \ldots \ldots$. . . . . . . . . . . . . . . . . 42

A7 Distances between capitals of governorates of birth and capitals of estimation sample destination countries in kilometres . . . . . . . . . . . . . . . . . . 43

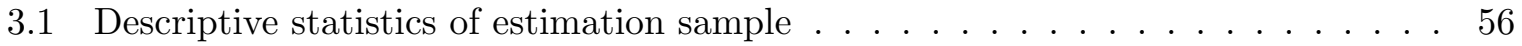

3.2 Transition probabilities between occupations of all respondents . . . . . . . 58

3.3 Transition probabilities between occupations of returnees . . . . . . . . . . 59

3.4 Transition probabilities between occupations of non-returnees . . . . . . . . 59

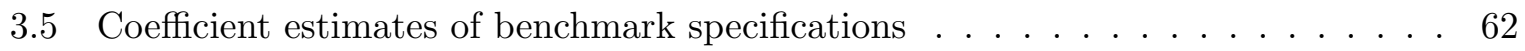

B1 Investigating panel attrition . . . . . . . . . . . . . . . 67

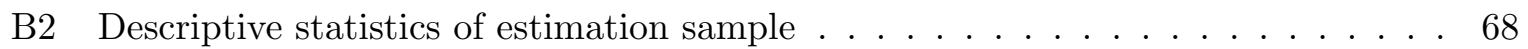

B3 Descriptive statistics of estimation sample by employment status . . . . . . . . 69

B4 Descriptive statistics of self-employed . . . . . . . . . . . . . 70

B5 Descriptive statistics of estimation sample by migration status . . . . . . . . 71

B6 Income sources and expenditures by household migration status . . . . . . . . . 72

B7 Coefficient estimates of benchmark specifications . . . . . . . . . . . 73

B8 Marginal effects of benchmark coefficient estimates . . . . . . . . . . . 75

B9 Coefficient estimates of benchmark specifications on matched sample . . . . . . 79

B10 Marginal effects of parsimonious combined model coefficient estimates on matched sample . . . . . . . . . . . . . . . . . . 80

B11 Coefficient estimates of household benchmark specifications . . . . . . . . . . 82

B12 Coefficient estimates of household specifications on matched sample . . . . . . 85

B13 Marginal effects of parsimonious combined model household specification

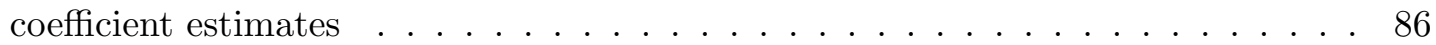

4.1 Descriptive statistics of estimation sample . . . . . . . . . . . . . . . 105 
4.2 SUR reduced-form coefficient estimates, extensive margin . . . . . . . . . . . 109

4.3 SUR reduced-form coefficient estimates, intensive margin . . . . . . . . . . . 110

4.4 Heterogenous effects . . . . . . . . . . . . . . . . . . . . . 112

4.5 Time specialisation estimates . . . . . . . . . . . . . . . 115

C1 Sensitivity to instrument definition . . . . . . . . . . . . . 118

C2 Average marginal effects of real exchange rate on the probability of return migration, holding migration distance constant at different values . . . . . . . . . 119

5.1 Descriptive statistics of estimation sample . . . . . . . . . . . . . . 134

5.2 Migration by year . . . . . . . . . . . . . . . . . 135

5.3 Covariates of estimation sample by year (period start) . . . . . . . . . 135

5.4 Descriptive statistics of estimation sample by migration status . . . . . . 136

5.5 Coefficient estimates of benchmark specifications _ . . . . . . . . . . 139

5.6 Robustness checks . . . . . . . . . . . . . . . . . . . . . . 142

5.7 Non-linearities . . . . . . . . . . . . . . . . . . . . . . . . . . 143

5.8 Heterogeneous effects . . . . . . . . . . . . . . . . . . . . . . 144

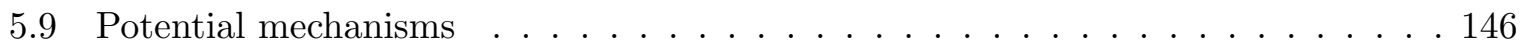




\section{List of Figures}

2.1 First stage test statistics for the real oil price . . . . . . . . . . . . . 21

2.2 Share of returnees by year of birth and real oil price at age $19 \ldots \ldots$. . . . . . 22

2.3 Average distance from governorate of birth to destination countries in kilometres 22

2.4 Skill mix profile by occupation . . . . . . . . . . . . . . . . . 27

2.5 Skill mix profile by migration experience . . . . . . . . . . . . . . 27

2.6 Skill mix profile of self-employed by migration experience . . . . . . . . . . 27

A1 Slopes for the probability of return migration on oil price, holding the value of migration distance constant . . . . . . . . . . . . . . . . . . 4 40

3.1 Kernel density estimates . . . . . . . . . . . . . . . . . . . 57

B1 Average marginal effects of return migration on self-emploment . . . . . . . 76

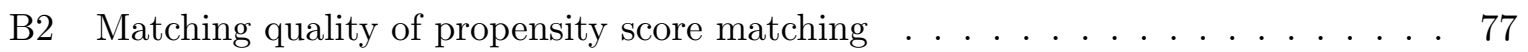

B3 Matching quality of covariate matching. . . . . . . . . . . 78

B4 Average marginal effects of return migration on self-employment, matched sample 81

B5 Matching quality of propensity score matching, household sample . . . . . . . . 83

B6 Matching quality of covariate matching, household sample . . . . . . . . . . 84

B7 Average marginal effects of return migration on self-employment, household sample 87

B8 Average marginal effects of return migration on self-employment, matched household sample . . . . . . . . . . . . . . . . . 88

4.1 First stage test statistics for the real exchange rate . . . . . . . . . . . . . 101

4.2 Share of returnees by year of birth and real exchange rate . . . . . . . . . . . 101

4.3 Average distance from governorate of birth to destination countries in kilometers 102

C1 Slopes for the probability of return migration on real exchange rate, holding the value of migration distance constant . . . . . . . . . . . . . . . 119

5.1 Linkages between publicly provided healthcare and migration . . . . . . . . 126

5.2 Seguro Popular beneficiaries and implementation phases . . . . . . . . . . . 128

5.3 Municipalities by change in coverage rate in the last quarter of 2004 (l) and 2008

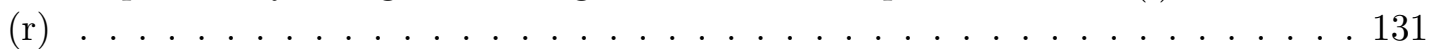

5.4 Municipalities by treatment status . . . . . . . . . . . . . . . . . . 132

5.5 Years of schooling (l), dependency ratio (r) and wealth index (b) by treatment

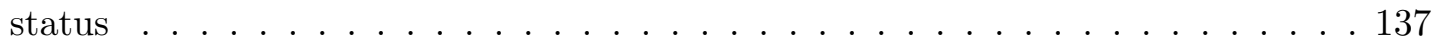





\section{Chapter 1}

\section{Introduction}

Motivated by the growing interest in migration as an economic and social phenomenon, this thesis explores several aspects of the relationship between migration and occupational choice. Here, migration is defined as the internal or international 'relocation of people within space that involves their permanent or temporary change of residence' (Mafukidze, 2006, 106). Occupational choice refers to how time is used - the choice between various forms of activities - to secure incomes and livelihoods over the life cycle. Occupational choice can take different forms: a contractual arrangement, such as wage or self-employment, or the allocation of the labour force to activities that are not remunerated on labour markets.

This thesis consists of four self-contained essays, preceded by an introductory chapter and followed by a concluding chapter. Chapters 2 and 3 investigate how migration affects the choice to enter and to leave an occupation, self-employment. Turning to those who stay behind, Chapter 4 assesses to what extent living in a household with a return migrant impacts the time use of relatives who did not migrate. Finally, Chapter 5 sheds light on migration decisions by looking at the links between publicly provided healthcare and migration. Each analytical chapter addresses a specific research question:

1. Can migrating develop entrepreneurial abilities? (Chapter 2)

2. Does migration disrupt self-employment trajectories? (Chapter 3)

3. Does living with return migrants affect time use? (Chapter 4)

4. Does publicly provided healthcare influence migration? (Chapter 5)

Table 1.1 presents and compares these four analytical chapters. Despite their differences in focus and context, these Essays seek to challenge existing thinking, by arguing that migration contributes to a dynamic, lifetime continuum of occupations, and that social health protection ${ }^{1}$

\footnotetext{
${ }^{1}$ Social protection refers to policy initiatives that aim at protecting individuals from financial losses. It includes protection against health risks through good quality of care and financial protection from health and care shocks. In this regard, non-contributory health insurance is a means to ensure financial protection in the healthcare sector (Arsenijevic et al., 2015).
} 
conditions migration, directly or indirectly, through effects on the labour force. The rest of this chapter provides the background of each essay and places their findings in this setting.

Table 1.1 - Thesis structure

\begin{tabular}{|c|c|c|c|c|}
\hline & Chapter 2 & Chapter 3 & Chapter 4 & Chapter 5 \\
\hline $\begin{array}{l}\text { Research } \\
\text { question }\end{array}$ & $\begin{array}{l}\text { Can migrating } \\
\text { develop } \\
\text { entrepreneurial } \\
\text { abilities? }\end{array}$ & $\begin{array}{l}\text { Does migration } \\
\text { disrupt } \\
\text { self-employment } \\
\text { trajectories? }\end{array}$ & $\begin{array}{c}\text { Does living } \\
\text { with returnees } \\
\text { affect } \\
\text { time use? }\end{array}$ & $\begin{array}{c}\text { Does publicly } \\
\text { provided health } \\
\text { insurance influence } \\
\text { migration? }\end{array}$ \\
\hline $\begin{array}{l}\text { Unit of } \\
\text { analysis }\end{array}$ & Individual & $\begin{array}{l}\text { Individual, } \\
\text { household }\end{array}$ & $\begin{array}{l}\text { Individual } \\
\text { (spouses) }\end{array}$ & Individual \\
\hline Dataset & $\begin{array}{l}\text { Egypt Labor } \\
\text { Market Panel } \\
\text { Survey }\end{array}$ & $\begin{array}{l}\text { Life in } \\
\text { Kyrgyzstan } \\
\text { Study }\end{array}$ & $\begin{array}{c}\text { Egypt Labor } \\
\text { Market Panel } \\
\text { Survey }\end{array}$ & $\begin{array}{l}\text { Mexico Family } \\
\text { Life Survey }\end{array}$ \\
\hline Estimator & $\begin{array}{l}\text { Generalised } \\
\text { simultaneous } \\
\text { equations } \\
\text { model }\end{array}$ & $\begin{array}{l}\text { (Correlated) } \\
\text { random effects, } \\
\text { matching }\end{array}$ & $\begin{array}{c}\text { Generalised } \\
\text { simultaneous } \\
\text { equations } \\
\text { model }\end{array}$ & $\begin{array}{c}\text { Difference-in- } \\
\text { differences }\end{array}$ \\
\hline
\end{tabular}

\subsection{Migration and occupational choice upon return}

One feature of migration is that it is rather temporary, because it is undertaken in support of an initiative in source countries, such as accumulating funds for household consumption or for entrepreneurial ventures (Dustmann and Gorlach, 2016). Investing in a business will result in migrants choosing self-employment upon return to their communities of origin. Understanding migrants' labour market adjustment process on return is essential in assessing if, and if yes, how, migration can contribute to developing source country labour markets and spurring economic growth (Piracha and Vadean, 2010), provided that the choice of occupation returnees and their non-migrant relatives make, because of migration, raises their productivity. Entrepreneurs are for instance often expected to generate innovation, create jobs, and hence promote economic growth, fight unemployment and alleviate poverty (Audretsch and Thurik, 2001; Koellinger and Thurik, 2012; Storey, 1994).

The existing theoretical and empirical research has specifically focused on whether return migrants and non-migrants differ in their propensity to be self-employed (see e.g. Dustmann and Kirchkamp, 2002). Return migrants have been found to have a higher propensity to be self-employed and to survive as entrepreneurs than non-migrants (Marchetta, 2012; Wahba and Zenou, 2012; Wahba, 2015; Batista et al., 2017). This raises questions on what it is about migrating that might affect the propensity of migrants to choose one occupation over another. Unpacking migration as a lifetime (learning) experience could help better understand the process of occupational choice.

In the absence or inefficiency of markets, savings accumulated during migration (and 
remittances) could act as substitutes for formal insurance, by facilitating access to capital and widening opportunities for income generation. Apart from the opportunity provided by migration to accumulate wealth, a possible explanation for these findings is that migrating could impart a variety of skills needed in entrepreneurship. Entering into and persisting in self-employment involve tasks that demand multiple skills, such as tolerance for risk, persistence, planning, budgeting or communicating across cultures - being successful requires entrepreneurs to be multi-skilled. Although there is no consensus on whether one is born with innate entrepreneurial abilities or whether entrepreneurial abilities can be taught (Silva, 2007), 'entrepreneurial human capital' or 'entrepreneurial ability' has been recognised as an essential, if often elusive, determinant of entrepreneurship (Hessels et al., 2014).

In Chapter 2, Can migrating develop entrepreneurial abilities?, I draw on Lazear's (2005) Jack-of-all-Trades (JAT) Hypothesis, stating that entrepreneurial skills can be learnt, not only through education but also experience. Offering quality data, Egypt provides a good example, and the 2012 wave of the Egypt Labor Market Panel Survey (ELMPS) (ERF and CAPMAS, 2013), by tracking job and migration history, forms a rich source of data. Micro- and small enterprises (MSEs) constitute almost 99\% of Egypt's total enterprises and around $80 \%$ of total employment, providing work for about $75 \%$ of new entrants into the job market (Ghanem, 2013). Considering the high incidence of youth unemployment, ${ }^{2}$ MSEs could offer socially and economically excluded youth better living standards. ${ }^{3}$ At the same time, Egypt was the first labour exporter among Middle Eastern and North African (MENA) countries since the opening up of the country in the 1970s. A survival strategy to escape poor social and economic development, international emigration from Egypt is mainly a function of overseas labour demand (Zohry, 2009). It is also strongly affected by the economic and political conditions of labour-importing countries (Wahba, 2009). Largely dominated by men, migration from Egypt to MENA countries is temporary in nature.

Empirical research on return migration and entrepreneurship in Egypt has mainly used the ELMPS. Overseas savings and the acquisition of skills during a stay abroad have been shown to increase the propensity to become self-employed upon return by compensating for their potential loss of social capital due to their absence from Egypt (Wahba and Zenou, 2012). However, the role of migration as a learning experience remains unclear. Being self-employed upon return could occur because of migration-induced wealth effects, through remittances and repatriated savings, or due to the development of a balanced skill set, i.e. migration-induced jack-of-all-trades effects.

By estimating the reduced form of a seemingly unrelated regression (SUR) model, this chapter reveals that not only migration-induced wealth effects, but also the work experience gained abroad per se, can affect migrants' occupational choice upon return. The more occupations, sectors and jobs migrants were exposed to over their work history, the more likely they are to be self-employed upon return to Egypt. Chapter 2 thus provides additional evidence to the

\footnotetext{
${ }^{2}$ In 2008, they represented around 95\% of Egypt's unemployed. Previous governmental strategies for youth job creation in the public sector have proven unsustainable (Ghanem, 2013).

${ }^{3}$ In 2008, $72 \%$ of new entrants into the labour market with secondary education found themselves working in the informal MSE sector, often as unpaid family workers (Ghanem, 2013).
} 
current debate on the development impacts of (return) migration on communities of origin. Moreover, this chapter contributes to the scarce literature on empirically testing Lazear's (2005) Jack-of-all-Trades (JAT) Hypothesis in developing economies where international migration is a prevalent labour market alternative. Because the self-employed evolve in underdeveloped, ill-functioning market-supporting institutions in those situations, they should be much more generalist to handle almost all dimensions of business management (Chen and Feng, 2012). By unpacking migration as a learning process, these results are in line with Lazear's (2005) framework. They confirm that entrepreneurship can be learnt, and that learning-by-doing and experiential learning matter for self-employment (Hessels et al., 2014). That migration plays a role in forming entrepreneurial abilities could be informative for entrepreneurship support policies. Entrepreneurship education policies could for instance focus on widening the work experience of potential, fledgling entrepreneurs. Broader labour market policies could allow for flexible transitions between wage and self-employment.

Since return migrants are frequently found more likely to be self-employed than non-migrants in the literature, it is believed that migration experience can facilitate economic development through return migrants' entrepreneurship (Naudé et al., 2017). However, these analyses tend to be static; they do not account for dependence in entering into and persisting in self-employment. Chapter 3, Does migration disrupt self-employment trajectories?, takes a dynamic approach to present evidence questioning and qualifying the positive link between return migration and origin country economic development through entrepreneurship.

There are at least two reasons why such an interpretation should be made with caution. First, this will depend on why returnees opt for self-employment. Return migrants may only choose self-employment as a temporary occupation, out of necessity, ${ }^{4}$ akin to Harris and Todaro's (1970) 'parking lot' hypothesis, from where to eventually move on to a wage job (Piracha and Vadean, 2010). This could be explained by difficult business conditions, or because sustaining a career in self-employment may require strong social capital that might have depreciated during their migration spell (Marchetta, 2012; Wahba and Zenou, 2012).

Second, the occupation migrants had before leaving their origin communities may influence their choices on return. It is likely, especially in a developing country context, that returnees who were self-employed before migrating, are less likely than non-migrants to choose self-employment as an occupation. They might have discovered that they lack sufficient entrepreneurial ability, or that the climate for doing business is too difficult in their origin countries, as per Jovanovic's (1979) learning mechanism.

Both reasons suggest that the potential for migration to stimulate entrepreneurship in origin countries should not be overestimated, as it would not be associated with sustaining a career in self-employment. To date, very few studies have simultaneously dealt with entry into and survival in self-employment in the broader context of whether (return) migration facilitates self-employment choices in developing economies. Chapter 3 addresses this lacuna by answering

\footnotetext{
${ }^{4}$ Individuals and households operate enterprises out of opportunity, because they perceive a promising business opportunity, or out of necessity, in a need to cope with adverse events. The motivation behind this choice is assumed to influence the choice of business activity, enterprise performance, growth and survival, and job creation potentials (Nagler, 2015).
} 
the following questions: (i) are return migrants more likely than non-migrants to enter into and to survive in self-employment? And (ii) is this decision influenced by whether return migrants were self-employed before migrating?

Chapter 3 uses a novel longitudinal database of a transition economy with prevalent international migration, the Life in Kyrgyzstan (LiK) Study. The structure of Kyrgyzstan's economy has led to high rates of emigration (Atamanov and van den Berg, 2012). ${ }^{5}$ Although numbers vary by sources, emigration from Kyrgyzstan is, on all accounts, significant. ${ }^{6}$ The organisation of Soviet-era planned economies has simultaneously left Kyrgyzstan without market-supporting institutions and with difficult access to financial support. ${ }^{7}$ Restrictions on private land ownership and state-led rent-seeking limit the growth of Kyrgyz family farms (Atamanov and van den Berg, 2012). Political instability, tax rates and corruption were recently listed as the first challenges that formal, non-agricultural enterprises faced in Kyrgyzstan (International Bank for Reconstruction and Development and World Bank, 2014). However, entrepreneurship has been found key to a successful transition from a planned to a market economy (McMillan and Woodruff, 2002). ${ }^{8}$

The extent of international migration in Kyrgyzstan, its dependence on economic prospects in destination countries and the role entrepreneurship could play in its unique transition setting thus point to the relevance of studying the potential implications of return migration for Kyrgyzstan's economic development through entrepreneurship. Consisting of four successive waves tracking the same households, the LiK allows shedding some light on these dynamics by estimating dynamic, non-linear probability models and using matching techniques.

Return migrants in Kyrgyzstan are found, like in other settings, more likely to be self-employed than non-migrants. Migration is positively correlated with entry into self-employment upon return to Kyrgyzstan. However, their motive to do so is rather based on necessity than opportunity, and thus tend to be more of a temporary choice, akin to a 'parking lot', as return migrants are more likely to exit from self-employment in subsequent periods than non-migrants. Results from Chapter 3 indicate that if migrants were self-employed specifically before leaving Kyrgyzstan, they would be less likely to be self-employed upon return, at least in the short term.

\footnotetext{
${ }^{5}$ Demographic pressure and (land) resource limitations coincided with economic opportunities in neighbouring countries to encourage migration. International migration became a natural response to economic challenges in Kyrgyzstan, to mainly Russia - hosting 92\% of Kyrgyzstani migrants - and Kazakhstan with 8\%. Russia's recent economic crisis therefore spurred many returns (The Diplomat, 2015).

${ }^{6}$ With a population of about 5.7 million in 2013, the number of permanent and seasonal labour migrants approximated 200,000 to 1 million people depending on information sources. The subsequent growth in remittances has ranked Kyrgyzstan second worldwide after Tajikistan. Remittances represented about a third of its gross domestic product (GDP) in 2014 (Karymshakov and Sulaimanova, 2017).

${ }^{7}$ In 2014, individual entrepreneurs and small farmers contributed to respectively $18 \%$ and $9 \%$ of gross domestic product (GDP), but accounted for $90 \%$ of entrepreneurial activities. Over 2001-2014, large enterprises were the main driver of GDP growth (Rudaz, 2017).

${ }^{8}$ In China, Poland or Vietnam for instance, new firms drove reforms by generating economic growth and jobs, offering goods and services otherwise inexistent, stimulating savings and limiting the power of public firms (McMillan and Woodruff, 2002).
} 
These novel findings suggest that temporary migration could be more disruptive to selfemployment trajectories than is often thought, and that the potential for return migration to stimulate entrepreneurship should not be overestimated. Such a 'disruption' could be viewed in a positive light, as it enables career development by offering an escape from necessitydriven self-employment. It also reduces the number of self-employed with low ability in the entrepreneurial pool. However, this 'disruption' caused by migration may hinder an economy from benefiting from the experience and resources migrants might have accumulated abroad. In particular in transition economies like Kyrgyzstan, migration might substitute for an imperfect legal framework and weak financial markets. Improving the conditions for doing business in origin countries might be necessary to harness the entrepreneurial acumen migrants might have developed.

Although seemingly contradictory, Chapter 2 and Chapter 3 can be seen as complementary. Chapter 2 suggests that migrating acts as a learning experience in that it develops entrepreneurial abilities and shapes human capital. One weakness of Chapter 2 is that the analysis is conducted in a static setting; it does not account for dependence between entry into and persistance in self-employment over time. This is addressed by Chapter 3. Chapter 3 shows that migrating does increase the probability to be self-employed upon return for those who were not self-employed before leaving their origin countries, but decreases the probability to be self-employed upon return for those who were self-employed before leaving. These results mean that the positive link between return migration and self-employment often found in the literature might be driven by return migrants who were not self-employed before leaving - those who entered into self-employment upon return. As the migration-induced learning mechanism suggests, the former group of returnees might have built their human capital while away, consistent with Chapter 2. As a result, they might have discovered their potential abilities as self-employed. The latter group of return migrants could have been self-employed before migrating out of necessity, as a means to ensure earnings while allowing for flexibility when planning to migrate. Migrating might thus have acted as a disruption that revealed their skills as entrepreneurs, and that reduced the number of necessity-driven self-empoyed. ${ }^{9}$

\subsection{Migration and female spouses who stay behind}

Chapter 4, Does living with return migrants affect time use?, looks at the effect of migration on non-migrating household members, specifically returnees' spouses. The out-migration of a household member has been shown to influence the occupations of household relatives who stay behind through the receipt of remittances and within-household labour reallocation (e.g. Binzel and Assaad, 2011). There is also evidence that migrants transfer destination country norms, and that their decision-making power is reinforced upon return relative to their spouses' (e.g. Antman, 2011, Bertoli and Marchetta, 2015 or Tuccio and Wahba, 2015).

Yet, whether men's returning affects the time allocation of their wives has been left unanswered

\footnotetext{
${ }^{9}$ While results seem to confirm the case of the latter group of returnees, data limitations made difficult a thorough analysis of the learning mechanism in Chapter 3.
} 
by the literature. On one hand, individuals' occupational and migration decisions are often made at the household level in developing economies. On the other hand, migration flows tend to alter returnees' choice of occupation (Marchetta, 2012; Wahba and Zenou, 2012; Wahba, 2015; Batista et al., 2017). This chapter exploits the documented effect of migration on occupational choice upon migrants' return to their origin country to establish a link between return migration of men and their wives' time allocation through within-couple occupational interdependence, i.e. some degree of dependence between spouses' occupations, as in Parker (2008).

The same database, the 2012 round of the ELMPS, and estimation strategy as in Chapter 2 are used. As mentioned above, migration from Egypt has been found to increase men's propensity to set up businesses upon return to Egypt, and to survive as entrepreneurs (Marchetta, 2012; Wahba and Zenou, 2012; Wahba, 2015). It has also been found that living in a household with men who temporarily migrated to a conservative country increases the likelihood of Egyptian women to internalise traditional gender norms (Bertoli and Marchetta, 2015).

At the same time, labour force participation of women in Egypt is one of the lowest, with 19\% engaged in paid work in 2010 (World Bank, 2017). Tradition limits women's mobility and restricts them to the domestic sphere or to small home-based income-generating activities with few opportunities to expand (Sadania, 2017). Not only work characteristics but also social norms attached to specific activities have rendered the Egyptian labour market gender-differentiated and, for women, segmented between public sector (44\% of Egyptian women engaged in public sector work in 2012), private sector $(32 \%)$ and household work $(24 \%) .{ }^{10}$

Not only instrumental in household livelihood strategies, how women use their time - whether they engage in, and how much time they spend on certain activities - has been found to be a major determinant of their autonomy and bargaining power, both within and outside their household. If return migrants were more likely to set up a firm upon return, demand for labour within returnees' households could increase. In this regard, returnees setting up a family firm and taking advantage of their wives' labour force could alter women's degree of control over resource allocation, among other household decisions, giving women more, or limiting, their financial responsibilities as they get involved in their husbands' businesses. However, the wealth men gathered abroad could simultaneously be used to start up a business and free up their wives' time. If this is the case, women could decide not to work, whether paid or unpaid, or to reallocate their time to relatively more income-generating activities outside their households. Estimates of the change in wives' time use in an exogenous change in their husbands being return migrants through their very choice of occupation, suggest that being married to a migrant who opted for self-employment upon return decreases women's likelihood to engage in paid work. It increases their likelihood to engage in family business, subsistence farming and domestic chores, at both the extensive and intensive margins. These results are explained by the existence of occupational interdependence between spouses - most likely to diversify income sources - and

\footnotetext{
${ }^{10}$ For instance, if working in the public sector is accepted by Egyptian society for the most educated, engaging in private work outside the household is in contrast seen as degrading. Contributing to family work, such as their husbands' farms or non-agricultural businesses, often carried out from home, is more accepted for those who cannot join the public sector (Sadania, 2017).
} 
assortative mating, ${ }^{11}$ along time-use gender differentiation lines. ${ }^{12}$ These findings highlight the need to buffer potentially time depriving migration-induced effects on women, even once migration is complete.

Chapter 4 contributes to the literature on women's occupational choices, specifically in a developing setting with prevalent international migration. This analysis is the first to show and quantify the effect of return migration of men on their wives' choices of occupation. It provides additional evidence to the literature on those who stay behind by questioning the idea that the return of migrant household members does not influence time allocation and task distribution within a household.

\subsection{Migration and publicly provided healthcare}

Departing from neo-classical models, ${ }^{13}$ later theoretical approaches, such as the New Economics of Labour Migration (NELM), consider migration as a decision made within a household to maximise wealth, diversify income sources between household members and across space, and minimise risks (Stark and Bloom, 1985). In this regard, migrating can be viewed as an informal livelihood coping strategy (Sabates-Wheeler and Waite, 2003). Whether and which household members migrate is decided jointly by those likely to migrate and those likely to stay behind and to support migrants or benefit from their migration, e.g. through the receipt of remittances. The decision to migrate depends on opportunities inside and outside households' places of residency, costs induced by moving and being absent, number and share of household dependants, and credit constraints. In other words, deciding to migrate is determined by financial and care (time) constraints and opportunities at potential destinations.

Assuming that household members share their resources, accessing alternative sources of livelihood through social protection could then influence the decision to migrate directly or indirectly through effects on labour market behaviours. By providing (near-)poor households with the means to deal with risk, not only might (formal) social protection programmes affect labour market behaviours, they might simultaneously alter household livelihood strategies.

In the last analytical chapter of this thesis, Does publicly provided healthcare influence migration?, I investigate whether social health protection affect migration propensity. Publicly provided healthcare has received increasing attention in the academic and policy debate. Extending public healthcare is claimed to be one of the most effective ways of reaching universal health coverage (Jamison et al., 2013). Positive impacts on health and poverty are more and more acknowledged (Finkelstein and McKnight, 2008; Limwattananon et al., 2015). Still, concerns about adverse labour market effects, such as disincentives to work or switching from formal to informal work, have been raised (Cutler et al., 1996; Gruber and Simon, 2008; Levy and Schady, 2013).

\footnotetext{
${ }^{11} \mathrm{~A}$ high level of resemblance across personal features such as education, age or earnings, revealing similar preferences between those who marry each other.

${ }^{12}$ Gender-specific constraints and choices in women's time allocation, resulting from prevalent genderspecific role stratification.

${ }^{13}$ See e.g. Harris and Todaro's (1970) model of rural-urban wage differences.
} 
Empirical evidence on labour market outcomes overall remains mixed. ${ }^{14}$ By minimising healthrelated shocks and expenditures, non-contributory health insurance might reduce the need to diversify income sources, i.e. working outside one's household and spatially reallocating its labour force. Labour and safety nets would be substitutes in this case: accessing healthcare would crowd out work, since households and individuals would not have to rely on the labour market to minimise risks. On the other hand, non-contributory healthcare could support affiliated households and their working-age members in looking for work, locally or outside their communities of origin. This could be effected by improving health and enabling the reallocation of their labour force and financial resources, previously used to tackle household (dependant) and individual health shocks, towards remunerative activities outside their households. In this case, healthcare and labour supply would be complements.

Providing healthcare for free could thus directly affect migration by relaxing financial constraints, reducing the occurrence and duration of health shocks, and therefore enabling (healthier) working-age household members to migrate. It could indirectly influence migration through its effects on local labour markets by inducing them to reallocate time from care giving to working outside their households, e.g. prompting their entry into the labour market, which might involve migrating. Chapter 5 analyses whether binding financial and care constraints prevent households from sending migrants, and whether benefiting from publicly provided healthcare helps households surmount such constraints: does publicly provided healthcare affect labour force attachment of working-age members in affiliated households?

Chapter 5 exploits the random expansion of a publicly provided healthcare programme, Sistema de Protección Social en Salud, introduced in Mexico in 2003 that aimed at improving household financial strength through health services. The analysis takes advantage of the timing of the Mexican Family Life Survey (MxFLS), a three-wave household panel conducted from 2002, before the start of its pilot phase, to 2009. A difference-in-differences specification is estimated to compare changes in migration between individuals living in municipalities where this programme was introduced earlier and individuals living in municipalities where it was implemented later. The panel structure of the MxFLS allows controlling for endogenous migration by assigning changes in coverage to individuals based on their municipality of residence at the beginning of each time period.

Estimates reveal that exposure to a change in coverage increases internal migration. It does not, however, affect international migration. This chapter answers the research question posed in Table 1.1 by suggesting that financial and care constraints prevent households from sending migrants. Accessing publicly provided healthcare appears to alleviate financial and care constraints, by freeing up working-age caregivers' time and strengthening household resilience in the face of health shocks. Affiliation seems to enable labour force detachment of working-age members in affiliated households.

The contributions of this chapter to the literature are, first, to suggest that the mixed evidence on the effects of publicly provided healthcare on labour market outcomes might be explained

\footnotetext{
${ }^{14}$ For a review, see Ravallion (2003); for evidence from the United States (US), Baicker et al. (2014), Dave et al. (2015) or Garthwaite et al. (2014); for evidence from Mexico, Azuara and Marinescu (2013), Bosch and Campos-Vázquez (2014) or del Valle (2016).
} 
by their very focus on recipients and household members who live with them. Results point to the relevance of looking at implications for migration, and of including non-resident household members, or household members who migrated, since affiliation to healthcare might enable working-age beneficiaries to migrate, who would then 'disappear' from estimation samples. Considering spatial mobility could bring insights into the heterogeneity of existing evidence. Not accounting for the potential effects of social (health) protection programmes on the likelihood to migrate might underestimate their effects.

Second, in contrast to contributory healthcare that tends to crowd out migration by tying affiliated to formal employment and to a specific location, Chapter 5 finds that non-contributory healthcare can increase the least costly type of migration, internal migration. Access to healthcare might not substitute for, but complement alternative livelihood strategies - in this case, migration. This might help clarify the migration decision-making process, and more broadly, livelihood strategies. Given the documented effects of migration on development, ${ }^{15}$ Chapter 5 could help better understand constraints on migration. This is necessary to improve the design and target of policies seeking to remove impediments to mobility for those who could benefit from welfare gains, and to leverage the contribution of migration to the development of origin communities (Cazzuffi and Modrego, 2017).

These Essays attempt to refine prevailing views on the relationship between migration and occupational choice, by analysing how migrating influences the occupational choices of migrants (Chapters 2 and 3) and of their relatives who stayed behind (Chapter 4), and to which extent publicly provided healthcare determine migration, directly or indirectly, through labour effects (Chapter 5).

Chapters 2 and 4 use data from Egypt; Chapter 3, from Kyrgyzstan; and Chapter 5, from Mexico. Egypt and Kyrgyzstan are lower middle-income economies with high youth unemployment, and for which international migration has become a survival strategy to escape poor social and economic development. It is mainly a function of overseas labour demand, and, for this reason, temporary in nature and strongly affected by the economic and political conditions of labour-importing countries. While both countries have a large and dynamic MSE sector, their respective pasts and cultural ties make inferences from findings of Chapters 2 and 4 more plausible to other MENA and, to some extent, South Asian countries; findings of Chapter 3, to Central Asian and transition economies. Mexico is an upper middle-income country, relatively more advanced than Egypt and Kyrgyzstan, seeking to reduce poverty through universal health coverage, among other measures. As a result of its development level, Mexico has been experiencing downward internal and international migration trends (Orrenius, 2001; Aroca and Maloney, 2005; Pimienta-Lastra et al., 2012; Cazzuffi and Pereira-López, 2016). Results from Chapter 5 might rather apply to economies of a similar economic development level. Albeit unique, using these different country cases gives a broader overview of the complex interactions between migration and occupational choice.

In the next four chapters, I elaborate on my research in detail. Chapter 6 summarises the main

\footnotetext{
${ }^{15}$ On the positive development impacts of migration, see e.g. Adams and Page (2005); on its negative effects, see Portes (2006).
} 
findings of the analyses presented in this thesis, draws policy implications and makes suggestions for future research. 



\section{Chapter 2}

\section{Can migrating develop entrepreneurial abilities?}

\subsection{Introduction}

Return migrants have been found to have a higher propensity to be self-employed and to survive as entrepreneurs than non-migrants (Marchetta, 2012; Wahba and Zenou, 2012; Wahba, 2015; Batista et al., 2017). Apart from the opportunity provided by migration to accumulate wealth, a possible explanation for these findings is that moving, living abroad or returning 'home' could impart a variety of skills needed in entrepreneurship. Entering into and persisting in selfemployment involve a variety of tasks that demand multiple skills, such as tolerance for risk, persistence, planning, budgeting and communicating across cultures - being successful requires entrepreneurs to be multi-skilled. 'Entrepreneurial human capital' or 'entrepreneurial ability' has been recognised as an essential, if often elusive, determinant of entrepreneurship (Hessels et al., 2014). However, there is no consensus on whether one is born with innate entrepreneurial ability or whether entrepreneurial ability can be taught (Silva, 2007).

According to Lazear (2005), entrepreneurial ability can be learnt, not only through education but also by experience. Entrepreneurs need a generalist, well-balanced skill mix profile: they need to be Jacks-of-all-trades, i.e. being exposed to a range of activities and contexts. Without acquiring a varied set of skills, one would be less likely to opt for self-employment, and less successful in starting up a firm. A growing literature has examined Lazear's (2005) Jack-of-all-

This chapter is based on Mahé, C. (2017). Occupational choice of return migrants: Is there a 'jack-of-all-trades' effect? UNU-MERIT Working Paper No. 2017-039, Maastricht: United Nations University Maastricht Economicand Social Research Institute on Innovation and Technology. I would like to acknowledge the Economic Research Forum for providing the database used in this chapter; Ragui Assaad and Caroline Krafft for kindly answering questions about the database. I am furthermore grateful to Neil Foster-McGregor, Tommaso Frattini, Micheline Goedhuys, Edward Lazear, Francesca Marchetta, Pierre Mohnen, Wim Naudé, Sergio Parra-Cely, Melissa Siegel and Tamer Taha, who provided comments, suggestions and encouragements, as well as participants of the 29th European Association of Labour Economists (EALE) Conference, held on September 21-23, 2017, in St Gallen, Switzerland; and of the Workshop on Migration and the Labour Markets, held on April 12-13, 2018, in Edinburgh, United Kingdom. 
Trades (JAT) Hypothesis. ${ }^{1}$ This chapter contributes to this literature by investigating whether migration is a process that can affect the likelihood of returnees becoming entrepreneurs; and if so, whether this is due to a migration-induced jack-of-all-trades effect on skill set balance. That migrating plays a role in forming entrepreneurial ability could be informative for entrepreneurship support policies.

This research uses the 2012 Egypt Labor Market Panel Survey (ELMPS) (ERF and CAPMAS, 2013). Offering quality data, Egypt provides a good example. Micro and small enterprises (MSEs) constitute almost $99 \%$ of Egypt's total enterprises, and around $80 \%$ of total employment, providing work for about $75 \%$ of new entrants into the job market (Ghanem, 2013). In light of the high incidence of youth unemployment, ${ }^{2}$ MSEs could offer socially and economically excluded youth better living standards. ${ }^{3}$ Simultaneously, a survival strategy to escape poor social and economic development (Zohry, 2009), international emigration from Egypt is mainly a function of overseas labour demand. It is also strongly affected by the economic and political conditions of labour-importing countries (Wahba, 2009). Largely dominated by men, migration from Egypt to Middle Eastern and North African (MENA) countries is temporary in nature.

Empirical research on return migration and entrepreneurship in Egypt has mainly used the ELMPS to look at occupational choice upon return. Overseas savings and the acquisition of skills during a stay abroad have been shown to increase the propensity to become selfemployed upon return by compensating for their potential loss of social capital (Wahba and Zenou, 2012). Marchetta (2012) finds that being a return migrant significantly increases the prospect of survival of entrepreneurial activities in Egypt. However, the role of migration as a learning experience remains unclear. Being self-employed upon return could occur due to migration-induced wealth effects - remittances and repatriated savings - or to the development of a balanced skill set, a migration-induced jack-of-all-trades effect.

Reduced-form estimates of a seemingly unrelated regression (SUR) model show that having migrated increases the propensity to be self-employed upon return to Egypt. The more occupations (11.91\% points), sectors (26.62) and jobs (5.15) return migrants were exposed to over their work history, the more likely they are to be self-employed. Results hold for non-agricultural sectors, individuals living in rural areas, and individuals without savings. Return migrants are also more likely to persist as self-employed, because of a more varied work experience.

I provide additional evidence to the current debate on the development impacts of (return) migration on communities of origin by showing that not only migration-induced wealth effects, but also the work experience gained abroad as such can affect migrants' occupational choice upon return. This evidence is robust to the endogeneity of migration, human capital strategy investment and occupational choice. I furthermore contribute to the scarce literature on

\footnotetext{
${ }^{1}$ For a recent review, see Hessels et al. (2014).

${ }^{2}$ In 2008, they represented around 95\% of Egypt's unemployed. Previous governmental strategies for youth job creation in the public sector have proven unsustainable (Ghanem, 2013).

${ }^{3}$ In $2008,72 \%$ of new entrants into the labour market with secondary education found themselves working in the informal MSE sector, often as unpaid family workers (Ghanem, 2013).
} 
empirically testing Lazear's (2005) Jack-of-all-Trades Hypothesis in developing economies where international migration is a prevalent labour market alternative. Since self-employed in those situations evolve in underdeveloped, ill-functioning market-supporting institutions, they should be much more generalist to be able to handle almost all dimensions of business management (Chen and Feng, 2012). By unpacking migration as a learning process, this chapter is eventually in line with Lazear's (2005) framework, as it confirms that entrepreneurship can be learnt, and that learning-by-doing and experiential learning matter in entering into and persisting in selfemployment (Hessels et al., 2014). Entrepreneurship (education) support policies should thus focus on widening the work experience of potential, fledging entrepreneurs. Broader labour market policies should allow for flexible transitions between self- and wage employment.

The rest of this chapter is structured as follows. Section 2.2 provides an overview of the relevant literature. Section 2.3 introduces the estimation strategy, followed by the data in section 2.4. Section 2.5 presents estimation results. Section 2.6 concludes.

\subsection{Conceptual background}

In the absence or inefficiency of markets, savings accumulated during migration (and remittances) could act as substitutes for formal insurance, by facilitating access to capital and widening opportunities for income generation. They also promote investments in new or existing ventures and enhance their productivity. ${ }^{4}$ Simultaneously, by moving abroad, emigrants are likely to weaken social ties with origin countries - a loss of social capital that may threaten any entrepreneurial activity upon return. Alternatively, it could enhance their employability as wage-employed upon return, which could lower returnees' will to initiate business activities (Wahba and Zenou, 2012). ${ }^{5}$

The human capital channel is relatively complex. Evidence is mixed with respect to higher education. For example, ? conclude from micro-economic evidence of five islands that, although return migration of the highly skilled is common, their involvement in entrepreneurial activities once back to origin countries is seldom, in contrast with Wahba and Zenou's (2012) findings. By inducing greater job turnover, migrating could affect returnees' mindsets, e.g. their propensity to take risks, be it in taking a new job or setting up a firm, as well as in their capabilities their skills and know-how. Occupation, integration processes in destination country and country choice might interact in the decision to set up a business upon return. ${ }^{6}$

\footnotetext{
${ }^{4}$ See for instance Dustmann and Kirchkamp (2002) or Mesnard (2004), who evidenced the endogeneity of time abroad and business start-up upon return.

${ }^{5}$ If Wahba and Zenou (2012) find that a loss in social capital during migration can be offset by gains in financial and human capitals for returnees to successfully set their businesses in place in homeland Egypt, Obukhova et al. (2012) show that returnee entrepreneurs to China do not outperform non-migrant, 'homegrown' entrepreneurs. Because of a lack of 'local' social networks - in this case, school ties - where high-tech enterprises are set in place, returnees are likely to underperform compared to non-migrant entrepreneurs or returnees entrepreneurs with such ties.

${ }^{6}$ Work experience abroad in a high-income economy, for instance, could explain returnees' propensity for self-employment, as suggested by McCormick and Wahba (2001) for Egypt, Kilic et al. (2009) for Albania, or Gubert and Nordman (2011) for Algeria.
} 
On the other hand, entrepreneurs might need a different skill profile than employees do. Instead of being 'specialists', entrepreneurs require a relatively balanced, varied set of skills - knowledge of financing, accounting, production processes, marketing and management. Entrepreneurs may not be expert in all these fields, but they need some notion of each of them, in particular if they are to hire experts for each role (Lazear and Gibbs, 2010). Lazear's (2005) Jack-of-all-Trades Hypothesis of entrepreneurship builds a framework in which an individual, who can have two skills such as product design and marketing, has the choice between having a wage-employed specialised job or becoming an entrepreneur. If an employee specialises in his or her best skill, an entrepreneur needs certain knowledge of both skills to carry out each task, or to supervise the others - the specialists - who perform them. An entrepreneur values his skills based on the level of each skill he possesses. His skill set is limited by his weakest skill. In other words, the more a potential entrepreneur is specialised (in one skill), the more he will be tied by his weakest skill. Maximizing his income is therefore limited by his knowledge level in his weakest skill.

As a consequence, the less balanced someone's skill set is - the more expert s/he is - the less likely s/he will opt for self-employment. Balanced skills are key for entrepreneurship. This is particularly the case in developing economies. In a context of highly imperfect markets, (would-be) entrepreneurs have to tackle a number of challenges that may not be as prominent in developed economies, rendering the need for well-balanced skills even more important (Chen and Feng, 2012). This suggests that potential entrepreneurs would give more value to a balanced investment in human capital, privileging investments in their weakest skill, in order to become less specialised. This prediction of the JAT hypothesis can be tested by looking at human capital investment patterns of self-employed and employed. Entrepreneurs should have a more generalist rather than specialised attitude to human capital - they should tend to invest in various skills at once.

Using a 1997 survey of about 5,000 Stanford MBA alumni, Lazear (2005) finds that entrepreneurs' past experience included a broader variety of activities and a greater number of jobs. They attended less specialised courses that deepened their knowledge compared to more specialised classmates who became wage-employed. Subsequent empirical research has supported (to some extent) and refined his findings, accounting for Silva's (2007) concern about endogeneity. ${ }^{7}$ Astebro and Thompson (2011) use Canadian data to show that inventorentrepreneurs tend to have more diverse experience on the labour market. Yet, they find varied work experience to be correlated with lower household income, contradicting the JAT prediction. Testing this theory with German data, Lechmann and Schnabel (2014) find that self-employed carry out more tasks, and that their work necessitates more skills, than wageemployed. However, self-employed are also found to want more expert skills as such; their results provide weak support for different human capital investment patterns between self- and wage-employed. Using data from Germany and the Netherlands, Hessels et al. (2014) show that those with more varied work experience are more likely to be self-employed, but being a

\footnotetext{
${ }^{7}$ Silva (2007) shows that individuals' unobservable characteristics such as innate abilities may simultaneously influence individuals' skills and occupational choice.
} 
generalist does not seem to be relevant. Constructing a measure of balance in abilities with military enlistment data from Sweden, Alden et al. (2017) find support for the Jack-of-AllTrades Hypothesis in showing that the probability of being self-employed is higher when skills are balanced.

In this regard, migration could be seen as a process that helps shape entrepreneurial spirit. Moving, living abroad or returning 'home' could induce building persistence, acquiring planning and financing skills, or communicating across cultures. By changing jobs in an alien environment, temporary migration could affect the propensity to take risks and the accumulation of occupation- and sector-specific skills - experiences that potentially contribute to a more balanced skill mix, i.e. beneficial for entrepreneurial activities. Acting as a learning process, migration experience could contribute to forging the entrepreneur. Upon return to their home country, migrants would differ from stayers in their propensity and attitudes towards selfemployment, entrepreneurial abilities and business characteristics. Studying the behaviour of return migrants could thus be an insightful test of Lazear's (2005) hypothesis. Chen and Feng (2012), investigating Lazear's (2005) JAT hypothesis in a migration setting, show in particular that the variety of skills - how 'balanced' their skill mix is, measured by the number of professional fields and accumulated skills ${ }^{8}$ - accumulated during migration to urban areas significantly increases returnees' likelihood to opt for self-employment upon return. Démurger and $\mathrm{Xu}$ (2011) confirm this hypothesis. Return migrants are found to be more likely to engage in entrepreneurial activities upon return to origin rural areas than stayers. This probability is increased by savings accumulated and professional experience gained during migration - in this case, migrants' job turnover.

However, resource accumulation abroad may be influenced by the perception of profitable investment opportunities in origin communities, reflected for instance in pre-existing business ownership in the migrants' household. Alternatively, family assets may attract returnees' investments, given the prospect of inheritance of these assets (Amuedo-Dorantes and Pozo, 2006). Once an investement target is reached, decision to return can be made. Resources gathered during migration might then lead to business investments, but it could also be that existing businesses at home reveal greater investment opportunities. In addition, along with future claims for bequest, existing businesses could act as incentives to invest - hence, potential reverse causality. Similarly, those with a taste for (professional) variety might seek a greater exposure to different occupations, sectors or jobs to acquire varied skills, and might simultaneously be more inclined to opt for self-employment because of their own, innate preferences (Chen and Feng, 2012).

Gaps in the existing literature, in particular regarding how temporary migration affects occupational choice upon return, thus remain to be filled. Despite a few works, such as Chen and Feng (2012), Démurger and Xu (2011) or Black and Castaldo (2009), the relative importance of the abilities gained during migration compared to remittances and repatriated savings - whether it is 'wealth' rather than 'skills' that are affected by migration - is not yet clear. Migrating, by

\footnotetext{
${ }^{8}$ Chen and Feng (2012) measure the accumulation of skills by ranging skills from no skill, nonmanagerial skill only, managerial skill only, and managerial and non-managerial skills.
} 
inducing greater job turnover could indeed affect returnees' mindsets, e.g. their propensity to take risks, be it in taking a new job or setting up a firm, as well as abilities - their skills and know-how, that is their work experience itself - whereby influencing their skill mix.

\section{$2.3 \quad$ Estimation strategy}

A major analytical issue in analysing the relationship between migration and self-employment is the endogeneity of temporary migration. First, migrating is subject to both negative and positive selection biases due to unobservable features that are likely to affect occupational choice and business performance upon return (Marchetta, 2012). Those who emigrate and return may do so because they are more endowed, i.e. have more balanced skills before departure, than non-migrants. If this is the case, empirical results comparing performance would be biased. On the other hand, dynamics between return migration and entrepreneurship may also be biased if returnees are innately more risk-taking, and so initiate riskier business strategies, or if returnees opt for self-employment due to lack of social capital or greater wage employment opportunities upon return. Emigrating itself could also be driven by the desire to set up an enterprise upon return. They could be simultaneous decisions, and temporary migration could be part of would-be entrepreneurs' business strategies (Wahba and Zenou, 2012; Batista et al., 2017).

The relationship between skill mix balance and occupational choice might similarly be biased by endogeneity. Unobservable characteristics might affect human capital investment strategy and occupation at the same time (self-selection). How (un)balanced one's skill set is might be a conscious effort to reach a well-defined position (reverse causality).

To tackle endogeneity in assessing, and recovering, the effect of migration experience on entrepreneurship through the human capital channel, the reduced-form of two distinct structural equations is estimated, linking (i) return migration to skill set, (ii) and skill set to the probability to be self-employed. A seemingly unrelated regression (SUR) linear probability model is used, since the three decisions - temporarily migrating, having a balanced skill set, and being selfemployed - form a non-recursive model with direct causal paths and correlated disturbances. ${ }^{9}$ Ignoring the interdependence in temporary migration, skill mix balance and occupational choice upon return, interdependence, when actually present, ${ }^{10}$ could lead to biased estimates. Exclusion restrictions play the role of instrumental variables.

The reduced-form model is specified as follows:

$$
\begin{aligned}
& \text { Returnee }_{i}=\delta_{0}+\delta_{1} X_{R i}+\delta_{2} Z_{R i}+\epsilon_{1 i} \\
& \text { SkillSet }_{i j}=\alpha_{0}+\alpha_{1} X_{S S i}+\alpha_{2} Z_{S S i}+\alpha_{3} Z_{R i}+\epsilon_{2 i} \\
& \text { SelfEmployed }_{i}=\gamma_{0}+\gamma_{1} X_{S E i}+\gamma_{2} Z_{S S i}+\epsilon_{3 i}
\end{aligned}
$$

\footnotetext{
${ }^{9}$ Correlated disturbances assume that corresponding endogenous variables share at least one common omitted explanatory variable.

${ }^{10}$ I.e. estimating this system of equations as single equations, in their structural rather than reduced form.
} 
where Returnee is alternatively a binary variable, taking unity if a working-age individual $i$ has worked at least six months abroad, and a continuous variable of years abroad. SkillSet is a continuous variable, with $j=1,2,3$, alternatively measuring the number of different occupations or industries accumulated over the last four job spells, or the number of positions over the entire job history. SelfEmployed is a binary variable taking unity if an individual is currently selfemployed.

$X_{R}$ is a vector of individual and household characteristics capturing gender, marital status, education, whether an individual's mother is literate, ${ }^{11}$ and child dependency ratio. $X_{S S}$ controls for the same variables as $X_{R}$. $X_{S E}$ controls for gender, household characteristics and lagged unemployment rates at the governorate level, as well as for variables thought to influence occupational choice such as vocational training, whether an individual's father was self-employed, whether his/her first job was self-employed, years of unemployment, tenure, tenure squared in years at current job, potential years of work experience and potential years of work experience squared. ${ }^{12}$

Equations (1) and (2) form the reduced-form equations of the first structural equation; equation (2), the reduced-form equations of the second structural equation. $Z_{R}, Z_{B S}$ and $X_{S E}$ act as exclusion restrictions of, respectively, equations (1), (2) and (3). As they are unique to each structural equation, the above model can be solved, and its structural parameters uniquely identified. These three structural model equations can be rewritten in the endogenous variables Returnee, SkillSet and SelfEmployed, so that each of these variables will depend on the exogenous variables in the entire system as well as the structural errors.

$$
\begin{aligned}
& \text { Returnee }_{i}=f\left(. ; Z_{R i}, \delta_{2}\right) \\
& \text { SkillSet }_{i j}=f\left(. ; Z_{S S i}, \alpha_{2} ; Z_{R i}, \alpha_{3}\right) \\
& \text { SelfEmployed }_{i}=f\left(. ; Z_{S S i}, \gamma_{2}\right)
\end{aligned}
$$

The reduced form is estimated via a generalized simultaneous equations model (GSEM) estimator, adding governorate fixed-effects, and excluding individuals living in a household with current or return migrants. Standard errors are clustered at the household level to account for potential correlation within families. By estimating the relationship between having a balanced skill set and being a returnee, controlling for the endogeneity of return migration, i.e. the change in the probability of having a balanced skill set in an exogenous change in being a return migrant, the marginal effect of balanced skills over return migration is obtained:

$$
\frac{\partial \text { SkillSet }_{i j}}{\text { Returnee }_{i}}=\frac{\frac{\partial \text { SkillSet }_{i j}}{\partial Z_{R i}}}{\frac{\partial \text { Returnee }_{i}}{\partial Z_{R i}}}=\frac{\alpha_{3}}{\delta_{2}}
$$

The marginal effect of self-employment over skill mix balance, controlling for the endogeneity of

\footnotetext{
${ }^{11}$ Mother's education proxies potential inequalities of opportunities that individuals might face based on their family background (Paxson and Schady, 2004; Paxson and Schady, 2007; in Atinc et al., 2005).

${ }^{12}$ Labour force-related information is measured over the last four job spells available in Module 6 of the ELMPS.
} 
a balanced skill mix, i.e. the change in the probability of being self-employed in an exogenous change in having a balanced skill set, is obtained by estimating the relationship between being self-employed and having a balanced skill set:

$$
\frac{\partial \text { SelfEmployed }_{i}}{\partial \text { SkillSet }_{i j}}=\frac{\frac{\partial \text { SelfEmployed }_{i}}{\partial Z_{S S i}}}{\frac{\partial \text { SkillSet }_{i j}}{\partial Z_{S S i}}}=\frac{\gamma_{2}}{\alpha_{2}}
$$

Migration-induced jack-of-all-trades effects on self-employment, i.e. the change in the probability of being self-employed in an exogenous change in being a return migrant, are given by the marginal effect of self-employment over return migration through skill set accumulation, computed by multiplying these two marginal effects:

$$
\frac{\partial_{\text {SelfEmployed }_{i}}}{\text { Eeturnee }_{i}}=\frac{\partial \text { SelfEmployed }_{i}}{\partial \text { EkillSet }_{i j}} \cdot \frac{\partial \text { SkillSet }_{i j}}{\text { Returnee }_{i}}=\frac{\gamma_{2}}{\alpha_{2}} \cdot \frac{\alpha_{3}}{\delta_{2}}
$$

$Z_{R}$, exclusion restriction for equation (1), is the interaction between (i) the real price of oil at some age of emigration and (ii) the average distance to estimation sample destination countries in 1,000 kilometers. As in Wahba and Zenou (2012), Marchetta (2012) or Bertoli and Marchetta (2015), changes in the real price of oil are used to obtain an exogenous source of variation in the probability of temporary migration. Inflation-adjusted prices of oil are assumed to drive the demand for non-native labour either directly in oil-producing countries - through employerbased immigration policies - responsive to change in local economic conditions or indirectly in non oil-producing countries, such as Jordan or Lebanon, as replacement workers. As argued by these authors, fluctuations in the historical real price of oil at a potential age of emigration should influence the decision to migrate, but should not be directly related to current - observed - occupational choice upon return. In addition, because migration to MENA countries tends to be temporary, predicting emigration should suffice to instrument for return migration. Following Bertoli and Marchetta (2015), selecting the age at which individuals have to be matched to the real oil price relies on an optimality criterion, chosen out of 11 alternatives, from age 18 to 28 . The selection of the age, i.e. year of potential emigration, at which an individual is matched to the real price of oil draws on Bertoli and Marchetta (2015). To do so, equation (1) is estimated, and the strength of this instrument is examined at different matching ages, ranging from age 18 to 28. This is achieved by testing the null hypothesis that the estimated coefficient on the real price of oil equals zero through a Wald test, implemented by Stata's test command, for each alternative. As Cameron and Trivedi (2009, p.196) note that 'a widely used rule of thumb [...] views an F-statistic of less than 10 as indicating weak instruments. This rule of thumb is ad hoc and may not be sufficiently conservative [...]', the age of potential emigration giving the highest F-statistic is selected.

Figure 2.1 depicts the values of the F-statistics for equation (1), with being a return migrant and the number of years abroad as alternative dependent variables, at each age, as well as the 10 F-statistic rule of thumb. The F-statistic is the highest for age 19 for the two dependent variables - being a return migrant, or the number of years spent working abroad - close to Bertoli and Marchetta's (2015) choice of age 20, but below 10 for 26, the age selected by Wahba 
and Zenou (2012) and El-Mallakh and Wahba (2016). The real price of oil is thus opted for when individuals were 19 as an instrument for temporary migration to MENA countries. Table 2.1 supports the selection of 19 as matching age. Real oil prices were, on average, statistically significantly higher for return migrants (USD49.87) at age 19 than for stayers (USD43.45), confirming the rationale behind this instrument.

Figure 2.1 - First stage test statistics for the real oil price at different ages

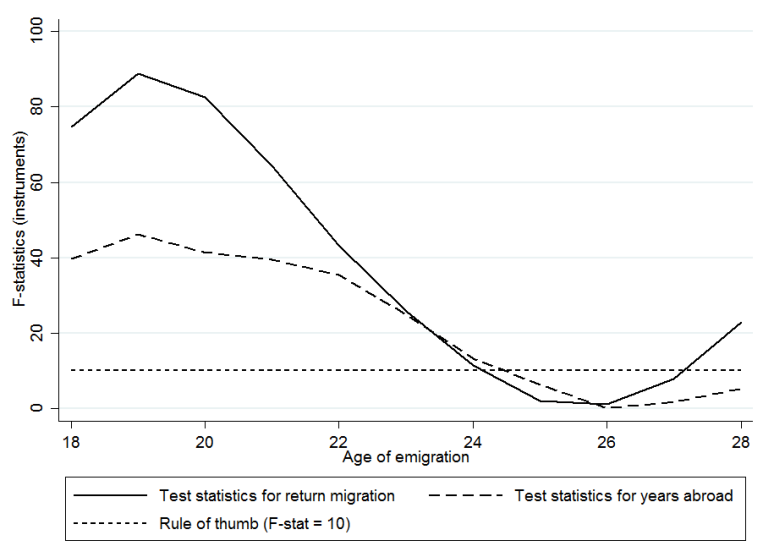

Following Bertoli and Marchetta (2015), Figure 2.2 shows the relationship between the share of returnees of the estimation sample, their year of birth and the real price of oil when they were 19 years old, from 1950 to 1990. The proportion of return migrants is the highest, approximately $25 \%$ for those born in the mid-1950s and early 1960s, who might have emigrated following the sharp increases in oil prices in the 1970s and 1980s. The proportion of returnees then falls, until the end of the series, 1989. ${ }^{13}$ The steady decrease in the share of returnees does not match the rise in real oil prices starting in the late 1980s. Egyptians, born in the late 1970s or onwards, who emigrated to MENA countries in the early 2000s may not have returned to Egypt yet. Those who have already returned may have failed their migratory project. They may not represent the pool of Egyptians who left in the 2000s well, which could induce bias hence their exclusion from the estimation sample.

This cohort-based instrument is interacted with the average distance from the capital of a respondent's governorate of birth $^{14}$ to estimation sample destination country capitals in 1,000 kilometers. ${ }^{15}$ Table A7 in the Appendix provides information on the construction of distances. Migrants are likely to migrate where it is cheaper because of geographical proximity, that is to countries closer to Egypt. ${ }^{16}$ Figure 2.3 presents the average distance to potential destination country capitals by governorate of birth in kilometers. The effect of oil prices on the probability to temporarily emigrate is thus allowed to differ across governorates through

\footnotetext{
${ }^{13}$ No return migrants born in 1990 or later were surveyed. The estimation sample thus only includes individuals with no missing information, who were born in 1989 or before.

${ }^{14}$ First level of Egypt's administrative subdivision.

${ }^{15}$ Respondents who were not born in Egypt were assigned an average distance based on their first governorate of residence in Egypt.

${ }^{16}$ The average distance is also weighted by the share, and its inverse, of migrants by destination countries. This yields similar estimates. Estimates are available on request.
} 
Figure 2.2 - Share of returnees by year of birth and real oil price at age 19

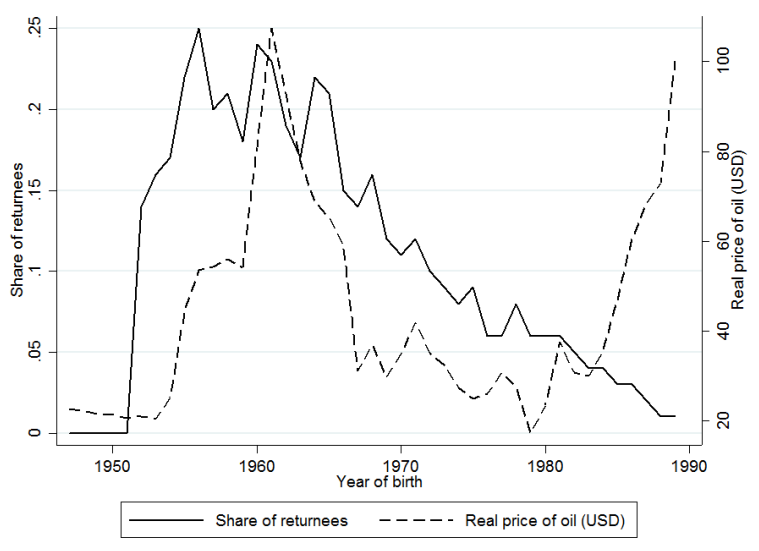

governorate (spatial) heterogeneity in migration costs to each potential destination. This interaction generates variation across time, via the cohort-based oil price, and across space, via the average distance from governorate of birth to destinations.

Figure 2.3 - Average distance from governorate of birth to destination countries in kilometres

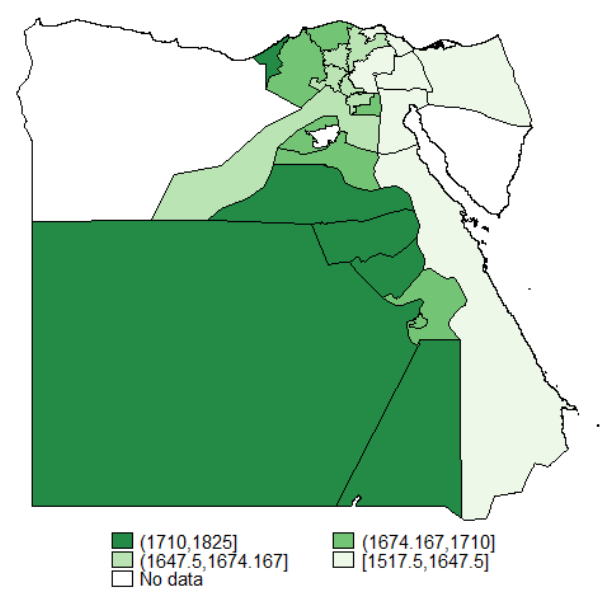

$Z_{S S}$, exclusion restriction for equation (2), is a binary variable taking unity if an individual worked in a micro-firm over his/her last four job spells, assumed to influence occupational choice only through the accumulation of entrepreneurial skills or abilities. The potential endogeneity between skill mix balance and occupational choice is tackled by using work experience in a micro-firm over workers' last four job spells as exclusion restriction, as it is assumed to influence occupational choice only through the accumulation of entrepreneurial skills or abilities. Microand small firms tend to lack complex hierarchical structures, and are less likely to be highly specialised work places where working conditions give employees the opportunity to perform a variety of tasks (Stuetzer et al., 2013). Performing various tasks might then develop balanced skills via learning-by-doing (Stuetzer et al., 2013). As Table 2.1 shows, self-employed are much more likely to have worked in a micro-enterprise than employees (61.4 against $33.2 \%$ ). 


\subsection{Data}

\subsubsection{Data source}

This chapter uses a longitudinal and nationally representative household survey, the ELMPS, administrated since 1998 by the Economic Research Forum in cooperation with the Central Agency for Public Mobilization and Statistics. The ELMPS is made up of four cross-sections 1988, 1998, 2006 and 2012 - the last three constituting a three-round panel. This chapter uses its last wave as a cross-section since, some variables only collected in its last wave are used. The 2012 round covers 12,060 households and 49,186 individuals, tracking households and individuals surveyed in 2006, plus a refresher sample or people interviewed in 1998. More details on data collection are available in Assaad and Kraft (2013). The ELMPS contains information on a variety of topics. Modules on labour market outcomes (4-6), residential mobility (3), current (12) and return (international) migration $(10)^{17}$ are of particular interest.

\subsubsection{Descriptive statistics}

Egypt has been a labour exporter since the 1970s economic reforms and opening of the country. It is the biggest labour exporter of the MENA region (Wahba, 2014). Two main trends have characterized Egyptian emigration: (i) relatively temporary migration to MENA countries, involving male household heads, for one to five years, and (ii) more permanent migration to Western countries, involving the entire nuclear family. Egyptians' first destinations were labourimporting MENA countries, in particular the oil-producing Gulf States, Libya and Iraq because of labour shortages. Since the 1980s and 1990s, the political instability some experienced and the replacement of Arab with Asian workers have had a significant effect on emigration destinations of Egyptians. Although the majority is still heading to MENA States, around $30 \%$ of Egyptian migrants were residing in OECD countries in 2000 (Wahba, 2009). Egypt's international migration comprises both low- and high-skilled migrants (Wahba, 2014). The early 1980s saw highly educated professionals (physicians, health workers, teachers), and less educated workers, usually working in construction, temporarily leaving for MENA countries. Nowadays, the proportion of less educated Egyptian migrants has decreased relative to the proportion of more educated workers, as demand from labour-importing MENA countries decreased with increasing inflows of Asian workers. Emigration flows have thus become more educated on average. Gulf States and Western countries tend to host the most educated Egyptian workers, whereas Libya, Jordan and Iraq host the least.

The estimation sample includes individuals born before 1990, as no return migrants are reported for individuals born after 1990. This is to avoid potential bias in the use of this estimation strategy. The sample excludes individuals who changed jobs after the January 2011 Uprising. It is also limited to those whose first destination country was a MENA country, as listed in Bertoli and Marchetta (2015) - Algeria, Iraq, Jordan, Kuwait, Lebanon, Libya, Oman, Qatar,

\footnotetext{
${ }^{17}$ This chapter uses this newly added module on return migration that surveys individuals between 15 and 59 years old, who worked abroad for at least six months, to classify individuals as return migrants.
} 
Saudi Arabia, Syria, the United Arab Emirates and Yemen. This helps to focus better on the effects induced by temporary migration since (i) Egyptians emigrating to Western countries tend to stay permanently, and (ii) the majority of Egyptians emigrates to MENA countries. Table 2.1 presents estimation sample descriptive statistics.

The outcome of interest is a binary variable taking value 1 if a working-age (16-64 year-old) individual is self-employed, and value 0, if employed. Out of 11,224 observations, $22.84 \%$ are self-employed. Three measures of a balanced skill profile are alternatively used:

(i) Accumulated occupations, a continuous variable capturing the number of occupational skills an individual has accumulated over the four last spells ${ }^{18}$ of his job history, either as a low-skilled blue-collar, high-skilled blue-collar, low-skilled white-collar or high-skilled white-collar workers; ${ }^{19}$

(ii) Accumulated industries, a continuous variable representing the number of industries (or sectors) an individual has worked in over the four last spells ${ }^{20}$ of his job history ${ }^{21}$ and

(iii) Accumulated jobs, a continuous variable recording the number of jobs an individual has had over his entire job history. ${ }^{22}$

These three measures of skill mix balance are not aggregated as each one may capture different dynamics. For instance, if accumulating occupational skills is likely to increase the degree of balance and how generalist an individual is, working in various industries may be correlated with a specialised skill profile. Only those with specialist occupational skills, either low- or high-skilled, would be able to work in different sectors, keeping the same occupation. Job accumulation - job turnover - in contrast, may affect the degree of risk aversion that plays a part in changing jobs. Individuals in the full estimation sample seem to have a relatively low degree of skill mix balance. They have accumulated, on average, 1.30 occupations, and worked in 1.20 sectors over their last four job spells. They have had 2.03 jobs on average over their entire job history. ${ }^{23}$

\footnotetext{
${ }^{18}$ In the 2012 wave of the ELMPS, information on occupations is reported only up to the last four job spells.

${ }^{19}$ Following the International Standard Classification of Occupations (ISCO-88), occupations are classified in terms of skill level and skill specialisation, forming four skill levels. Low-skilled blue-collar occupations correspond to skill level 1 occupations; high-skilled blue-collar to skill level 2; low-skilled white-collar to skill level 3; and high-skilled white-collar occupations to skill level 4 occupations.

${ }^{20}$ In the 2012 wave of the ELMPS, information sectors is reported only up to the last four job spells.

${ }^{21}$ Following the International Standard Industrial Classification of all economic activities (ISIC4).

${ }^{22}$ In the 2012 wave of the ELMPS, information on number of jobs is reported for the entire job history.

${ }^{23}$ This means that if an individual has only had two jobs in his lifetime, only these two jobs will be observed.
} 
Table 2.1 - Descriptive statistics of estimation sample

\begin{tabular}{|c|c|c|c|c|c|c|c|c|}
\hline & \multicolumn{2}{|c|}{ Full sample } & \multicolumn{2}{|c|}{ By status } & \multicolumn{2}{|c|}{ By migration } & \multicolumn{2}{|c|}{ Self-employed } \\
\hline & & & Empl. & Self. & Stay. & Retu. & Stay. & Retu. \\
\hline & Mean & $\mathrm{SD}$ & Mean & Mean & Mean & Mean & Mean & Mean \\
\hline Self-employed & .228 & .420 & .000 & 1.00 & .217 & .331 & 1.00 & 1.00 \\
\hline Returnee & .097 & .296 & .084 & .141 & .000 & 1.000 & .000 & 1.000 \\
\hline Years abroad & .442 & 2.02 & .343 & .779 & .000 & 4.55 & .000 & 5.53 \\
\hline Occupations & 1.30 & .510 & 1.28 & 1.38 & 1.27 & 1.58 & 1.35 & 1.56 \\
\hline Sectors & 1.20 & .471 & 1.20 & 1.22 & 1.16 & 1.65 & 1.17 & 1.55 \\
\hline Jobs & 2.03 & .877 & 1.98 & 2.21 & 1.90 & 3.25 & 2.04 & 3.23 \\
\hline Male & .837 & .369 & .822 & .887 & .821 & .983 & .870 & .992 \\
\hline Age & 38.2 & 10.8 & 37.1 & 42.0 & 37.6 & 44.1 & 41.5 & 45.0 \\
\hline Married & .825 & .380 & .808 & .881 & .810 & .960 & .866 & .972 \\
\hline Illiterate & .187 & .390 & .135 & .361 & .183 & .217 & .361 & .363 \\
\hline Literate (w/o diploma) & .045 & .206 & .038 & .066 & .042 & .067 & .065 & .069 \\
\hline Elementary sch. & .095 & .293 & .087 & .122 & .094 & .098 & .124 & .114 \\
\hline Middle sch. & .050 & .219 & .050 & .050 & .050 & .050 & .050 & .053 \\
\hline High sch. & .356 & .479 & .385 & .261 & .350 & .416 & .253 & .305 \\
\hline Post-sec., uni. and higher & .268 & .443 & .305 & .140 & .280 & .152 & .147 & .097 \\
\hline Literate mother & .213 & .409 & .235 & .137 & .223 & .122 & .144 & .094 \\
\hline Child dep. ratio & .296 & .231 & .291 & .312 & .293 & .320 & .310 & .325 \\
\hline Vocational sch. & .334 & .472 & & .238 & & & & .296 \\
\hline Father self-employed & .357 & .479 & .303 & .537 & .346 & .454 & .536 & .546 \\
\hline Past self-employment & .039 & .192 & .027 & .078 & .032 & .095 & .062 & .175 \\
\hline First job self-employed & .062 & .241 & .013 & .227 & .066 & .027 & .257 & .047 \\
\hline Years of unemployment & .688 & 1.962 & .768 & .415 & .700 & .573 & .418 & .396 \\
\hline Tenure & 14.1 & 9.97 & 13.7 & 15.5 & 14.0 & 15.0 & 15.6 & 14.9 \\
\hline Potential years work & 22.4 & 12.7 & 20.5 & 28.8 & 21.7 & 29.1 & 28.3 & 31.9 \\
\hline Savings & .077 & .267 & .075 & .085 & .075 & .093 & .083 & .097 \\
\hline Agriculture & .152 & .359 & .096 & .340 & .145 & .211 & .33 & .402 \\
\hline Mining & .003 & .050 & .003 & .000 & .003 & .003 & .001 & .000 \\
\hline Manufacturing & .127 & .333 & .139 & .089 & .131 & .091 & .090 & .078 \\
\hline Utilities & .020 & .139 & .026 & .000 & .020 & .017 & .000 & .000 \\
\hline Construction & .113 & .317 & .128 & .062 & .109 & .148 & .055 & .103 \\
\hline Trade & .169 & .375 & .115 & .352 & .173 & .131 & .366 & .263 \\
\hline Transport & .089 & .284 & .091 & .080 & .089 & .098 & .076 & .108 \\
\hline Business services & .036 & .185 & .037 & .032 & .037 & .027 & .034 & .022 \\
\hline Government & .258 & .438 & .332 & .007 & .260 & .243 & .008 & .003 \\
\hline Personal services & .035 & .184 & .034 & .038 & .035 & .031 & .041 & .022 \\
\hline Extraterrit. org. & .000 & .016 & .000 & .001 & .000 & .090 & .000 & .000 \\
\hline 2007 unemployment & .090 & .030 & .092 & .082 & .091 & .089 & .086 & .087 \\
\hline Micro-enterprise & .397 & .489 & .332 & .614 & .357 & .767 & .569 & .892 \\
\hline Oil price & 44.1 & 22.0 & 44.7 & 41.9 & 43.5 & 49.9 & 40.8 & 49.1 \\
\hline Distance $(1,000 \mathrm{kms})$ & 1.684 & .0379 & 1.684 & 1.686 & 1.685 & 1.681 & 1.687 & 1.681 \\
\hline $\mathbf{N}$ & & & 8,660 & 2,565 & 10,134 & 1,090 & 2,203 & 361 \\
\hline
\end{tabular}

Notes: Summary statistics for variables included in the analysis, after dropping observations with missing information, for the full sample, broken down by occupation and by migration experience as well as limited to self-employed individuals by migration. The sample consists of 16-64 year-old individuals $(\mathrm{N}=11,224)$. Means between treated (self-employed, returnees and selfemployed returnees) and control groups (respectively employees, stayers and self-employed stayers) statistically significantly different at the $10 \%$ significance level are in bold. 
Table 2.1 reveals notable differences between self-employed and employees. On average, those self-employed are more likely to be men, married, older and less educated than individuals working as employees. They are more likely to come from a poorer family and to have a father who was also self-employed at the time of their fifteenth birthday. They tend to have been self-employed in the past (including their first job), to have worked in a micro-enterprise, and to have experienced fewer years of unemployment than employees. Self-employed also tend to work relatively more in agriculture and in trade and employees as public servants. Figure 2.4 shows that those self-employed have accumulated significantly more occupational skills (1.38), sectors (1.22) and jobs (2.20), compared to employees (respectively 1.28, 1.99 and 1.9). ${ }^{24}$

Being a return migrant is defined as a binary variable, taking 1 if an individual has emigrated at 15 or older for work for at least six months, and returned to Egypt at the time of the survey; otherwise, 0 . About $10 \%$ of the estimation sample are return migrants who, on average, spent 4.55 years abroad. Those self-employed are more likely to have migrated than employees. Return migrants are significantly more often men, older, and less educated than stayers. They come from poorer households with a greater number of dependents. They are more likely to have had vocational training and self-employed father, and to have been self-employed in the past. They tend to work relatively more in agriculture and construction. Returnees show a higher rate of self-employment: 33.12 compared to $21.74 \%$ of stayers, the rest being wage-employed. Return migrants also display a significantly greater number of occupational skills, sectors and jobs, accumulated over their work experience, suggesting that they have a more balanced skill mix profile, as shown in Figure 2.5. ${ }^{25}$

It should also be noted that the real price of oil at 19 years old is significantly higher for return migrants compared to non-migrants, consistent with the oil price acting as a factor encouraging emigration. The average distance from governorate of birth to potential destination countries is, in contrast, significantly lower for return migrants compared to migrants. This is line with the previous section suggesting that distance proxies costs to migrate - the closer the average distance to destination countries, the greater the likelihood to migrate.

Moreover, limiting the sample to working-age self-employed, those who migrated appear to be more often men, older and more likely to be married and to come from poorer families than those who did not migrate. The former are also more likely to have had vocational training and to have set up a firm in the past, but less likely to have been self-employed in their first job. Figure 2.6 reveals that self-employed returnees have acquired substantially more skills (1.56, 1.55 and 3.23), worked in more sectors, and had a greater number of jobs than self-employed who have not migrated (respectively 1.35, 1.17 and 2.04). ${ }^{26}$

\footnotetext{
${ }^{24}$ Differences in occupational skills, sectors and jobs between wage and self-employed are statistically significant at the $10 \%$ significance level (cf. Table 2.1 ).

${ }^{25}$ Differences in occupational skills, sectors and jobs between return and non-migrants are statistically significant at the $10 \%$ significance level (cf. Table 2.1 ).

${ }^{26}$ Differences in occupational skills, sectors and jobs between self-employed return and non-migrants are statistically significant at the $10 \%$ significance level (cf. Table 2.1 ).
} 
Figure 2.4 - Skill mix profile by occupation

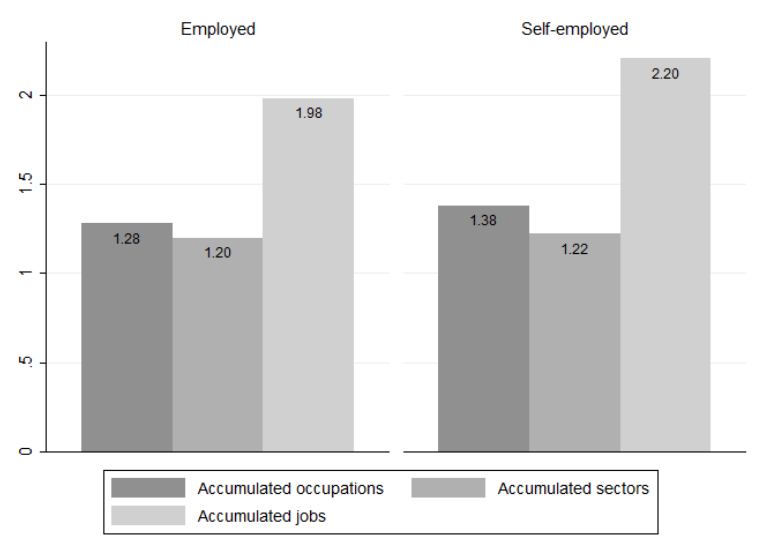

Figure 2.5 - Skill mix profile by migration experience

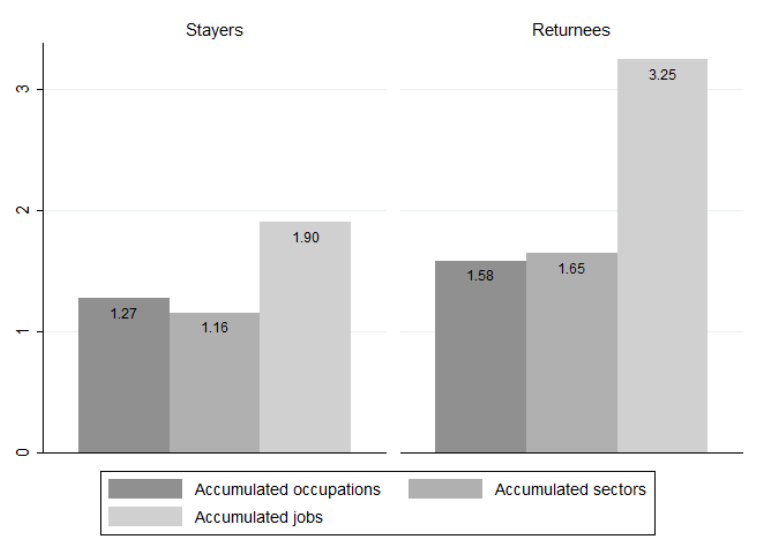

Figure 2.6 - Skill mix profile of self-employed by migration experience

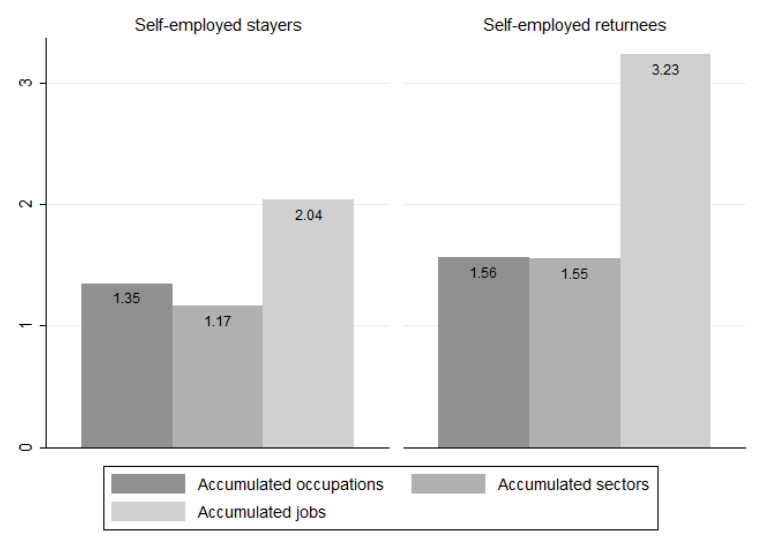




\subsection{Results}

\subsubsection{Benchmark specifications}

Table 2.2 presents GSEM reduced-form coefficient estimates of a SUR linear probability model of return migration, number of occupational skills, sectors or jobs accumulated, and selfemployment.

The sign and significance of the control variables do not significantly differ across specifications. Being male, having a father who was self-employed, reflecting a 'family' (cultural) entrepreneurial capital, and having been self-employed in his/her first job, a measure of entrepreneurial motivation, tend to increase the probability of a working-age individual of being self-employed. Years of potential work experience seem to have a negative, non-linear relationship with self-employment, suggesting that younger Egyptians often privilege selfemployed positions, whereas older ones, who are more averse to risk, have a lower propensity than prime-aged individuals to set up their own firms. Vocational training and past selfemployment experiences decrease the propensity to self-employment, suggesting that varied, non self-employed occupations are required prior to starting a business. Having to support children tends to increase the likelihood of self-employment, maybe out of necessity.

Micro-firm experience is positively correlated with exposure to different occupations, sectors and having held several jobs. This is consistent with the hypothesis that working in a micro-firm gives employees the opportunity to perform a variety of tasks, helping to develop a balanced skill mix via learning-by-doing (Stuetzer et al., 2013). Inflation-adjusted price of oil at age 19 interacted with the average distance to destination countries is a positive, strong and statistically significant instrument for return migration across all specifications. Despite the rather small magnitude of its coefficient estimates, it is close to what Wahba and Zenou (2012), Wahba (2015) and Bertoli and Marchetta (2015) obtain. While the interaction of these two variables has a significant and positive association with temporary migation, estimates from equation (1) run with only one of these variables, presented in Table A1, confirm that oil price increases, and average distance to destination countries decreases the probability to migrate, in line with the assumptions made in section 3. Table A2 presents the average marginal effects of oil price on the probability of return migration, holding migration distance constant at different values by increment of $25 \mathrm{kms}$. These simple slopes for oil price are significant for all values of migration distance, and increase in migration distance. Table A2, combined with Figure A1, plotting slopes for each value of migration distance, suggests that the importance of oil price as a pull factor for emigrating increases the further the average migration distance between respondents' governorates of birth and destination countries. In other words, the oil price and the average migration distance seem to compensate each other: the further a respondent is from the average destination country, i.e. the more discouraging migrating might be, the stronger the pulling effect of the oil price to emigrate. 
Table 2.2 - Benchmark coefficient estimates

\begin{tabular}{|c|c|c|c|c|c|c|c|c|c|}
\hline Variables & $\begin{array}{c}\text { Self- } \\
\text { employed } \\
(1)\end{array}$ & $\begin{array}{c}\text { Accumulated } \\
\text { occupations } \\
\text { (2) }\end{array}$ & $\begin{array}{c}\text { Returnee } \\
\text { (3) }\end{array}$ & $\begin{array}{c}\text { Self- } \\
\text { employed } \\
(4)\end{array}$ & $\begin{array}{c}\text { Accumulated } \\
\text { sectors } \\
(5)\end{array}$ & $\begin{array}{c}\text { Returnee } \\
\text { (6) }\end{array}$ & $\begin{array}{c}\text { Self- } \\
\text { employed } \\
(7)\end{array}$ & $\begin{array}{c}\text { Accumulated } \\
\text { jobs } \\
(8)\end{array}$ & $\begin{array}{c}\text { Returnee } \\
\text { (9) }\end{array}$ \\
\hline Father was self-employed & $\begin{array}{c}0.0975^{* * *} \\
(0.0081)\end{array}$ & & & $\begin{array}{c}0.0975^{* * *} \\
(0.0081)\end{array}$ & & & $\begin{array}{c}0.0975^{* * *} \\
(0.0081)\end{array}$ & & \\
\hline Vocational high-school & $\begin{array}{c}-0.0217^{* * *} \\
(0.0073)\end{array}$ & & & $\begin{array}{c}-0.0217^{* * *} \\
(0.0073)\end{array}$ & & & $\begin{array}{c}-0.0217^{* * *} \\
(0.0073)\end{array}$ & & \\
\hline Past self-employment & $\begin{array}{c}-0.1786^{* * *} \\
(0.0293)\end{array}$ & & & $\begin{array}{c}-0.1786^{* * *} \\
(0.0293)\end{array}$ & & & $\begin{array}{c}-0.1786^{* * * *} \\
(0.0293)\end{array}$ & & \\
\hline First job was self-employed & $\begin{array}{c}0.6909^{* * *} \\
(0.0154)\end{array}$ & & & $\begin{array}{c}0.6909^{* * *} \\
(0.0154)\end{array}$ & & & $\begin{array}{c}0.6909^{* * *} \\
(0.0154)\end{array}$ & & \\
\hline Years of unemployment & $\begin{array}{c}-0.0033^{*} \\
(0.0018)\end{array}$ & & & $\begin{array}{c}-0.0033^{*} \\
(0.0018)\end{array}$ & & & $\begin{array}{c}-0.0033^{*} \\
(0.0018)\end{array}$ & & \\
\hline Tenure & $\begin{array}{l}-0.0022 \\
(0.0015)\end{array}$ & & & $\begin{array}{l}-0.0022 \\
(0.0015)\end{array}$ & & & $\begin{array}{l}-0.0022 \\
(0.0015)\end{array}$ & & \\
\hline Tenure squared & $\begin{array}{c}-0.0001^{* * *} \\
(0.0000)\end{array}$ & & & $\begin{array}{c}-0.0001^{* * *} * \\
(0.0000)\end{array}$ & & & $\begin{array}{c}-0.0001^{* * *} \\
(0.0000)\end{array}$ & & \\
\hline Years of potential work experience & $\begin{array}{c}-0.0024^{*} \\
(0.0014)\end{array}$ & & & $\begin{array}{c}-0.0024^{*} \\
(0.0014)\end{array}$ & & & $\begin{array}{c}-0.0024^{*} \\
(0.0014)\end{array}$ & & \\
\hline Years of potential work experience squared & $\begin{array}{c}0.0003^{* * *} \\
(0.0000)\end{array}$ & & & $\begin{array}{c}0.0003 * * * \\
(0.0000)\end{array}$ & & & $\begin{array}{c}0.0003^{* * *} \\
(0.0000)\end{array}$ & & \\
\hline 2007 unemployment rate & $\begin{array}{l}-0.8277 \\
(0.5431)\end{array}$ & & & $\begin{array}{l}-0.8277 \\
(0.5431)\end{array}$ & & & $\begin{array}{l}-0.8277 \\
(0.5431)\end{array}$ & & \\
\hline Micro-firm & $\begin{array}{c}0.1448^{* * *} \\
(0.0095)\end{array}$ & $\begin{array}{c}0.4655^{* * *} \\
(0.0110)\end{array}$ & & $\begin{array}{c}0.1448^{* * *} \\
(0.0095)\end{array}$ & $\begin{array}{c}0.2829^{* * *} \\
(0.0109)\end{array}$ & & $\begin{array}{c}0.1448^{* * *} \\
(0.0095)\end{array}$ & $\begin{array}{c}0.9142^{* * *} \\
(0.0165)\end{array}$ & \\
\hline$\frac{\gamma_{2}}{\alpha_{2}} \cdot \frac{\alpha_{3}}{\delta_{2}}$ & & $\begin{array}{c}.1191^{* * *} \\
(.0421)\end{array}$ & & & $\begin{array}{c}.2662^{* * *} \\
(.0706)\end{array}$ & & & $\begin{array}{l}.0515 \\
(.0345)\end{array}$ & \\
\hline Observations & 10,592 & 10,592 & 10,592 & 10,592 & 10,592 & 10,592 & 10,592 & 10,592 & 10,592 \\
\hline Variance of errors & $\begin{array}{c}0.1243^{* * *} \\
(0.0020)\end{array}$ & $\begin{array}{c}0.2055^{* * *} \\
(0.0039)\end{array}$ & $\begin{array}{c}0.0884^{* * *} \\
(0.0022)\end{array}$ & $\begin{array}{c}0.1243^{* * *} \\
(0.0020)\end{array}$ & $\begin{array}{c}0.2041^{* * *} \\
(0.0053)\end{array}$ & $\begin{array}{c}0.0884^{* * *} \\
(0.0022)\end{array}$ & $\begin{array}{c}0.1243^{* * *} \\
(0.0020)\end{array}$ & $\begin{array}{c}0.5561^{* * *} \\
(0.0080)\end{array}$ & $\begin{array}{c}0.0884^{* * *} \\
(0.0022)\end{array}$ \\
\hline F-statistics (returnee) & & & 100.73 & & & 100.73 & & & 100.73 \\
\hline P-value (returnee) & & & .0000 & & & .0000 & & & .0000 \\
\hline
\end{tabular}

Notes: The dependent variable is a binary variable taking unity if a working-age individual is self-employed; 0 , if employed, wage-employed or unpaid, contributing to family work. Observations are working-age individuals with no migration experience or return migrants from abroad, excluding individuals living in a household with members currently abroad and those living in a household with members who returned from migration abroad, adding governorate fixed effects. Columns (1), (4) and (7) present GSEM coefficient estimates of the self-employment equation; columns (2), (5) and (8) present GSEM coefficient estimates of the balanced skill mix (accumulated occupations, sectors or jobs, respectively) equation; and
columns (3), (6) and (9) present GSEM coefficient estimates of the return migration equation. Standard errors clustered at the household level are in parentheses. ${ }^{* * *} \mathrm{p}<0.01,{ }^{* *} \mathrm{p}<0.05$, columns
${ }^{*} \mathrm{p}<0.1$. 
Benchmark coefficient estimates (continued)

\begin{tabular}{|c|c|c|c|c|c|c|c|c|c|}
\hline Variables & $\begin{array}{c}\text { Self- } \\
\text { employed } \\
(1)\end{array}$ & $\begin{array}{c}\text { Accumulated } \\
\text { occupations } \\
\text { (2) }\end{array}$ & $\begin{array}{c}\text { Returnee } \\
\text { (3) }\end{array}$ & $\begin{array}{c}\text { Self- } \\
\text { employed } \\
(4)\end{array}$ & $\begin{array}{c}\text { Accumulated } \\
\text { sectors } \\
(5)\end{array}$ & $\begin{array}{c}\text { Returnee } \\
\text { (6) }\end{array}$ & $\begin{array}{c}\text { Self- } \\
\text { employed } \\
(7)\end{array}$ & $\begin{array}{c}\text { Accumulated } \\
\text { jobs } \\
(8)\end{array}$ & $\begin{array}{c}\text { Returnee } \\
\qquad(9)\end{array}$ \\
\hline Male & $\begin{array}{c}0.0222^{* * *} \\
(0.0081)\end{array}$ & $\begin{array}{c}0.1027^{* * *} \\
(0.0086)\end{array}$ & $\begin{array}{c}0.0872^{* * *} \\
(0.0046)\end{array}$ & $\begin{array}{c}0.0222^{* * *} \\
(0.0081)\end{array}$ & $\begin{array}{c}0.0996^{* * *} \\
(0.0075)\end{array}$ & $\begin{array}{c}0.0872^{* * *} \\
(0.0046)\end{array}$ & $\begin{array}{c}0.0222^{* * *} \\
(0.0081)\end{array}$ & $\begin{array}{c}0.1702^{* * *} \\
(0.0194)\end{array}$ & $\begin{array}{c}0.0872^{* * * *} \\
(0.0046)\end{array}$ \\
\hline Married & $\begin{array}{c}-0.0230^{* *} \\
(0.0096)\end{array}$ & $\begin{array}{c}0.0628^{* * *} \\
(0.0114)\end{array}$ & $\begin{array}{c}0.0916^{* * *} \\
(0.0065)\end{array}$ & $\begin{array}{c}-0.0230^{* *} \\
(0.0096)\end{array}$ & $\begin{array}{c}0.0756^{* * *} \\
(0.0107)\end{array}$ & $\begin{array}{c}0.0916^{* * *} \\
(0.0065)\end{array}$ & $\begin{array}{c}-0.0230^{* *} \\
(0.0096)\end{array}$ & $\begin{array}{c}0.2768^{* * *} \\
(0.0206)\end{array}$ & $\begin{array}{c}0.0916^{* * *} \\
(0.0065)\end{array}$ \\
\hline Literate mother & $\begin{array}{c}0.0136 \\
(0.0087)\end{array}$ & $\begin{array}{c}0.0071 \\
(0.0115)\end{array}$ & $\begin{array}{c}-0.0191 * * * \\
(0.0070)\end{array}$ & $\begin{array}{c}0.0136 \\
(0.0087)\end{array}$ & $\begin{array}{c}0.0168 \\
(0.0117)\end{array}$ & $\begin{array}{c}-0.0191 * * * \\
(0.0070)\end{array}$ & $\begin{array}{c}0.0136 \\
(0.0087)\end{array}$ & $\begin{array}{c}0.0333 \\
(0.0213)\end{array}$ & $\begin{array}{c}-0.0191^{* * *} \\
(0.0070)\end{array}$ \\
\hline Under 15 dependency ratio & $\begin{array}{c}0.1319 * * * \\
(0.0180)\end{array}$ & $\begin{array}{c}0.0034 \\
(0.0221)\end{array}$ & $\begin{array}{l}-0.0067 \\
(0.0147)\end{array}$ & $\begin{array}{c}0.1319 * * * \\
(0.0180)\end{array}$ & $\begin{array}{l}-0.0077 \\
(0.0224)\end{array}$ & $\begin{array}{l}-0.0067 \\
(0.0147)\end{array}$ & $\begin{array}{c}0.1319^{* * *} \\
(0.0180)\end{array}$ & $\begin{array}{c}-0.0852^{* *} \\
(0.0374)\end{array}$ & $\begin{array}{l}-0.0067 \\
(0.0147)\end{array}$ \\
\hline Literate (without diploma) & & $\begin{array}{c}0.1358^{* * * *} \\
(0.0278)\end{array}$ & $\begin{array}{c}0.0281 \\
(0.0176)\end{array}$ & & $\begin{array}{c}0.0937^{* * *} \\
(0.0285)\end{array}$ & $\begin{array}{c}0.0281 \\
(0.0176)\end{array}$ & & $\begin{array}{c}0.2114^{* * *} \\
(0.0361)\end{array}$ & $\begin{array}{c}0.0281 \\
(0.0176)\end{array}$ \\
\hline Elementary school & & $\begin{array}{c}0.1076^{* * *} \\
(0.0191)\end{array}$ & $\begin{array}{l}-0.0143 \\
(0.0119)\end{array}$ & & $\begin{array}{c}0.0582^{* * *} \\
(0.0185)\end{array}$ & $\begin{array}{l}-0.0143 \\
(0.0119)\end{array}$ & & $\begin{array}{c}0.1065^{* * *} \\
(0.0252)\end{array}$ & $\begin{array}{l}-0.0143 \\
(0.0119)\end{array}$ \\
\hline Middle school & & $\begin{array}{c}0.0825^{* * * *} \\
(0.0239)\end{array}$ & $\begin{array}{l}-0.0179 \\
(0.0147)\end{array}$ & & $\begin{array}{c}0.0501^{* *} \\
(0.0229)\end{array}$ & $\begin{array}{l}-0.0179 \\
(0.0147)\end{array}$ & & $\begin{array}{c}0.1578^{* * *} \\
(0.0332)\end{array}$ & $\begin{array}{l}-0.0179 \\
(0.0147)\end{array}$ \\
\hline High school & & $\begin{array}{c}0.1759^{* * *} * \\
(0.0135)\end{array}$ & $\begin{array}{c}0.0109 \\
(0.0090)\end{array}$ & & $\begin{array}{c}0.1209^{* * *} \\
(0.0131)\end{array}$ & $\begin{array}{c}0.0109 \\
(0.0090)\end{array}$ & & $\begin{array}{c}0.3140^{* * *} \\
(0.0196)\end{array}$ & $\begin{array}{c}0.0109 \\
(0.0090)\end{array}$ \\
\hline Post-secondary, university and higher & & $\begin{array}{c}0.1166^{* * *} \\
(0.0145)\end{array}$ & $\begin{array}{c}-0.0272^{* * *} \\
(0.0092)\end{array}$ & & $\begin{array}{c}0.0872^{* * *} \\
(0.0142)\end{array}$ & $\begin{array}{c}-0.0272^{* * *} \\
(0.0092)\end{array}$ & & $\begin{array}{c}0.3127^{* * *} \\
(0.0237)\end{array}$ & $\begin{array}{c}-0.0272^{* * *} \\
(0.0092)\end{array}$ \\
\hline Oil price X Distance & & $\begin{array}{c}0.0004^{* * * *} \\
(0.0001)\end{array}$ & $\begin{array}{c}0.0009^{* * *} \\
(0.0001)\end{array}$ & & $\begin{array}{c}0.0005^{* * *} \\
(0.0001)\end{array}$ & $\begin{array}{c}0.0009^{* * *} \\
(0.0001)\end{array}$ & & $\begin{array}{c}0.0003 \\
(0.0002)\end{array}$ & $\begin{array}{c}0.0009^{* * *} * \\
(0.0001)\end{array}$ \\
\hline Constant & $\begin{array}{c}0.1090 \\
(0.0704)\end{array}$ & $\begin{array}{c}0.8404^{* * *} \\
(0.0194)\end{array}$ & $\begin{array}{c}-0.1060^{* * *} \\
(0.0123)\end{array}$ & $\begin{array}{c}0.1090 \\
(0.0704)\end{array}$ & $\begin{array}{c}0.8331^{* * *} \\
(0.0191)\end{array}$ & $\begin{array}{c}-0.1060^{* * * *} \\
(0.0123)\end{array}$ & $\begin{array}{c}0.1090 \\
(0.0704)\end{array}$ & $\begin{array}{c}1.0783^{* * *} \\
(0.0337)\end{array}$ & $\begin{array}{c}-0.1060^{* * *} \\
(0.0123)\end{array}$ \\
\hline Governorate fixed effects & Yes & No & No & Yes & No & No & Yes & No & No \\
\hline$\frac{\gamma_{2}}{\alpha_{2}} \cdot \frac{\alpha_{3}}{\delta_{2}}$ & & $\begin{array}{c}.1191^{* * *} \\
(.0421)\end{array}$ & & & $\begin{array}{c}.2662^{* * *} \\
(.0706)\end{array}$ & & & $\begin{array}{l}.0515 \\
(.0345)\end{array}$ & \\
\hline Observations & 10,592 & 10,592 & 10,592 & 10,592 & 10,592 & 10,592 & 10,592 & 10,592 & 10,592 \\
\hline Variance of errors & $\begin{array}{c}0.1243^{* * *} \\
(0.0020)\end{array}$ & $\begin{array}{c}0.2055^{* * *} \\
(0.0039)\end{array}$ & $\begin{array}{c}0.0884 * * * \\
(0.0022)\end{array}$ & $\begin{array}{c}0.1243^{* * *} \\
(0.0020)\end{array}$ & $\begin{array}{c}0.2041^{* * *} * \\
(0.0053)\end{array}$ & $\begin{array}{c}0.0884 * * * \\
(0.0022)\end{array}$ & $\begin{array}{c}0.1243^{* * *} \\
(0.0020)\end{array}$ & $\begin{array}{c}0.5561^{* * *} \\
(0.0080)\end{array}$ & $\begin{array}{c}0.0884^{* * *} \\
(0.0022)\end{array}$ \\
\hline $\begin{array}{l}\text { F-statistics (returnee) } \\
\text { P-value (returnee) }\end{array}$ & & & $\begin{array}{c}100.73 \\
.0000\end{array}$ & & & $\begin{array}{c}100.73 \\
.0000\end{array}$ & & & $\begin{array}{c}100.73 \\
.0000\end{array}$ \\
\hline
\end{tabular}

Notes: The dependent variable is a binary variable taking unity if a working-age individual is self-employed; 0 , if employed, wage-employed or unpaid, contributing to family work Observations are working-age individuals with no migration experience or return migrants from abroad, excluding individuals living in a household with members currently abroad and those living in a household with members who returned from migration abroad, adding governorate fixed effects. Columns (1), (4) and (7) present GSEM coefficient estimates of the self-employment equation; columns (2), (5) and (8) present GSEM coefficient estimates of the balanced skill mix (accumulated occupations, sectors or jobs, respectively) equation; and columns (3), (6) and (9) present GSEM coefficient estimates of the return migration equation. Standard errors clustered at the household level are in parentheses. ${ }^{* * *}$ $\mathrm{p}<0.01, * * \mathrm{p}<0.05, * \mathrm{p}<0.1$ 
The marginal effects of return migration on self-employment through the development of a balanced skill profile are displayed at the bottom of Table 2.2. Having migrated statistically significantly increases the probability of being self-employed, as accumulating occupational and sectoral experience increases the likelihood of being self-employed by 11.91, 26.62 percentage points, respectively. The marginal effect of migration on self-employment through the accumulation of jobs has a positive but insignificant effect. Using a continuous variable measuring return migration, years abroad, as in Table 2.3, yields estimates similar in sign and significance, albeit of a much smaller magnitude. An additional year abroad increases the likelihood of being self-employed by 1.99 percentage points via exposure to diverse occupations; by 4.44 , when exposed to multiple industries; and by 0.86 , the greater the number of jobs had (insignificant). ${ }^{27}$

These results suggest that migration can contribute to the formation of entrepreneurial abilities by building skills through varied occupations and industrial sectors. These findings corroborate those of Lechmann and Schnabel (2014) and Hessels et al. (2014). Migration appears to be a process shaping entrepreneurs. The job accumulation channel is weaker. Changing jobs - job turnover - could affect entrepreneurial mindsets ${ }^{28}$ by lowering the degree of risk aversion to job change, rather than affecting entrepreneurial abilities, ${ }^{29}$ as accumulating occupations and sectors do. Job experience might thus not be a relevant measure of, or might not contribute to the formation of, a skill mix conducive to entrepreneurship as such; this might happen by an alternative mechanism such as the degree of risk aversion.

\subsubsection{Robustness checks}

The robustness of the identification strategy is checked, as in Bertoli and Marchetta (2015). First, Figure 2.2 showed that the steady decrease in the share of returnees from 1979 till the end of the series, in 1989, does not match the peak in real oil price starting in the late 1980s. It is possible that Egyptians born in 1979 or later, and who emigrated to MENA countries in the early 2000s have not yet returned to Egypt. Alternatively, if they have, they may not be representative of the pool of Egyptians who left in the 2000s. Therefore, this trend might not necessarily mirror a change in the relationship between historical real price of oil and temporary migration used to control for the endogeneity of migration.

Table 2.3 presents estimates of a sample limited to working-age individuals born before 1979, for which the real price of oil at age 20 is used, applying the same selection criterion for instrument selection as above. Coefficient estimates and marginal effects of return migration on self-employment do not differ in sign from benchmark results, but magnitude and statistical significance increase. Being a return migrant of working age and born before 1979 increases the

\footnotetext{
${ }^{27}$ Readers should be cautious in interpreting these results as the estimated linear probability model does not account for the censored nature of the number of years abroad.

${ }^{28}$ Entrepreneurial mindsets are defined as 'the socio-emotional skills and overall awareness of entrepreneurship associated with entrepreneurial motivation and future success as an entrepreneur' such as self-confidence, leadership, creativity, risk propensity or resilience (Valerio et al., 2014, p. 36).

${ }^{29}$ Entrepreneurial abilities are defined as 'entrepreneurs' competencies, knowledge, and associated technical skills', e.g. general business skills and basic skills to set up a firm (Valerio et al., 2014, p. 38).
} 
likelihood of self-employment with the number of occupations (17.98 percentage points), sectors (28.17) and jobs (21.42) (significant).

Second, if the historical price of oil is assumed to drive the demand for non-native labour both directly, in oil-producing countries, and indirectly, in non-oil producing countries, some could argue that the later effect is weaker, if not insignificant. As in Bertoli and Marchetta (2015), people who first emigrated to non-oil producing countries - Jordan, Lebanon, Syria and Yemen - are excluded from the estimation sample. Table 2.3 shows that coefficient estimates and marginal effects of return migration on self-employment follow the same pattern as benchmark results. Return migration increases the likelihood of self-employment with the number of occupations (10.13 percentage points), and with the number of sectors (27.40). The job accumulation channel, with a positive sign, remains statistically insignificant. In contrast, results do not hold for non-oil producing countries, as the last set of rows of Table 2.3 suggests. The coefficient estimate of the exclusion restriction of equation (1), albeit positive, is not statistically significant. In spite of not being precisely estimated, signs are negative, indicating that migrating to non-oil producing countries, i.e. migrating as replacement workers, could decrease the probability to be self-employed on return to Egypt, the more varied migrants' skill mix is compared to non-migrants. ${ }^{30}$

\subsubsection{Heterogeneity}

In Table 2.4, the sample is split up by sector of occupation, location and possession of savings, to understand which subgroups drive the migration effect found on self-employment. The positive effect of a migration-induced jack-of-all-trades effect on self-employment is driven by those working in non-agricultural sectors. Table 2.4 points to an insignificant relationship between return migration and self-employment through the development of a balanced skill set. None marginal effect is significant, and the sign on the number of occupations is negative. Benchmark results are driven by those working in non-agricultural sectors.

This difference in sign and significance suggests that agricultural entrepreneurship might not require the same set of occupational skills as non-agricultural sectors, but a rather specialized skill mix. Alternatively, it can mean that return migration affects self-employment in agricultural sectors through channels other than the accumulation of human capital, e.g. migration-induced monetary flows. This would support McCormick and Wahba's (2001) findings that overseas savings have a stronger effect on self-employment in agriculture than human capital, if the self-employed in agriculture are of lower educational attainment or did not change occupations while away or upon return - if migrating did not give them the opportunity to accumulate diverse enough occupational skills. This may also reflect the fact that the Egyptian agricultural sector has a rather traditional structure, marked by a high degree of land fragmentation (Morsy et al., 2014). As a consequence, a substantial part of individual farmers work on small low-productivity plots, and are unable to benefit from economies of scale. Working in agriculture, and in particular being farmer, may not require the experience gathered

\footnotetext{
${ }^{30}$ Regressions could not be run for the different destination countries separately because of too few respondents migrating to each country.
} 
while working abroad. In other words, having migrated may not be 'enough' or relevant, as it may not provide the capital necessary to start agricultural activities or access land.

Table 2.3 - Robustness checks

\begin{tabular}{|c|c|c|c|c|}
\hline & & $\begin{array}{c}\text { Accumulated } \\
\text { occupations } \\
\text { (1) }\end{array}$ & $\begin{array}{c}\text { Accumulated } \\
\text { sectors } \\
(2)\end{array}$ & $\begin{array}{c}\text { Accumulated } \\
\text { jobs } \\
(3)\end{array}$ \\
\hline \multirow[t]{4}{*}{ Benchmark } & $\frac{\gamma_{2}}{\alpha_{2}} \cdot \frac{\alpha_{3}}{\delta_{2}}$ & $\begin{array}{c}.1191 * * * \\
(.0421)\end{array}$ & $\begin{array}{c}.2662^{* * * *} \\
(.0706)\end{array}$ & $\begin{array}{l}.0515 \\
(.0345)\end{array}$ \\
\hline & F-statistic (returnee) & 100.73 & 100.73 & 100.73 \\
\hline & $\mathrm{P}$-value (returnee) & .0000 & .0000 & .0000 \\
\hline & $\mathrm{N}$ & 10,592 & 10,592 & 10,592 \\
\hline \multirow[t]{4}{*}{ Years abroad } & $\frac{\gamma_{2}}{\alpha_{2}} \cdot \frac{\alpha_{3}}{\delta_{2}}$ & $.0199 * * *$ & $.0444^{* * *}$ & $\begin{array}{l}.0086 \\
(0058)\end{array}$ \\
\hline & F-statistics (years abroad) & $\begin{array}{c}(.0073) \\
54.57\end{array}$ & $\begin{array}{c}(.0127) \\
54.57\end{array}$ & $\begin{array}{c}(.0058) \\
54.57\end{array}$ \\
\hline & P-value (years abroad) & .0000 & .0000 & .0000 \\
\hline & $\mathrm{N}$ & 10,592 & 10,592 & 10,592 \\
\hline \multirow[t]{4}{*}{ Born before 1979} & $\frac{\gamma_{2}}{\alpha_{2}} \cdot \frac{\alpha_{3}}{\delta_{2}}$ & $\begin{array}{c}.1798^{* * *} \\
(.0435)\end{array}$ & $\begin{array}{c}.2817^{* * *} \\
(.0658)\end{array}$ & $\begin{array}{c}.2142^{* * *} \\
(.0363)\end{array}$ \\
\hline & F-statistics (returnee) & 139.15 & 139.15 & 139.15 \\
\hline & $\mathrm{P}$-value (returnee) & .0000 & .0000 & .0000 \\
\hline & $\mathrm{N}$ & 6,434 & 6,434 & 6,434 \\
\hline \multirow[t]{4}{*}{ Oil-producing countries } & $\frac{\gamma_{2}}{\alpha_{2}} \cdot \frac{\alpha_{3}}{\delta_{2}}$ & $.1013^{* *}$ & $.2740^{* * *}$ & .0384 \\
\hline & F-statistics (returnee) & $\begin{array}{l}(.0423) \\
101.37\end{array}$ & $\begin{array}{l}(.0738) \\
101.37\end{array}$ & $\begin{array}{l}(.0361) \\
101.37\end{array}$ \\
\hline & $\mathrm{P}$-value (returnee) & .0000 & .0000 & .0000 \\
\hline & $\mathrm{N}$ & 10,409 & 10,409 & 10,409 \\
\hline \multirow[t]{4}{*}{ Non oil-producing countries } & $\frac{\gamma_{2}}{\alpha_{2}} \cdot \frac{\alpha_{3}}{\delta_{2}}$ & $\begin{array}{l}-.0545 \\
(.4903)\end{array}$ & $\begin{array}{c}-1.2882 \\
(1.1860)\end{array}$ & $\begin{array}{r}-1.5246 \\
(.9722)\end{array}$ \\
\hline & F-statistics (returnee) & 4.10 & 4.10 & 4.10 \\
\hline & P-value (returnee) & 0.0430 & 0.0430 & 0.0430 \\
\hline & $\mathrm{N}$ & 9,685 & 9,685 & 9,685 \\
\hline
\end{tabular}

Notes: Please, refer to Table 2.2 .

In addition, Table 2.4 shows that return migration increases the likelihood of self-employment with the number of distinct occupations, sectors and jobs, mostly in rural areas. This suggests that return migration in Egypt might affect rural off-farm entrepreneurship, potentially contributing to the structural reallocation of its labour force.

Lastly, since return migrants are significantly more likely to have savings (9.27\%) than nonmigrants (7.23) (see Table 2.1), not accounting for potentially migration-induced savings could bias the estimates. In the absence of an additional instrumental variable, the financial and human capital channels are disentangled by running the above SUR linear probability model on two subsamples, based on possession of savings. Table 2.4 reveals that having migrated increases the probability of being self-employed upon return by developing a balanced skill mix only for those who do not have savings. These estimates support the previous set of results for individuals who do not have savings, indicating the existence of a migration-induced entrepreneurial human capital, beyond any potential wealth effect. 
Table 2.4 - Heterogenous effects

\begin{tabular}{|c|c|c|c|c|}
\hline & & $\begin{array}{l}\text { Accumulated } \\
\text { occupations } \\
\text { (1) }\end{array}$ & $\begin{array}{c}\text { Accumulated } \\
\text { sectors } \\
(2)\end{array}$ & $\begin{array}{c}\text { Accumulated } \\
\text { jobs } \\
(3)\end{array}$ \\
\hline \multirow[t]{4}{*}{ Benchmark } & $\frac{\gamma_{2}}{\alpha_{2}} \cdot \frac{\alpha_{3}}{\delta_{2}}$ & $\begin{array}{c}.1191^{* * *} \\
(.0421)\end{array}$ & $\begin{array}{c}.2662^{* * *} \\
(.0706)\end{array}$ & $\begin{array}{c}.0515 \\
(.0345)\end{array}$ \\
\hline & F-statistic (returnee) & 100.73 & 100.73 & 100.73 \\
\hline & P-value (returnee) & .0000 & .0000 & .0000 \\
\hline & $\mathrm{N}$ & 10,592 & 10,592 & 10,592 \\
\hline \multirow[t]{4}{*}{ Agriculture } & $\frac{\gamma_{2}}{\alpha_{2}} \cdot \frac{\alpha_{3}}{\delta_{2}}$ & $\begin{array}{l}-.4427 \\
(.5679)\end{array}$ & $\begin{array}{c}.0591 \\
(.3478)\end{array}$ & $\begin{array}{c}.0330 \\
(.0947)\end{array}$ \\
\hline & F-statistics (returnee) & 14.61 & 14.61 & 14.61 \\
\hline & P-value (returnee) & .0001 & .0001 & .0001 \\
\hline & $\mathrm{N}$ & 1,587 & 1,587 & 1,587 \\
\hline \multirow[t]{4}{*}{ Non agriculture } & $\frac{\gamma_{2}}{\alpha_{2}} \cdot \frac{\alpha_{3}}{\delta_{2}}$ & $\begin{array}{c}.0879 * * * \\
(.0307)\end{array}$ & $\begin{array}{c}.2245^{* * *} \\
(.0604)\end{array}$ & $\begin{array}{c}.0453 \\
(.0322)\end{array}$ \\
\hline & F-statistics (returnee) & 89.25 & 89.25 & 89.25 \\
\hline & P-value (returnee) & .0000 & .0000 & .0000 \\
\hline & $\mathrm{N}$ & 9,005 & 9,005 & 9,005 \\
\hline \multirow[t]{4}{*}{ Rural } & $\frac{\gamma_{2}}{\alpha_{2}} \cdot \frac{\alpha_{3}}{\delta_{2}}$ & $.1672^{* * *}$ & $\begin{array}{c}3039^{* * *} \\
(0882)\end{array}$ & $.07927^{* *}$ \\
\hline & F-statistics (returnee) & 68.81 & 68.81 & 68.81 \\
\hline & P-value (returnee) & .0000 & .0000 & .0000 \\
\hline & $\mathrm{N}$ & 5,454 & 5,454 & 5,454 \\
\hline \multirow[t]{4}{*}{ Urban } & $\frac{\gamma_{2}}{\alpha_{2}} \cdot \frac{\alpha_{3}}{\delta_{2}}$ & $\begin{array}{c}.0802 \\
(.0635)\end{array}$ & $\begin{array}{l}.2343^{*} \\
(.1250)\end{array}$ & $\begin{array}{c}.0205 \\
(.0705)\end{array}$ \\
\hline & F-statistics (returnee) & 33.49 & 33.49 & 33.49 \\
\hline & P-value (returnee) & .0000 & .0000 & .0000 \\
\hline & $\mathrm{N}$ & 5,138 & 5,138 & 5,138 \\
\hline \multirow[t]{4}{*}{ Without savings } & $\frac{\gamma_{2}}{\alpha_{2}} \cdot \frac{\alpha_{3}}{\delta_{2}}$ & $\begin{array}{c}.1247^{* * *} \\
(.0421)\end{array}$ & $\begin{array}{c}.2597^{* * *} \\
(.0689)\end{array}$ & $\begin{array}{c}.0437 \\
(.0326)\end{array}$ \\
\hline & F-statistics (instrument) & 91.07 & 91.07 & 91.07 \\
\hline & $\mathrm{P}$-value (instrument) & .0000 & .0000 & .0000 \\
\hline & $\mathrm{N}$ & 9,790 & 9,790 & 9,790 \\
\hline \multirow[t]{4}{*}{ With savings } & $\frac{\gamma_{2}}{\alpha_{2}} \cdot \frac{\alpha_{3}}{\delta_{2}}$ & $\begin{array}{c}.0333 \\
(.2620)\end{array}$ & $\begin{array}{c}.3895 \\
(.5946)\end{array}$ & $\begin{array}{c}.3383 \\
(.3783)\end{array}$ \\
\hline & F-statistics (returnee) & 9.88 & 9.88 & 9.88 \\
\hline & P-value (returnee) & .0017 & .0017 & .0017 \\
\hline & $\mathrm{N}$ & 802 & 802 & 802 \\
\hline
\end{tabular}

Notes: Please, refer to Table 2.2 .

With reference to benchmark specifications (Table 2.2), whether return migration influences entrepreneurship is eventually assessed through the formation of a varied skill set not only in terms of productivity, as a measure of entrepreneurial performance. Not all entrepreneurial activities have lasting impacts on economic development. Being self-employed might not be a good indicator of entrepreneurship, since most self-employed neither innovate much nor generate jobs; many fail. Whether return migrants survive in their entrepreneurial activities has received relatively little attention in the literature. ${ }^{31}$ Business survival might indeed be a precondition for a lasting, positive effect of migrants' activities upon return, in particular in a developing

\footnotetext{
${ }^{31}$ To the best of the author's knowledge, only Marchetta (2012) has specifically studied the persistence of returnees' entrepreneurial activities.
} 
country context, where the turnover of MSEs is high (Marchetta, 2012).

Similarly to the decision to become self-employed, the accumulation of financial, human or social capitals while abroad could, respectively, loosen financial constraints to set up a firm, grow or thrive by improving entrepreneurs' abilities and developing their networks. Migration experience could thus help to establish more stable activities. However, during their migration, migrants may lose some social capital at home, a disadvantage upon return as contacts can be useful in managing rather small entities. Returnees might also enjoy more or better wage-employed opportunities upon return, which could reduce their incentives to opt for self-employment, or the interest in persisting as self-employed (Marchetta, 2012).

Tables 2.5 and A3-A6 consider the productivity of self-employed activities. Correlations suggest that, upon return to Egypt, migrants who were self-employed at the time of the survey experience more occupational (Table A5) and sectoral (Table A6) immobility compared to the whole sample of migrants (Tables A3-A4). Although self-employed returnees are more likely to switch to managerial occupations, they present less upward occupational mobility overall. In addition, Table A6 indicates that self-employed returnees are more likely to switch to jobs in agriculture, manufacturing, trade and transport than the entire group of returnees.

Table 2.5 seeks to measure the productivity of self-employed activities. Because self-employed activities tend to cluster at earning levels where there are jumps in the marginal tax rate, they might incorrectly report earnings (Alden et al., 2017). If the scale of misreporting varies over the probability of being a return migrant, the effect of return migration on self-employed earnings might be inaccurately estimated. Therefore, earnings should be read only as an imperfect proxy for self-employment productivity, and three alternative measures of performance are used: the natural logarithm of average net earnings per month, whether self-employed are own-account workers or employers, and length in self-employment.

The second row of Table 2.5 presents average net earnings per month in the past year from self-employed activities (in natural logarithm plus 1). ${ }^{32}$ Estimates of temporary migration on self-employed earnings through the accumulation of occupations, sectors and jobs are all negative. Albeit imprecisely estimated, these results question whether the development of a balanced skill set during migration contributes to setting in place successful entrepreneurial ventures.

The third set of rows suggests that having migrated significantly increases the number of years of current self-employment with occupations (2.34 years) and sectors (5.24), in line with the dynamics between return migration and occupational choice presented above. Using the average number of years of self-employment over the four last spells of job as outcome variable, the average tenure of self-employment ${ }^{33}$ is found to be significantly affected by return migration through the number of number of industries (1.33 years) and occupations (.60) an individual was exposed to.

\footnotetext{
${ }^{32}$ The estimation sample is restricted to self-employed respondents in all sectors who reported nonmissing earnings.

${ }^{33}$ Measured as the number of years as self-employed divided by number of jobs over a maximum of four job spells.
} 
Table 2.5 - Productivity of entrepreneurial activities

\begin{tabular}{|c|c|c|c|c|}
\hline & & $\begin{array}{c}\text { Accumulated } \\
\text { occupations } \\
\text { (1) }\end{array}$ & $\begin{array}{c}\text { Accumulated } \\
\text { sectors } \\
(2)\end{array}$ & $\begin{array}{c}\text { Accumulated } \\
\text { jobs } \\
(3)\end{array}$ \\
\hline Benchmark & $\begin{array}{l}\frac{\gamma_{2}}{\alpha_{2}} \cdot \frac{\alpha_{3}}{\delta_{2}} \\
\text { F-statistic (returnee) } \\
\text { P-value (returnee) } \\
\mathrm{N}\end{array}$ & $\begin{array}{c}.1191^{* * *} \\
(.0421) \\
100.73 \\
.0000 \\
10,592\end{array}$ & $\begin{array}{c}.2662^{* * *} \\
(.0706) \\
100.73 \\
.0000 \\
10,592\end{array}$ & $\begin{array}{c}.0515 \\
(.0345) \\
100.73 \\
.0000 \\
10,592\end{array}$ \\
\hline $\begin{array}{l}\text { Log of average } \\
\text { net earnings } \\
\text { per month } \\
\text { in past year }\end{array}$ & $\begin{array}{l}\frac{\gamma_{2}}{\alpha_{2}} \cdot \frac{\alpha_{3}}{\delta_{2}} \\
\text { F-statistics (returnee) } \\
\text { P-value (returnee) } \\
\mathrm{N}\end{array}$ & $\begin{array}{c}-.1203 \\
(.1122) \\
30.29 \\
.0000 \\
1,691\end{array}$ & $\begin{array}{c}-.1300 \\
(.1864) \\
30.29 \\
.0000 \\
1,691\end{array}$ & $\begin{array}{c}-.0756 \\
(.0734) \\
30.29 \\
.0000 \\
1,691\end{array}$ \\
\hline $\begin{array}{l}\text { Length of } \\
\text { current } \\
\text { self-employment }\end{array}$ & $\begin{array}{l}\frac{\gamma_{2}}{\alpha_{2}} \cdot \frac{\alpha_{3}}{\delta_{2}} \\
\text { F-statistic (returnee) } \\
\text { P-value (returnee) } \\
\mathrm{N}\end{array}$ & $\begin{array}{c}2.344^{* * *} \\
(.8249) \\
100.73 \\
.0000 \\
10,592\end{array}$ & $\begin{array}{c}5.237^{* * *} \\
(1.372) \\
100.73 \\
.0000 \\
10,592\end{array}$ & $\begin{array}{c}1.013 \\
(.6765) \\
100.73 \\
.0000 \\
10,592\end{array}$ \\
\hline $\begin{array}{l}\text { Average } \\
\text { tenure of } \\
\text { self-employment }\end{array}$ & $\begin{array}{l}\frac{\gamma_{2}}{\alpha_{2}} \cdot \frac{\alpha_{3}}{\delta_{2}} \\
\text { F-statistic (returnee) } \\
\text { P-value (returnee) } \\
\mathrm{N}\end{array}$ & $\begin{array}{c}.5959 * * \\
(.2217) \\
100.73 \\
.0000 \\
10,592\end{array}$ & $\begin{array}{c}1.332^{* * *} \\
(.3804) \\
100.73 \\
.0000 \\
10,592\end{array}$ & $\begin{array}{c}.2577 \\
(.1746) \\
100.73 \\
.0000 \\
10,592\end{array}$ \\
\hline Employer & $\begin{array}{l}\frac{\gamma_{2}}{\alpha_{2}} \cdot \frac{\alpha_{3}}{\delta_{2}} \\
\text { F-statistics (returnee) } \\
\mathrm{P} \text {-value (returnee) } \\
\mathrm{N}\end{array}$ & $\begin{array}{c}.0769^{* *} \\
(.0337) \\
84.44 \\
.0000 \\
9,452\end{array}$ & $\begin{array}{c}.1846^{* * *} \\
(.0566) \\
84.44 \\
.0000 \\
9,452\end{array}$ & $\begin{array}{c}.0313 \\
(.0294) \\
84.44 \\
.0000 \\
9,452\end{array}$ \\
\hline Own-account & $\begin{array}{l}\frac{\gamma_{2}}{\alpha_{2}} \cdot \frac{\alpha_{3}}{\delta_{2}} \\
\text { F-statistics (returnee) } \\
\text { P-value (returnee) } \\
\mathrm{N}\end{array}$ & $\begin{array}{c}.0624^{* * *} \\
(.0212) \\
76.90 \\
.0000 \\
9,299\end{array}$ & $\begin{array}{c}.1348^{* * *} \\
(.0363) \\
76.90 \\
.0000 \\
9,299\end{array}$ & $\begin{array}{c}.0210 \\
(.0179) \\
76.90 \\
.0000 \\
9,299\end{array}$ \\
\hline
\end{tabular}

Notes: In the second set of row, the dependent variable is a continuous variable measuring the average net earnings per month of those self-employed in log. In the third, the dependent variable is a continuous variable measuring the number of years of current self-employed activities; in the fourth, the number of years as self-employed divided by the number of jobs over a maximum of four job spells; in the fifth, a binary variable taking unity if a working-age individual is an employer and in the sixth, if s/he is an own-account worker (middle panel), and 0 , if employed, wage-employed or unpaid, contributing to family work. Observations are working-age individuals with no migration experience or return migrants from abroad, excluding individuals living in a household with members currently abroad, and those living in a household with members who returned from migration abroad in the first, second and third sets of rows. The estimation sample excludes own-account workers in the fifth, and employers in the sixth. It excludes respondents who are not self-employed in the first panel. Columns (1), (2) and (3) present the average marginal effects of return migration on the associated row dependent variables through the accumulation of occupations, sectors and jobs, respectively. Standard errors clustered at the household level are in parentheses. ${ }^{* * *} \mathrm{p}<0.01,{ }^{* *} \mathrm{p}<0.05,{ }^{*} \mathrm{p}<0.1$. 
In comparison, gaining experience in diverse occupations and industries abroad similarly affects the propensity to be an employer or own-account worker upon return (last set of rows in Table 2.5). These estimates confirm the influence of migration in developing human capital critical for entrepreneurship to set up a business and persist as self-employed. In line with descriptive statistics presenting lower upward occupational mobility among self-employed returnees, productive self-employment might require more.

\subsection{Concluding remarks}

There is no consensus on whether one is born with innate entrepreneurial ability or whether entrepreneurial ability can be learnt. This chapter contributes to filling gaps in the empirical literature on entrepreneurship by unpacking migration as a learning experience for selfemployment. Using Lazear's (2005) Jack-of-all-Trades Hypothesis, migration was posited to lead to a more balanced skill set, resulting in a greater propensity to self-employment among return migrants than among those who never migrated, so-called stayers.

The results, robust to the endogeneity of temporary migration and skill accumulation, indicate that return migration increases the propensity to be self-employed by affecting entrepreneurial mindsets and abilities. Migration increases the likelihood of self-employment and survival of entrepreneurial activities through the development of entrepreneurial abilities - in this chapter, the exposure to varied occupations or industries. By inducing job changes, migration leads to greater job turnover, likely to enhance the propensity to take risks, to either change jobs or opt for self-employment. Results hold for non-agricultural activities, rural areas, and controlling for the possession of savings.

I provide additional evidence to the current debate on the development impacts of (return) migration on communities of origin by showing that not only migration-induced wealth effects, but also the work experience gained abroad as such can, affect migrants' occupational choice upon return. Migration could contribute to the formation of a balanced human capital conducive to entrepreneurship by facilitating the accumulation of skills. It can be seen as a process shaping entrepreneurial abilities.

I also contribute to the scarce literature on empirically testing Lazear's (2005) Jack-of-allTrades Hypothesis in a developing economy with prevalent international migration, where understanding the development potentials of migration might be relevant. Because selfemployed evolve in underdeveloped, ill-functioning market-supporting institutions in those situations, they should be much more generalist to handle almost all dimensions of business management (Chen and Feng, 2012). As migrating tends to occur out of necessity in Egypt, this chapter confirms that entrepreneurship can be learnt, by understanding how migration might offer learning opportunities. It also confirms that learning-by-doing and experiential learning matter for entering into and persisting in self-employment (Hessels et al., 2014), especially since the MSE sector has often been thought of a potential solution to Egypt's high youth unemployment.

Entrepreneurship (education) support policies should thus focus on widening the work 
experience of potential, fledging entrepreneurs, accounting for differences in sectors of occupation (farm versus off-farm) and location (rural versus urban). Agricultural entrepreneurship in particular might be facing institutional and geography-specific challenges, and might require easier access to land as well as skill specialisation rather than diversification of the human capital critical for successful entrepreneurship. Easier access to land, land consolidation and modernisation of the farming sector could enable farmers to move away from subsistence farming towards higher efficiency and economies of scale. It could allow them to reallocate labour towards sectors of higher productivity - potentially seizing more of what migration can bring (Morsy et al., 2014). 


\subsection{Appendix}

Table A1 - Sensitivity to exclusion restriction definition in equation (1)

\begin{tabular}{|c|c|c|c|}
\hline & Returnee & Returnee & Returnee \\
\hline Variables & (1) & $(2)$ & $(3)$ \\
\hline Male & $\begin{array}{c}0.0876^{* * *} \\
(0.0046)\end{array}$ & $\begin{array}{c}0.0851^{* * * *} \\
(0.0044)\end{array}$ & $\begin{array}{c}0.0872^{* * * *} \\
(0.0046)\end{array}$ \\
\hline Literate (without diploma) & $\begin{array}{c}0.0278 \\
(0.0176)\end{array}$ & $\begin{array}{c}0.0232 \\
(0.0178)\end{array}$ & $\begin{array}{c}0.0281 \\
(0.0176)\end{array}$ \\
\hline Elementary school & $\begin{array}{l}-0.0145 \\
(0.0119)\end{array}$ & $\begin{array}{c}-0.0199^{*} \\
(0.0120)\end{array}$ & $\begin{array}{l}-0.0143 \\
(0.0119)\end{array}$ \\
\hline Middle school & $\begin{array}{l}-0.0181 \\
(0.0147)\end{array}$ & $\begin{array}{l}-0.0192 \\
(0.0148)\end{array}$ & $\begin{array}{l}-0.0179 \\
(0.0148)\end{array}$ \\
\hline High school & $\begin{array}{c}0.0106 \\
(0.0090)\end{array}$ & $\begin{array}{c}0.0084 \\
(0.0090)\end{array}$ & $\begin{array}{c}0.0109 \\
(0.0090)\end{array}$ \\
\hline Post-secondary, university and higher & $\begin{array}{c}-0.0273^{* * *} \\
(0.0092)\end{array}$ & $\begin{array}{c}-0.0337^{* * *} \\
(0.0093)\end{array}$ & $\begin{array}{c}-0.0272^{* * *} \\
(0.0093)\end{array}$ \\
\hline Literate mother & $\begin{array}{c}-0.0192^{* * *} \\
(0.0070)\end{array}$ & $\begin{array}{c}-0.0226^{* * *} \\
(0.0070)\end{array}$ & $\begin{array}{c}-0.0191^{* * *} \\
(0.0070)\end{array}$ \\
\hline Married & $\begin{array}{c}0.0915^{* * *} \\
(0.0065)\end{array}$ & $\begin{array}{c}0.0852^{* * *} \\
(0.0064)\end{array}$ & $\begin{array}{c}0.0916^{* * *} \\
(0.0065)\end{array}$ \\
\hline Under 15 dependency ratio & $\begin{array}{l}-0.0054 \\
(0.0147)\end{array}$ & $\begin{array}{c}-0.0380 * * * \\
(0.0145)\end{array}$ & $\begin{array}{l}-0.0067 \\
(0.0147)\end{array}$ \\
\hline Oil price & $\begin{array}{c}0.0016^{* * *} \\
(0.0002)\end{array}$ & & \\
\hline Distance & & $\begin{array}{c}-0.2987^{* * *} \\
(0.0712)\end{array}$ & \\
\hline Oil price X Distance & & & $\begin{array}{c}0.0009 * * * \\
(0.0001)\end{array}$ \\
\hline Constant & $\begin{array}{c}-0.1082^{* * *} \\
(0.0123)\end{array}$ & $\begin{array}{c}0.4861^{* * *} \\
(0.1204)\end{array}$ & $\begin{array}{c}-0.1060^{* * *} \\
(0.0123)\end{array}$ \\
\hline Observations & 10,592 & 10,592 & 10,592 \\
\hline R-squared & 0.0428 & 0.0319 & 0.0422 \\
\hline F-statistic (instrument) & 104.91 & 17.62 & 100.73 \\
\hline p-value (instrument) & .0000 & .0000 & .0000 \\
\hline
\end{tabular}

Notes: Please, refer to Table 2.2. 
Table A2 - Average marginal effects of oil price on the probability of return migration, holding migration distance constant at different values

\begin{tabular}{|c|c|c|c|c|c|c|c|}
\hline & & $\begin{array}{c}\mathrm{dy} / \mathrm{dx} \\
\text { (1) }\end{array}$ & $\begin{array}{l}\text { SE } \\
(2)\end{array}$ & $\begin{array}{c}\mathrm{t} \\
(3)\end{array}$ & $\begin{array}{c}\text { p-value } \\
(4)\end{array}$ & \multicolumn{2}{|c|}{$\begin{array}{l}95 \% \text { Conf. interval } \\
(5)\end{array}$} \\
\hline \multicolumn{8}{|c|}{ Oil price (19) } \\
\hline \multirow[t]{10}{*}{ At } & 1.596667 & .0014795 & .0001474 & 10.04 & 0.000 & .0011906 & .0017685 \\
\hline & 1.621667 & .0015027 & .0001497 & 10.04 & 0.000 & .0012092 & .0017962 \\
\hline & 1.646667 & .0015259 & .000152 & 10.04 & 0.000 & .0012278 & .0018239 \\
\hline & 1.671667 & .001549 & .0001543 & 10.04 & 0.000 & .0012465 & .0018516 \\
\hline & 1.696667 & .0015722 & .0001566 & 10.04 & 0.000 & .0012651 & .0018793 \\
\hline & 1.721667 & .0015954 & .000159 & 10.04 & 0.000 & .0012838 & .0019069 \\
\hline & 1.746667 & .0016185 & .0001613 & 10.04 & 0.000 & .0013024 & .0019346 \\
\hline & 1.771667 & .0016417 & .0001636 & 10.04 & 0.000 & .0013211 & .0019623 \\
\hline & 1.796667 & .0016649 & .0001659 & 10.04 & 0.000 & .0013397 & .00199 \\
\hline & 1.821667 & .001688 & .0001682 & 10.04 & 0.000 & .0013583 & .0020177 \\
\hline
\end{tabular}

Notes: Average marginal effects of real oil price (in USD) on the probability of return migration, holding the average migration distance (in 1,000 kms) constant at different values by increment of $25\left(0.025^{*} 1,000\right) \mathrm{kms}$. Estimates of column (1) give the amount of change in the probability to be a return migrant with a one unit change in oil price while holding migration distance constant at different values.

Figure A1 - Slopes for the probability of return migration on oil price, holding the value of migration distance constant

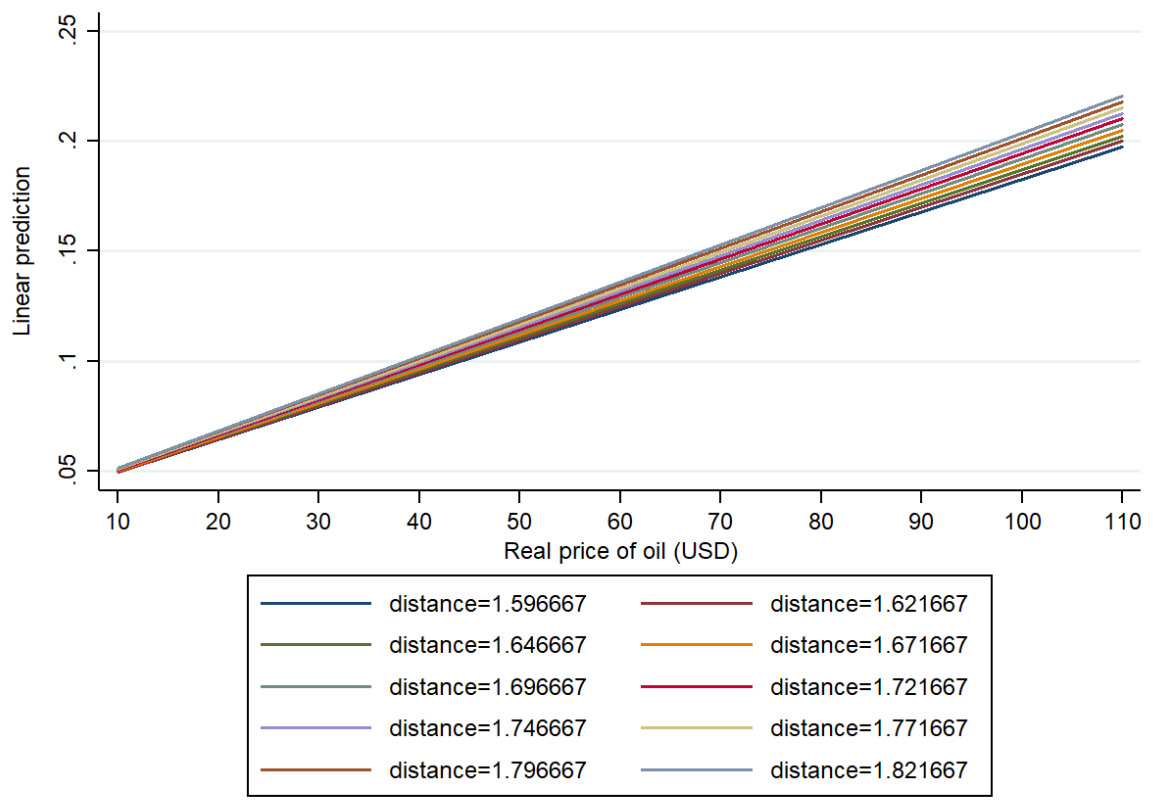


Table A3 - Occupational transition of returnees, before and after migration (\%)

\begin{tabular}{|c|c|c|c|c|c|c|c|c|c|c|c|}
\hline \multirow{12}{*}{$\begin{array}{l}0 \\
0 \\
0 \\
0 \\
0\end{array}$} & & & & & & After & & & & & \\
\hline & & Manag & Prof & Tech & Clerk & Serv & $\mathrm{Ag}$ & Craft & Plant & Elem & $\%$ \\
\hline & Manag & 76.92 & 7.69 & 0.00 & 0.00 & 0.00 & 0.00 & 7.69 & 7.69 & 0.00 & 100.00 \\
\hline & Prof & 7.46 & 77.61 & 5.97 & 1.49 & 1.49 & 0.00 & 2.99 & 1.49 & 1.49 & 100.00 \\
\hline & Tech & 14.29 & 4.08 & 73.47 & 2.04 & 0.00 & 0.00 & 4.08 & 2.04 & 0.00 & 100.00 \\
\hline & Clerk & 0.00 & 12.50 & 12.50 & 62.50 & 0.00 & 0.00 & 0.00 & 12.50 & 0.00 & 100.00 \\
\hline & Serv & 14.89 & 6.38 & 12.77 & 2.13 & 29.79 & 4.26 & 10.64 & 10.64 & 8.51 & 100.00 \\
\hline & $\mathrm{Ag}$ & 3.90 & 2.27 & 4.87 & 0.32 & 4.55 & 59.09 & 8.12 & 7.14 & 9.74 & 100.00 \\
\hline & Craft & 10.20 & 1.18 & 9.41 & 3.14 & 4.71 & 5.10 & 52.55 & 9.02 & 4.71 & 100.00 \\
\hline & Plant & 10.00 & 0.00 & 10.00 & 4.00 & 0.00 & 6.00 & 4.00 & 62.00 & 4.00 & 100.00 \\
\hline & Elem & 6.25 & 18.75 & 0.00 & 0.00 & 6.25 & 0.00 & 18.75 & 31.25 & 18.75 & 100.00 \\
\hline & $\begin{array}{l}\text { Obs. } \\
\%\end{array}$ & $\begin{array}{c}73 \\
8.98\end{array}$ & $\begin{array}{c}72 \\
8.86\end{array}$ & $\begin{array}{c}91 \\
11.19\end{array}$ & $\begin{array}{c}19 \\
2.34\end{array}$ & $\begin{array}{c}42 \\
5.17\end{array}$ & $\begin{array}{c}200 \\
24.60\end{array}$ & $\begin{array}{c}174 \\
21.40\end{array}$ & $\begin{array}{c}90 \\
11.07\end{array}$ & $\begin{array}{c}52 \\
6.40\end{array}$ & $\begin{array}{c}813 \\
100.00\end{array}$ \\
\hline
\end{tabular}

Notes: Entries represent correlations between returnees' occupations before migrating and upon return to Egypt. Entries are computed with information available for returnees before and after migration. Manag stands for managers; Prof, professionals; Tech, technicians; Clerk, clerical support; Serv, service workers; $\mathrm{Ag}$, skilled agriculture; Craft, craft worker; Plant, plant and machinery; Elem, elementary occupations. Below diagonal, upward occupational mobility from before to after migration. Above diagonal, downward occupational mobitlity from before to after migration.

Table A4 - Sectoral transition of returnees, before and after migration (\%)

\begin{tabular}{|c|c|c|c|c|c|c|c|c|c|c|c|c|c|}
\hline \multirow{15}{*}{$\begin{array}{l}0 \\
\stackrel{0}{0} \\
\stackrel{0}{0} \\
\oplus\end{array}$} & & & & & & After & & & & & & & \\
\hline & & $\mathrm{Ag}$ & $\mathrm{Mi}$ & $\mathrm{Ma}$ & $\mathrm{Ut}$ & Cons & Trade & Trans & Bus & Gov & Perso & Extr & $\%$ \\
\hline & $\mathrm{Ag}$ & 59.35 & 0.32 & 2.58 & 0.97 & 7.42 & 7.10 & 5.81 & 0.32 & 11.94 & 3.87 & 0.32 & 100.00 \\
\hline & Mi & 0.00 & 0.00 & 100.00 & 0.00 & 0.00 & 0.00 & 0.00 & 0.00 & 0.00 & 0.00 & 0.00 & 100.00 \\
\hline & $\mathrm{Ma}$ & 3.45 & 0.00 & 60.92 & 0.00 & 1.15 & 10.34 & 9.20 & 1.15 & 13.79 & 0.00 & 0.00 & 100.00 \\
\hline & $\mathrm{Ut}$ & 0.00 & 0.00 & 0.00 & 66.67 & 16.67 & 0.00 & 0.00 & 0.00 & 16.67 & 0.00 & 0.00 & 100.00 \\
\hline & Cons & 6.70 & 0.56 & 3.91 & 2.23 & 52.51 & 11.17 & 8.94 & 1.12 & 10.61 & 2.23 & 0.00 & 100.00 \\
\hline & Trade & 2.53 & 1.27 & 3.80 & 1.27 & 8.86 & 58.23 & 11.39 & 2.53 & 8.86 & 1.27 & 0.00 & 100.00 \\
\hline & Trans & 5.13 & 0.00 & 5.13 & 0.00 & 10.26 & 5.13 & 61.54 & 5.13 & 7.69 & 0.00 & 0.00 & 100.00 \\
\hline & Bus & 0.00 & 0.00 & 0.00 & 0.00 & 0.00 & 7.14 & 14.29 & 50.00 & 28.57 & 0.00 & 0.00 & 100.00 \\
\hline & Gov & 0.00 & 0.00 & 2.27 & 0.00 & 3.41 & 2.27 & 1.14 & 1.14 & 88.64 & 1.14 & 0.00 & 100.00 \\
\hline & Perso & 0.00 & 0.00 & 0.00 & 0.00 & 0.00 & 10.00 & 20.00 & 0.00 & 10.00 & 60.00 & 0.00 & 100.00 \\
\hline & Extr & 0.00 & 0.00 & 0.00 & 0.00 & 0.00 & 0.00 & 0.00 & 0.00 & 0.00 & 0.00 & 0.00 & 100.00 \\
\hline & Obs. & 203 & 3 & 76 & 12 & 133 & 103 & 80 & 16 & 162 & 24 & 1 & 813 \\
\hline & $\%$ & 24.97 & 0.37 & 9.35 & 1.48 & 16.36 & 12.67 & 9.84 & 1.97 & 19.93 & 2.95 & 0.12 & 100.00 \\
\hline
\end{tabular}

Notes: Entries represent correlations between returnees' sectors before migrating and upon return to Egypt. Entries are computed with information available for returnees before and after migration. Ag stands for agriculture; Mi, mining; Ma, manufacturing; Ut, utilities; Cons, construction; Trade, trade; Trans, transportation; Bus, business services; Gov, government; Perso, personal services; Extr, extraterritorial organisations. 
Table A5 - Occupational transition of returnees self-employed at the time of the survey, before and after migration (\%)

\begin{tabular}{|c|c|c|c|c|c|c|c|c|c|c|c|}
\hline \multirow{13}{*}{ 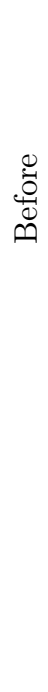 } & \multicolumn{11}{|c|}{ After } \\
\hline & & Manag & Prof & Tech & Clerk & Serv & $\mathrm{Ag}$ & Craft & Plant & Elem & $\%$ \\
\hline & Manag & 90.00 & 0.00 & 0.00 & 0.00 & 0.00 & 0.00 & 10.00 & 0.00 & 0.00 & 100.00 \\
\hline & Prof & 20.00 & 40.00 & 0.00 & 0.00 & 20.00 & 0.00 & 0.00 & 20.00 & 0.00 & 100.00 \\
\hline & Tech & 71.43 & 0.00 & 14.29 & 0.00 & 0.00 & 0.00 & 14.29 & 0.00 & 0.00 & 100.00 \\
\hline & Clerk & 0.00 & 0.00 & 0.00 & 0.00 & 0.00 & 0.00 & 0.00 & 0.00 & 0.00 & 100.00 \\
\hline & Serv & 38.89 & 5.56 & 5.56 & 0.00 & 16.67 & 5.56 & 0.00 & 22.22 & 5.56 & 100.00 \\
\hline & $\mathrm{Ag}$ & 7.69 & 0.70 & 0.00 & 0.00 & 3.50 & 78.32 & 1.40 & 6.99 & 1.40 & 100.00 \\
\hline & Craft & 26.37 & 0.00 & 9.89 & 0.00 & 4.40 & 12.09 & 40.66 & 6.59 & 0.00 & 100.00 \\
\hline & Plant & 20.00 & 0.00 & 6.67 & 0.00 & 0.00 & 20.00 & 6.67 & 46.67 & 0.00 & 100.00 \\
\hline & Elem & 33.33 & 0.00 & 0.00 & 0.00 & 33.33 & 0.00 & 0.00 & 33.33 & 0.00 & 100.00 \\
\hline & Obs. & 61 & 4 & 12 & 0 & 14 & 127 & 42 & 29 & 3 & 292 \\
\hline & $\%$ & 20.89 & 1.37 & 4.11 & 0.00 & 4.79 & 43.49 & 14.38 & 9.93 & 1.03 & 100.00 \\
\hline
\end{tabular}

Notes: Please, refer to Table A3.

Table A6 - Sectoral transition of returnees self-employed at the time of the survey, before and after migration (\%)

\begin{tabular}{|c|c|c|c|c|c|c|c|c|c|c|c|c|c|}
\hline \multirow{15}{*}{$\begin{array}{l}0 \\
\stackrel{0}{0} \\
\stackrel{0}{0} \\
n\end{array}$} & & & & & & After & & & & & & & \\
\hline & & $\mathrm{Ag}$ & Mi & Ma & $\mathrm{Ut}$ & Cons & Trade & Trans & Bus & Gov & Perso & Extr & $\%$ \\
\hline & $\mathrm{Ag}$ & 78.47 & 0.00 & 1.39 & 0.00 & 0.69 & 11.11 & 7.64 & 0.69 & 0.00 & 0.00 & 0.00 & 100.00 \\
\hline & $\mathrm{Mi}$ & 0.00 & 0.00 & 0.00 & 0.00 & 0.00 & 0.00 & 0.00 & 0.00 & 0.00 & 0.00 & 0.00 & 100.00 \\
\hline & $\mathrm{Ma}$ & 6.45 & 0.00 & 61.29 & 0.00 & 0.00 & 22.58 & 9.68 & 0.00 & 0.00 & 0.00 & 0.00 & 100.00 \\
\hline & $\mathrm{Ut}$ & 0.00 & 0.00 & 0.00 & 0.00 & 0.00 & 0.00 & 0.00 & 0.00 & 0.00 & 0.00 & 0.00 & 100.00 \\
\hline & Cons & 17.86 & 0.00 & 0.00 & 0.00 & 44.64 & 26.79 & 8.93 & 1.79 & 0.00 & 0.00 & 0.00 & 100.00 \\
\hline & Trade & 2.78 & 0.00 & 2.78 & 0.00 & 5.56 & 72.22 & 13.89 & 2.78 & 0.00 & 0.00 & 0.00 & 100.00 \\
\hline & Trans & 18.18 & 0.00 & 18.18 & 0.00 & 18.18 & 0.00 & 45.45 & 0.00 & 0.00 & 0.00 & 0.00 & 100.00 \\
\hline & Bus & 0.00 & 0.00 & 0.00 & 0.00 & 0.00 & 25.00 & 25.00 & 50.00 & 0.00 & 0.00 & 0.00 & 100.00 \\
\hline & Gov & 0.00 & 0.00 & 25.00 & 0.00 & 0.00 & 50.00 & 0.00 & 0.00 & 0.00 & 25.00 & 0.00 & 100.00 \\
\hline & Perso & 0.00 & 0.00 & 0.00 & 0.00 & 0.00 & 16.67 & 16.67 & 0.00 & 0.00 & 66.67 & 0.00 & 100.00 \\
\hline & Extr & 0.00 & 0.00 & 0.00 & 0.00 & 0.00 & 0.00 & 0.00 & 0.00 & 0.00 & 0.00 & 0.00 & 100.00 \\
\hline & Obs. & 128 & 0 & 25 & 0 & 30 & 68 & 31 & 5 & 0 & 5 & 0 & 292 \\
\hline & & 43.84 & 0.00 & 8.56 & 0.00 & 10.27 & 23.29 & 10.62 & 1.71 & 0.00 & 1.71 & 0.00 & 100 \\
\hline
\end{tabular}

Notes: Please, refer to Table A4. 
Table A7 - Distances between capitals of governorates of birth and capitals of estimation sample destination countries in kilometres

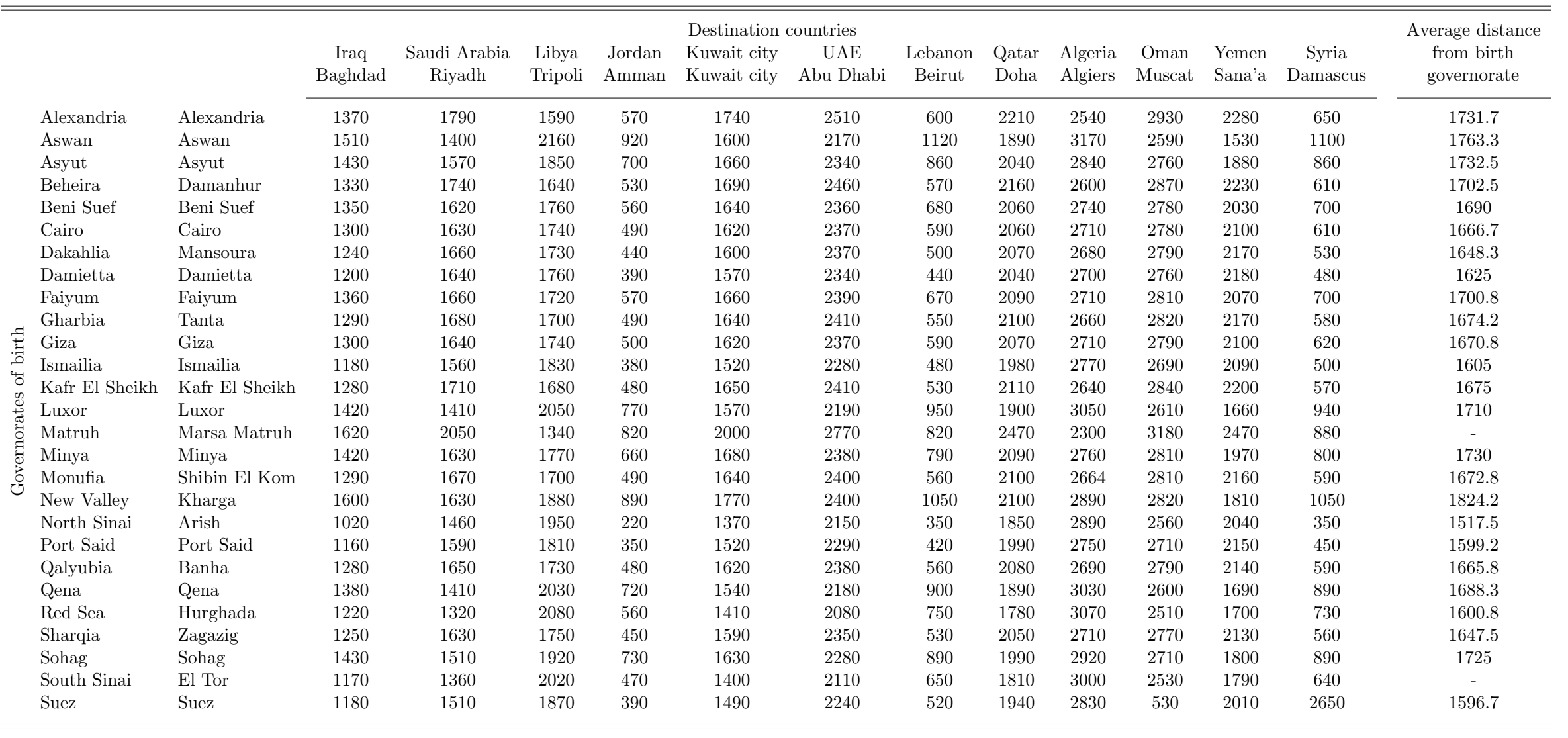

Notes: A cell should be read as the distance in kilometres between the capital of a respondent's governorate of birth and the capital of one of the 12 estimation sample destination countries. The second and third columns list Egyptian governorates and their respective capitals. Columns (4)-(15) present distances from each birth governorate capital to each destination country capital. The last column presents average migration distances from each birth governorate capital to estimation sample destination country capitals. Distances were measured using Google Maps. 



\section{Chapter 3}

\section{Does migration disrupt self-employment trajectories?}

\subsection{Introduction}

Temporary migration is often undertaken in support of an initiative in the home country, such as accumulating funds for household consumption or for investment in a business (Dustmann and Gorlach, 2016). ${ }^{1}$ The latter would result in return migrants choosing self-employment as an occupation. Indeed, a number of studies have found that return migrants are more likely to be self-employed than non-migrants (Wahba and Zenou, 2012; Wahba, 2015; Batista et al., 2017). This has been interpreted as migration facilitating entrepreneurship and hence economic development in sending countries. ${ }^{2}$

There are at least two reasons why such an interpretation should be made with caution. The first is that it will depend on why return migrants choose self-employment. Return migrants may only opt for self-employment as a temporary occupation, akin to Harris and Todaro's (1970) 'parking lot' hypothesis, from where to eventually move on to a wage job (Piracha and Vadean, 2010). This could be because of difficult business conditions or because sustaining a

This chapter is based on Brück, T., Mahé, C. and Naudé, W. (2018). Return migration and selfemployment dynamics: Evidence from Kyrgyzstan. IZA Discussion Paper No. 11332, Bonn: Institute of Labor Economics. Tilman Brück would like to acknowledge the support of the DFID/IZA GLM-LIC research grant 'Gender and Employment in Central Asia: Evidence from Panel Data (Grant Agreement No. GA-C1-RA5-064). The authors are furthermore grateful to various colleagues who provided comments, suggestions and encouragements, in particular Neil Foster-McGregor, Eleonora Nillesen, Sergio Parra-Cely, and Pui-Hang Wong, as well as participants of the final TRANSMIC conference held on May 18-19, 2017, in Florence, Italy; of the third Life in Kyrgyzstan conference held on October 12-13, 2017, in Bishkek, Kyrgyzstan; of the third GLM/LIC Research Network Conference, held on October 1921, 2017, in Washington (DC), USA; of the inaugural AASLE Conference, held on December 7-9, 2017, in Canberra, Australia; and of the 1st IZA/World Bank/NJD Conference on Jobs and Development, held on May 11-12, 2018, in Bogotá, Colombia.

${ }^{1}$ In this chapter, migration is defined as the 'relocation of people within space that involves their permanent or temporary change of residence' (Mafukidze, 2006, p.106).

${ }^{2}$ See Naudé et al. (2017) for a review of the empirical evidence on migration, development and entrepreneurship. 
career in self-employment may require strong social capital, which may have depreciated during their migration spell (Marchetta, 2012).

The second reason is that the occupation of the migrant before $\mathrm{s} /$ he migrated may influence her/his choice on return. It is likely, especially in a developing country context, that return migrants who were self-employed before they left, are less likely than non-migrants to choose self-employment as an occupation. This is because they might have discovered that they lack sufficient entrepreneurial ability or that the climate for doing business is too difficult, as per Jovanovic's (1979) learning mechanism.

Both reasons suggest that the potential for migration to stimulate entrepreneurship in origin countries should not be overestimated, as it would not be associated with sustaining a career in self-employment. To date, very few studies have simultaneously dealt with entry into and exit from self-employment in the broader context of whether (return) migration facilitates or constrains self-employment choices in developing economies.

The contribution of this study is to address this lacuna by specifically answering the following questions: (i) are return migrants more likely than non-migrants to enter into and to sustain a career in self-employment? And (ii) is this decision influenced by whether return migrants were self-employed before migrating?

These questions are answered by using a rich longitudinal database of a transition economy, with significant international migration, the 2010-2013 Life in Kyrgyzstan (LiK) Study. Correlated random effects models and matching techniques are used to control for dependence between the choice to enter into and/ to exit self-employment (dynamics), time-invariant and time-varying endogeneity.

Return migrants in Kyrgyzstan are found, as in other settings, more likely to be self-employed than non-migrants. However, their motive to do so is rather based on necessity than opportunity. It thus tends to be more of a temporary choice, as return migrants are more likely to exit from self-employment in subsequent periods than non-migrants. Transition probabilities by migration status confirm that return migrants display lower occupational stability than non-migrants both before and after migrating. Benchmark estimates indicate that, on average, return migration increases the likelihood of being self-employed by 18.5 percentage points for returnees who were self-employed in the previous time period; by 22.4, if they were not.

If return migrants were self-employed before migrating, they are found to less likely to choose self-employment on their return. To be specific, matched difference-in-differences estimates reveal that, on average, return migration increases the likelihood of being self-employed by 1.19 percentage points for returnees who were self-employed before leaving Kyrgyzstan. This likelihood increases to 19.98 percentage points if they were not. These novel findings suggest that temporary migration could be more disruptive of self-employment trajectories than is often thought.

The rest of the chapter is structured as follows. Section 3.2 reviews the relevant literature on the relationship between return migration and self-employment. Section 3.3 sets out the estimation strategy and data. Section 3.4 presents the empirical results and robustness checks. Section 3.5 concludes. 


\subsection{Relevant literature}

With an estimated more than one billion of international and internal migrants worldwide by 2017, the scholarly literature on migration as a social and economic phenomenon has understandably grown in recent years, reflecting the humanitarian disasters, political controversies and divided views that have accompanied the global rise in migration (Clemens and Pritchett, 2016). This literature has built on a core of academic work that has dealt with why individuals and households migrate ${ }^{3}$ and how migration impacts migrants, left-behind family members and host and sending countries' development (Beegle et al., 2011; Christiaensen and Todo, 2014; Gibson et al., 2011; Gibson and McKenzie, 2012). A sizeable subset of this literature has studied the impact of migrants' remittances on their home regions, including whether and how remittances are used to invest in entrepreneurial ventures (Amuedo-Dorantes and Pozo, 2006; Rapoport and Docquier, 2006; Stark, 2009; Taylor and Lopez-Feldman, 2010).

One feature of migration is that it is very often temporary, because it is undertaken in support of an initiative in their home countries, such as accumulating funds for household consumption or for investment in a business (Dustmann and Gorlach, 2016). Return migrants can bring back better education, experience, networks and wealth, with the resulting entrepreneurial activity benefiting the development of their origin countries. The bulk of studies have so far found migrants to be more likely to choose self-employment on return to their origin countries than non-migrants, ${ }^{4}$ suggesting that migration facilitates self-employment and therefore entrepreneurship.

In the absence or inefficiency of markets, savings accumulated during migration (and remittances) have been found to act as substitutes for formal insurance, facilitating access to capital and promoting investments in new or existing ventures in origin communities (Wahba and Zenou, 2012; Wahba, 2015; Batista et al., 2017). By inducing changes in occupation, emigrating and returning 'home' have been shown to affect returnees' mindsets, e.g. their propensity to take risks, be it for taking a new job or setting up a firm, as well as their capabilities - their skills and know-how (Black and Castaldo, 2009; Démurger and Xu, 2011; Chen and Feng, 2012). These resources could simultaneously offset the loss of local social capital that migrants experienced while away, which may threaten the start-up, growth or survival of any entrepreneurial activity upon return (Marchetta, 2012; Wahba and Zenou, 2012).

As a consequence, as Naudé et al. (2017) point out, there is a pervasive belief that return migration can stimulate entrepreneurship and economic development in sending countries.

\footnotetext{
${ }^{3}$ Neoclassical models of migration, such as Lewis (1954), Ranis and Fei (1961), Harris and Todaro (1970) or Piore (1979), explain the decision to migrate by individuals comparing their present value of lifetime earnings from employment opportunities in alternative locations. Push and pull factors are typically identified as triggering migration (King, 2012). In the New Economics of Labour Migration (NELM) potential migrants are embedded in a social context so that the relevant unit of analysis is argued to be, not the individual, but rather the household. Migration decisions are assumed to be jointly taken by household members (Stark and Bloom, 1985).

${ }^{4}$ This finding applies to return migrants back in their (developing) home countries. In contrast, immigrants are less likely to be self-employed in their host countries. For instance, a review from the Organisation for Economic Co-operation and Development (OECD) found that, in about half of OECD countries, immigrants were less likely than natives to be self-employed (OECD, 2010).
} 
There are at least two reasons why such a belief may be mistaken. The first is that whether return migrants as self-employed agents provide growth-enhancing entrepreneurship depends on why they choose self-employment. Return migrants might not be able to find a wage-paying job immediately. Self-employment upon return might be a transitory phase for reintegrating into the domestic labour market in the spirit of Harris and Todaro's (1970) 'parking lot' hypothesis. Facing limited formal sector employment opportunities, returnees would often work in small, informal, self-employed activities until finding formal wage employment or migrating again (Piracha and Vadean, 2010). The latter is often an option in countries where migration is structural and a means to secure an economic basis at home, such as in the case of Kyrgyzstan (Thieme, 2014).

Furthermore, return migrants may opt for self-employment as a temporary occupation and not as a sustained career choice due to difficult business conditions or because self-employment can require strong social capital, which may have depreciated during the migration spell (Marchetta, 2012; Wahba and Zenou, 2012). For instance, Obukhova et al. (2012) show that returnee entrepreneurs to China do not outperform non-migrant, 'homegrown' entrepreneurs. Because of a lack of local social networks (school ties), high-tech enterprises returnees set in place tend to underperform non-migrant entrepreneurs or returnee entrepreneurs with such ties. ${ }^{5}$

The second reason that explains why assuming return migrants' entrepreneurial prowess may be mistaken is that the occupation of migrants before they migrated may influence their choices of occupation upon return to their origin countries. Individuals who were self-employed before migration might be more likely to opt out of self-employment on return. In this case, the link between return migration and self-employment might be more complex than is currently assumed. It seems plausible, especially in a developing country context, that migrants who were self-employed before they left, may be less likely than non-migrants to choose self-employment as an occupation upon return. They might have had the opportunity to discover their own entrepreneurial abilities and learnt about the climate for doing business in their origin countries, so that, on return, they would rather opt for wage employment (Jovanovic, 1979). This is consistent with a developing economy setting, where wage and self-employment coexist and individuals frequently transition between these two occupations, as suggested by Koelle's (2016) theoretical and empirical evidence. ${ }^{6}$

By entailing a change in occupations, migration could act like an 'experience good' (Nelson, 1970) that helps to determine the quality of a worker's occupation-productivity match, by

\footnotetext{
${ }^{5}$ There is nonetheless evidence suggesting that migration enhances participation in formal and informal networks (Gallego and Mendola, 2013; Morten, 2016). In particular, and of interest in this chapter, households with migrants have been found to insure their social networks against shocks and to redistribute wealth to poorer (non-migrant) households in sending communities in Kyrgyzstan (Chakraborty et al., 2015).

${ }^{6}$ If they expect to receive better rewards as wage-employed, self-employed will shift to wage employment and shut down their firm. This very possibility to exit self-employment decreases incentives to invest in entrepreneurial activities, and so to persist in entrepreneurship over time. Using data from Colombia, Koelle (2016) confirms that those self-employed with attractive wage-employed opportunities, i.e. who have the resources and abilities required in wage employment, are less likely to expand their entrepreneurial ventures and hence tend to exit self-employment and switch to wage employment.
} 
updating information on their tastes and abilities. ${ }^{7}$ This transition pattern could be viewed as part of a dynamic lifecycle sequence of sorting through gradual learning and experimentation, in which individuals self-select into their preferred options over time (Dillon and Stanton, 2017). Emigrating and returning to their source communities could thus nudge migrants to discover the best allocation of their capital and labour resources by getting in and out of self-employment. This could lead return migrants who were initially self-employed, now better informed about their lower chances of success as entrepreneurs or with stronger interests in wage employment, to switch to wage employment upon return. In such a case, the 'disruption' caused by migration to self-employment can be viewed in a positive light. It enables career development by offering an escape from self-employment, and it reduces the number of entrepreneurs with low abilities in the entrepreneurial pool.

If the reasons return migrants choose self-employment on return are any of the above, the implications are that they will not sustain a career in self-employment but will revert to wage employment soon after their return. Any businesses they may create will not have a significant development impact.

To summarise, return migrants may only be more likely to choose self-employment for entrepreneurial reasons if they discovered they had good entrepreneurial abilities. That means they decided to migrate to obtain experience and resources to help them on their return to sustain their career in self-employment - deciding to migrate is part of their choice to be selfemployed - as their home countries' business environment is not so constraining. In addition, social capital deterioration is not an insurmountable obstacle to thrive as entrepreneur. These conditions may be hard to hold, especially in developing economies. Hence, the hypotheses of this chapter are that (i) if return migrants choose self-employment they may tend to do so as a temporary mechanism for eventually facilitating entry into wage employment or for future re-migration, and that (ii) they would be less likely to choose self-employment on return if they had been in self-employment before migration.

Very few studies in the scholarly literature have yet focused on these two hypotheses in integrated and consistent fashion. As this review implies, the impact of return migration on selfemployment and entrepreneurship has been relatively neglected in the literature. More generally, the occupational stability of migrants is a topic about which relatively little empirical evidence has so far been gathered. Whether return migrants sustain their entrepreneurial activities has received even less attention in the literature. To the best of the authors' knowledge, only Marchetta (2012) has specifically studied the survival of returnees' entrepreneurial activities. Entry into and exit from self-employment have been either analysed separately or not specifically modeled as two separate decisions. There is thus a lacuna in the literature this study aims to fill.

These hypotheses are tested using longitudinal data from Kyrgyzstan to answer the following questions: (i) are return migrants more likely than non-migrants to enter into and to sustain a career in self-employment in Kyrgyzstan? And (ii) is this decision influenced by whether return

\footnotetext{
${ }^{7}$ See also White and Wolaver (2003) on how the decision to migrate might result from the degree of a worker's occupation-productivity match.
} 
migrants were self-employed before migrating?

In finding empirically sound answers to these questions, several potential sources of endogeneity are faced. First, the dependence between the choice (state) and the duration in self-employment, i.e. dynamics, should be taken into account. While a person is more likely to be self-employed at time $t$ if $\mathrm{s} /$ he were self-employed in $t-1$, the determinants of entry into and persistence in selfemployment might differ. Second, time-invariant effects, inducing omitted variable bias, have to be controlled for. Temporary migrants might self-select into both temporary migration and self-employment, which might influence their chances of sustaining a career in self-employment. Third, time-varying effects, i.e. reverse causality, need to be accounted for. Migrating and accumulating resources during migration might be influenced by the perception of profitable investment opportunities in origin communities. The decision to emigrate, to return and to set up a firm could be simultaneous decisions, and migration an ex-ante business strategy to start up or expand existing ventures upon return. Those self-employed might also decide to migrate if their entrepreneurial ventures were unsuccessful.

In the next section of this chapter, the estimation strategy used to test these hypotheses and deal with these challenges is presented and the 2010-2013 LiK database introduced.

\subsection{Methodology}

The estimation strategy is set out in subsection 3.1 and the database to be used in subsection 3.2 .

\subsubsection{Estimation strategy}

The estimation strategy proceeds as in de Ree and Nillesen (2009) and Bleaney and Dimico (2011) by running a series of non-linear probability models, in which the outcome variable $Y_{i t}$ is a binary variable defined if a working-age (18-64-year-old) individual $i$ has reported a primary occupation at time $t$. This variable takes value 1 if $\mathrm{s} /$ he is self-employed in year $t$, and zero otherwise - a (paid or unpaid) employee or member of a cooperative. ${ }^{8}$

\section{Baseline model}

The baseline specification follows what has usually been estimated in the literature, ignoring entry- and exit-specific dynamics:

$$
Y_{i t}=\alpha_{0}+\sum_{k=1}^{K} \beta_{0 k} X_{k i t}+u_{i t}
$$

where $X_{k i t}$ is a $k$-vector of explanatory variables, including 1 to model a constant, returnee $i t$, defined as a binary variable taking value 1 if an individual has lived abroad for at least one month since 2005, and $k-2$ exogenous variables. Exogenous variables control for individual-

\footnotetext{
${ }^{8}$ These three categories are lumped together because of their status as they all imply dependence on co-workers or supervisors, family members or not.
} 
(gender, age, ethnicity, household headship, educational attainment), household- (household size, below 15 dependency ratio), location- and year-specific characteristics. $\alpha_{j}$ and $\beta_{j k}$ are parameters to be estimated; $u_{i t}$, an unobserved random disturbance. Standard errors are clustered at the household level to account for interdependence of labour market outcomes between household members.

\section{Entry model}

To disentangle the relationship between return migration and entrepreneurship in analysing entry into self-employment, individuals observed as self-employed in $t-1$ are excluded. Discarding observations for which $Y_{i, t-1}=1$, the entry model can be written as the probability of being self-employed in $t$, conditional on not being self-employed in $t-1$ as:

$$
Y_{i t}=\alpha_{1}+\sum_{k=1}^{K} \beta_{1 k} X_{k i t}+u_{i t}
$$

Estimating this model should provide an answer on whether return migrants are more likely to opt for self-employment compared to non-migrants.

\section{'Survival' model}

To analyse the likelihood for a return migrant to sustain a career in self-employment, individuals not observed as self-employed in $t-1$ are excluded. Conditioning the probability of selfemployment at $t$ on being self-employed in $t-1$ yields a 'survival' model:

$$
Y_{i t}=\alpha_{2}+\sum_{k=1}^{K} \beta_{2 k} X_{k i t}+u_{i t}
$$

While it is unlikely that $\alpha_{1}=\alpha_{2}$, since an individual is more likely to be self-employed at time $t$ if $\mathrm{s} /$ he was self-employed in $t-1$, the 'true' model might be such that $\beta_{1 k}=\beta_{2 k}$. The literature on business survival has tended to study enterprise survival on one hand, and on the other hand, the persistence of entrepreneurs' occupational choice, based on individual features. However, such a distinction is less clear when the sample of interest includes rather micro and small units (Marchetta, 2012). Factors associated with continuing in self-employment are assumed to be similar to those associated with entry into self-employment, in particular in a context of small entrepreneurial units, as in the estimation sample. If this is the case, estimating equations (2) and (3) separately is inefficient, leading to relatively wide confidence intervals on estimated coefficients, specifically in smaller subsets of the data.

\section{Combined model}

The model to be estimated on the whole data set should combine entry into and 'survival' in self-employment models, as in:

$$
Y_{i t}=\alpha_{3}+\sum_{k=1}^{K} \beta_{3 k} X_{k i t}+\lambda_{3} Y_{i, t-1}+u_{i t}
$$


Equation (4) reduces to equation (2) if $Y_{i, t-1}=0$, and to equation (3) if $Y_{i, t-1}=1$. However, equation (4) imposes $\beta_{3 k}$ to be the same in both cases and implies that the errors of the two different subsamples come from the same population. Relaxing this equality on the coefficients leads to the following model:

$$
Y_{i t}=\alpha_{4}+\sum_{k=1}^{K} \beta_{4 k} X_{k i t}+\lambda_{4} Y_{i, t-1}+\sum_{k=1}^{K} \theta_{4 k} X_{k j t} Y_{i, t-1}+u_{i t}
$$

Equation (5) reduces to equation (4) if $\theta_{4 k}$ is a vector of zeros. If it is not certain whether return migration is similarly related to entry into and persistence in self-employment, i.e. whether any element of $\theta_{4 k}$ is zero, the appropriate model to estimate is (5) (combined model). This model is then re-estimated, setting to zero any elements of $\theta_{4 k}$ that are not significantly different from zero at the first stage (parsimonious combined model). Equation (5) allows testing parameter restrictions across entry and 'survival' model coefficient estimates.

\section{Dealing with endogeneity}

Potential endogeneity between return migration and self-employment is accounted for by exploiting the longitudinal dimension of the data set to control for time-invariant unobserved heterogeneity. It is done so by incorporating a Mundlak 'correction' (Mundlak, 1978). The Mundlak model assumes that the (individual) fixed effects are projected on the group means of time-varying variables, imposing a form on the relationship between the time-invariant random disturbance and the regressors. Regressions are estimated by adding individual-specific (group) means across time, and then estimated as random effects models. Rejecting the null hypothesis that the joint significance of the group means coefficient estimates is not different from zero is evidence of time-invariant unobserved heterogeneity at the individual level.

Since $u_{i t}$, the unobserved random disturbance, has a time-invariant $\gamma_{i}$ and a time-varying component $\epsilon_{i t}$, augmenting the baseline specification (equation (1)) with a Mundlak correction assumes that:

$$
E\left[\gamma_{i} \mid X_{k i t}\right]=g\left(X_{k i t}\right)
$$

where time-invariant effects are correlated with the other exogenous variables, $X_{k i t}$. The expected value of $\gamma_{i}$, conditional on the exogenous regressors, is a linear combination of the average panel of the time-varying regressors. The Mundlak correction yields:

$$
\begin{aligned}
& \gamma_{i}=\delta_{0}+\sum_{k=1}^{K} \delta_{1 k} \bar{X}_{k i}+\epsilon_{i} \\
& Y_{i t}=\left(\alpha_{0}+\delta_{0}\right)+\sum_{k=1}^{K} \beta_{0 k} X_{k i t}+\sum_{k=1}^{K} \delta_{1 k} \bar{X}_{k i}+u_{i t}+\epsilon_{i}
\end{aligned}
$$

where $\epsilon_{i}$ is assumed to be uncorrelated with $X_{i}$. Equation (5) is estimated as in Wooldridge (2005), who proposes an extension to the Mundlak estimator to estimate dynamic non-linear panel data models with unobserved heterogeneity. Wooldridge (2005) suggests modeling 
the distribution of the outcome variable $\left\{Y_{i 1}, \ldots, Y_{i T}\right\}$, given $Y_{i 0}$ (its initial value) using conditional Maximum Likelihood (ML). The distribution of $u_{i}$, time-invariant, individualspecific heterogeneity is directly specified, given $y_{i 0}$ and other exogenous variables, such that:

$$
g\left(\gamma_{i} \mid y_{i 0}, X_{k i t}\right) \sim N\left(\delta_{0}+\delta_{1} Y_{i 0}+\sum_{k=1}^{K} \delta_{2 k} \bar{X}_{k i}, \sigma_{\epsilon}^{2}\right)
$$

This can be re-written as:

$$
\gamma_{i}=\delta_{0}+\delta_{1} Y_{i 0}+\sum_{k=1}^{K} \delta_{2 k} \bar{X}_{k i}+\epsilon_{i}
$$

where $\epsilon_{i} \sim N\left(0, \sigma_{\epsilon}^{2}\right)$ is independent of $Y_{i 0}$ and $X_{k i}$. As in Mundlak's approach, fixed effects are projected on the group means of time-varying variables. Regressions are run by regressing the outcome variable at time $t$ on the set of explanatory variables, the individual-specific (group) means across time, the initial outcome value (at time $t=1,2010$ ), the lagged $t-1$ outcome and the interaction of the lagged outcome with the set of explanatory variables, as in Bleaney and Dimico (2011). Estimated by a standard random effects probit, equation (5) can then be re-written as:

$$
Y_{i t}=\left(\alpha_{4}+\delta_{0}\right)+\sum_{k=1}^{K} \beta_{4 k} X_{k i t}+\delta_{1} Y_{i 0}+\lambda_{4} Y_{i, t-1}+\sum_{k=1}^{K} \theta_{4 k} X_{k j t} Y_{i, t-1}+\sum_{k=1}^{K} \delta_{2 k} \bar{X}_{k i}+u_{i t}+\epsilon_{i}
$$

Selection into having reported a primary occupation at time $t$ is accounting for by adding to the below specifications Inverse Mills Ratios (IMR), based on the predictions of the probability to be observed working at time $t$. The selection (dependent) variable is a binary variable taking unity if an individual has a primary occupation; zero, otherwise, i.e. either inactive or unemployed. The IMRs for selection into working are calculated for each specification and then added to the corresponding models for self-employment probability. In line with the existing literature, being married is used as exclusion restriction. ${ }^{9}$

To conclude this subsection, it should be indicated that controlling for individual fixed effects does not exclude measurement errors and time-varying endogeneity. Not only is it difficult to find an instrumental variable per se, but the explanatory variable of interest also only records return migration up to 2005. There might be some return migrants in the data that cannot be identified. Even if a relevant and strong instrument is found, i.e. the treatment is correctly allocated, estimates will be biased because migrants who migrated and returned to Kyrgyzstan before 2005 cannot be identified. For this reason, time-varying variables are included as controls in the benchmark specifications and later perform a matched difference-in-differences analysis to check the robustness of these estimates.

\footnotetext{
${ }^{9}$ Estimates of sample selection regressions are available on request.
} 


\subsubsection{Data source}

This analysis uses data from the Life in Kyrgyzstan Study (LiK), a multi-topic longitudinal survey carried out annually from 2010 to 2013 in Kyrgyzstan, tracking the same households over time in all seven regions (oblasts) and the two major cities, Bishkek and Osh. Data were collected once a year around October-November, although there were a few deviations in dates of field works in each wave, in particular in 2013. Detailed information on the LiK can be found in Brück et al. (2014).

The structure of Kyrgyzstan's economy has led to high rates of emigration (Atamanov and van den Berg, 2012). Demographic pressure and (land) resource limitations coincided with economic opportunities in neighbouring countries to encourage migration. Often undertaken as a means to set up an economic basis at home (Thieme, 2014), (temporary) international migration became a natural response to economic challenges in Kyrgyzstan, to mainly Russia hosting $92 \%$ of Kyrgyzstani migrants - and Kazakhstan - 8\%. Russia's recent economic crisis therefore spurred many returns (The Diplomat, 2015). Although numbers vary by sources, emigration from Kyrgyzstan is, on all accounts, significant. ${ }^{10}$

The organisation of Soviet-era planned economies has simultaneously left Kyrgyzstan without market-supporting institutions, and difficult access to financial support. ${ }^{11}$ Restrictions on private land ownership and state-led rent-seeking limit the growth of Kyrgyz family farms (Atamanov and van den Berg, 2012). Political instability, tax rates and corruption were recently listed as the first challenges that formal, non-agricultural enterprises faced in Kyrgyzstan (International Bank for Reconstruction and Development and World Bank, 2014).

However, entrepreneurship has been found key to a successful transition from planned to market economy (McMillan and Woodruff, 2002). ${ }^{12}$ The extent of international migration in Kyrgyzstan, its dependence on destination country economic prospects and the role entrepreneurship could play in its unique transition setting point to the relevance of studying the potential implications of return migration for Kyrgyzstan's economic development through entrepreneurship. By following the same thousands of individuals across four consecutive years, the LiK can help to shed light on these dynamics.

The unit of analysis is a working-age (18-64-year-old) individual born in Kyrgyzstan, interviewed in all four waves. This resulted in a total of 4,765 respondents across 2,195 original, non-splitting households. From the original sample of 3,000 households identified in 2010, 2,450 households $(81.6 \%)$ participated in all four waves of the project. ${ }^{13}$

\footnotetext{
${ }^{10}$ With a population of about 5.7 million in 2013, the number of permanent and seasonal labour migrants approximated 200,000 to 1 million people depending on information sources. The subsequent growth in remittances has ranked Kyrgyzstan second worldwide after Tajikistan. Remittances represented about a third of its gross domestic product (GDP) in 2014 (Karymshakov and Sulaimanova, 2017).

${ }^{11}$ In 2014, individual entrepreneurs and small farmers contributed to respectively $18 \%$ and $9 \%$ of gross domestic product (GDP), but accounted for 90\% of entrepreneurial activities. Over 2001-2014, large enterprises were the main driver of GDP growth (Rudaz, 2017).

${ }^{12}$ In China, Poland or Vietnam for instance, new firms drove reforms by generating economic growth and jobs, offering goods and services otherwise inexistent, stimulating savings, and limiting the power of public firms (McMillan and Woodruff, 2002).

${ }^{13}$ Household members currently away are treated as absent: they are present on household rosters,
} 
The exclusion of 2,099 individuals from 557 households initially interviewed in 2010 could represent a threat to the analysis, if attrition across waves is structural, i.e. if the probability of attrition is different between returnees and non-migrants. For instance, return migrants who plan to re-migrate might take self-employment as a transitory occupation while waiting for future migration, and might not have any interest in lasting entrepreneurial activities. Alternatively, returnees whose entrepreneurial activities fail might be more likely to migrate again. In these cases, non-response might be selective. This would provide a non-random picture of the population and bias estimates.

In the absence of longitudinal and cross-sectional weights, potentially structural attrition is controlled for by including background characteristics that might determine the probability of participation. Since this attrition problem can be viewed as a sample selection problem, sample selection is controlled for in all specifications by adding IMR, based on the predictions of the probability of being interviewed in all four waves regressed on benchmark specification covariates as well as an exclusion restriction, (individual) perception of safety, on the 2010 sample of working-age individuals (cross-section). This exclusion restriction takes a value from 1 to 5 , the greater its value, the less safe an individual feels walking alone in the neighbourhood at night.

As Table B1 shows, its statistical significance and negative sign suggests that the less safe an individual interviewed in the first wave of the survey feels, the less likely s/he will be successfully interviewed in subsequent waves. In other words, the more likely s/he might have left her place of residence during the first wave, or the more suspicious s/he might be, leading to refusal to being interviewed in subsequent waves.

The outcome of interest is a binary variable defined for individuals who reported a primary occupation in any industry, taking the value of 1 if an individual $i$ is self-employed as primary occupation in year $t$, and zero otherwise. Independent variables include: return migration, defined as a binary variable taking value 1 if an individual has lived abroad for at least one month since 2005; gender; age and age squared; ethnicity (three major groups: Kyrgyz, Uzbek, Russian); household headship, marital status, household size and below 15 dependency ratio; secondary, vocational, university education; rural/urban location; and year-specific binary variables to capture wave-specific characteristics and control for year-specific date of fieldwork (month of interview was not recorded).

\subsection{Empirical results}

This section provides a descriptive statistical analysis of the variables of interest in subsection 3.4.1. Regression estimates are presented and discussed in subsection 3.4.2. The robustness of

but are not tracked and left out of individual surveys. They are tracked again once they return to their households, and share common living arrangements. No new sample was added, but new individuals joined the survey in the following rounds because of changes in household composition. New individuals who moved into a surveyed household were surveyed and tracked, even in case of their eventual departure from the household in the following years. Since all adult household members were to be re-interviewed individually, all children of surveyed households became part of the sample once they turned 18 . 
these results is assessed in subsection 3.4.3.

\subsubsection{Descriptive results}

\section{Occupational status and profile of all respondents}

The dependent variable of interest is the occupational status of respondents, i.e. whether they are self-employed at time $t$. Table 3.1 (and, in more details, Table B2) reports that $21.8 \%$ and $29.5 \%$ of the sample are respectively self- and wage-employed. This suggests that both sectors coexist in Kyrgyzstan, consistent with Koelle's (2016) findings for developing economies. Figure 5.1 plots the Kernel density estimates of self- and wage employment earning distributions. While Table B3 reports that self-employed earn on average relatively more than employees, this figure indicates that no sector provides earnings, making it strictly (always) superior.

In addition, earnings from self-employment show greater variability than earnings from wage employment. This could reflect some degree of unpredictability in self-employed activities in Kyrgyzstan and the coexistence of poverty- and opportunity-driven self-employment. This is supported by the fact that working-age individuals who reported being self-employed in some waves earn on average relatively less in a month (KGS8,311) than those who reported being self-employed in all waves of the survey (KGS6,082).

Table 3.1 - Descriptive statistics of estimation sample

\begin{tabular}{lcc}
\hline \hline & Mean & SD \\
\hline Has worked over last week? & 0.600 & 0.490 \\
Self-employed & 0.218 & 0.413 \\
Wage-employed & 0.295 & 0.456 \\
Family worker & 0.085 & 0.278 \\
Has ever lived abroad & 0.063 & 0.243 \\
\hline Total & \multicolumn{2}{c}{19,060} \\
\hline \hline
\end{tabular}

Notes: Means and standard deviations (SD) of variables of interest of the estimation sample (4,765 individuals observed each wave of the survey).

More generally, those in the sample that report being 'Always' self-employed are older, more likely to be men, head of their household and married than individuals 'Sometimes' or 'Never' self-employed. 'Sometimes' self-employed tend to come from bigger households that have experienced relatively more shocks over the preceding 12 months. This may indicate that transitions between occupations occur out of necessity.

As for the labour market activity of self-employed respondents, Table B4 indicates that individuals who reported being 'Always' self-employed are slightly more likely to employ non-household members $(3.2 \%)$ than 'Sometimes' self-employed $(1.9 \%)$. They are also more likely to run registered businesses than those who report being 'Sometimes' self-employed $(54.7 \%$ against $44.8 \%)$. They tend to work more in wholesale, retail and manufacturing 
Figure 3.1 - Kernel density estimates

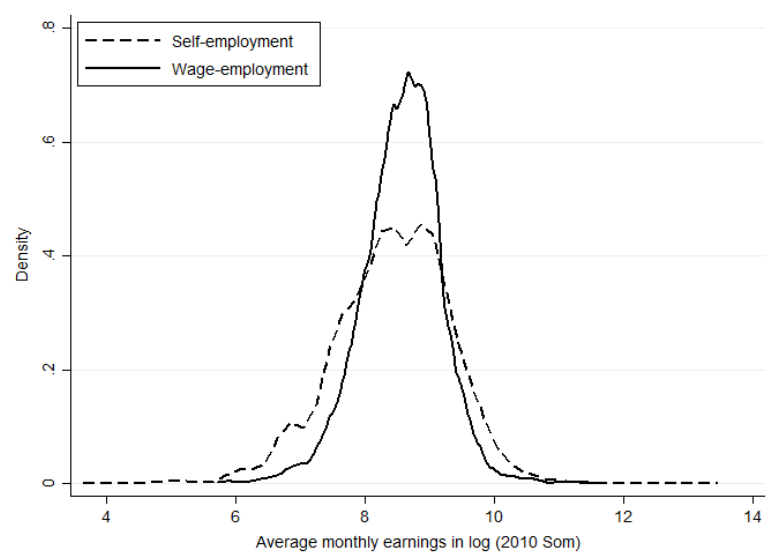

sectors, while 'Sometimes' self-employed are more present in agriculture and construction. These statistics suggest that individuals who reported being self-employed in some waves of the survey, but not all, might be less successful in self-employment and establish less stable entrepreneurial activities than those who reported being self-employed in every wave.

\section{Profile and occupational status of return migrants}

Table B5 indicates that return migrants are on average more likely to be self-employed compared to non-migrants, and Table B3, that on average, return migrants are most present among those who report being 'Sometimes' (9.1\%) and 'Always' (8.6\%) self-employed. It is therefore no surprise that households with return migrants receive a greater share of their income from household entrepreneurial activities compared to individuals living in a non-migrant household, as shown in the upper panel of Table B6. Furthermore, apart from the heterogeneity present among self-employed described above, the almost equal representation of return migrants in these two self-employed types indicates some level of diversity among return migrants.

Considering household expenditure patterns in the lower panel of Table B6, migration seems to be undertaken to meet consumption rather than 'productive' needs. For instance, households with return migrants are more likely to spend their income on 'celebrations' and 'clothing' than non-migrant households. This is consistent with existing qualitative research in Kyrgyzstan suggesting that a frequent reason for migration is to obtain funds to cover daily expenditures or events such as festivities (Thieme, 2014).

\section{Occupational transitions over time}

Given the interest of this chapter in return migrants' occupational choice over time, respondents' labour market transitions across the four years of the survey are considered in Tables 3.2 (full estimation sample), 3.3 (return migrants) and 3.4 (non-migrants). In these tables, a cell should be read as the probability in percentage to transition from a row employment status in year $t$ to a column employment status in year $t+1$. The main diagonal measures inertia, i.e. the proportion of individuals who stayed in the same occupation in two subsequent years.

While Table 3.2 shows general flexibility between occupations, the persistence of the working- 
age population in self-employment $(64 \%)$ is lower than in wage employment $(77 \%)$. Bilateral movements between unemployment, self- and wage employment are more prevalent than movements to other sectors. Specifically, $1.7 \%$ and $7.9 \%$ of the wage-employed are likely to be respectively unemployed and self-employed in the next year compared to $0.9 \%$ and $11 \%$ of the self-employed likely to be respectively unemployed and wage-employed. Transitions thus appear more frequent from self- to wage employment (11\%), and from unemployment to self(11\%) and wage employment (35.6\%), than from wage to self-employment (7.9\%).

Table 3.2 - Transition probabilities between occupations of all respondents

\begin{tabular}{|c|c|c|c|c|c|c|}
\hline \multirow{2}{*}{$\begin{array}{l}\text { Employment } \\
\text { status } t\end{array}$} & \multicolumn{6}{|c|}{ Employment status $t+1$} \\
\hline & Inactive & Unemployed & Self-employed & Wage-employed & Other & Total \\
\hline Inactive & 71.29 & 2.68 & 8.74 & 10.59 & 6.69 & 100.00 \\
\hline Unemployed & 36.67 & 13.85 & 11.03 & 35.64 & 2.82 & 100.00 \\
\hline Self-employed & 19.67 & 0.94 & 63.97 & 10.95 & 4.47 & 100.00 \\
\hline Wage-employed & 11.73 & 1.69 & 7.93 & 77.02 & 1.64 & 100.00 \\
\hline Other & 33.74 & 0.85 & 12.29 & 15.55 & 37.57 & 100.00 \\
\hline Total $t+1$ & 36.92 & 2.11 & 21.71 & 31.66 & 7.60 & 100.00 \\
\hline
\end{tabular}

Notes: Transition frequencies and probabilities between occupations of estimation sample. Rows reflect the initial $t$ values; columns reflect the final $t+1$ values. Inactive includes individuals who have not worked in the last seven days, nor have looked for a job. Unemployed includes individuals who have not worked in the last week, but have been looking for a job. Self-employed includes own-account workers and employers. Wage-employed includes wage-employed and members of a producer's cooperative. Other includes unpaid labour and unspecified.

Labour market transitions of return migrants and non-migrants further indicate that return migrants (Table 3.3) have less stable occupations than non-migrants (Table 3.4), either over the four years ('ever' returnees, upper panel) or upon return (lower panel). While the persistence of both groups in self-employment is similar (around 63\%), the persistence of returnees in wage employment is lower (about 59\%) than that of non-migrants (about 78\%). Moreover, if selfemployed return migrants have a similar probability to transition to wage employment than non-migrants (about 10-11\%), 18.7\% of wage-employed return migrants are likely to be selfemployed in the next year, compared to only $7.2 \%$ of wage-employed non-migrants. 18 and $28.2 \%$ of unemployed 'ever' returnees (upper panel) are likely to be respectively self- and wageemployed in the next year, compared to 10.3 and $36.5 \%$ of unemployed never migrants. In contrast, of those unemployed return migrants upon return (lower panel), 9.1 and $40.9 \%$ are likely to be respectively self- and wage-employed in the next year, which is somewhat similar to never migrants.

From this subsection, it can be concluded that self-employment in Kyrgyzstan is a rather transitory choice of occupation, consistent with Harris and Todaro's (1970) 'parking lot' hypothesis. It is also one seemingly more often selected by return migrants, who display lower occupational stability, both before and after migrating, than non-migrants. In the following subsections, the determinants of these occupational choices are investigated. 
Table 3.3 - Transition probabilities between occupations of returnees

\begin{tabular}{|c|c|c|c|c|c|c|}
\hline \multirow{2}{*}{$\begin{array}{l}\text { Employment } \\
\text { status } t\end{array}$} & \multicolumn{6}{|c|}{ Employment status $t+1$} \\
\hline & Inactive & Unemployed & Self-employed & Wage-employed & Other & Total \\
\hline & \multicolumn{6}{|c|}{ Returnees before/after migrating) } \\
\hline Inactive & 61.49 & 2.80 & 14.91 & 13.98 & 6.83 & 100.00 \\
\hline Unemployed & 35.90 & 15.38 & 17.95 & 28.21 & 2.56 & 100.00 \\
\hline Self-employed & 19.72 & 0.83 & 63.89 & 11.39 & 4.17 & 100.00 \\
\hline Wage-employed & 15.81 & 1.72 & 18.56 & 59.11 & 4.81 & 100.00 \\
\hline Other & 41.84 & 0.00 & 15.31 & 16.33 & 26.53 & 100.00 \\
\hline \multirow[t]{2}{*}{ Total $t+1$} & 33.33 & 2.07 & 31.89 & 25.68 & 7.03 & 100.00 \\
\hline & \multicolumn{6}{|c|}{ Returnees upon return } \\
\hline Inactive & 65.04 & 2.65 & 13.72 & 10.62 & 7.96 & 100.00 \\
\hline Unemployed & 36.36 & 9.09 & 9.09 & 40.91 & 4.55 & 100.00 \\
\hline Self-employed & 22.18 & 0.70 & 63.03 & 10.21 & 3.87 & 100.00 \\
\hline Wage-employed & 18.43 & 1.38 & 16.59 & 58.99 & 4.61 & 100.00 \\
\hline Other & 42.68 & 0.00 & 12.20 & 17.07 & 28.05 & 100.00 \\
\hline Total $t+1$ & 35.26 & 1.56 & 31.05 & 24.55 & 7.58 & 100.00 \\
\hline
\end{tabular}

Notes: Please, refer to Table 3.2 The upper panel present transitions of returnees (before/after migrating), i.e. individuals observed as return migrants at some point in time in the data; the lower panel, of individuals migrants specifically upon return.

Table 3.4 - Transition probabilities between occupations of non-returnees

\begin{tabular}{|c|c|c|c|c|c|c|}
\hline \multirow{2}{*}{$\begin{array}{l}\text { Employment } \\
\text { status } t\end{array}$} & \multicolumn{6}{|c|}{ Employment status $t+1$} \\
\hline & Inactive & Unemployed & Self-employed & Wage-employed & Other & Total \\
\hline & \multicolumn{6}{|c|}{ Never returnees } \\
\hline Inactive & 71.98 & 2.68 & 8.31 & 10.35 & 6.68 & 100.00 \\
\hline Unemployed & 36.75 & 13.68 & 10.26 & 36.47 & 2.85 & 100.00 \\
\hline Self-employed & 19.67 & 0.95 & 63.98 & 10.90 & 4.50 & 100.00 \\
\hline Wage-employed & 11.43 & 1.69 & 7.15 & 78.33 & 1.41 & 100.00 \\
\hline Other & 33.13 & 0.92 & 12.06 & 15.50 & 38.40 & 100.00 \\
\hline \multirow[t]{2}{*}{ Total $t+1$} & 37.22 & 2.11 & 20.86 & 32.17 & 7.65 & 100.00 \\
\hline & \multicolumn{6}{|c|}{ Never returnees and returnees before migration } \\
\hline Inactive & 71.85 & 2.67 & 8.39 & 10.46 & 6.62 & 100.00 \\
\hline Unemployed & 36.94 & 13.89 & 10.56 & 35.83 & 2.78 & 100.00 \\
\hline Self-employed & 19.57 & 0.97 & 63.93 & 11.04 & 4.48 & 100.00 \\
\hline Wage-employed & 11.43 & 1.70 & 7.16 & 78.31 & 1.40 & 100.00 \\
\hline Other & 33.08 & 0.91 & 12.09 & 15.51 & 38.40 & 100.00 \\
\hline Total $t+1$ & 37.16 & 2.13 & 20.93 & 32.17 & 7.61 & 100.00 \\
\hline
\end{tabular}

Notes: Please, refer to Table 3.2. The upper panel present transitions of never returnees, i.e. individuals observed as non return migrants in all years; the lower panel, of individuals observed as non-migrants at some point in time, such as never returnees and returnees who might have left after the first, second or third wave of the survey, and observed as returnees in subsequent waves. 


\subsubsection{Benchmark regression results}

In section 3.3, the estimating strategy was presented, deriving regression equations for a baseline model, a model for entry into self-employment, for 'survival' in self-employment and a combined model accounting for dynamics in and out of self-employment. Regression results for each of these models are presented in Tables 3.5 and B7. Columns (1) and (2) presents baseline estimates, columns (3) and (4) estimates of the entry model, and columns (5) and (6) that of the 'survival' model. Column (7) contains the estimates of the combined model, and column (8), of a parsimoniously combined model. Table B8 displays associated average marginal effects. What can these estimates say about the research questions?

First, baseline model results (columns (1)-(2) of Table 3.5) show that the probability of being self-employed is significantly and positively correlated with return migration. Column (2) of Table B8 suggests that return migration increases the probability of being self-employed by 14.2 percentage points. This result is consistent with results elsewhere in the literature, as reported in section 3.2. These estimates are confirmed by the entry model (columns (3)-(4) of Table 3.5 ), indicating that opting for self-employment is positively correlated with return migration in both random and correlated random effects models. On the contrary, return migration is not significantly related to persistence in self-employment (columns (5)-(6)), which might be explained by the reduction in sample size - 2,620 observations out of 11,361 - inducing wide confidence intervals on individual coefficients.

Second, column (7) of Table 3.5 presents coefficient estimates of a combined model that takes into account dependence between the choice of and the duration in self-employment, as in Wooldridge (2005). Interactions between the lagged outcome variable, Self-employed $(\mathrm{t}-1)$, and all covariates are included. ${ }^{14}$ Although coefficient estimates on interaction terms are jointly significantly different from their corresponding non-interacted variables, column (7) of Table 3.5 suggests that out of 16 interaction terms, 11 are statistically significant. Column (8) thus presents coefficient estimates of a parsimonious combined model including these 11 interaction terms, setting to zero any other interaction terms. Combined and parsimonious combined models indicate that return migration is significantly and positively associated with entry into self-employment. Its interacted term, negatively associated with self-employment, is significant across both specifications and of a smaller magnitude than the non-interacted return migration term. This suggests that return migrants who were self-employed in $t-1$ are less likely to be self-employed in year $t$, i.e. to persist in self-employment over time. In other words, return migrants are less likely to persist in self-employment over time.

Column (7) of Table B8 suggests that, on average, return migration increases the likelihood of entering into self-employment by 18.6 percentage points. While migrants who were not selfemployed in $t-1$ are 23 percentage points more likely to be self-employed upon return at time $t$ (column (8)), migrants who were self-employed in $t-1$ are 18.3 percentage points more likely to be self-employed at time $t$ (column (9)). Marginal effects of coefficient estimates of a

\footnotetext{
${ }^{14}$ This model assesses whether covariates are similarly related to entry into and persistence in selfemployment. If these interaction terms are not significantly different from zero, the null hypothesis that they are equally associated with entry and persistence cannot be rejected.
} 
parsimonious combined model (columns (10)-(12)) present similar estimates. ${ }^{15}$

Benchmark estimates provide an answer to the first research question asked, namely whether return migrants were more likely than non-migrants to enter into and to sustain a career in self-employment in Kyrgyzstan. Return migrants were found to be more likely to enter into selfemployment than non-migrants in the setting studied. However, had they been self-employed in previous waves of the survey, they were found to be less likely to sustain a career in selfemployment. The positive relationship between return migration and self-employment often found in the literature might thus be driven by entry into rather than persistence in selfemployment. One likely reason for this we inferred from descriptive statistics is that selfemployment can act as a 'parking lot'. Specifically, labour market transitions appear more frequent from self- to wage employment than from wage to self-employment, indicating that self-employment in Kyrgyzstan is a rather transitory choice of occupation and one seemingly more often selected by return migrants than non-migrants.

\subsubsection{Robustness checks}

\section{Matched difference-in-differences analyses}

To assess the robustness of these estimates, benchmark specifications are run on a matched sample of control (non-returnees) and treated (returnees), following Egger et al. (2008) and Falvey and Foster-McGregor (2015). The data set consists of four years (2010 to 2013). There is no 'new' return migrant in 2013. For each year $t$, controls are defined as individuals who are not return migrants, and treated, as individuals who are reported as return migrants in year $t$, but who were not in the previous year, $t-1$. Only those 'newly' treated in year $t$ are used in the matching procedure; those existing treated are dropped.

Using either propensity score or covariate matching, new returnees are matched to non-returnees at time $t$ (2011 and 2012) on the basis of $t-1$ (respectively, 2010 and 2011) explanatory variables. Two-year pooled cross-sections of matched individuals are obtained, on which benchmark specifications are run applying matching weights as frequency weights. These 'matched' regressions should control for observed heterogeneity between returnees and nonmigrants as well as self-selection into temporary migration. Although the existence of reverse causality cannot be ruled out, estimates should bring potentially causal evidence on the effects of migration on self-employment propensity upon return in the short term.

Working-age individuals, members of non-splitting households, who were born in Kyrgyzstan, and who reported a primary activity at time $t$, are matched. Either covariate (Mahalanobis) (CVM) or propensity score matching (PSM) techniques are used. PSM is successively applied with one nearest neighbour, five nearest neighbours, radius and kernel density matching, using a logit equation for the probability of being a return migrant; ${ }^{16} \mathrm{CVM}$ with one nearest neighbour

\footnotetext{
${ }^{15}$ Figure B1, in the appendix, graphically depicts marginal effects of return migration on the selfemployment probability for this last specification.

${ }^{16}$ Since the matching procedure is performed to use weights that are generated to then run specifications, but not to compute average treatment effects of return migration on self-employment propensity, standard errors are not bootstrapped.
} 
Table 3.5 - Coefficient estimates of benchmark specifications

\begin{tabular}{|c|c|c|c|c|c|c|c|c|}
\hline \multirow[b]{2}{*}{ Variables } & \multicolumn{2}{|c|}{ Baseline } & \multicolumn{2}{|c|}{ Entry } & \multicolumn{2}{|c|}{ 'Survival' } & \multirow{2}{*}{$\begin{array}{c}\text { Combined } \\
\text { model } \\
\text { CRE } \\
(7)\end{array}$} & \multirow{2}{*}{$\begin{array}{c}\text { Parsimonious } \\
\text { combined } \\
\text { model } \\
\text { CRE } \\
(8)\end{array}$} \\
\hline & $\begin{array}{l}\mathrm{RE} \\
(1)\end{array}$ & $\begin{array}{l}\text { CRE } \\
(2)\end{array}$ & $\begin{array}{l}\mathrm{RE} \\
(3)\end{array}$ & $\begin{array}{l}\text { CRE } \\
(4)\end{array}$ & $\begin{array}{l}\mathrm{RE} \\
(5)\end{array}$ & $\begin{array}{c}\mathrm{CRE} \\
(6)\end{array}$ & & \\
\hline Returnee & $\begin{array}{c}0.5659^{* * *} \\
(0.1436)\end{array}$ & $\begin{array}{c}0.6244^{* * *} \\
(0.2424)\end{array}$ & $\begin{array}{c}0.5571^{* * *} \\
(0.1461)\end{array}$ & $\begin{array}{c}0.8097^{*} \\
(0.4141)\end{array}$ & $\begin{array}{c}0.1200 \\
(0.1351)\end{array}$ & $\begin{array}{c}0.5563 \\
(0.3905)\end{array}$ & $\begin{array}{c}0.9162^{* * *} \\
(0.2873)\end{array}$ & $\begin{array}{c}0.8977^{* * *} \\
(0.2858)\end{array}$ \\
\hline Self-employed $_{(t=0)}$ & & & & & & & $\begin{array}{c}1.0602^{* * *} \\
(0.1246)\end{array}$ & $\begin{array}{c}1.0610^{* * *} \\
(0.1237)\end{array}$ \\
\hline Self-employed $_{(\mathrm{t}-1)}$ & & & & & & & $\begin{array}{l}-0.4154 \\
(0.9229)\end{array}$ & $\begin{array}{c}1.0144^{* * *} \\
(0.2378)\end{array}$ \\
\hline ... X Returnee & & & & & & & $\begin{array}{c}-0.2866^{*} \\
(0.1597)\end{array}$ & $\begin{array}{c}-0.2678^{*} \\
(0.1599)\end{array}$ \\
\hline Control variables & No & Yes & No & Yes & No & Yes & Yes & Yes \\
\hline Time fixed effects & No & Yes & No & Yes & No & Yes & Yes & Yes \\
\hline $\mathrm{IMR}_{\text {retention }}$ & Yes & Yes & Yes & Yes & Yes & Yes & Yes & Yes \\
\hline $\mathrm{IMR}_{\text {working }}$ & Yes & Yes & Yes & Yes & Yes & Yes & Yes & Yes \\
\hline Group means & No & Yes & No & Yes & No & Yes & Yes & $\begin{array}{c}\text { Yes } \\
\text { Returnee, } \\
\text { Male, } \\
\text { Ethnicity, }\end{array}$ \\
\hline Interaction terms & No & No & No & No & No & No & All & $\begin{array}{c}\text { Vocational, } \\
\text { University, } \\
\text { Household size, } \\
\text { Urban, Year }\end{array}$ \\
\hline $\operatorname{lnsig} 2 \mathrm{u}$ & $\begin{array}{c}1.2246^{* * *} \\
(0.0718)\end{array}$ & $\begin{array}{c}1.2462^{* * *} \\
(0.0728)\end{array}$ & $\begin{array}{c}0.3376^{*} \\
(0.2036)\end{array}$ & $\begin{array}{c}0.3683^{*} \\
(0.2045)\end{array}$ & $\begin{array}{c}-0.8696^{*} \\
(0.4559)\end{array}$ & $\begin{array}{c}-0.7797^{*} \\
(0.4463)\end{array}$ & $\begin{array}{c}-0.2255 \\
(0.2137)\end{array}$ & $\begin{array}{c}-0.2156 \\
(0.2119)\end{array}$ \\
\hline $\bar{X}_{k i t}=0$ & & 54.99 & & 21.96 & & 144.91 & 20.19 & 21.18 \\
\hline & & 0.0000 & & 0.0560 & & 0.0000 & 0.0907 & 0.0694 \\
\hline$\beta_{k}=\theta_{k}$ & & & & & & & 46.92 & 34.47 \\
\hline & & & & & & & 0.0000 & 0.0003 \\
\hline Observations & 11,361 & 11,361 & 6,031 & 6,031 & 2,620 & 2,620 & 8,651 & 8,651 \\
\hline Number of groups & 3,849 & 3,849 & 3,044 & 3,044 & 1,371 & 1,371 & 3,736 & 3,736 \\
\hline
\end{tabular}

Notes: The dependent variable is a binary variable taking unity if a working-age individual is self-employed; 0 , if employed, wageemployed or unpaid, or member of a cooperative. Observations are working-age individuals, members of non-splitting households, who were born in Kyrgyzstan. Columns (1)-(2) present coefficient estimates of probit model of equation (1); Columns (3)-(4), of equation (2); Columns (5)-(6), of equation (3); and Columns (7)-(8), coefficient estimates of a dynamic, non-linear probability model with unobserved heterogeneity, as in equation (5). Tests of joint significance of group means and interaction terms when applicable report $\chi^{2}$ with associated statistical significance. Standard errors clustered at the household level are in parentheses. $* * * \mathrm{p}<0.01, * * \mathrm{p}<0.05, * \mathrm{p}<0.1$.

and five nearest neighbours, with Abadie and Imbens's (2006) bias correction. The best matches are given using five nearest neighbours with PSM and CVM. ${ }^{17}$ Matching quality is reported in Figures B2 and B3.

Table B9 presents coefficient estimates of specifications run with these two matched samples. Signs are similar to, but magnitudes and statistical significance slightly differ from, benchmark estimates. In a model that does not distinguish between entry into and persistence in selfemployment (column (1)), having migrated is positively but not significantly associated with self-employment. As in the baseline model estimates, entry into self-employment is positively and significantly correlated with return migration (column (2)). In contrast, return migration is negatively but not significantly related to persistence in self-employment, which might also

\footnotetext{
${ }^{17}$ Matching estimates for alternative techniques are available on request.
} 
be explained by the reduction in sample size (434 observations for PSM; 428 for CVM). Column (4) presents coefficient estimates of a 'combined' model, including as additional regressors the initial value of the outcome variable, Self-employed $\mathrm{e}_{(\mathrm{t}=0)}$, and its lagged Self$\operatorname{employed}_{(\mathrm{t}-1)}$, as well as its interaction with all covariates. In column (5), only interaction terms with coefficient estimates significantly different from zero are kept. Coefficient estimates on return migration and its interaction with lagged self-employment are statistically significant and differ in sign. This confirms benchmark estimates in showing that, controlling for observed heterogeneity and self-selection into temporary migration, migration increases the propensity to enter into self-employment, but decreases (increases) the probability to persist in (exit from) self-employment in the short term, in line with the 'parking lot' hypothesis. Return migrants who were self-employed in period $t$, i.e. before leaving Kyrgyzstan, were found to have a negative probability of being self-employed in period $t+1$, i.e. to persist in self-employment upon return to Kyrgyzstan.

Column (1) of Table B9 suggests that return migration significantly increases self-employment propensity by 10.94 to 12.40 percentage points on average. This is driven by the greater probability of entering into than of persisting in self-employment. When migrants had not been self-employed before leaving Kyrgyzstan, they were 19.98 to 20.09 percentage points more likely to be self-employed (column (2)). When they had been, they were however 4.32 less to 1.19 more likely to be self-employed (non-significant). Although marginal effects only give information at distribution average, these estimates confirm that temporary migration increases the likelihood of opting for self-employment upon return, but increases the likelihood of exiting from selfemployment upon return, if returnees had been self-employed before leaving Kyrgyzstan. In other words, return migration is associated with a smaller increase in the probability of being self-employed for those who were self-employed in the past. This is as if temporary migration disrupts self-employment at least in the short term. ${ }^{18}$

Matched difference-in-differences estimates thus provide an answer to the second research question asked, namely if being self-employed upon return is influenced by whether return migrants had been self-employed before migrating. Return migrants were found to be more likely to enter into self-employment than non-migrants if they had not been self-employed before leaving Kyrgyzstan. If they had been, they were found to be less likely to be self-employed upon return. This result suggests that temporary migration could be more disruptive of self-employment trajectories than is often thought.

\section{Household-level analyses}

Lastly, the fact that the decision to migrate tends to be taken at the household level is exploited. Remittances sent to non-migrating household members or resources repatriated upon return such as savings could induce newly reunited families to switch to entrepreneurial activities or invest in existing ventures. Not only have migrants returning to their origin country been found to be more likely to start their own enterprises, they have also been found to stimulate

\footnotetext{
${ }^{18}$ Figure B4 graphically shows marginal effects of return migration on the self-employment probability of the last specification, for both matched samples.
} 
the entrepreneurship of non-migrant family members, through spill-over effects (Mansuri, 2007; Giulietti et al., 2013).

In Kyrgyzstan, where international migration is partly seasonal and typically involves repeated episodes, a household with returnees could be expected to be more likely to set up a family enterprise that might survive future migration episodes of its members. Descriptive statistics indeed suggest that non-migrants living in a household with returnees are more likely to contribute to family work than those who do not (Table B5), and that they gain relatively more income from household enterprises (Table B6).

The above specifications are run on a panel of households. Potential endogeneity between migration and family enterprise is addressed by assuming that endogeneity mainly comes from unobserved time-invariant household characteristics, following Antman (2015). Using correlated random effects estimators with longitudinal data should ensure (household) migration status to be as good as randomly assigned conditional on observed and unobserved covariates. ${ }^{19}$ Household panel attrition is controlled for as previously by including IMR computed after running a regression of the probability of being interviewed in all waves of the survey on a sample of households in 2010. Household heads' perception of safety is used as exclusion restriction. ${ }^{20}$ Tables B11 and B12 present coefficient estimates respectively on a full and matched estimation sample. ${ }^{21}$ The dependent variable is a binary variable taking unity if at least one workingage individual is self-employed in a household; zero, otherwise. Observations are for nonsplitting households, whose heads were born in Kyrgyzstan. Standard errors are robust to heteroscedasticity.

Estimates of household specifications are similar to results of individual specifications, except for combined models. If a household has members who returned from abroad, having at least one self-employed member in $t-1$ does not affect the probability of at least one member being self-employed at time $t$ any differently from if they had not had any self-employed member in $t-1$. However, estimates with matched samples show a statistically different effect, in line with individual specifications. This, in addition to descriptive statistics, suggests that, although households with returnees are more likely to have members contributing to family work, i.e. to capture some of its members' labour force, they are less likely to persist in self-employment in the short term.

Average marginal effects of household specifications are presented in Table B13. They indicate that, on average, despite the negative effect of members' return migration on the persistence of household family enterprise, the effect is positive on the likelihood of households having at least one self-employed member. ${ }^{22}$

\footnotetext{
${ }^{19}$ Although readers should remain cautious about any causal interpretations (see e.g. Steinmayr's (2015) case for invisible sample selection), any potential endogeneity bias should be lowered because emigration from Kyrgyzstan tends to be temporary in nature and only non-splitting households observed in all four waves are kept in the estimation sample. Households of the estimation sample are thus either households that could not afford migration of the entire family, or never-migrant households - families with no migrants that would not send out one or several members anyway.

${ }^{20}$ Estimates are available on request.

${ }^{21}$ Matching quality is shown in Figures B5 and B6.

${ }^{22}$ Marginal effects by lagged self-employment status are depicted in Figures B7 and B8.
} 


\subsection{Concluding remarks}

This chapter questions and qualifies the assumption that return migration stimulates entrepreneurship in origin countries by simultaneously dealing with entry into and exit from selfemployment in the broader context of whether (return) migration facilitates self-employment choices in developing economies. Correlated random effects models and a matched difference-indifferences analysis were used to account for self-employment dynamics, time-invariant and timevarying endogeneity, with a rich longitudinal database from Kyrgyzstan, a transition economy with prevalent international migration.

As in other contexts, return migrants in Kyrgyzstan are found more likely to be self-employed than non-migrants. Disregarding occupations in previous waves of the survey, return migration increases the likelihood of being self-employed by 18.2 percentage points compared to nonmigrants. While migrants who were not self-employed in $t-1$ are 22.4 percentage points more likely to be self-employed upon return at time $t$, migrants who were self-employed in $t-1$ were 18.5 percentage points more likely to be self-employed at time $t$. One likely reason for this that can be inferred from descriptive statistics is that self-employment acts as a 'parking lot'. Labour market transitions appear more frequent from self- to wage employment than from wage to self-employment, and return migrants less likely to persist in self-employment over time compared to non-migrants. This indicates that self-employment in Kyrgyzstan is a rather transitory choice of occupation, and one seemingly more often selected by temporary migrants than non-migrants, either before migrating or upon return to their origin countries.

In addition, results indicate that the decision of a return migrant to be self-employed is negatively affected if $\mathrm{s} /$ he had been self-employed before migrating. Robustness checks reveal that, on average, return migration increases the likelihood of being self-employed by 1.19 percentage points for returnees who had been self-employed before leaving Kyrgyzstan, though it is not statistically significant. This likelihood increases to 19.98 percentage points if they had not been self-employed before leaving, which is statistically significant.

These novel findings suggest that migration can disrupt self-employment trajectories. The finding that, if migrants were self-employed before leaving, they are less likely to be selfemployed upon return is a 'disruption' that can be viewed in a positive light as it enables career development by offering an escape from poverty-driven self-employment. Exiting self-employment in origin countries because of emigration might reveal preferences for wage employment or a better allocation of workers' capabilities as wage-employed. This 'disruption' thus reduces the number of self-employed with low abilities in the entrepreneurial pool. In this case, the appropriate policy response is to support smooth occupational transitions in labour markets and fast reintegration of return migrants to help them make the best use of their resources and reduce their need for self-employment out of necessity.

However, the finding that self-employment might be a temporary occupational choice suggests that the 'disruption' caused by migration may hinder an economy from benefiting entrepreneurially from the experience and resources migrants might have accumulated abroad. In this case, the appropriate policy response is to improve the conditions for doing business in source countries. In a context of transition from planned to market economy, entrepreneurial 
success requires a mix of both microeconomic reform and macroeconomic and institutional stability and efficiency. This evidence from Kyrgyzstan suggests that temporary migration might substitute for an imperfect legal framework and weak financial markets. As such, support for formal market-supporting institutions is advised if firms are to grow, and countries are to harness the entrepreneurial acumen migrants might have accumulated abroad. 


\subsection{Appendix}

Table B1 - Investigating panel attrition

\begin{tabular}{|c|c|}
\hline Variables & (1) \\
\hline Returnee & $\begin{array}{c}-0.2597^{* * *} \\
(0.0794)\end{array}$ \\
\hline Male & $\begin{array}{c}-0.1123^{* * *} \\
(0.0315)\end{array}$ \\
\hline Head & $\begin{array}{c}0.0444 \\
(0.0413)\end{array}$ \\
\hline Married & $\begin{array}{c}0.2129 * * * \\
(0.0471)\end{array}$ \\
\hline Age & $\begin{array}{c}0.0282^{* *} \\
(0.0116)\end{array}$ \\
\hline Age squared & $\begin{array}{l}-0.0001 \\
(0.0002)\end{array}$ \\
\hline Kyrgyz & $\begin{array}{c}-0.0890 \\
(0.0821)\end{array}$ \\
\hline Uzbek & $\begin{array}{c}0.1311 \\
(0.0985)\end{array}$ \\
\hline Russian & $\begin{array}{c}-0.2231^{* *} \\
(0.1076)\end{array}$ \\
\hline Secondary & $\begin{array}{c}0.0063 \\
(0.0650)\end{array}$ \\
\hline Vocational & $\begin{array}{l}-0.0323 \\
(0.0770)\end{array}$ \\
\hline University & $\begin{array}{c}0.0384 \\
(0.0809)\end{array}$ \\
\hline Household size & $\begin{array}{c}-0.0141 \\
(0.0123)\end{array}$ \\
\hline$<16$ dependency ratio & $\begin{array}{c}0.5303^{* * *} \\
(0.1315)\end{array}$ \\
\hline Rural & $\begin{array}{c}0.0293 \\
(0.0515)\end{array}$ \\
\hline Safety & $\begin{array}{c}-0.0703^{* * *} \\
(0.0144)\end{array}$ \\
\hline Constant & $\begin{array}{l}-0.2713 \\
(0.2275)\end{array}$ \\
\hline Observations & 6,910 \\
\hline
\end{tabular}

Notes: Coefficient estimates of the probability of being interviewed in all four waves of the survey. Observations are working-age individuals interviewed in 2010, members of non-splitting households, who were born in Kyrgyzstan. Robust standard errors clustered at the household level are in parentheses. *** $\mathrm{p}<0.01,{ }^{* *} \mathrm{p}<0.05,{ }^{*} \mathrm{p}<0.1$. 
Table B2 - Descriptive statistics of estimation sample

\begin{tabular}{|c|c|c|}
\hline & Mean & $\mathrm{SD}$ \\
\hline \multicolumn{3}{|l|}{ Individual } \\
\hline Male & 0.4717 & 0.4992 \\
\hline Age & 39.5579 & 12.3972 \\
\hline Head & 0.3612 & 0.4804 \\
\hline Married & 0.7542 & 0.4305 \\
\hline Kyrgyz & 0.6944 & 0.4607 \\
\hline Uzbek & 0.1393 & 0.3463 \\
\hline Russian & 0.0675 & 0.2508 \\
\hline Vocational & 0.1572 & 0.3640 \\
\hline Secondary & 0.5734 & 0.4946 \\
\hline University & 0.1739 & 0.3790 \\
\hline Has worked over last week? & 0.6002 & 0.4899 \\
\hline Self-employed & 0.2182 & 0.4130 \\
\hline Wage-employed & 0.2947 & 0.4559 \\
\hline Family worker & 0.0846 & 0.2783 \\
\hline Has ever lived abroad & 0.0630 & 0.2430 \\
\hline \multicolumn{3}{|l|}{ Household } \\
\hline Household size & 5.6549 & 2.4114 \\
\hline 0-15 dependency ratio & 0.2689 & 0.2023 \\
\hline Living with returnee(s) & 0.1637 & 0.3701 \\
\hline Member(s) currently working abroad & 0.1287 & 0.3349 \\
\hline Owns land & 0.7715 & 0.4199 \\
\hline Total land area (ha.) & 0.8080 & 1.6696 \\
\hline Land area distributed (ha.) & 0.7006 & 1.5892 \\
\hline Number of shocks & 1.9453 & 2.2251 \\
\hline \multicolumn{3}{|l|}{ Location } \\
\hline Urban & 0.3644 & 0.4813 \\
\hline Total & \multicolumn{2}{|c|}{19,060} \\
\hline
\end{tabular}

Notes: Means and standard deviations (SD) of variables of interest of balanced panel estimation sample of 4,765 individuals observed each four year of the survey. 
Table B3 - Descriptive statistics of estimation sample by employment status

\begin{tabular}{|c|c|c|c|}
\hline & $\begin{array}{c}\text { Always } \\
\text { self-employed }\end{array}$ & $\begin{array}{c}\text { Sometimes } \\
\text { self-employed }\end{array}$ & $\begin{array}{c}\text { Never } \\
\text { self-employed }\end{array}$ \\
\hline \multicolumn{4}{|l|}{ Individual } \\
\hline Male & 0.8486 & 0.6666 & 0.3246 \\
\hline Age & 42.1363 & 40.3391 & 38.8457 \\
\hline Head & 0.7041 & 0.4753 & 0.2610 \\
\hline Married & 0.8697 & 0.8196 & 0.7062 \\
\hline Kyrgyz & 0.7764 & 0.6942 & 0.6852 \\
\hline Uzbek & 0.0904 & 0.1655 & 0.1311 \\
\hline Russian & 0.0309 & 0.0300 & 0.0916 \\
\hline Vocational & 0.1747 & 0.1394 & 0.1648 \\
\hline Secondary & 0.6107 & 0.6679 & 0.5188 \\
\hline University & 0.1544 & 0.1017 & 0.2146 \\
\hline Has worked last week & 1.0000 & 0.7025 & 0.4998 \\
\hline Self-employed & 1 & 0.4591 & 0.0000 \\
\hline Wage-employed & 0 & 0.1624 & 0.3990 \\
\hline Family worker & 0 & 0.0767 & 0.0985 \\
\hline Average monthly profits (real, oblasts) & $8,310.878^{*}$ & $6,082.414^{*}$ & $6,243.931^{*}$ \\
\hline Has ever lived abroad & 0.0858 & 0.0909 & 0.0456 \\
\hline \multicolumn{4}{|l|}{ Household } \\
\hline Household size & 5.3102 & 5.9408 & 5.5421 \\
\hline 0-15 dependency ratio & 0.3016 & 0.2943 & 0.2516 \\
\hline Living with returnee(s) & 0.1363 & 0.1937 & 0.1509 \\
\hline $\begin{array}{l}\text { Member(s) currently } \\
\text { working abroad }\end{array}$ & 0.0828 & 0.1497 & 0.1228 \\
\hline Owns land & 0.8170 & 0.8504 & 0.7242 \\
\hline Total land area (ha.) & 1.2243 & 0.9623 & 0.6779 \\
\hline Land area distributed (ha.) & 1.0761 & 0.8360 & 0.5853 \\
\hline Number of shocks & 2.0813 & 2.1188 & 1.8373 \\
\hline \multicolumn{4}{|l|}{ Location } \\
\hline Urban & 0.3253 & 0.2262 & 0.4425 \\
\hline Total & 1,328 & 6,164 & 11,568 \\
\hline
\end{tabular}

Notes: Means of variables of interest of balanced panel estimation sample of 4,765 individuals observed each four years of the survey, by employment status of primary occupation. * Statistics reported for individuals always, sometimes or never self-employed who worked and received a salary (respectively 1,274, 3,676 and 4,646 individuals). 
Table B4 - Descriptive statistics of self-employed

\begin{tabular}{lccc}
\hline \hline & All self-employed & $\begin{array}{c}\text { Always } \\
\text { self-employed }\end{array}$ & $\begin{array}{c}\text { Sometimes } \\
\text { self-employed }\end{array}$ \\
\hline Employer & 0.0228 & 0.0316 & 0.0187 \\
Own-account & 0.9772 & 0.9684 & 0.9813 \\
Months in activity & 112.5171 & 124.7651 & 106.7696 \\
Business is registered & 0.4798 & 0.5467 & 0.4484 \\
Employs non household members & 0.1000 & 0.1408 & 0.0809 \\
Number of employees (cond.) & 3.5361 & 3.5989 & 3.4847 \\
Average monthly profits (real, oblasts) & $6,752.205^{*}$ & $8,310.878^{*}$ & $6,001.733^{*}$ \\
Agriculture & 0.5464 & 0.5256 & 0.5562 \\
Wholesale and retail & 0.2071 & 0.2470 & 0.1883 \\
Transportation & 0.1142 & 0.1175 & 0.1127 \\
Manufacturing & 0.0214 & 0.0377 & 0.0138 \\
Construction & 0.0418 & 0.0203 & 0.0519 \\
Hotels and restaurants & 0.0072 & 0.0060 & 0.0078 \\
Other services & 0.0618 & 0.0459 & 0.0693 \\
Owns land & 0.8523 & 0.8170 & 0.8689 \\
Number of shock & 2.1174 & 2.0813 & 2.1343 \\
\hline Total & 4,158 & 1,328 & 2,830 \\
\hline \hline
\end{tabular}

Notes: Means of variables of interest of balanced panel estimation sample of self-employed individuals. The first column reports descriptive statistics of individuals observed as self-employed in the survey. The second column reports descriptive statistics of individuals always observed as self-employed throughout the survey. The last column reports descriptive statistics of individuals sometimes self-employed, when observed as self-employed. Real profits are computed at 2010 contact price for the whole country. Agriculture includes agriculture, hunting, forestry, fishing and extractive industry. Other services include financial intermediation, education, health, social work and private households. *Statistics reported for all, always and sometimes self-employed who reported a salary different from 0 (respectively 3,920, 1,274 and 2,646 individuals). 
Table B5 - Descriptive statistics of estimation sample by migration status

\begin{tabular}{|c|c|c|c|c|}
\hline & \multirow[b]{2}{*}{ Returnees } & \multicolumn{3}{|c|}{ Non-migrants } \\
\hline & & All & With returnee(s) & Without returnee \\
\hline \multicolumn{5}{|l|}{ Individual } \\
\hline Male & 0.6819 & 0.4576 & 0.3906 & 0.4657 \\
\hline Age & 38.8493 & 39.6056 & 39.8021 & 39.5819 \\
\hline Head & 0.4280 & 0.3567 & 0.2396 & 0.3708 \\
\hline Married & 0.7802 & 0.7525 & 0.7802 & 0.7492 \\
\hline Kyrgyz & 0.6495 & 0.6975 & 0.5875 & 0.7107 \\
\hline Uzbek & 0.2256 & 0.1335 & 0.2526 & 0.1192 \\
\hline Russian & 0.0300 & 0.0700 & 0.0422 & 0.0733 \\
\hline Vocational & 0.1174 & 0.1599 & 0.1313 & 0.1634 \\
\hline Secondary & 0.5970 & 0.5718 & 0.6469 & 0.5628 \\
\hline University & 0.1807 & 0.1734 & 0.1104 & 0.1810 \\
\hline Has worked last week & 0.6386 & 0.5976 & 0.5552 & 0.6027 \\
\hline Self-employed & 0.3189 & 0.2114 & 0.1901 & 0.2139 \\
\hline Wage-employed & 0.2406 & 0.2983 & 0.2417 & 0.3052 \\
\hline Family worker & 0.0741 & 0.0853 & 0.1198 & 0.0812 \\
\hline Has ever lived abroad & 1 & 0 & 0 & 0 \\
\hline \multicolumn{5}{|l|}{ Household } \\
\hline Household size & 6.1424 & 5.6221 & 6.9771 & 5.4589 \\
\hline 0-15 dependency ratio & 0.2802 & 0.2682 & 0.2469 & 0.2707 \\
\hline Living with returnee(s) & 1 & 0.1075 & 1 & 0 \\
\hline $\begin{array}{l}\text { Member(s) currently } \\
\text { working abroad }\end{array}$ & 0.1757 & 0.1255 & 0.1870 & 0.1181 \\
\hline Owns land & 0.7968 & 0.7698 & 0.8391 & 0.7615 \\
\hline Total land area (ha.) & 0.7034 & 0.8150 & 0.6919 & 0.8298 \\
\hline Land area distributed (ha.) & 0.5827 & 0.7085 & 0.5952 & 0.7221 \\
\hline Number of shocks & 2.0275 & 1.9398 & 1.9625 & 1.9371 \\
\hline \multicolumn{5}{|l|}{ Location } \\
\hline Urban & 0.3172 & 0.3675 & 0.2630 & 0.3801 \\
\hline Total & 1,201 & 17,859 & 1,920 & 15,939 \\
\hline
\end{tabular}

Notes: Means of variables of interest of balanced panel estimation sample of 4,765 individuals observed each four years of the survey, by individual and household migration status. 
Table B6 - Income sources and expenditures by household migration status

\begin{tabular}{|c|c|c|c|c|c|}
\hline & \multicolumn{2}{|c|}{ All households } & \multirow{2}{*}{$\begin{array}{c}\text { With } \\
\text { returnee(s) } \\
\text { Mean }\end{array}$} & \multirow{2}{*}{$\begin{array}{l}\text { Without } \\
\text { returnee } \\
\text { Mean }\end{array}$} & \multirow[t]{2}{*}{ t-test } \\
\hline & Mean & S.D. & & & \\
\hline & \multicolumn{5}{|c|}{ Incomes } \\
\hline \multicolumn{6}{|l|}{ Share from: } \\
\hline Household enterprise & .3384 & .3715 & .37433 & .33213 & $3.84^{* * *}$ \\
\hline Property & .0097 & .0651 & .00931 & .00978 & -0.24 \\
\hline Social transfers & .1853 & .2746 & .15697 & .19043 & $-4.11^{* * *}$ \\
\hline Material aid & .0878 & .2069 & .12274 & .08184 & $6.68^{* * *}$ \\
\hline Wage employment & .3544 & .3937 & .30877 & .36205 & $-4.57 * * *$ \\
\hline Other incomes & .0244 & .1152 & .02789 & .02377 & 1.21 \\
\hline Total & \multicolumn{2}{|c|}{9,031} & 1,336 & 7,695 & \\
\hline & \multicolumn{5}{|c|}{ Expenditures } \\
\hline \multicolumn{6}{|l|}{ Share from: } \\
\hline Health & .1381 & .1065 & .11773 & .14164 & $-7.64 * * *$ \\
\hline Housing and utilities & .3063 & .1622 & .30543 & .30649 & -0.22 \\
\hline Education & .0205 & .0687 & .0225 & .02019 & 1.14 \\
\hline Transportation & .1030 & .1006 & .10661 & .1024 & 1.42 \\
\hline Leisure & .1124 & .0898 & .11049 & .11269 & -0.83 \\
\hline Celebrations & .0987 & .1323 & .10757 & .09714 & $2.67^{* * *}$ \\
\hline Clothing & .2210 & .1485 & .22968 & .21945 & $2.34^{* *}$ \\
\hline Total & \multicolumn{2}{|c|}{9,106} & 1,349 & 7,757 & \\
\hline
\end{tabular}

Notes: In upper panel, share of monthly average household income by sources of balanced panel households for non-missing values are reported. Household enterprises include income from agricultural and non-agricultural enterprises. Property includes income from building, land, interests and dividends. Social transfers include pensions, monthly benefits, compensatory and social payments. Material aid includes humanitarian aid, global and regional remittances. Share of monthly average household expenditures on non-food items of balanced panel households for non-missing values are reported in lower panel. Health expenditures include soap, detergents, personal care, medicine and medical care. Housing and utilities expenditures include energy, taxes, construction, maintenance, household goods and vehicles. Education expenditures exclude school expenditures. Transportation expenditures include transportation services and fuel used for transportation. Leisure expenditures include communication, entertainment, TV, radio, Internet, jewellery. Celebration expenditures include celebrations, funerals and rituals. Clothing expenditures include clothing, shoes and fabrics. 
Table B7 - Coefficient estimates of benchmark specifications

\begin{tabular}{|c|c|c|c|c|c|c|c|c|}
\hline \multirow[b]{2}{*}{ Variables } & \multicolumn{2}{|c|}{ Baseline } & \multicolumn{2}{|c|}{ Entry } & \multicolumn{2}{|c|}{ 'Survival' } & \multirow{2}{*}{$\begin{array}{c}\text { Combined } \\
\text { model } \\
\text { CRE } \\
(7)\end{array}$} & \multirow{2}{*}{$\begin{array}{c}\text { Parsimonious } \\
\text { combined } \\
\text { model } \\
\text { CRE } \\
(8)\end{array}$} \\
\hline & $\begin{array}{l}\mathrm{RE} \\
(1)\end{array}$ & $\begin{array}{l}\mathrm{CRE} \\
(2)\end{array}$ & $\begin{array}{l}\mathrm{RE} \\
(3)\end{array}$ & $\begin{array}{l}\text { CRE } \\
(4)\end{array}$ & $\begin{array}{l}\mathrm{RE} \\
(5)\end{array}$ & $\begin{array}{l}\mathrm{CRE} \\
(6)\end{array}$ & & \\
\hline Returnee & $\begin{array}{c}0.5659^{* * *} \\
(0.1436)\end{array}$ & $\begin{array}{c}0.6244^{* * *} \\
(0.2424)\end{array}$ & $\begin{array}{c}0.5571^{* * *} \\
(0.1461)\end{array}$ & $\begin{array}{c}0.8097^{*} \\
(0.4141)\end{array}$ & $\begin{array}{c}0.1200 \\
(0.1351)\end{array}$ & $\begin{array}{c}0.5563 \\
(0.3905)\end{array}$ & $\begin{array}{c}0.9162^{* * *} \\
(0.2873)\end{array}$ & $\begin{array}{c}0.8977^{* * *} \\
(0.2858)\end{array}$ \\
\hline Male & $\begin{array}{c}1.7852^{* * *} \\
(0.2373)\end{array}$ & $\begin{array}{c}0.5934 \\
(0.4510)\end{array}$ & $\begin{array}{c}0.8801 * * * \\
(0.2603)\end{array}$ & $\begin{array}{l}-1.9887 \\
(3.2860)\end{array}$ & $\begin{array}{l}0.3700^{*} \\
(0.2022)\end{array}$ & $\begin{array}{c}2.1122 \\
(3.0860)\end{array}$ & $\begin{array}{l}-0.4583 \\
(2.2325)\end{array}$ & $\begin{array}{l}-0.5841 \\
(2.2436)\end{array}$ \\
\hline Age & $\begin{array}{c}0.2533^{* * * *} \\
(0.0636)\end{array}$ & $\begin{array}{c}0.2862^{* * *} \\
(0.0717)\end{array}$ & $\begin{array}{c}0.0872 \\
(0.0760)\end{array}$ & $\begin{array}{c}0.3043^{* *} \\
(0.1200)\end{array}$ & $\begin{array}{c}0.0800 \\
(0.0498)\end{array}$ & $\begin{array}{c}0.1440 \\
(0.0954)\end{array}$ & $\begin{array}{c}0.1804^{* *} \\
(0.0757)\end{array}$ & $\begin{array}{c}0.2119^{* * *} \\
(0.0702)\end{array}$ \\
\hline Age squared & $\begin{array}{c}-0.0032^{* * * *} \\
(0.0008)\end{array}$ & $\begin{array}{c}-0.0032^{* * * *} \\
(0.0008)\end{array}$ & $\begin{array}{l}-0.0010 \\
(0.0009)\end{array}$ & $\begin{array}{l}-0.0012 \\
(0.0010)\end{array}$ & $\begin{array}{l}-0.0009 \\
(0.0006)\end{array}$ & $\begin{array}{c}-0.0010 \\
(0.0006)\end{array}$ & $\begin{array}{c}-0.0009 \\
(0.0007)\end{array}$ & $\begin{array}{c}-0.0012^{* *} \\
(0.0005)\end{array}$ \\
\hline Kyrgyz & $\begin{array}{c}-0.2734^{*} \\
(0.1495)\end{array}$ & $\begin{array}{c}0.1292 \\
(0.7721)\end{array}$ & $\begin{array}{c}-0.0549 \\
(0.1338)\end{array}$ & $\begin{array}{c}1.0359 \\
(1.5082)\end{array}$ & $\begin{array}{c}-0.3123^{* *} \\
(0.1341)\end{array}$ & $\begin{array}{l}-4.6563 \\
(4.5458)\end{array}$ & $\begin{array}{c}0.7556 \\
(0.9856)\end{array}$ & $\begin{array}{c}0.7258 \\
(1.0010)\end{array}$ \\
\hline Uzbek & $\begin{array}{l}-0.2179 \\
(0.1881)\end{array}$ & $\begin{array}{c}-1.6129 * * * \\
(0.6042)\end{array}$ & $\begin{array}{c}0.0896 \\
(0.1725)\end{array}$ & $\begin{array}{l}-2.1362 \\
(1.6543)\end{array}$ & $\begin{array}{c}-0.3531^{* *} \\
(0.1758)\end{array}$ & $\begin{array}{l}-4.6676 \\
(3.9201)\end{array}$ & $\begin{array}{l}-1.2087 \\
(1.1490)\end{array}$ & $\begin{array}{l}-1.2035 \\
(1.1519)\end{array}$ \\
\hline Russian & $\begin{array}{c}-0.9143^{* * *} \\
(0.2550)\end{array}$ & $\begin{array}{c}-0.4359 \\
(0.7060)\end{array}$ & $\begin{array}{c}-0.4718^{* *} \\
(0.2345)\end{array}$ & $\begin{array}{c}0.9941 \\
(0.9988)\end{array}$ & $\begin{array}{c}-0.6587^{* *} \\
(0.2617)\end{array}$ & $\begin{array}{l}-5.6670 \\
(4.5837)\end{array}$ & $\begin{array}{c}0.1022 \\
(0.8684)\end{array}$ & $\begin{array}{c}0.1407 \\
(0.8859)\end{array}$ \\
\hline Head & $\begin{array}{c}0.7333^{* * *} \\
(0.1124)\end{array}$ & $\begin{array}{c}0.7299^{* * *} \\
(0.2737)\end{array}$ & $\begin{array}{c}0.3067^{* * *} \\
(0.1138)\end{array}$ & $\begin{array}{l}0.6892^{*} \\
(0.3879)\end{array}$ & $\begin{array}{c}0.2035^{* *} \\
(0.1020)\end{array}$ & $\begin{array}{c}0.6510 \\
(0.4158)\end{array}$ & $\begin{array}{c}0.5866^{* *} \\
(0.2974)\end{array}$ & $\begin{array}{c}0.6072^{* *} \\
(0.2934)\end{array}$ \\
\hline Secondary & $\begin{array}{c}0.3672^{* *} \\
(0.1824)\end{array}$ & $\begin{array}{l}-0.0250 \\
(0.3619)\end{array}$ & $\begin{array}{c}0.0544 \\
(0.2036)\end{array}$ & $\begin{array}{c}0.6101 \\
(0.7346)\end{array}$ & $\begin{array}{c}0.3459^{* *} \\
(0.1636)\end{array}$ & $\begin{array}{c}-0.1866 \\
(0.5528)\end{array}$ & $\begin{array}{c}0.0071 \\
(0.4497)\end{array}$ & $\begin{array}{c}0.2124 \\
(0.4244)\end{array}$ \\
\hline Vocational & $\begin{array}{c}0.1374 \\
(0.2510)\end{array}$ & $\begin{array}{c}0.2900 \\
(0.3862)\end{array}$ & $\begin{array}{c}-0.5758^{*} \\
(0.3194)\end{array}$ & $\begin{array}{c}0.2855 \\
(0.7466)\end{array}$ & $\begin{array}{c}0.3349^{*} \\
(0.1964)\end{array}$ & $\begin{array}{c}0.0933 \\
(0.5385)\end{array}$ & $\begin{array}{l}-0.1778 \\
(0.4621)\end{array}$ & $\begin{array}{c}0.0498 \\
(0.4306)\end{array}$ \\
\hline University & $\begin{array}{l}-0.4364 \\
(0.3200)\end{array}$ & $\begin{array}{c}0.0900 \\
(0.5038)\end{array}$ & $\begin{array}{c}-0.8918^{* *} \\
(0.4044)\end{array}$ & $\begin{array}{c}0.4356 \\
(0.8787)\end{array}$ & $\begin{array}{c}0.1695 \\
(0.2155)\end{array}$ & $\begin{array}{l}-0.1875 \\
(0.7010)\end{array}$ & $\begin{array}{l}-0.1964 \\
(0.5646)\end{array}$ & $\begin{array}{c}0.0647 \\
(0.5323)\end{array}$ \\
\hline Household size & $\begin{array}{c}0.0074 \\
(0.0221)\end{array}$ & $\begin{array}{c}0.0093 \\
(0.0404)\end{array}$ & $\begin{array}{c}0.0200 \\
(0.0223)\end{array}$ & $\begin{array}{c}0.0207 \\
(0.0494)\end{array}$ & $\begin{array}{l}-0.0218 \\
(0.0229)\end{array}$ & $\begin{array}{c}0.0788 \\
(0.0627)\end{array}$ & $\begin{array}{c}0.0454 \\
(0.0378)\end{array}$ & $\begin{array}{c}0.0442 \\
(0.0379)\end{array}$ \\
\hline$<16$ dependency ratio & $\begin{array}{c}-0.4111^{*} \\
(0.2380)\end{array}$ & $\begin{array}{c}-0.6841^{* *} \\
(0.3373)\end{array}$ & $\begin{array}{c}0.0546 \\
(0.2765)\end{array}$ & $\begin{array}{l}-0.0615 \\
(0.4943)\end{array}$ & $\begin{array}{l}-0.0607 \\
(0.2633)\end{array}$ & $\begin{array}{l}-0.6775 \\
(0.6084)\end{array}$ & $\begin{array}{l}-0.2864 \\
(0.3756)\end{array}$ & $\begin{array}{l}-0.3528 \\
(0.3567)\end{array}$ \\
\hline Urban & $\begin{array}{c}-0.6899^{* * *} * \\
(0.1303)\end{array}$ & $\begin{array}{c}-2.1461^{* * *} \\
(0.7270)\end{array}$ & $\begin{array}{c}-0.5442^{* * * *} \\
(0.1444)\end{array}$ & $\begin{array}{c}-1.4259^{* *} \\
(0.6276)\end{array}$ & $\begin{array}{c}0.3679^{* * *} * \\
(0.1098)\end{array}$ & $\begin{array}{c}13.3892^{* * *} \\
(1.2764)\end{array}$ & $\begin{array}{c}-0.6429^{*} \\
(0.3820)\end{array}$ & $\begin{array}{l}-0.6449^{*} \\
(0.3757)\end{array}$ \\
\hline 2011 & $\begin{array}{c}-0.0558 \\
(0.0704)\end{array}$ & $\begin{array}{l}-0.0972 \\
(0.0789)\end{array}$ & $\begin{array}{c}-0.3530^{* * *} * \\
(0.1264)\end{array}$ & $\begin{array}{c}0.0797 \\
(0.2346)\end{array}$ & $\begin{array}{c}0.3782 \\
(0.2564)\end{array}$ & $\begin{array}{c}0.5599^{*} \\
(0.3203)\end{array}$ & $\begin{array}{c}0.0391 \\
(0.1515)\end{array}$ & $\begin{array}{c}0.0598 \\
(0.1493)\end{array}$ \\
\hline 2012 & $\begin{array}{l}-0.0367 \\
(0.0995)\end{array}$ & $\begin{array}{l}-0.0824 \\
(0.1258)\end{array}$ & $\begin{array}{l}-0.1599 \\
(0.1457)\end{array}$ & $\begin{array}{c}0.0616 \\
(0.1705)\end{array}$ & $\begin{array}{c}0.1171 \\
(0.2638)\end{array}$ & $\begin{array}{c}0.1995 \\
(0.2805)\end{array}$ & $\begin{array}{c}0.0016 \\
(0.1199)\end{array}$ & $\begin{array}{c}0.0358 \\
(0.1144)\end{array}$ \\
\hline 2013 & $\begin{array}{c}-0.2465^{* * *} \\
(0.0794)\end{array}$ & $\begin{array}{c}-0.3161^{* *} \\
(0.1359)\end{array}$ & & & & & & \\
\hline Group means & No & Yes & No & Yes & No & Yes & Yes & Yes \\
\hline $\ln \operatorname{sig} 2 \mathrm{u}$ & $\begin{array}{c}1.2246^{* * *} \\
(0.0718)\end{array}$ & $\begin{array}{c}1.2462^{* * *} \\
(0.0728)\end{array}$ & $\begin{array}{l}0.3376^{*} \\
(0.2036)\end{array}$ & $\begin{array}{l}0.3683^{*} \\
(0.2045)\end{array}$ & $\begin{array}{c}-0.8696^{*} \\
(0.4559)\end{array}$ & $\begin{array}{c}-0.7797^{*} \\
(0.4463)\end{array}$ & $\begin{array}{l}-0.2255 \\
(0.2137)\end{array}$ & $\begin{array}{c}-0.2156 \\
(0.2119)\end{array}$ \\
\hline $\begin{array}{l}\bar{X}_{k i t}=0 \\
\beta_{k}=\theta_{k}\end{array}$ & & $\begin{array}{c}54.99 \\
0.0000\end{array}$ & & $\begin{array}{l}21.96 \\
0.0560\end{array}$ & & $\begin{array}{l}144.91 \\
0.0000\end{array}$ & $\begin{array}{c}20.19 \\
0.0907 \\
46.92 \\
0.0000\end{array}$ & $\begin{array}{c}21.18 \\
0.0694 \\
34.47 \\
0.0003\end{array}$ \\
\hline Observations & 11,361 & 11,361 & 6,031 & 6,031 & 2,620 & 2,620 & 8,651 & 8,651 \\
\hline Number of groups & 3,849 & 3,849 & 3,044 & 3,044 & 1,371 & 1,371 & 3,736 & 3,736 \\
\hline
\end{tabular}

Notes: Please, refer to Table 3.5 . 
Coefficient estimates of benchmark specifications (continued)

\begin{tabular}{|c|c|c|c|c|c|c|c|c|}
\hline \multirow[b]{2}{*}{ Variables } & \multicolumn{2}{|c|}{ Baseline } & \multicolumn{2}{|c|}{ Entry } & \multicolumn{2}{|c|}{ 'Survival' } & \multirow{2}{*}{$\begin{array}{c}\text { Combined } \\
\text { model } \\
\text { CRE } \\
(7)\end{array}$} & \multirow{2}{*}{$\begin{array}{l}\text { Parsimonious } \\
\text { combined } \\
\text { model } \\
\text { CRE } \\
(8)\end{array}$} \\
\hline & $\begin{array}{l}\mathrm{RE} \\
(1)\end{array}$ & $\begin{array}{l}\text { CRE } \\
(2)\end{array}$ & $\begin{array}{l}\mathrm{RE} \\
(3)\end{array}$ & $\begin{array}{l}\mathrm{CRE} \\
(4)\end{array}$ & $\begin{array}{l}\mathrm{RE} \\
(5)\end{array}$ & $\begin{array}{l}\mathrm{CRE} \\
(6)\end{array}$ & & \\
\hline Self-employed $_{(\mathrm{t}=0)}$ & & & & & & & $\begin{array}{c}1.0602^{* * *} \\
(0.1246)\end{array}$ & $\begin{array}{c}1.0610^{* * *} \\
(0.1237)\end{array}$ \\
\hline Self-employed $_{(t-1)}$ & & & & & & & $\begin{array}{l}-0.4154 \\
(0.9229)\end{array}$ & $\begin{array}{c}1.0144^{* * * *} \\
(0.2378)\end{array}$ \\
\hline ... X Returnee & & & & & & & $\begin{array}{c}-0.2866^{*} \\
(0.1597)\end{array}$ & $\begin{array}{l}-0.2678^{*} \\
(0.1599)\end{array}$ \\
\hline ... X Male & & & & & & & $\begin{array}{l}-0.2242^{*} \\
(0.1340)\end{array}$ & $\begin{array}{c}-0.2843^{* *} \\
(0.1144)\end{array}$ \\
\hline ... X Age & & & & & & & $\begin{array}{c}0.0553 \\
(0.0423)\end{array}$ & \\
\hline ... X Age squared & & & & & & & $\begin{array}{l}-0.0006 \\
(0.0005)\end{array}$ & \\
\hline ... X Kyrgyz & & & & & & & $\begin{array}{c}-0.3271^{* *} \\
(0.1656)\end{array}$ & $\begin{array}{l}-0.2532 \\
(0.1590)\end{array}$ \\
\hline ... X Uzbek & & & & & & & $\begin{array}{c}-0.4441^{* *} \\
(0.2128)\end{array}$ & $\begin{array}{c}-0.4404^{* *} \\
(0.2131)\end{array}$ \\
\hline ... X Russian & & & & & & & $\begin{array}{l}-0.5558^{*} \\
(0.3352)\end{array}$ & $\begin{array}{l}-0.5037 \\
(0.3367)\end{array}$ \\
\hline ... X Head & & & & & & & $\begin{array}{c}0.0028 \\
(0.1350)\end{array}$ & \\
\hline ... X Secondary & & & & & & & $\begin{array}{c}0.3209 \\
(0.2144)\end{array}$ & \\
\hline ... X Vocational & & & & & & & $\begin{array}{c}0.8134^{* * *} \\
(0.2727)\end{array}$ & $\begin{array}{c}0.5215^{* * *} \\
(0.1556)\end{array}$ \\
\hline ... X University & & & & & & & $\begin{array}{c}0.8143^{* * *} \\
(0.3069)\end{array}$ & $\begin{array}{c}0.4896^{* * *} \\
(0.1877)\end{array}$ \\
\hline ... X Household size & & & & & & & $\begin{array}{l}-0.0430^{*} \\
(0.0248)\end{array}$ & $\begin{array}{c}-0.0475^{* *} \\
(0.0221)\end{array}$ \\
\hline$\ldots \mathrm{X}<16$ dependency ratio & & & & & & & $\begin{array}{l}-0.0293 \\
(0.2979)\end{array}$ & \\
\hline ... X Urban & & & & & & & $\begin{array}{c}0.7692^{* * *} \\
(0.1563)\end{array}$ & $\begin{array}{c}0.7812^{* * *} \\
(0.1551)\end{array}$ \\
\hline ... X 2011 & & & & & & & $\begin{array}{c}0.6980^{* * *} \\
(0.1847)\end{array}$ & $\begin{array}{c}0.7282^{* * *} \\
(0.1823)\end{array}$ \\
\hline ... X 2012 & & & & & & & $\begin{array}{c}0.3441^{* *} \\
(0.1402)\end{array}$ & $\begin{array}{c}0.3758^{* * * *} \\
(0.1364)\end{array}$ \\
\hline $\mathrm{IMR}_{\text {retention }}$ & $\begin{array}{c}-1.8509 * * * \\
(0.5365)\end{array}$ & $\begin{array}{c}-1.4439^{* *} \\
(0.6269)\end{array}$ & $\begin{array}{l}-0.6906 \\
(0.5263)\end{array}$ & $\begin{array}{l}-0.5274 \\
(0.6009)\end{array}$ & $\begin{array}{l}-1.0095^{*} \\
(0.5849)\end{array}$ & $\begin{array}{l}-0.7027 \\
(0.6672)\end{array}$ & $\begin{array}{l}-0.6307 \\
(0.4341)\end{array}$ & $\begin{array}{l}-0.5622 \\
(0.4296)\end{array}$ \\
\hline $\mathrm{IMR}_{\text {working }}$ & $\begin{array}{l}1.2281^{* *} \\
(0.5381)\end{array}$ & $\begin{array}{l}1.1892^{* *} \\
(0.5399)\end{array}$ & $\begin{array}{c}0.1753 \\
(0.6373)\end{array}$ & $\begin{array}{c}0.2269 \\
(0.6468)\end{array}$ & $\begin{array}{l}-0.2035 \\
(0.6356)\end{array}$ & $\begin{array}{l}-0.1905 \\
(0.6453)\end{array}$ & $\begin{array}{c}0.1710 \\
(0.4325)\end{array}$ & $\begin{array}{c}0.3467 \\
(0.3946)\end{array}$ \\
\hline Constant & $\begin{array}{c}-6.0365^{* * *} \\
(1.8174)\end{array}$ & $\begin{array}{c}-6.4416^{* * *} \\
(1.8742)\end{array}$ & $\begin{array}{l}-2.9000 \\
(2.2104)\end{array}$ & $\begin{array}{l}-3.6806 \\
(2.2738)\end{array}$ & $\begin{array}{c}-0.6423 \\
(1.5853)\end{array}$ & $\begin{array}{l}-1.1039 \\
(1.6569)\end{array}$ & $\begin{array}{c}-2.7632^{*} \\
(1.5408)\end{array}$ & $\begin{array}{c}-3.6925^{* * *} \\
(1.3214)\end{array}$ \\
\hline Group means & No & Yes & No & Yes & No & Yes & Yes & Yes \\
\hline $\operatorname{lnsig} 2 u$ & $\begin{array}{c}1.2246^{* * *} \\
(0.0718)\end{array}$ & $\begin{array}{c}1.2462^{* * *} \\
(0.0728)\end{array}$ & $\begin{array}{c}0.3376^{*} \\
(0.2036)\end{array}$ & $\begin{array}{l}0.3683^{*} \\
(0.2045)\end{array}$ & $\begin{array}{c}-0.8696^{*} \\
(0.4559)\end{array}$ & $\begin{array}{c}-0.7797^{*} \\
(0.4463)\end{array}$ & $\begin{array}{l}-0.2255 \\
(0.2137)\end{array}$ & $\begin{array}{l}-0.2156 \\
(0.2119)\end{array}$ \\
\hline $\begin{array}{l}\bar{X}_{k i t}=0 \\
\beta_{k}=\theta_{k}\end{array}$ & & $\begin{array}{c}54.99 \\
0.0000\end{array}$ & & $\begin{array}{c}21.96 \\
0.0560\end{array}$ & & $\begin{array}{l}144.91 \\
0.0000\end{array}$ & $\begin{array}{c}20.19 \\
0.0907 \\
46.92 \\
0.0000\end{array}$ & $\begin{array}{c}21.18 \\
0.0694 \\
34.47 \\
0.0003\end{array}$ \\
\hline Observations & 11,361 & 11,361 & 6,031 & 6,031 & 2,620 & 2,620 & 8,651 & 8,651 \\
\hline Number of groups & 3,849 & 3,849 & 3,044 & 3,044 & 1,371 & 1,371 & 3,736 & 3,736 \\
\hline
\end{tabular}

Notes: Please, refer to Table 3.5 . 
Table B8 - Marginal effects of benchmark coefficient estimates

\begin{tabular}{|c|c|c|c|c|c|c|c|c|c|c|c|c|}
\hline \multirow[b]{2}{*}{ Variables } & \multicolumn{2}{|c|}{ Baseline } & \multicolumn{2}{|c|}{ Entry } & \multicolumn{2}{|c|}{ 'Survival' } & \multicolumn{3}{|c|}{$\begin{array}{l}\text { Combined } \\
\text { model }\end{array}$} & \multicolumn{3}{|c|}{$\begin{array}{l}\text { Parsimonious } \\
\text { combined model }\end{array}$} \\
\hline & $\begin{array}{l}\mathrm{RE} \\
(1)\end{array}$ & $\begin{array}{l}\text { CRE } \\
(2)\end{array}$ & $\begin{array}{l}\mathrm{RE} \\
(3)\end{array}$ & $\begin{array}{l}\text { CRE } \\
(4)\end{array}$ & $\begin{array}{l}\mathrm{RE} \\
(5)\end{array}$ & $\begin{array}{l}\text { CRE } \\
(6)\end{array}$ & $\begin{array}{l}\text { Average } \\
\quad(7)\end{array}$ & $\begin{array}{c}\mathrm{SE}_{(\mathrm{t}-1)}=0 \\
(8)\end{array}$ & $\begin{array}{c}\mathrm{SE}_{(\mathrm{t}-1)}=1 \\
(9)\end{array}$ & $\begin{array}{c}\text { Average } \\
(10)\end{array}$ & $\begin{array}{c}\mathrm{SE}_{(\mathrm{t}-1)}=0 \\
(11)\end{array}$ & $\begin{array}{c}\mathrm{SE}_{(\mathrm{t}-1)}=1 \\
(12)\end{array}$ \\
\hline Returnee & $\begin{array}{c}0.132^{* * *} \\
(0.0346)\end{array}$ & $\begin{array}{l}0.142^{* *} \\
(0.0572)\end{array}$ & $\begin{array}{c}0.109 * * * \\
(0.0331)\end{array}$ & $\begin{array}{c}0.168 \\
(0.104)\end{array}$ & $\begin{array}{c}0.0273 \\
(0.0293)\end{array}$ & $\begin{array}{c}0.106^{*} \\
(0.0574)\end{array}$ & $\begin{array}{c}0.186^{* * *} \\
(0.0687)\end{array}$ & $\begin{array}{c}0.230^{* * *} \\
(0.0780)\end{array}$ & $\begin{array}{l}0.183^{* *} \\
(0.0790)\end{array}$ & $\begin{array}{c}0.182^{* * *} \\
(0.0678)\end{array}$ & $\begin{array}{c}0.224^{* * * *} \\
(0.0774)\end{array}$ & $\begin{array}{l}0.185^{* *} \\
(0.0785)\end{array}$ \\
\hline Male & $\begin{array}{c}0.409^{* * *} \\
(0.0450)\end{array}$ & $\begin{array}{c}0.134 \\
(0.106)\end{array}$ & $\begin{array}{c}0.140^{* * *} \\
(0.0416)\end{array}$ & $\begin{array}{l}-0.307 \\
(0.386)\end{array}$ & $\begin{array}{l}0.0962^{*} \\
(0.0561)\end{array}$ & $\begin{array}{c}0.585 \\
(0.598)\end{array}$ & $\begin{array}{r}-0.0968 \\
(0.384)\end{array}$ & $\begin{array}{l}-0.0971 \\
(0.455)\end{array}$ & $\begin{array}{l}-0.181 \\
(0.487)\end{array}$ & $\begin{array}{l}-0.121 \\
(0.372)\end{array}$ & $\begin{array}{l}-0.122 \\
(0.443)\end{array}$ & $\begin{array}{l}-0.223 \\
(0.428)\end{array}$ \\
\hline Age & $\begin{array}{l}-0.00165 \\
(0.00145)\end{array}$ & $\begin{array}{c}0.00613 \\
(0.00790)\end{array}$ & $\begin{array}{l}0.000848 \\
(0.00106)\end{array}$ & $\begin{array}{c}0.0334^{* *} \\
(0.0152)\end{array}$ & $\begin{array}{l}0.000964 \\
(0.00189)\end{array}$ & $\begin{array}{c}0.0152 \\
(0.0191)\end{array}$ & $\begin{array}{c}0.0217^{* *} \\
(0.0110)\end{array}$ & $\begin{array}{l}0.0242^{*} \\
(0.0125)\end{array}$ & $\begin{array}{c}0.0356^{* *} \\
(0.0173)\end{array}$ & $\begin{array}{l}0.0215^{*} \\
(0.0110)\end{array}$ & $\begin{array}{l}0.0240^{*} \\
(0.0124)\end{array}$ & $\begin{array}{l}0.0352^{* *} \\
(0.0177)\end{array}$ \\
\hline Kyrgyz & $\begin{array}{l}-0.0608^{*} \\
(0.0336)\end{array}$ & $\begin{array}{l}0.0273 \\
(0.162)\end{array}$ & $\begin{array}{c}-0.00888 \\
(0.0219)\end{array}$ & $\begin{array}{c}0.136 \\
(0.164)\end{array}$ & $\begin{array}{c}-0.0694^{* *} \\
(0.0274)\end{array}$ & $\begin{array}{c}-0.354^{* * *} \\
(0.0101)\end{array}$ & $\begin{array}{c}0.113 \\
(0.169)\end{array}$ & $\begin{array}{c}0.150 \\
(0.174)\end{array}$ & $\begin{array}{c}0.129 \\
(0.293)\end{array}$ & $\begin{array}{l}0.114 \\
(0.174)\end{array}$ & $\begin{array}{c}0.144 \\
(0.178)\end{array}$ & $\begin{array}{c}0.145 \\
(0.301)\end{array}$ \\
\hline Uzbek & $\begin{array}{l}-0.0467 \\
(0.0393)\end{array}$ & $\begin{array}{c}-0.260^{* * *} \\
(0.0589)\end{array}$ & $\begin{array}{c}0.0148 \\
(0.0292)\end{array}$ & $\begin{array}{c}-0.169^{* * *} \\
(0.0472)\end{array}$ & $\begin{array}{c}-0.0926^{*} \\
(0.0497)\end{array}$ & $\begin{array}{c}-0.734^{* * *} \\
(0.0116)\end{array}$ & $\begin{array}{l}-0.237 \\
(0.144)\end{array}$ & $\begin{array}{l}-0.201 \\
(0.128)\end{array}$ & $\begin{array}{c}-0.406^{* *} \\
(0.175)\end{array}$ & $\begin{array}{l}-0.237 \\
(0.146)\end{array}$ & $\begin{array}{l}-0.199 \\
(0.128)\end{array}$ & $\begin{array}{c}-0.416^{* *} \\
(0.180)\end{array}$ \\
\hline Russian & $\begin{array}{c}-0.176^{* * *} \\
(0.0407)\end{array}$ & $\begin{array}{c}-0.0884 \\
(0.135)\end{array}$ & $\begin{array}{c}-0.0620^{* *} \\
(0.0243)\end{array}$ & $\begin{array}{c}0.215 \\
(0.263)\end{array}$ & $\begin{array}{l}-0.194^{* *} \\
(0.0883)\end{array}$ & $\begin{array}{c}-0.811^{* * *} \\
(0.0118)\end{array}$ & $\begin{array}{c}-0.0228 \\
(0.192)\end{array}$ & $\begin{array}{l}0.0227 \\
(0.197)\end{array}$ & $\begin{array}{l}-0.139 \\
(0.278)\end{array}$ & $\begin{array}{l}-0.0103 \\
(0.197)\end{array}$ & $\begin{array}{l}0.0313 \\
(0.202)\end{array}$ & $\begin{array}{l}-0.114 \\
(0.294)\end{array}$ \\
\hline Head & $\begin{array}{l}0.180^{* * *} \\
(0.0291)\end{array}$ & $\begin{array}{l}0.174^{* *} \\
(0.0696)\end{array}$ & $\begin{array}{c}0.0514^{* * *} \\
(0.0195)\end{array}$ & $\begin{array}{c}0.121 \\
(0.0742)\end{array}$ & $\begin{array}{l}0.0495^{* *} \\
(0.0252)\end{array}$ & $\begin{array}{c}0.163 \\
(0.109)\end{array}$ & $\begin{array}{c}0.122^{*} \\
(0.0653)\end{array}$ & $\begin{array}{c}0.136^{*} \\
(0.0717)\end{array}$ & $\begin{array}{c}0.188^{*} \\
(0.0979)\end{array}$ & $\begin{array}{c}0.127^{*} \\
(0.0656)\end{array}$ & $\begin{array}{l}0.140^{* *} \\
(0.0706)\end{array}$ & $\begin{array}{l}0.196^{* *} \\
(0.0941)\end{array}$ \\
\hline Secondary & $\begin{array}{c}0.0811^{* *} \\
(0.0403)\end{array}$ & $\begin{array}{r}-0.00533 \\
(0.0771)\end{array}$ & $\begin{array}{l}0.00866 \\
(0.0323)\end{array}$ & $\begin{array}{l}0.0927 \\
(0.109)\end{array}$ & $\begin{array}{c}0.0862^{* *} \\
(0.0419)\end{array}$ & $\begin{array}{l}-0.0424 \\
(0.122)\end{array}$ & $\begin{array}{c}0.0245 \\
(0.0837)\end{array}$ & $\begin{array}{l}0.00156 \\
(0.0982)\end{array}$ & $\begin{array}{l}0.100 \\
(0.127)\end{array}$ & $\begin{array}{c}0.0411 \\
(0.0824)\end{array}$ & $\begin{array}{c}0.0463 \\
(0.0926)\end{array}$ & $\begin{array}{l}0.0663 \\
(0.133)\end{array}$ \\
\hline Vocational & $\begin{array}{c}0.0304 \\
(0.0561)\end{array}$ & $\begin{array}{c}0.0629 \\
(0.0847)\end{array}$ & $\begin{array}{c}-0.0778^{* *} \\
(0.0359)\end{array}$ & $\begin{array}{l}0.0490 \\
(0.138)\end{array}$ & $\begin{array}{l}0.0715^{*} \\
(0.0368)\end{array}$ & $\begin{array}{l}0.0212 \\
(0.119)\end{array}$ & $\begin{array}{c}0.0174 \\
(0.0693)\end{array}$ & $\begin{array}{l}-0.0379 \\
(0.0962)\end{array}$ & $\begin{array}{l}0.185^{*} \\
(0.109)\end{array}$ & $\begin{array}{c}0.0414 \\
(0.0750)\end{array}$ & $\begin{array}{c}0.0109 \\
(0.0946)\end{array}$ & $\begin{array}{c}0.170 \\
(0.115)\end{array}$ \\
\hline University & $\begin{array}{l}-0.0935 \\
(0.0664)\end{array}$ & $\begin{array}{l}0.0193 \\
(0.108)\end{array}$ & $\begin{array}{c}-0.111^{* * *} \\
(0.0396)\end{array}$ & $\begin{array}{l}0.0779 \\
(0.175)\end{array}$ & $\begin{array}{c}0.0379 \\
(0.0451)\end{array}$ & $\begin{array}{r}-0.0466 \\
(0.184)\end{array}$ & $\begin{array}{c}0.0135 \\
(0.0844)\end{array}$ & $\begin{array}{r}-0.0419 \\
(0.117)\end{array}$ & $\begin{array}{c}0.174 \\
(0.128)\end{array}$ & $\begin{array}{c}0.0416 \\
(0.0922)\end{array}$ & $\begin{array}{l}0.0141 \\
(0.117)\end{array}$ & $\begin{array}{c}0.160 \\
(0.133)\end{array}$ \\
\hline Household size & $\begin{array}{c}0.00163 \\
(0.00485)\end{array}$ & $\begin{array}{c}0.00200 \\
(0.00863)\end{array}$ & $\begin{array}{c}0.00320 \\
(0.00356)\end{array}$ & $\begin{array}{c}0.00328 \\
(0.00781)\end{array}$ & $\begin{array}{l}-0.00517 \\
(0.00540)\end{array}$ & $\begin{array}{c}0.0184 \\
(0.0147)\end{array}$ & $\begin{array}{c}0.00574 \\
(0.00720)\end{array}$ & $\begin{array}{c}0.00990 \\
(0.00825)\end{array}$ & $\begin{array}{c}0.000730 \\
(0.0127)\end{array}$ & $\begin{array}{c}0.00518 \\
(0.00720)\end{array}$ & $\begin{array}{c}0.00960 \\
(0.00824)\end{array}$ & $\begin{array}{r}-0.00101 \\
(0.0125)\end{array}$ \\
\hline$<16$ dependency ratio & $\begin{array}{l}-0.0903^{*} \\
(0.0523)\end{array}$ & $\begin{array}{l}-0.146^{* *} \\
(0.0722)\end{array}$ & $\begin{array}{l}0.00874 \\
(0.0442)\end{array}$ & $\begin{array}{l}-0.00975 \\
(0.0783)\end{array}$ & $\begin{array}{l}-0.0144 \\
(0.0624)\end{array}$ & $\begin{array}{l}-0.159 \\
(0.142)\end{array}$ & $\begin{array}{l}-0.0572 \\
(0.0695)\end{array}$ & $\begin{array}{l}-0.0625 \\
(0.0821)\end{array}$ & $\begin{array}{r}-0.0960 \\
(0.125)\end{array}$ & $\begin{array}{l}-0.0681 \\
(0.0689)\end{array}$ & $\begin{array}{l}-0.0766 \\
(0.0776)\end{array}$ & $\begin{array}{l}-0.109 \\
(0.111)\end{array}$ \\
\hline Urban & $\begin{array}{c}-0.150^{* * *} \\
(0.0271)\end{array}$ & $\begin{array}{c}-0.388^{* * *} \\
(0.0868)\end{array}$ & $\begin{array}{c}-0.0801 * * * \\
(0.0195)\end{array}$ & $\begin{array}{c}-0.192^{* *} \\
(0.0786)\end{array}$ & $\begin{array}{c}0.0804^{* * *} \\
(0.0215)\end{array}$ & $\begin{array}{l}0.358^{* * * *} \\
(0.00994)\end{array}$ & $\begin{array}{l}-0.0645 \\
(0.0658)\end{array}$ & $\begin{array}{l}-0.136^{*} \\
(0.0767)\end{array}$ & $\begin{array}{l}0.0383 \\
(0.120)\end{array}$ & $\begin{array}{l}-0.0638 \\
(0.0647)\end{array}$ & $\begin{array}{l}-0.136^{*} \\
(0.0750)\end{array}$ & $\begin{array}{l}0.0422 \\
(0.120)\end{array}$ \\
\hline 2011 & $\begin{array}{l}-0.0122 \\
(0.0154)\end{array}$ & $\begin{array}{l}-0.0206 \\
(0.0166)\end{array}$ & & & & & & & & & & \\
\hline 2012 & $\begin{array}{c}-0.00804 \\
(0.0217)\end{array}$ & $\begin{array}{l}-0.0175 \\
(0.0266)\end{array}$ & & & & & & & & & & \\
\hline 2013 & $\begin{array}{c}-0.0530 * * * \\
(0.0168)\end{array}$ & $\begin{array}{c}-0.0657^{* *} \\
(0.0275)\end{array}$ & & & & & & & & & & \\
\hline Self-employed $_{(t-1)}$ & & & & & & & $\begin{array}{c}0.3061^{* * *} \\
(0.0448)\end{array}$ & $\begin{array}{c}0.290^{* * *} \\
(0.0472)\end{array}$ & $\begin{array}{c}0.290^{* * *} \\
(0.0472)\end{array}$ & $\begin{array}{c}0.2897^{* * *} \\
(0.0472)\end{array}$ & $\begin{array}{c}0.306^{* * *} \\
(0.0448)\end{array}$ & $\begin{array}{c}0.306^{* * *} \\
(0.0448)\end{array}$ \\
\hline Self-employed $_{(\mathrm{t}=0)}$ & & & & & & & $\begin{array}{c}0.2047^{* * *} \\
(0.0177)\end{array}$ & $\begin{array}{c}0.231^{* * *} \\
(0.0207)\end{array}$ & $\begin{array}{c}0.322^{* * *} \\
(0.0296)\end{array}$ & $\begin{array}{c}0.2042^{* * *} \\
(0.0178)\end{array}$ & $\begin{array}{c}0.230^{* * *} \\
(0.0206)\end{array}$ & $\begin{array}{c}0.329^{* * * *} \\
(0.0305)\end{array}$ \\
\hline Observations & 11,361 & 11,361 & 6,031 & 6,031 & 2,620 & 2,620 & 8,651 & 8,651 & 8,651 & 8,651 & 8,651 & 8,651 \\
\hline
\end{tabular}

Notes: Columns (1)-(7) and (10) present average marginal effects corresponding of coefficient estimates presented in Table 10. Columns (8) and (11) present corresponding marginal effects when lagged self-employment is equal to 0 ; Columns $(9)$ and $(12)$, when lagged self-employment is equal to 1 . Standard errors are in parentheses. ${ }^{* * *} \mathrm{p}<0.01,{ }^{* *} \mathrm{p}<0.05,{ }^{*}$ $\mathrm{p}<0.1$. 
Figure B1 - Average marginal effects of return migration on self-employment with $95 \%$ confidence intervals, parsimonious combined model

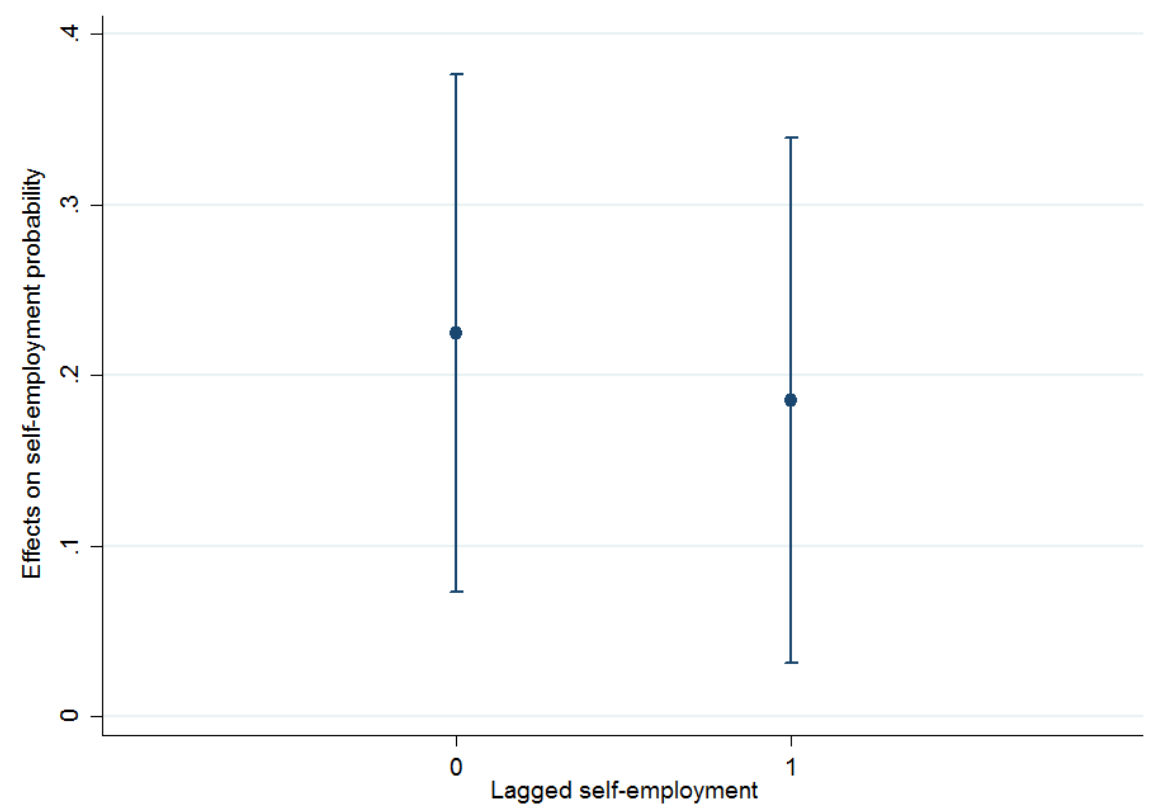


Figure B2 - Matching quality of 2011 (l) and 2012 (r) propensity score matching with 5 nearest neighbours
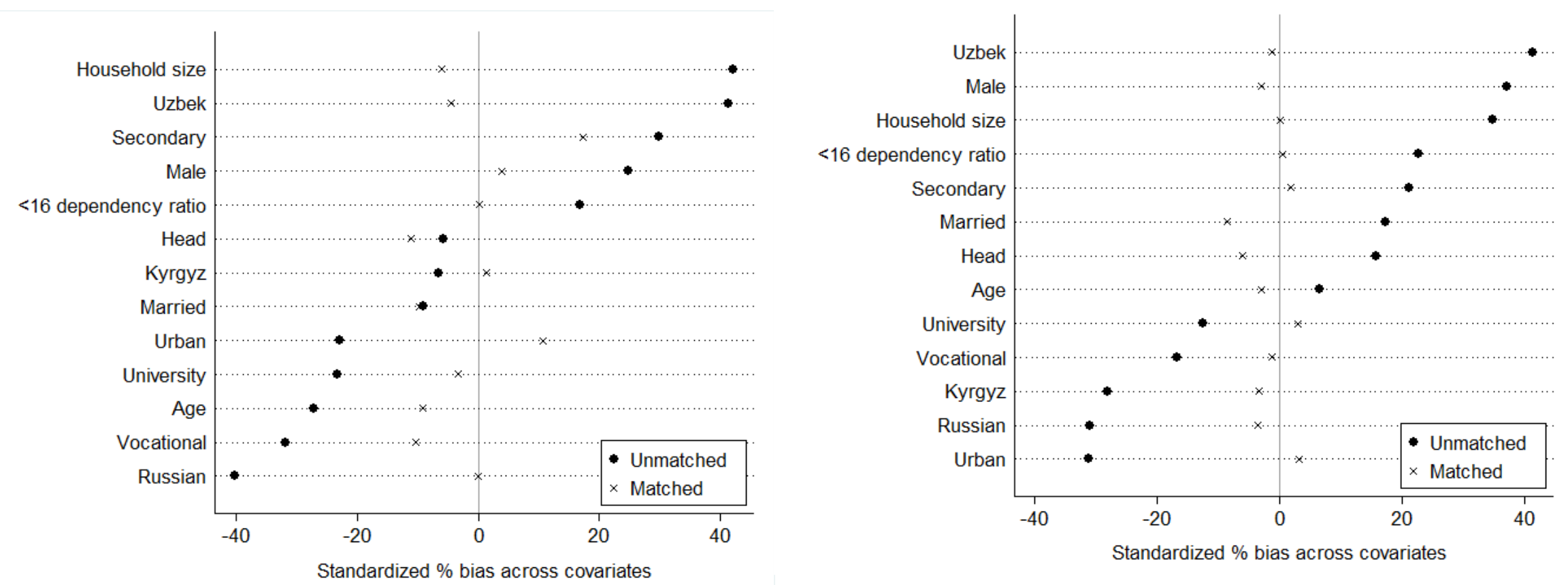
Figure B3 - Matching quality of 2011 (l) and 2012 (r) covariate matching with 5 nearest neighbours
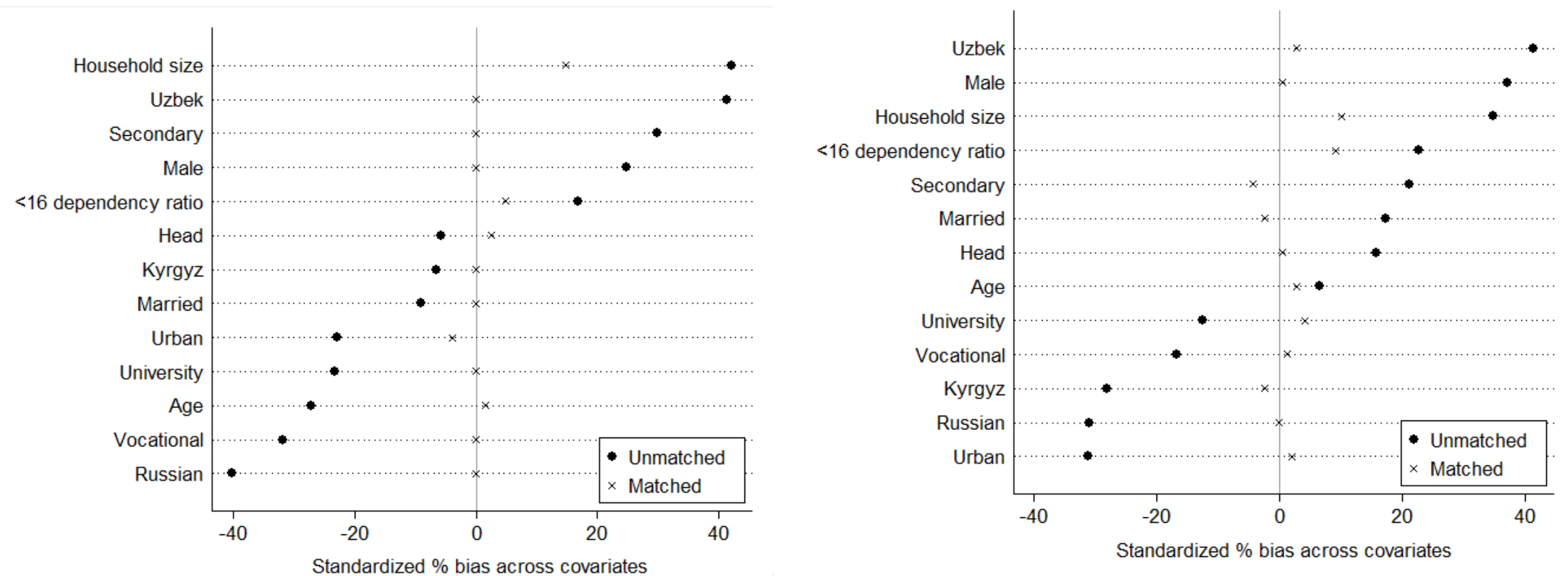
Table B9 - Coefficient estimates of benchmark specifications on matched sample

\begin{tabular}{|c|c|c|c|c|c|}
\hline Variables & $\begin{array}{c}\text { Baseline } \\
\text { (1) }\end{array}$ & $\begin{array}{l}\text { Entry } \\
(2)\end{array}$ & $\begin{array}{c}\text { 'Survival' } \\
(3)\end{array}$ & $\begin{array}{c}\text { Combined } \\
\text { model } \\
(4)\end{array}$ & $\begin{array}{c}\text { Parsimonious } \\
\text { combined } \\
\text { model } \\
(5)\end{array}$ \\
\hline & \multicolumn{5}{|c|}{ Propensity score matching, $5 \mathrm{NN}$} \\
\hline Returnee & $\begin{array}{c}0.2343 \\
(0.1456)\end{array}$ & $\begin{array}{c}0.6435^{* * *} \\
(0.1888)\end{array}$ & $\begin{array}{l}-0.0302 \\
(0.2737)\end{array}$ & $\begin{array}{c}0.6462^{* * *} \\
(0.1882)\end{array}$ & $\begin{array}{c}0.6325^{* * *} \\
(0.1841)\end{array}$ \\
\hline Self-employed $_{(\mathrm{t}=0)}$ & & & & $\begin{array}{c}0.7408^{* * *} \\
(0.2135)\end{array}$ & $\begin{array}{c}0.7357^{* * *} \\
(0.2103)\end{array}$ \\
\hline Self-employed $(\mathrm{t}-1)$ & & & & $\begin{array}{l}-3.9184 \\
(2.4404)\end{array}$ & $\begin{array}{c}1.2250^{* * *} \\
(0.2094)\end{array}$ \\
\hline ... X Returnee & & & & $\begin{array}{c}-0.6415^{*} \\
(0.3366)\end{array}$ & $\begin{array}{c}-0.5931^{*} \\
(0.3344)\end{array}$ \\
\hline Control variables & Yes & Yes & Yes & Yes & Yes \\
\hline Time fixed effects & Yes & Yes & Yes & Yes & Yes \\
\hline Interaction terms & No & No & No & All & $\begin{array}{c}\text { Returnee } \\
\text { Vocational } \\
\text { Year }\end{array}$ \\
\hline$\beta_{k}=\theta_{k}$ & & & & $\begin{array}{c}23.65 \\
0.0345\end{array}$ & $\begin{array}{l}16.55 \\
0.0009\end{array}$ \\
\hline \multirow[t]{2}{*}{ Observations } & 1,190 & 743 & 434 & 1,177 & 1,190 \\
\hline & \multicolumn{5}{|c|}{ Covariate matching, $5 \mathrm{NN}$} \\
\hline Returnee & $\begin{array}{c}0.1601 \\
(0.1414)\end{array}$ & $\begin{array}{c}0.6274^{* * *} \\
(0.1785)\end{array}$ & $\begin{array}{l}-0.3648 \\
(0.2905)\end{array}$ & $\begin{array}{c}0.6195^{* * *} \\
(0.1772)\end{array}$ & $\begin{array}{c}0.5895^{* * *} \\
(0.1792)\end{array}$ \\
\hline Self-employed $_{(\mathrm{t}=0)}$ & & & & $\begin{array}{c}0.5734^{* * *} \\
(0.2220)\end{array}$ & $\begin{array}{c}0.5927^{* * *} \\
(0.2259)\end{array}$ \\
\hline Self-employed $_{(\mathrm{t}-1)}$ & & & & $\begin{array}{l}-3.6235 \\
(2.3462)\end{array}$ & $\begin{array}{c}1.4785^{* * *} \\
(0.2361)\end{array}$ \\
\hline ... X Returnee & & & & $\begin{array}{c}-0.8953^{* *} \\
(0.3498)\end{array}$ & $\begin{array}{c}-0.7480 * * \\
(0.3316)\end{array}$ \\
\hline Control variables & Yes & Yes & Yes & Yes & Yes \\
\hline Time fixed effects & Yes & Yes & Yes & Yes & Yes \\
\hline Interaction terms & No & No & No & All & $\begin{array}{c}\text { Returnee } \\
\text { Vocational } \\
\text { Urban } \\
\text { Year }\end{array}$ \\
\hline$\beta_{k}=\theta_{k}$ & & & & $\begin{array}{c}30.10 \\
0.0074\end{array}$ & $\begin{array}{c}20.88 \\
0.0003\end{array}$ \\
\hline Observations & 1,190 & 762 & 428 & 1,190 & 1,190 \\
\hline
\end{tabular}

Notes: The dependent variable is a binary variable taking unity if a working-age individual is self-employed; 0 , if employed, wage-employed or unpaid, or member of a cooperative. Observations are working-age individuals, members of non-splitting households, who were born in Kyrgyzstan. In the upper panel of the Table, observations form a matched sample of control (non-returnees) and treated (returnees) applying propensity score matching techniques (5 nearest neighbours). In the lower panel, observations form a matched sample of control (non-returnees) and treated (returnees) applying covariate matching techniques (Mahalanobis metric, 5 nearest neighbours). Columns (1) presents coefficient estimates of probit model of the baseline specification; Columns (2), of entry in self-employment; Columns (3), of persistence in self-employment; and Columns (4)-(5), coefficient estimates of a dynamic, non-linear probability model. Tests of joint significance of interaction terms when applicable report $\chi^{2}$ with associated statistical significance. Standard errors clustered at the household level are in parentheses. *** $\mathrm{p}<0.01,{ }^{* *} \mathrm{p}<0.05,{ }^{*} \mathrm{p}<0.1$. 
Table B10 - Marginal effects of parsimonious combined model coefficient estimates on matched sample

\begin{tabular}{|c|c|c|c|}
\hline Variables & $\begin{array}{c}\text { Average } \\
\text { (1) }\end{array}$ & $\begin{array}{c}\mathrm{SE}_{(\mathrm{t}-1)}=0 \\
(2)\end{array}$ & $\begin{array}{c}\mathrm{SE}_{(\mathrm{t}-1)}=1 \\
(3)\end{array}$ \\
\hline & \multicolumn{3}{|c|}{ Propensity score matching, $5 \mathrm{NN}$} \\
\hline Returnee & $\begin{array}{c}0.1240^{* * *} \\
(0.0443)\end{array}$ & $\begin{array}{c}0.1998^{* * *} * \\
(0.0593)\end{array}$ & $\begin{array}{c}0.0119 \\
(0.0832)\end{array}$ \\
\hline Self-employed $_{(\mathrm{t}=0)}$ & $\begin{array}{c}0.2048^{* * *} * \\
(0.0550)\end{array}$ & $\begin{array}{c}0.2304^{* * *} \\
(0.0598)\end{array}$ & $\begin{array}{c}0.2219^{* * *} \\
(0.0611)\end{array}$ \\
\hline Self-employed $_{(t-1)}$ & $\begin{array}{c}0.2509^{* * *} \\
(0.0677)\end{array}$ & $\begin{array}{c}0.2509^{* * *} \\
(0.0677)\end{array}$ & $\begin{array}{c}0.2509^{* * *} \\
(0.0677)\end{array}$ \\
\hline \multirow[t]{2}{*}{ Observations } & 1,190 & 1,190 & 1,190 \\
\hline & \multicolumn{3}{|c|}{ Covariate matching, $5 \mathrm{NN}$} \\
\hline Returnee & $\begin{array}{c}0.1094^{* *} \\
(0.0436)\end{array}$ & $\begin{array}{c}0.2009^{* * *} \\
(0.0587)\end{array}$ & $\begin{array}{l}-0.0432 \\
(0.0766)\end{array}$ \\
\hline Self-employed $_{(\mathrm{t}=0)}$ & $\begin{array}{c}0.1588^{* * *} \\
(0.0597)\end{array}$ & $\begin{array}{c}0.1864^{* * *} \\
(0.0699)\end{array}$ & $\begin{array}{c}0.1554^{* *} \\
(0.0633)\end{array}$ \\
\hline Self-employed $_{(\mathrm{t}-1)}$ & $\begin{array}{c}0.3613^{* * *} \\
(0.0677)\end{array}$ & $\begin{array}{c}0.3613^{* * *} \\
(0.0677)\end{array}$ & $\begin{array}{c}0.3613^{* * *} \\
(0.0677)\end{array}$ \\
\hline Observations & 1,190 & 1,190 & 1,190 \\
\hline
\end{tabular}

Notes: Columns (1) presents average marginal effects corresponding of coefficient estimates presented in Table 10, Column (5). Columns (2) presents corresponding marginal effects when lagged self-employment is equal to 0; Columns (3), when lagged self-employment is equal to 1 . Standard errors are in parentheses. ${ }^{* * *} \mathrm{p}<0.01,{ }^{* *} \mathrm{p}<0.05,{ }^{*} \mathrm{p}<0.1$. 
Figure B4 - Average marginal effects of return migration with 95\% confidence intervals of parsimonious combined model, PSM (l) and CVM (r) matched sample
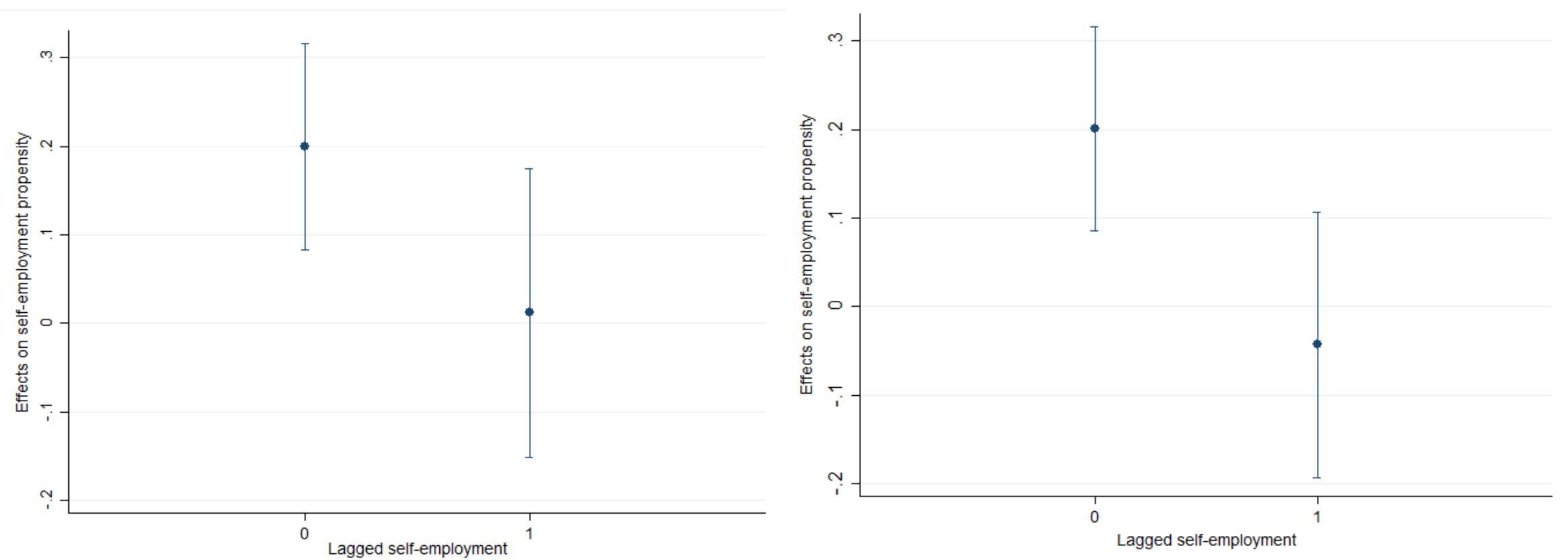
Table B11 - Coefficient estimates of household benchmark specifications

\begin{tabular}{|c|c|c|c|c|c|c|c|c|}
\hline \multirow[b]{2}{*}{ Variables } & \multicolumn{2}{|c|}{ Baseline } & \multicolumn{2}{|c|}{ Entry } & \multicolumn{2}{|c|}{ 'Survival' } & \multirow{2}{*}{$\begin{array}{c}\text { Combined } \\
\text { model } \\
\text { CRE } \\
(7)\end{array}$} & \multirow{2}{*}{$\begin{array}{c}\text { Parsimonious } \\
\text { combined } \\
\text { model } \\
\text { CRE } \\
(8)\end{array}$} \\
\hline & $\begin{array}{l}\mathrm{RE} \\
(1)\end{array}$ & $\begin{array}{l}\mathrm{CRE} \\
(2)\end{array}$ & $\begin{array}{l}\mathrm{RE} \\
(3)\end{array}$ & $\begin{array}{l}\text { CRE } \\
(4)\end{array}$ & $\begin{array}{l}\mathrm{RE} \\
(5)\end{array}$ & $\begin{array}{l}\mathrm{CRE} \\
(6)\end{array}$ & & \\
\hline Returnee & $\begin{array}{c}0.2666^{* * *} \\
(0.0688)\end{array}$ & $\begin{array}{c}0.2598^{* * *} \\
(0.0700)\end{array}$ & $\begin{array}{c}0.2447 * * * \\
(0.0846)\end{array}$ & $\begin{array}{c}0.2361^{* * *} \\
(0.0860)\end{array}$ & $\begin{array}{c}0.1155 \\
(0.0829)\end{array}$ & $\begin{array}{c}0.1148 \\
(0.0851)\end{array}$ & $\begin{array}{c}0.2347^{* * * *} \\
(0.0836)\end{array}$ & $\begin{array}{c}0.2379^{* * * *} \\
(0.0833)\end{array}$ \\
\hline Family enterprise $_{(t=0)}$ & & & & & & & $\begin{array}{c}0.5367 * * * \\
(0.0897)\end{array}$ & $\begin{array}{c}0.5408^{* * *} \\
(0.0888)\end{array}$ \\
\hline Family enterprise $_{(\mathrm{t}-1)}$ & & & & & & & $\begin{array}{c}0.7622^{* * *} \\
(0.2837)\end{array}$ & $\begin{array}{c}0.7496 * * * \\
(0.1763)\end{array}$ \\
\hline ... X Returnee & & & & & & & $\begin{array}{l}-0.0728 \\
(0.1074)\end{array}$ & $\begin{array}{l}-0.0781 \\
(0.1070)\end{array}$ \\
\hline Control variables & Yes & Yes & Yes & Yes & Yes & Yes & Yes & Yes \\
\hline Time fixed effects & Yes & Yes & Yes & Yes & Yes & Yes & Yes & Yes \\
\hline Interaction terms & No & No & No & No & No & No & All & $\begin{array}{c}\text { Returnee } \\
\text { Household size } \\
\text { Urban } \\
\text { Years }\end{array}$ \\
\hline $\operatorname{lnsig} 2 u$ & $\begin{array}{c}0.1909^{* * *} \\
(0.0673)\end{array}$ & $\begin{array}{c}0.2022^{* * *} \\
(0.0672)\end{array}$ & $\begin{array}{c}-1.2086^{* * *} \\
(0.3582)\end{array}$ & $\begin{array}{c}-1.1838^{* * *} \\
(0.3548)\end{array}$ & $\begin{array}{c}-0.7704^{* *} \\
(0.3019)\end{array}$ & $\begin{array}{c}-0.7684^{* *} \\
(0.3039)\end{array}$ & $\begin{array}{c}-1.1958^{* * *} \\
(0.3269)\end{array}$ & $\begin{array}{c}-1.2016^{* * *} \\
(0.3226)\end{array}$ \\
\hline $\bar{X}_{k i t}=0$ & & 26.13 & & 10.70 & & 5.93 & 6.11 & $\begin{array}{c}6.48 \\
08392\end{array}$ \\
\hline$\beta_{k}=\theta_{k}$ & & 0.0062 & & & & & $\begin{array}{l}0.8658 \\
105.64 \\
0.0000\end{array}$ & $\begin{array}{l}0.8392 \\
113.59 \\
0.0000\end{array}$ \\
\hline Observations & 9,112 & 9,112 & 3,587 & 3,587 & 3,244 & 3,244 & 6,831 & 6,831 \\
\hline Number of households & 2,282 & 2,282 & 1,613 & 1,613 & 1,489 & 1,489 & 2,280 & 2,280 \\
\hline
\end{tabular}

Notes: The dependent variable is a binary variable taking unity if at least one working-age individual is self-employed in a household; 0 , if not. Observations are non-splitting households, whose heads were born in Kyrgyzstan. Columns (1)-(2) present coefficient estimates of probit model of equation (1); Columns (3)-(4), of equation (2); Columns (5)-(6), of equation (3); and Columns (7)-(8), coefficient estimates of a dynamic, non-linear probability model with unobserved heterogeneity, as in equation (5). Tests of joint significance of group means and interaction terms when applicable report $\chi^{2}$ with associated statistical significance. Robust standard errors are in parentheses. $* * *$ $\mathrm{p}<0.01,{ }^{* *} \mathrm{p}<0.05,{ }^{*} \mathrm{p}<0.1$. 
Figure B5 - Matching quality of 2011 (l) and 2012 (r) propensity score matching with 5 nearest neighbours, household sample
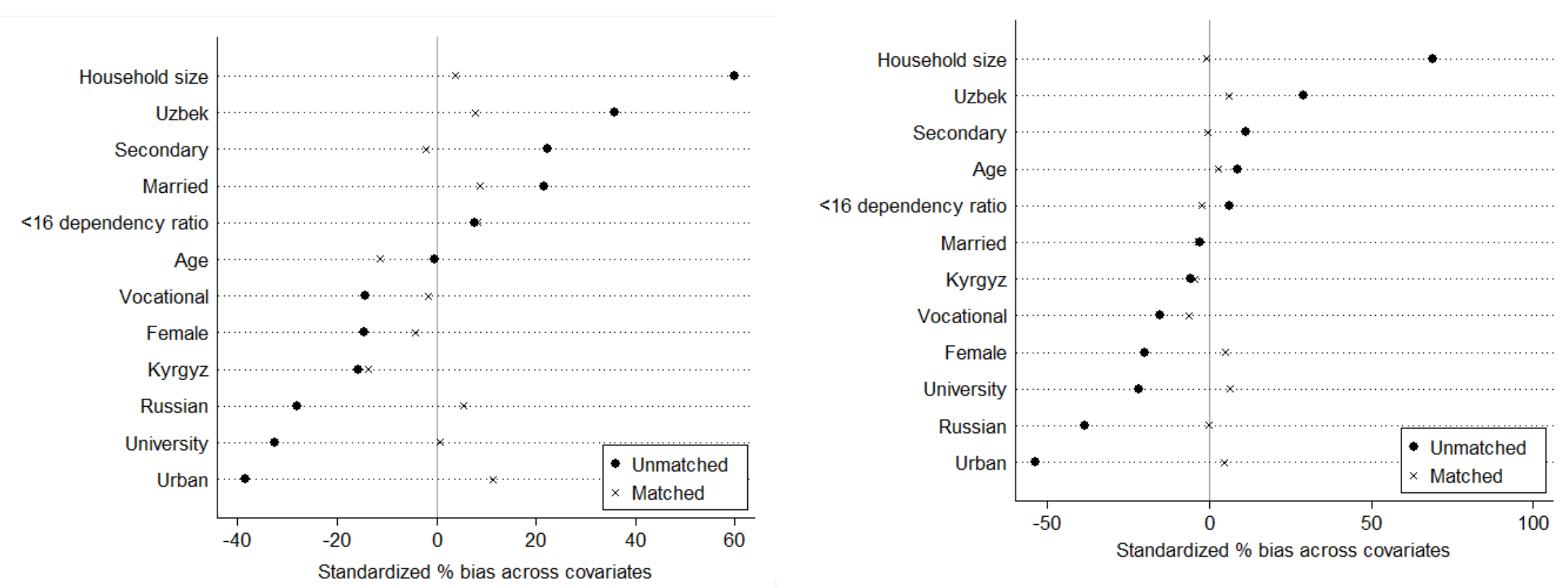
Figure B6 - Matching quality of 2011 (l) and 2012 (r) covariate matching with 5 nearest neighbours, household sample
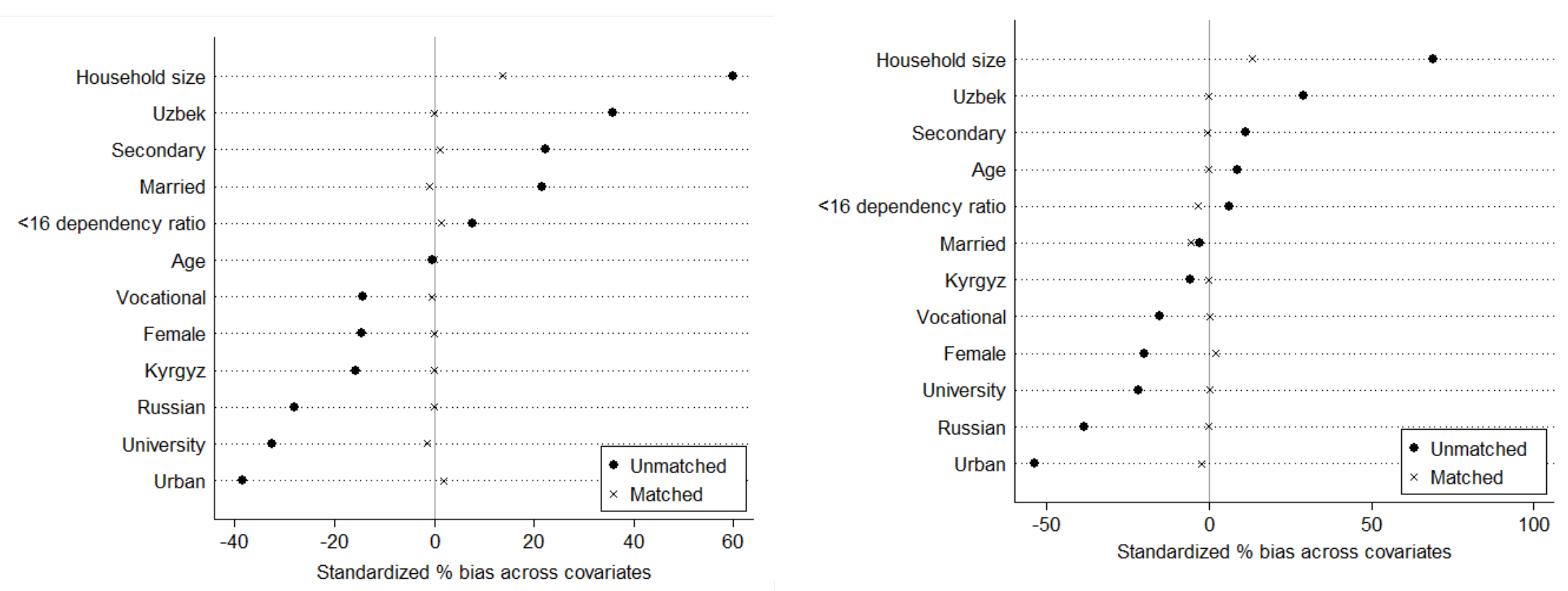
Table B12 - Coefficient estimates of household specifications on matched sample

\begin{tabular}{|c|c|c|c|c|c|}
\hline Variables & $\begin{array}{c}\text { Baseline } \\
\text { (1) }\end{array}$ & $\begin{array}{c}\text { Entry } \\
(2)\end{array}$ & $\begin{array}{c}\text { 'Survival' } \\
(3)\end{array}$ & $\begin{array}{c}\text { Combined } \\
\text { model } \\
(4)\end{array}$ & $\begin{array}{l}\text { Parsimonious } \\
\text { combined } \\
\text { model } \\
(5)\end{array}$ \\
\hline & \multicolumn{5}{|c|}{ Propensity score matching, $5 \mathrm{NN}$} \\
\hline Returnee & $\begin{array}{l}0.1042^{*} \\
(0.0546)\end{array}$ & $\begin{array}{c}0.4431^{* * * *} \\
(0.0823)\end{array}$ & $\begin{array}{c}0.1289 \\
(0.0865)\end{array}$ & $\begin{array}{c}0.4362^{* * *} \\
(0.0823)\end{array}$ & $\begin{array}{c}0.4390^{* * *} \\
(0.0821)\end{array}$ \\
\hline Self-employed $_{(\mathrm{t}=0)}$ & & & & $\begin{array}{c}0.4008^{* * *} \\
(0.0845)\end{array}$ & $\begin{array}{c}0.3994^{* * *} \\
(0.0831)\end{array}$ \\
\hline Self-employed $_{(t-1)}$ & & & & $\begin{array}{c}2.5299^{* * *} \\
(0.3407)\end{array}$ & $\begin{array}{c}2.2685^{* * *} \\
(0.2650)\end{array}$ \\
\hline ... X Returnee & & & & $\begin{array}{c}-0.3002^{* *} \\
(0.1201)\end{array}$ & $\begin{array}{c}-0.2904^{* *} \\
(0.1198)\end{array}$ \\
\hline Control variables & Yes & Yes & Yes & Yes & Yes \\
\hline Time fixed effects & Yes & Yes & Yes & Yes & Yes \\
\hline Interaction terms & No & No & No & All & $\begin{array}{c}\text { Returnee } \\
\text { Age } \\
\text { Household size } \\
\text { Location } \\
\text { Year }\end{array}$ \\
\hline$\beta_{k}=\theta_{k}$ & & & & $\begin{array}{c}75.70 \\
0.0000\end{array}$ & $\begin{array}{c}71.86 \\
0.0000\end{array}$ \\
\hline \multirow[t]{2}{*}{ Observations } & 2,274 & 1,081 & 1,193 & 2,274 & 2,274 \\
\hline & \multicolumn{5}{|c|}{ Covariate matching, $5 \mathrm{NN}$} \\
\hline Returnee & $\begin{array}{c}0.0038 \\
(0.0550)\end{array}$ & $\begin{array}{c}0.3333^{* * *} \\
(0.0817)\end{array}$ & $\begin{array}{l}-0.0241 \\
(0.0887)\end{array}$ & $\begin{array}{c}0.3431^{* * *} \\
(0.0816)\end{array}$ & $\begin{array}{c}0.3399^{* * *} \\
(0.0815)\end{array}$ \\
\hline Self-employed $_{(t=0)}$ & & & & $\begin{array}{c}0.3725^{* * *} \\
(0.0838)\end{array}$ & $\begin{array}{c}0.3764^{* * *} \\
(0.0836)\end{array}$ \\
\hline Self-employed $_{(\mathrm{t}-1)}$ & & & & $\begin{array}{c}2.5849 * * * \\
(0.3363)\end{array}$ & $\begin{array}{c}2.3635^{* * * *} \\
(0.2849)\end{array}$ \\
\hline ... X Returnee & & & & $\begin{array}{c}-0.3658^{* * *} \\
(0.1211)\end{array}$ & $\begin{array}{c}-0.3486^{* * *} \\
(0.1210)\end{array}$ \\
\hline Control variables & Yes & Yes & Yes & Yes & Yes \\
\hline Time fixed effects & Yes & Yes & Yes & Yes & Yes \\
\hline Interaction terms & No & No & No & All & $\begin{array}{c}\text { Returnee } \\
\text { Vocational } \\
\text { Urban } \\
\text { Year }\end{array}$ \\
\hline$\beta_{k}=\theta_{k}$ & & & & $\begin{array}{c}84.44 \\
0.0000\end{array}$ & $\begin{array}{c}72.56 \\
0.0000\end{array}$ \\
\hline Observations & 2,270 & 1,093 & 1,177 & 2,270 & 2,270 \\
\hline
\end{tabular}

Notes: The dependent variable is a binary variable taking unity if a working-age individual is self-employed in a household; 0, otherwise. Observations are non-splitting households, whose heads were born in Kyrgyzstan. In the upper panel of the Table, observations form a matched sample of control (households with non-returnees) and treated (with returnees) applying propensity score matching techniques (5 nearest neighbours). In the lower panel, observations form a matched sample of control and treated applying covariate matching techniques (Mahalanobis metric, 5 nearest neighbours). Columns (1) presents coefficient estimates of probit model of the baseline specification; Columns (2), of entry in self-employment; Columns (3), of persistence in self-employment; and Columns (4)-(5), coefficient estimates of a dynamic, non-linear probability model. Tests of joint significance of interaction terms when applicable report $\chi^{2}$ with associated statistical significance. Robust standard errors in parentheses. ${ }^{* * *} \mathrm{p}<0.01,{ }^{* *} \mathrm{p}<0.05,{ }^{*} \mathrm{p}<0.1$ 
Table B13 - Marginal effects of parsimonious combined model household specification coefficient estimates

\begin{tabular}{lccc}
\hline \hline \multirow{2}{*}{ Variables } & Average & $\mathrm{FE}_{(\mathrm{t}-1)=0}$ & $\mathrm{FE}_{(\mathrm{t}-1)=1}$ \\
& $(1)$ & $(2)$ & $(3)$ \\
& \multicolumn{4}{c}{ Full } & estimation & sample \\
\multirow{4}{*}{ Returnee } & $.0525^{* * *}$ & $.0675^{* * *}$ & $.0477^{* *}$ \\
& $(.0159)$ & $(.0240)$ & $(.0226)$ \\
Family enterprise $_{(\mathrm{t}=0)}$ & $.1540^{* * *}$ & $.1564^{* * *}$ & $.1654^{* * *}$ \\
& $(.0234)$ & $(.0236)$ & $(.0243)$ \\
Family enterprise $_{(\mathrm{t}-1)}$ & $.2608^{* * *}$ & $.2608^{* * *}$ & $.2608^{* * *}$ \\
& $(.0362)$ & $(.0362)$ & $(.0362)$ \\
Observations & 6,831 & 6,831 & 6,831 \\
\hline
\end{tabular}

Matched sample, PSM

\begin{tabular}{|c|c|c|c|}
\hline Returnee & $\begin{array}{c}.0944^{* * *} \\
(.0179)\end{array}$ & $\begin{array}{c}.1588^{* * *} \\
(.0292)\end{array}$ & $\begin{array}{l}.0433^{*} \\
(.0252)\end{array}$ \\
\hline Family enterprise $_{(t=0)}$ & $\begin{array}{c}.1294^{* * * *} \\
(.0278)\end{array}$ & $\begin{array}{c}.1455^{* * *} \\
(.0303)\end{array}$ & $\begin{array}{c}.1172^{* * *} \\
(.0261)\end{array}$ \\
\hline Family enterprise $_{(\mathrm{t}-1)}$ & $\begin{array}{c}.3083^{* * *} \\
(.0278)\end{array}$ & $\begin{array}{c}.3083^{* * *} \\
(.0278)\end{array}$ & $\begin{array}{c}.3083^{* * *} \\
(.0278)\end{array}$ \\
\hline Observations & 2,274 & 2,274 & 2,274 \\
\hline & \multicolumn{3}{|c|}{ Matched sample, CVM } \\
\hline Returnee & $\begin{array}{c}.0577^{* * * *} \\
(.0180)\end{array}$ & $\begin{array}{c}.1236^{* * *} \\
(.0294)\end{array}$ & $\begin{array}{c}-.0024 \\
(.0252)\end{array}$ \\
\hline Family enterprise $_{(t=0)}$ & $\begin{array}{c}.1190^{* * *} \\
(.0272)\end{array}$ & $\begin{array}{c}.1374 * * * \\
(.0304)\end{array}$ & $\begin{array}{c}.1071^{* * *} \\
(.0255)\end{array}$ \\
\hline Family enterprise $(\mathrm{t}-1)$ & $\begin{array}{c}.3162^{* * *} \\
(.0275)\end{array}$ & $\begin{array}{c}.3162^{* * *} \\
(.0275)\end{array}$ & $\begin{array}{c}.3162^{* * * *} \\
(.0275)\end{array}$ \\
\hline Observations & 2,270 & 2,270 & 2,270 \\
\hline \multicolumn{4}{|c|}{$\begin{array}{l}\text { Notes: Columns (1) presents average marginal effects } \\
\text { corresponding of coefficient estimates presented in Tables } 14 \\
\text { (upper panel) and } 15 \text { (middle and lower panels), Column (5). } \\
\text { Columns (2) presents corresponding marginal effects when } \\
\text { lagged self-employment is equal to 0; Columns (3), when } \\
\text { lagged self-employment is equal to } 1 \text {. Standard errors are in } \\
\text { parentheses. } * * * \mathrm{p}<0.01,{ }^{* *} \mathrm{p}<0.05 \text {, } * \mathrm{p}<0.1 \text {. }\end{array}$} \\
\hline
\end{tabular}


Figure B7 - Average marginal effects of return migration with $95 \%$ confidence intervals of parsimonious combined model, household sample

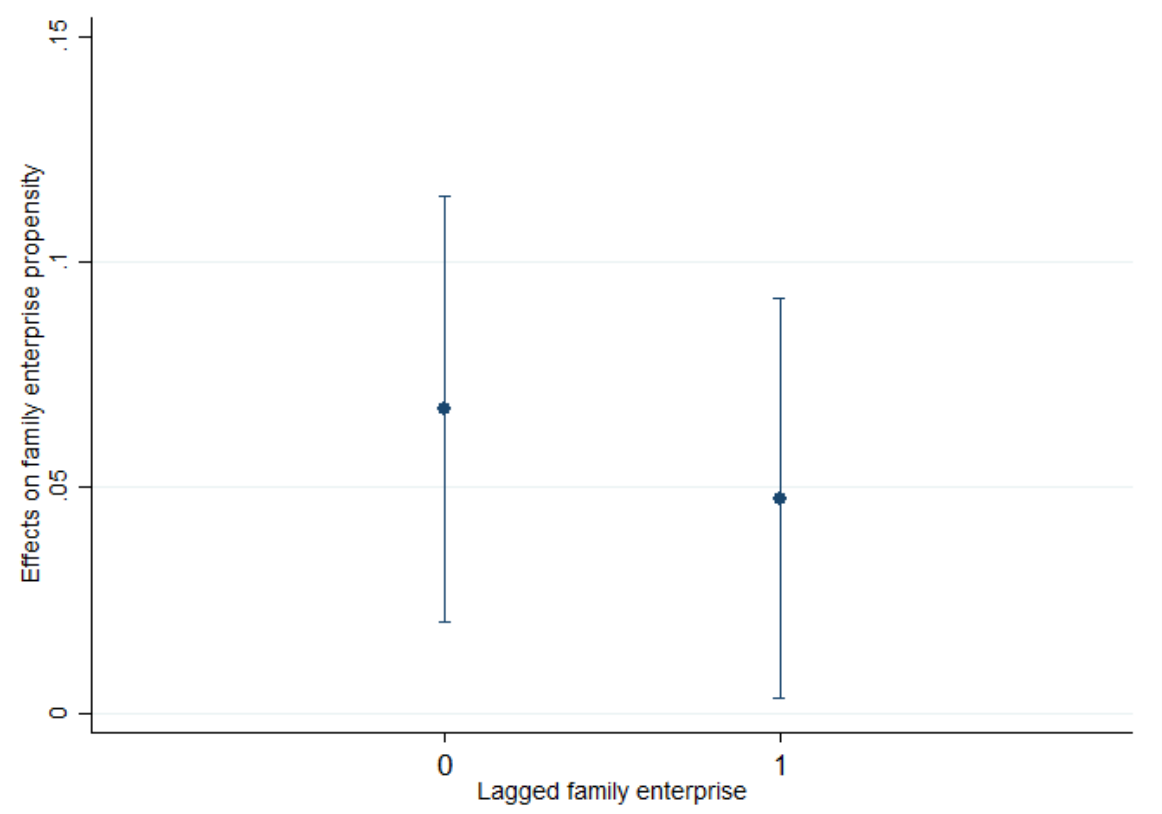


Figure B8 - Average marginal effects of return migration with 95\% confidence intervals of parsimonious combined models, PSM (1) and CVM (r) matched sample
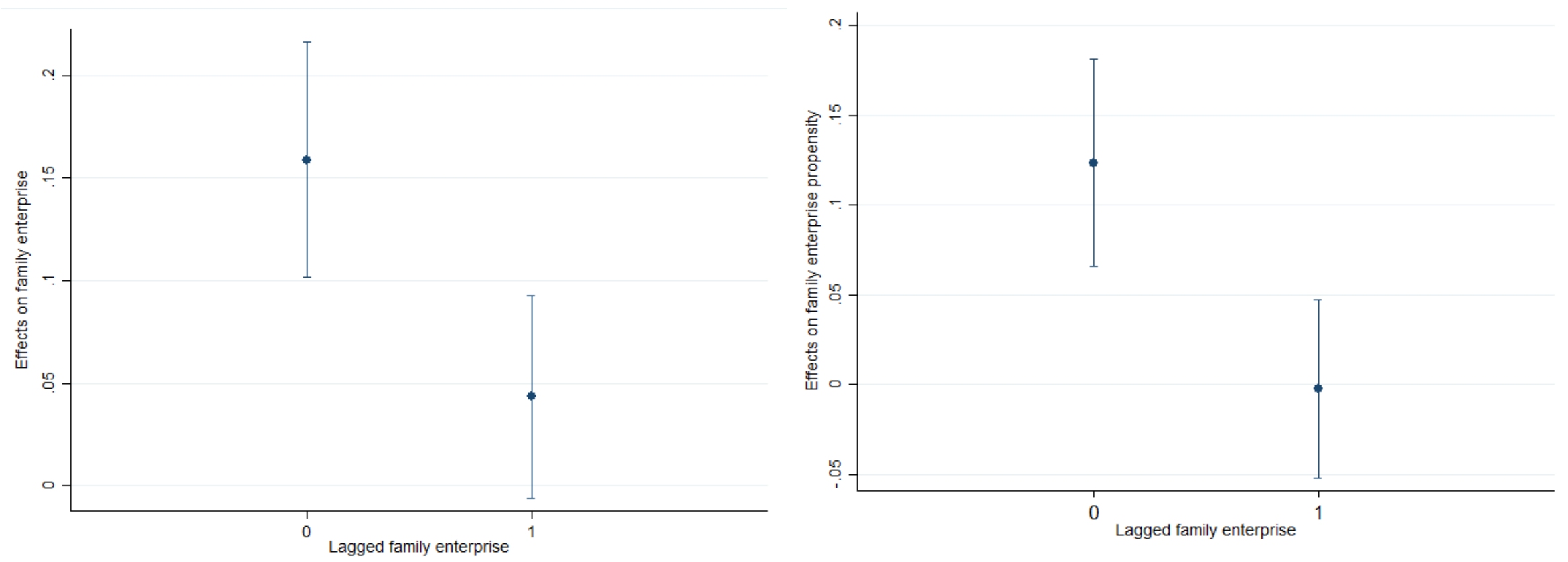


\section{Chapter 4}

\section{Does living with return migrants affect time use?}

\subsection{Introduction}

The out-migration of a household member has been shown to influence left-behind, nonmigrating members' occupations through the receipt of remittances and within-household labour reallocation (e.g. Binzel and Assaad, 2011). There is also evidence that migrants transfer destination country norms, and that their decision-making power is reinforced upon return relative to their spouses' (e.g. Antman, 2011, Bertoli and Marchetta, 2015 or Tuccio and Wahba, 2015). Yet, whether men's returning affects the time allocation of their wives has been left unanswered by the literature. On the one hand, individuals' occupational and migration decisions are often made at the household level in developing economies, and local labour markets segregate along gender lines. On the other hand, migration flows tend to alter returnees' choice of occupation. This chapter exploits the documented effect of migration on occupational choice upon migrants' return to their origin country to establish a link between return migration of men and their wives' time allocation through within-couple occupational interdependence.

This chapter contributes to the literature on women's occupational choice, specifically in a developing setting with prevalent international migration. Not only instrumental in household livelihood strategies, how women use their time - whether they engage in, or how much time they spent on certain activities - has been found to be a key determinant of their autonomy and

This chpater is based on Mahé, C. (2017). Husbands' return migration and wives' occupational choices. UNU-MERIT Working Paper No. 2017-031, Maastricht: United Nations University Maastricht Economic and Social Research Institute on Innovation and Technology. I would like to acknowledge the Economic Research Forum for providing the database used in this paper; Ragui Assaad and Caroline Krafft for kindly answering questions about the database. I am furthermore grateful to Wim Naudé, Sergio Parra-Cely, Isabel Ruiz Olaya, Clémentine Sadania, Melissa Siegel, Tobias Stöhr, Tamer Taha and Neda Trifkovic, who provided comments, suggestions and encouragements, as well as participants of the 1st UNU-MERIT Internal Conference, held on June 29-30, 2017, in Maastricht, the Netherlands; and of the UNU-WIDER Development Conference on Migration and Mobility, held on October 5-6, 2017, in Accra, Ghana. 
bargaining power, both within and outside their household. ${ }^{1}$ If return migrants were more likely to set up a firm upon return, demand for labour within returnees' households could increase. Returnees setting up a family firm could then alter women's degree of control over resource allocation, among other household decisions. However, the wealth men gathered abroad could simultaneously be used to start up a business, and free up their wives' time. If this is the case, women could decide not to work, or to reallocate their time to relatively more income-generating activities outside their household. This analysis is the first to show and quantify the effect of return migration of men on their wives' choices of occupation.

It uses the 2012 Egypt Labor Market Panel Survey (ELMPS) (ERF and CAPMAS, 2013). With quality data, Egypt provides a good example. Largely dominated by men, migration from Egypt to Arab countries is temporary in nature. It has been found to increase men's propensity to set up businesses upon return to Egypt, and to survive as entrepreneurs (Marchetta, 2012; Wahba and Zenou, 2012; Wahba, 2015). It has also been found that living in a household with a man who migrated to a conservative country increases the likelihood of Egyptian women to internalise traditional gender norms (Bertoli and Marchetta, 2015). At the same time, female labour participation is rather low in Egypt. The labour market is segregated, and women's labour options remain segmented (Sadania, 2017).

Reduced-form estimates of a seemingly unrelated regression (SUR) model show that being married to a migrant who opted for self-employment upon return decreases a woman's likelihood to engage in paid work. It increases her likelihood to engage in family work, subsistence farming and domestic chores, at both the extensive and intensive margins. Results differ by education level, with illiterate wives engaging significantly more in paid as well as unpaid work compared to more educated women. Questioning the idea that their return automatically induces going back to pre-departure within-household time and task allocation, these results are explained by the existence of occupational interdependence between spouses most likely in order to diversify income sources and as a result of assortative mating, along time-use gender differentiation lines. Findings highlight the need to buffer potentially depriving migration-induced effects on women's time use, even once migration is complete.

The rest of this chapter is structured as follows. Section 4.2 reviews possible channels explaining how husbands' migration experience could affect their wives' time allocation through their occupational choice upon return. Section 4.3 introduces the context of this chapter, followed by the estimation strategy in section 4.4 , and the data used in section 4.5. Section 4.6 presents estimation results. Section 4.7 concludes.

\footnotetext{
${ }^{1}$ Female autonomy is defined following Anderson and Eswaran (2009) as 'the ability of women to make choices/decisions within the household relative to their husband.' For a review on the literature on the relationships between women's empowerment, earnings and control over income, or women's empowerment and development/economic growth, see Sadania (2017).
} 


\subsection{Conceptual background}

From the literature, four non-mutually exclusive categories of women's time use are identified: household work, ${ }^{2}$ subsistence work, ${ }^{3}$ unpaid market labour activities and paid ones. Time spent caring for children, the sick or the elderly while doing or not doing other activities is excluded. Household chores, seen as household public goods, do not generate any income. Subsistence work is defined as farming for one's own household consumption; it does not generate income. Unpaid market labour measures the contribution of a household member to a family enterprise, i.e. marketable, and productive labour, from which one does not earn any revenue. Labour force could be hired for such an activity, but family labour, accounting for supervision costs, is seen as cheaper since it does not need supervision. Paid market labour is an income-generating activity, either as self- or wage-employed, outside the household.

In line with the extensive evidence contradicting the unitary models of the household $\grave{a}$ la Becker $(1973 ; 1981)$, the possibility of bargaining between household members is acknowledged. ${ }^{4}$ Getting divorced - suggested as an outside option by cooperative models - might not be realistic in a country like Egypt, where women do not face equal rights regarding divorce, ${ }^{5}$ or where the labour market does not ensure the existence of viable outside options for women. ${ }^{6}$ For that reason, this chapter adopts a non-unitary model of household bargaining, with non-cooperation within marriage as a relevant threat option, more relevant to Egyptian realities, as in Sadania (2017).

However, because data only allow observing the outcome of this bargaining process, a theoretical framework of the channels at stake is not provided, nor a test for the relevance of one model over another. Intra-family decision-making is assumed to take place collectively, either cooperatively or non-cooperatively. Cooperation might be limited, and complete pooling of resources might not always occur, rendering the hypothesis of joint decision-making inappropriate. In an environment of traditional, strict gender roles, as is the case in Egypt, women may be limited

\footnotetext{
${ }^{2}$ Household chores include time spent on shopping for food, clothing and household items; on accompanying family members to their activities; on maintenance activities and helping in construction work for the household for the purpose of one's own household consumption; on cooking, washing dishes, doing laundry, ironing and cleaning one's house; and collecting water, firewood or other fuels.

${ }^{3}$ Subsistence work includes time spent on agricultural activities, raising poultry/livestock and producing ghee/butter/cheese for the purpose of one's own household consumption.

${ }^{4}$ For a review of the evidence contradicting the unitary model of the household, see Browning et al. (1994). Unitary theories of family decision-making include different family structure models that assume a family to act 'as if' it were maximising a unique, family utility function. In contrast, bargaining models suggest that household members have individual weight they use in a bargaining process, determined by the existence of threat points - outside options in case of marriage dissolution - that affect household outcomes such as resource allocation. The comparison of each spouse's outcomes within marriage to its breakdown (in cooperative models), or to non-cooperation (in non-cooperative models), determines their degree of bargaining power, and hence their behaviour. Cooperative and non-cooperative models thus take into account intra-family income distribution.

${ }^{5}$ Despite their 2004 modification in favour of women, women's rights have remained unequal to men's regarding divorce. In addition, rather difficult social acceptance and risk of social exclusion leave divorce rate at a low $2,2 \%$ in 2012 (Sadania, 2017).

${ }^{6}$ There may not exist labour market options offered to women in case cooperation with their spouses breaks down, as suggested by the World Development Report 2012 that ranked Egypt 124 out of 132 countries in terms of opportunities and economic participation of Egyptian women (World Bank, 2012).
} 
in deciding on how to allocate their time, not only by a 'typical' lack of productive assets, ${ }^{7}$ but also by some level of inflexibility attached to how women are allowed to allocate their time. This gender differentiated availability of labour might constrain women's time use to certain activities (Serra, 2009). ${ }^{8}$

This chapter thus follows Serra (2009) in accounting for gender-specific constraints and choices in women's time allocation, resulting from prevalent gender-specific role stratification. For instance, if household public goods such as cooked food, cleaning or fuel collection, are key to household production, women tend to take an excessive part in their production, regardless of their participation in other remunerative and more productive activities. In comparison, men tend to dedicate their time exclusively to income-generating activities. Because of tradition, men and women are assigned distinct tasks, based on their gender. Women are more likely to not only give up leisure time, but also, and of interest in this chapter, potentially remunerative activities outside their household. Due to greater constraints on their ability to allocate time between activities, women will be less inclined to engage in relatively time-intensive, albeit remunerative, occupations (Serra, 2009).

Husbands' migration could simultaneously affect the need for, or the offer of, paid, unpaid, subsistence or domestic work upon return, because of some degree of dependence between spouses' occupations, as Parker (2008) suggests, since return migrants have been found to significantly diverge in their occupational choice from non-migrants. Using a simultaneous probit equation system, Parker (2008) finds significant positive business ownership dynamics between spouses, attributed to knowledge transfers. ${ }^{9}$ Alternative explanations, with little data support in Parker (2008), can be considered, such as assortative mating, ${ }^{10}$ role models, ${ }^{11}$ minimising risk ${ }^{12}$ or intra-household wealth transfers. ${ }^{13}$

Within Parker's (2008) framework of occupational interdependence, how households allocate labour and time between members is understood in the context of a developing economy, where there might be a need to diversify income sources between farm or non-farm activities, within non-farm sectors, in terms of location or type of occupation. Households diversify their activities in order to maximise household earnings, subject to limited resources, and to minimise risk, either (i) for accumulation objectives, i.e. 'pull factors'; or (ii) to manage risk to smooth income over time, cope with shocks or escape from activities in stagnation or decline, i.e. 'push factors.' Whether and how households decide to diversify their activities depends not only on

\footnotetext{
${ }^{7}$ Such as educational, financial and technical assets that can help women to access economic activities of higher return.

${ }^{8}$ Gender-specific time constraints might result from socially sanctioned norms that characterise tasks as being female or male, as well as from the difficulty in substituting market inputs for time inputs, i.e. inefficiency or absence local labour markets.

${ }^{9}$ Knowledge transfers are defined as business-related information readily shared within couples.

${ }^{10} \mathrm{~A}$ high level of resemblance across personal features such as education, age or earnings, revealing similar preferences between those who marry each other.

${ }^{11}$ A spouse's occupational choice being influenced by the performance of his/her spouse in a specific activity, so they might follow in their footsteps.

${ }^{12}$ Spouses deciding how each one allocates their time interdependently in order to diversify any risks attached to their income source activities they might face.

${ }^{13}$ A spouse's occupation being influenced by the ability of their wealthy co-spouse to overcome e.g. financial constraints.
} 
their incentives, ${ }^{14}$ but also on their capacity. ${ }^{15}$ In particular and of interest in this chapter, the availability of labour force within a household can allow for diversification across members of the same household ${ }^{16}$ (Reardon et al., 2006).

As supported by empirical evidence from Asia, Latin America and sub-Saharan Africa, the participation in multiple activities, 'pluriactivity', tends to occur within a household between members, each one specialising in an activity relatively to the others. Poorer households are expected to diversify in order to manage risk to compensate for few assets, and to survive. With lower risk attached to their (main) activity, wealthier families show a more extensive degree of diversification (Reardon et al., 2006), with specialisation between individuals, some typically specialising in non-farm activities, often highly-paid wage employment. Wealthy and poor households thus diversify differently. Wealthier, profit-maximising families tend to participate in higher-return activities; more vulnerable families, in an attempt to survive by minimising risk and stabilising income, diversify into labour-intensive, low-return activities. Income diversification can be seen either as signalling households' ability to seize opportunities, or as a survival strategy. In this sense, repatriating savings accumulated abroad could help further diversify income sources within a household by relaxing budget constraints and facilitating access to financial capital.

In sum, in a context of occupational interdependence between spouses, household income diversification and gender differentiated time allocation, (male) migrants setting up a firm upon return could affect how their wives allocate their time. Specifically:

- Women's participation in paid or unpaid market labour depends on the type and sector of occupation of their husbands, their households' livelihood strategy, the level of risk their household has to cope with and the degree of their observed productivity. For instance, women with a relatively high education level might not only have stronger bargaining power, but might also have 'revealed' they were more efficient working outside their household, on the labour market. Alternatively, husbands working in a rather risky or low-productivity sector might induce women to allocate their time out of their husbands' enterprises, towards less risky activities, even if with low returns, in order to reduce risk and smooth their household income.

- The greater probability of men opting for self-employment upon return could be expected to increase their wives' likelihood to engage in subsistence work, because of gender differentiation of men's and women's time use. In developing societies, women tend to take care of food crops for household consumption, whereas men deal with cash crops or more remunerative non-farm activities, sold on the market. Depending on the level of risk attached to the main household occupation - often the first activity of the head of the

\footnotetext{
${ }^{14}$ Incentives to diversify include prices of outputs and inputs of nonfarm activities relative to farm activities, as well as the relative risks attached to such activities.

${ }^{15}$ Household capacity includes assets such as human, social, financial, organisational or physical capital, that can be public or private, common to all households or specific to a household or a group of households.

${ }^{16}$ See examples from Burkina Faso or the Philippines as cited in Reardon et al. (2006).
} 
family, in this case, the husband - women would be expected to engage with, if not invest more time in, household crops. If a migration-induced wealth effect enables families to hire external labour to work on food crops, and so free women from subsistence farming, women can allocate time to other activities. However, it could be that conservative gender norms place a higher time burden on women, with increased time spent on subsistence work.

- The impacts of husbands' migration on their wives' participation in domestic work is not clear. On the one hand, migration-induced wealth effects could free women from spending time on household chores thanks to the use of domestic gadgets. On the other hand, if outside labour is hired on local labour markets instead of using household members for subsistence farming or to contribute to the family enterprise, their participation in domestic work could increase in relative terms. However, it could be that, in a traditional society with conservative gender norms, the decision to engage in or the number of hours spent on household work is not altered. The wealth men gathered abroad and repatriated could simultaneously be used to start up a business and free up their wives' time. If this is the case, women can decide not to work, either paid or unpaid, which would increase their time spent on domestic chores in relative terms, or to reallocate their time to relatively more income-generating activities outside their household.

- Allocating their time to one activity does not prevent women from engaging in other activities, household work being the best example. In this case, the increased probability of a man who has migrated setting up a business upon return would raise the (work) burden placed on women in more than one activity - the level of diversification of their time - potentially decreasing their outside options.

- These dynamics are expected to differ (i) by location since household livelihood strategies, local labour market opportunities and gender norms vary between rural and urban areas; (ii) by husband's sector of occupation. Provided that the agricultural sector has a rather traditional structure, marked by a high degree of land fragmentation, a substantial number of individual farmers will work on small, low productivity plots, unable to benefit from economies of scale and likely to tie up available labour supply within a household (Morsy et al., 2014); or (iii) by women's skill levels. The higher their level of education is, the higher their bargaining power is within their family, either through a greater control over resources or their competencies acting as 'signal' of their abilities.

\subsection{Context}

A survival strategy to escape poor social and economic development (Zohry, 2009), international emigration from Egypt is mainly a function of overseas labour demand. For this reason, it is strongly affected by the economic and political conditions of (Arab) labour-importing countries (Wahba, 2009). Egypt has been a labour exporter since the economic reforms and opening of the country in the 1970s. It is the biggest labour exporter of the Middle East and North 
Africa (MENA) region (Wahba, 2014). Two main trends characterized Egyptian emigration: (i) relatively temporary migration to Arab countries, involving male household heads, for four to five years; ${ }^{17}$ and (ii) more permanent migration to Western countries, involving the entire nuclear family. Egyptians' first destinations were labour-importing Arab countries, in particular the oil-producing Gulf States, Libya and Iraq, because of labour shortages. Since the 1980s and 1990s, the political instability some experienced and the replacement of Arab with Asian workers have had a significant effect on emigration destinations of Egyptians. Although the majority still migrates to Arab and Gulf States, around 30\% of Egyptian migrants were residing in Western countries in 2000 (Wahba, 2009).

On the other hand, micro- and small enterprises (MSEs) constitute almost $99 \%$ of Egypt's total enterprises, and around $80 \%$ of total employment, providing work for about $75 \%$ of new entrants into the job market (Ghanem, 2013). Egyptian MSEs are mainly family businesses, with low capital-labour ratios that use simple, traditional technologies, with limited access to financing, infrastructure and public services.

It has been shown that return migration is significantly related to entrepreneurship in Egypt. McCormick and Wahba (2001) use the ELMPS to show that overseas savings and the acquisition of skills over a stay abroad is associated with increased propensity to become self-employed of literate returnees; even overseas savings alone raise illiterate returnees' propensity for selfemployment. Controlling for the endogeneity of temporary migration, Wahba and Zenou (2012) find that an international migrant has a higher probability of becoming self-employed upon return than a non-migrant, as the accumulation of savings and skills abroad compensates for their potential loss of social capital. Exploiting the longitudinal dimension of these data and controlling for selection in international return migration, Marchetta (2012) finds that being a return migrant increases the prospect of survival of entrepreneurial activities in Egypt.

Furthermore, labour force participation of women in Egypt is one of the lowest, with 19\% engaged in paid work in 2010 (World Bank, 2017). The development of male-dominated nontrade sectors over traditional export sectors, combined with the interruption of an employment guarantee scheme for higher education graduates in the 1990s that offered women attractive working conditions, ${ }^{18}$ have triggered growing unemployment ${ }^{19}$ and led to a de-feminisation of its labour force. The 2008 economic crisis and the economic slowdown following the January 2011 Uprising have accentuated such trends.

At the same time, tradition limits women's mobility, and restricts them to the domestic sphere or to small home-based income-generating activities with few opportunities to expand (Sadania, 2017). Not only work characteristics but also social norms attached to specific activities have rendered the Egyptian labour market gender differentiated and, for women in particular, segmented between public sector (44\% of Egyptian women engaged in public sector work in

\footnotetext{
${ }^{17}$ Lucas (2008) indicates that the average length of migration in Gulf countries is about 4-5 years. This might be explained by Arab countries relying on a sponsorship scheme. This system ensures entry visas can only be obtained through a local sponsor (Gardner, 2011).

${ }^{18}$ By providing some flexibility to combine work with family life, in line with Egyptian customs, working in the public sector has been deemed socially acceptable for highly qualified women (Assaad and El-Hamidi, 2009; in Sadania, 2017).

${ }^{19}$ Egypt's unemployment rate among women was of $27.1 \%$ in 2012 ; that of men was of $7 \%$.
} 
2012), private sector (32) and household work (24). If working in the public sector is accepted by Egyptian society for the most educated, engaging in private work outside the household is in contrast seen as degrading. Contributing to family work, such as their husbands' farms or non-agricultural businesses, often carried out from home, is more accepted for those who cannot join the public sector (Sadania, 2017).

Investigating the determinants of Egypt's low female labour force participation, Binzel and Assaad (2011) find that male out-migration decreases women's participation in wage work in both rural and urban areas. Those living in a rural household where a male member is currently away are more likely to contribute to family work (as unpaid workers) and to subsistence work. This labour supply response is found to be due to families' need to compensate for the absence of migrants' labour despite the receipt of remittances. Binzel and Assaad's (2011) results are in line with Taylor's (1984) who finds that rural women are in general mostly limited to household work, and traditionally in charge of livestock as well as, to some extent, selling goods on markets. Yet, communities with high migration rates see a greater work load placed on women who have to take over agricultural work, usually perceived as 'male'.

In addition, empirical research on return migration suggests that the return of male heads husbands - from migration, alters intra-household resource allocation, benefitting boys relatively more than girls. This is evidence of greater authority for the household head, i.e. relative loss of a wife's degree of bargaining power upon the husband's return. ${ }^{20}$ Living in a household where a man has ever migrated, either before or after marriage, has also been found to affect gender norms. Bertoli and Marchetta (2015) for instance show that couples of which husbands temporarily emigrated to Arab countries, where fertility is higher, have significantly more children. Looking at Jordan, a country with similar migration trends to MENA countries as Egypt, Tuccio and Wahba (2015) find that women living in a household with a man who temporarily migrated to a conservative Arab country display a higher internalisation of discriminatory gender norms, upon men's return to Jordan.

These empirical findings point to migration as a means for transferring (potentially conservative) destination country gender norms. If this the case, migrants who return from conservative destination countries might prefer stay-at-home wives rather than wives working outside the home. However, it seems difficult to disentangle social, cultural preferences from economic considerations, since returnees' wives might be less likely to engage in outside activities if their husbands have a business they could contribute to as cheap-to-supervise labour, which additionally depends on the risk and productivity attached to these very entrepreneurial activities. That women work outside their household and the degree of dependence between spouses' occupations might be affected by cultural as much as economic preferences since wives' contribution to family work - their husbands' businesses, subsistence farming or domestic chores - might be out of a thoughtful 'cost-benefit' analysis.

\footnotetext{
${ }^{20}$ See for instance Antman (2011) for the case of migration of Mexican men to the United States.
} 


\subsection{Estimation strategy}

A major analytical issue is the endogeneity of (i) temporary migration and occupational choice, and (ii) husband and wife's occupation and time use. First, migrating is subject to selection biases due to unobservable features, likely to affect occupational choice and business performance upon return (Marchetta, 2012). Those who emigrate and return may do so because they are more endowed, i.e. have innate entrepreneurial skills before departure, than non-migrants. Dynamics between return migration and entrepreneurship may be biased if returnees are genuinely more risk-takers and so initiate riskier business strategies, or if returnees opt for self-employment due to lack of social capital or wage employment opportunities upon return. Apart from omitted variable bias, endogeneity could result from bidirectionality, since emigrating itself could be driven by the desire to set up an enterprise upon return. They could be simultaneous decisions, part of would-be entrepreneurs' business strategies (Wahba and Zenou, 2012; Batista et al., 2017).

Occupation and time allocation within couples are also likely to be interdependent. A wife's occupational choice might both affect and be affected by the occupation of her husband, and vice versa. The availability of (potentially) cheap labour supply within a family - of their wives, in this case - might increase the likelihood of men to opt for self-employment, since their wives represent potentially available labour. This labour can be allocated to their business, to subsistence farming or to paid labour outside their households, if the husband's main activity is too risky or not remunerative enough. Their occupations could also be simultaneously affected by omitted variables, and men (women) self-selecting in their choice of spouse, as in the case of assortative mating.

To tackle endogeneity in assessing, and recovering, the effect of husbands' migration on their wives' time allocation through self-employment, the reduced-form of two distinct structural equations is estimated, linking (i) return migration to the probability of husbands to be self-employed, (ii) and husbands' self-employment to their wives' occupational choices. A seemingly unrelated regression (SUR) linear probability model is used, since the three decisions - husbands' migration experience, their propensity to be self-employed and wives' time use form a non-recursive model with direct causal paths and correlated disturbances. ${ }^{21}$ Ignoring the interdependence in temporary migration, occupational choice upon return and wives' time allocation, interdependence, when actually present, ${ }^{22}$ could lead to biased estimates. Exclusion restrictions play the role of instrumental variables.

The reduced-form model is specified as follows:

$$
\begin{aligned}
& \text { Returnee }_{h}=\delta_{0}+\delta_{1} X_{R h}+\delta_{2} Z_{R h}+\epsilon_{1 h} \\
& \text { SelfEmployed }_{h}=\alpha_{0}+\alpha_{1} X_{S E h}+\alpha_{2} Z_{S E h}+\alpha_{3} Z_{R h}+\epsilon_{2 h} \\
& \text { Occupation }_{w j}=\gamma_{0}+\gamma_{1} X_{O w}+\gamma_{2} Z_{S E h}+\epsilon_{3 w}
\end{aligned}
$$

\footnotetext{
${ }^{21}$ Correlated disturbances assume that corresponding endogenous variables share at least one common omitted explanatory variable.

${ }^{22}$ I.e. estimating this system of equations as single equations, in their structural rather than reduced form.
} 
where Returnee is a binary variable taking unity if a working-age (16-64) married man (husband) $h$ has worked at least six months abroad. Self Employed is a binary variable taking unity if a working-age married man $h$ is currently self-employed. Occupation, with $j=1,2,3,4$, is alternatively a set of binary variables taking value 1 if a married woman in reproductive age (15-49) (wife) $w$ has been engaged in paid market work, unpaid market work contributing to family work, subsistence work (farming for own consumption) or domestic work in the last seven days, with a corresponding set of continuous variables measuring the number of hours spent in each of these activities. The set of binary variables captures the decision to participate in an activity, i.e. the extensive margin; the set of continuous variables, the intensive margin.

$X_{R}$ is a vector of individual and household characteristics capturing education, household size, child dependency ratio and whether an individual's mother is literate. Mother's education proxies potential inequalities of opportunities individuals might face based on their family background (Paxson and Schady, 2004; Paxson and Schady, 2007; in Atinc et al., 2005). $X_{S E}$ is a vector of variables thought to influence occupational choice such as vocational training, whether an individual's father was self-employed. This variable is thought to capture the existence of knowledge transfers between self-employed parents and their children, as found in the literature, as in Laband and Lentz (1983) or Dunn and Holtz-Eakin (2000) (Parker, 2008). It reflects a 'family' (cultural) entrepreneurial capital.

$X_{S E}$ also includes a variable capturing whether his first job was self-employed, as a of measure entrepreneurial motivation, years of unemployment, ${ }^{23}$ lagged unemployment rate at the governorate level and household level characteristics such as household size and under 15 dependency ratio. ${ }^{24}$

$X_{O}$ is a vector of variables influencing women's time allocation, such as age, literacy, mother's educational background, family size, under 15 and above 65 dependency ratios, governorate-level lagged unemployment rate, share of agricultural work and public sector work, and proportion of the population with at least secondary education. This set of governorate-level variables is included to take into account the fact that returns to local non-farm activities happen to occur in areas with growth motors (agriculture, mining, tourism, etc.), generating consumption and production dynamics with non-farm sectors, and increasing the demand for non-farm products (Reardon et al., 2006).

Equations (1) and (2) form the reduced-form equations of the first structural equation; equation (2), the reduced-form equations of the second structural equation. As $Z_{R}, Z_{S E}$ and $X_{O}$ are unique to each structural equation, the above model can be solved and its structural parameters uniquely identified. These three structural model equations can be rewritten as three reduced form equations in the endogenous variables Returnee, Self Employed and Occupation, so that each of these variables will depend on the exogenous variables in the entire system as well as on the structural errors.

\footnotetext{
${ }^{23}$ Labour force related information are measured over the last four job spells available in the module 6 of the ELMPS.

${ }^{24}$ Because the variable used as instrument to deal with the endogeneity of migration is age-specific, age or age-related variables such as tenure or years of potential work experience were not included in these two first regressions because of multicollinearity. Limiting the estimation sample to working-age married men should reduce a potential omitted variable bias.
} 


$$
\begin{aligned}
& \text { Returnee }_{h}=f\left(. ; Z_{R h}, \delta_{2}\right) \\
& \text { SelfEmployed }_{h}=f\left(. ; Z_{S E h}, \alpha_{2} ; Z_{R h}, \alpha_{3}\right) \\
& \text { Occupation }_{w j}=f\left(. ; Z_{S E h}, \gamma_{2}\right)
\end{aligned}
$$

The reduced form is estimated via a generalized simultaneous equations model (GSEM) estimator, with standard errors robust to heterogeneity. ${ }^{25}$ By estimating the relationship between a husband being self-employed and having migrated, controlling for the endogeneity of emigration, i.e. the change in the probability of being self-employment in an exogenous change in being a return migrant, the marginal effect of self-employment over return migration is obtained.

$$
\frac{\partial \text { SelfEmployed }_{h}}{\partial \text { Returnee }_{h}}=\frac{\frac{\partial \text { SelfEmployed }_{h}}{\partial Z_{R h}}}{\frac{\partial \text { Returnee }_{h}}{\partial Z_{R h}}}=\frac{\alpha_{3}}{\delta_{2}}
$$

The marginal effect of wives' time use over their husbands' propensity to be self-employed, controlling for within-couple occupational interdependence, i.e. the change in the probability and number of hours of women to spend time in a certain activity in an exogenous change in their husbands' occupations, is obtained by estimating the relationship between women's time allocation and the occupational choice of their husbands:

$$
\frac{\text { OOccupation }_{w j}}{\partial \text { SelfEmployed }}=\frac{\frac{\partial \text { Occupation }_{w j}}{\partial Z_{\text {SEh }}}}{\frac{\partial \text { EelfEmployed }_{h}}{\partial Z_{S E h}}}=\frac{\gamma_{2}}{\alpha_{2}}
$$

The effect of return migration of men on their wives' time use through within-couple occupational interdependence, i.e. the change in wives' time use in an exogenous change in their husbands being return migrants, is given by multiplying these two marginal effects: ${ }^{26}$

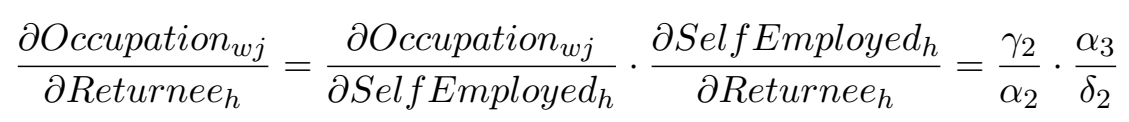

$Z_{R}$ is the interaction of (i) changes in the yearly average of the real exchange rate of the Egyptian Pound to the US dollar ${ }^{27}$ at a potential age of emigration, with (ii) the average distance to estimation sample destination countries in 1,000 kilometres is used to obtain an exogenous source of variations in temporary migration.

Changes in real exchange rates are thought to reflect how much a basket of goods costs in Egypt compared to in the US. The lower Egypt's real exchange rate - the stronger the Egyptian Pound

\footnotetext{
${ }^{25}$ Standard errors could not be clustered at the kism level since, despiste having a relatively large number of clusters (more than 100), cluster size was not balanced, ranging for one observation to more than 130 in a cluster.

${ }^{26}$ Standard errors of these marginal effects are computed by the delta method.

${ }^{27}$ Data on official exchange rates in local currency unit per US dollar and consumer price index (CPI) are available on the website of the World Bank. Real exchange rates are obtained by multiplying the official exchange rate by US CPI, and then dividing by Egypt CPI.
} 
- the cheaper it is for Egyptians to consume in Egypt, hence the lower the incentive to emigrate. Historical, matched exchange rates are assumed to act as a pull factor, reflecting how profitable, in monetary terms, working abroad is. Exchange rates could influence the contemporaneous profitability of some industries more than others, and affect the occupational choice upon return observed in the data. By including both wage and self-employment in all sectors of the economy and matching exchange rates to some potential age of emigration, (past) exchange rates should not be related to the occupational choice upon return observed at the time of the survey (2012). In addition, because emigration to Arab countries is temporary in nature, predicting emigration should suffice to instrument for return migration.

The age at which individuals have to be matched to the exchange rate is selected as in Bertoli and Marchetta (2015) who rely on an optimality criterion to choose out of 11 alternative ages, from ages 18 to 28 . Three different measures of exchange rates are used: yearly real exchange rate per se, yearly changes in real exchange rates, and a series of central moving average using two to five observations $(\mathrm{MA}(2)$ to $\mathrm{MA}(5))$, to deal with potential seasonality in the exchange rate.

The selection of the age, i.e. year of potential emigration, at which an individual is matched to the real exchange rate draws on Bertoli and Marchetta (2015). To do so, equation (1) is estimated, and the strength of this instrument is examined at different matching ages, ranging from ages 18 to 28 , by testing for each alternative the null hypothesis that the estimated coefficient on the real exchange rate equals zero through a Wald test, implemented by Stata's test command. In line with Cameron and Trivedi (2009, p.196) who note that 'a widely used rule of thumb [...] views an $\mathrm{F}$ statistic of less than 10 as indicating weak instruments. This rule of thumb is ad hoc and may not be sufficiently conservative [...]', the age of potential emigration giving the highest F-statistic is selected.

Figure 4.1 depicts the values of the F-statistics for equation (1), at each age, as well as the 10 F-statistic rule of thumb. The F-statistic is the highest for age 22 for the real exchange rate moving average based on 5 consecutive observations, MA(5), close to Bertoli and Marchetta's (2015) choice of 20 years old using the real price of oil as instrument. The central moving average with 5 observations of the real exchange rate when individuals were 22 is selected as instrument for temporary migration to MENA countries. Table 4.1 supports the selection of this instrument. It is, on average, statistically significantly lower for return migrants (EGP5.76) than for stayers (EGP6.49), confirming the rationale behind this instrument. ${ }^{28}$

Following Bertoli and Marchetta (2015), Figure 4.2 shows the relationship between the share of returnees of the estimation sample and the real exchange rate by cohort of birth, from 1950 to 1990. The proportion of return migrants is the highest, approximately $35 \%$ for those born in the mid-1950s and early 1960s. This increase in the proportion of return migrants coincides with a downward trend in the real exchange rate. The proportion of returnees then falls, until the end of the series in $1989,{ }^{29}$ which concurs with an upward trend in real exchange rate.

\footnotetext{
${ }^{28}$ Specifications are also run with historical real prices of oil matched at some potential age of emigration as in Bertoli and Marchetta (2015). The instrument was not strong enough across specifications for the estimation sample considered in this paper.

${ }^{29}$ No return migrants born in 1990 or later were surveyed. The estimation sample thus only includes
} 
Figure 4.1 - First stage test statistics for the real exchange rate at different emigration ages

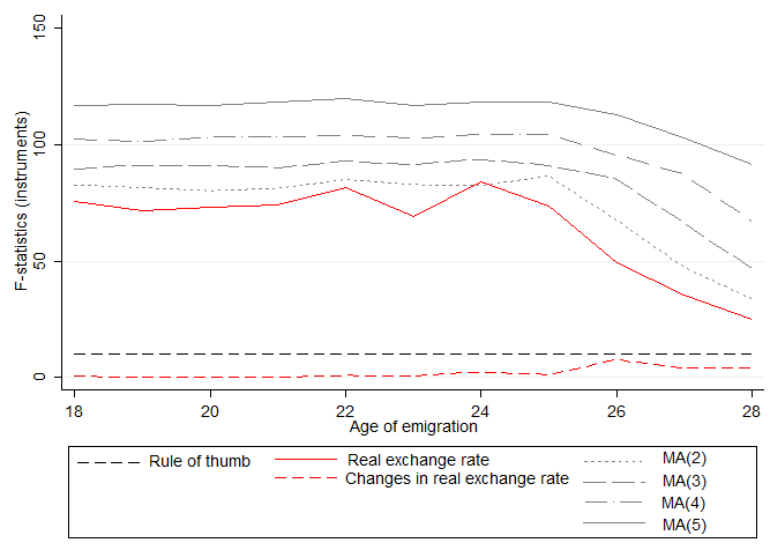

Figure 4.2 - Share of returnees by year of birth and real exchange rate

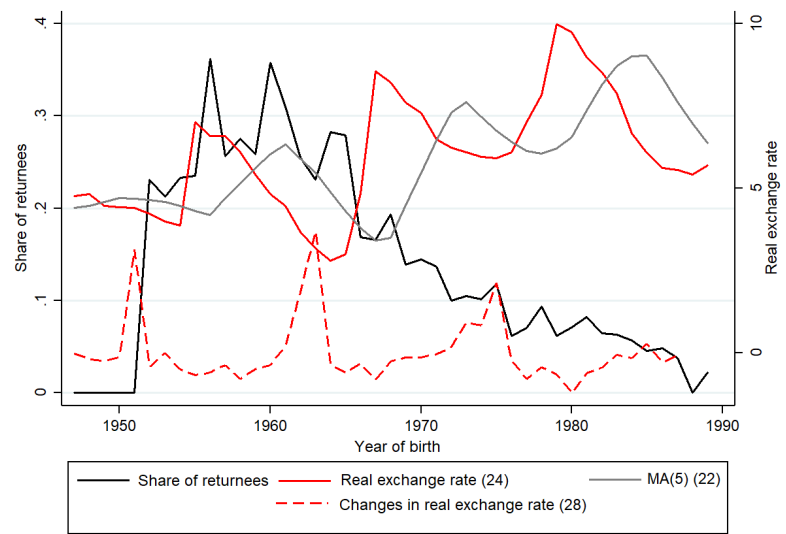

This cohort-based instrument is interacted with the average distance from the capital of a respondent's governorate of birth ${ }^{30}$ to estimation sample destination country capitals in 1,000 kilometres. ${ }^{31}$ Table A7 provides information on the construction of distances. Migrants are likely to migrate where it is cheaper because of geographical proximity, that is to countries closer to Egypt. ${ }^{32}$ Figure 4.3 presents the average distance to potential destination country capitals by governorate of birth in kilometres. The effect of real exchange rates on the probability to temporarily emigrate is thus allowed to differ across governorates through governorate (spatial) heterogeneity in migration costs to each potential destination. This interaction generates variation across time, via the cohort-based exchange rate, and across space, via the average distance from governorate of birth to destinations.

$Z_{S E}$ is a binary variable taking unity if a husband has worked in a micro-firm over his last four

individuals with no missing information, who were born in 1989 or before.

${ }^{30}$ First level of Egypt's administrative subdivision.

${ }^{31}$ Respondents who were not born in Egypt were assigned an average distance based on their first governorate of residence in Egypt.

${ }^{32}$ The average distance is also weighted by the share, and its inverse, of migrants by destination countries. This yields similar estimates. Estimates are available on request. 
Figure 4.3 - Average distance from governorate of birth to destination countries in kilometers

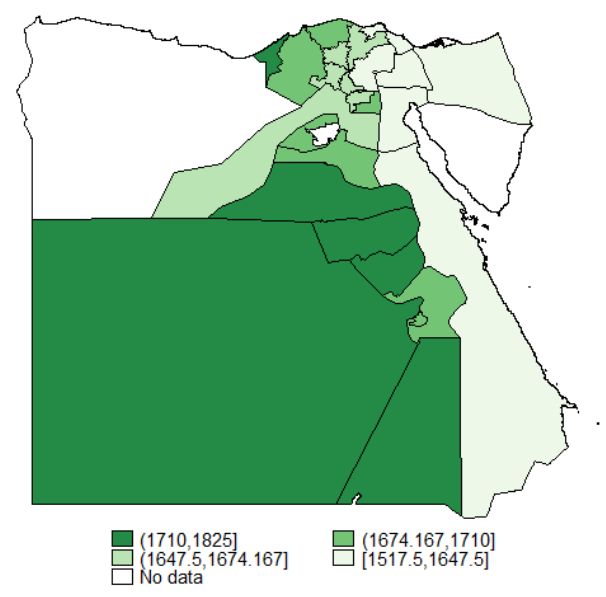

job spells, assumed to influence occupational choice through the accumulation of entrepreneurial skills or abilities. It is assumed to influence occupational choice through the accumulation of entrepreneurial skills or abilities. Micro and small enterprises tend to lack complex hierarchical structures, and are less likely to be highly-specialised workplaces. Working conditions give employees the opportunity to perform a variety of tasks. Performing various tasks might then increase their propensity to start up a firm by developing generalistic skills via learning-by-doing (Stuetzer et al., 2013). Table 4.1 indicates that self-employed are more likely to have worked in a micro-enterprise than employees (69.2 against $43.0 \%)$.

Last, $X_{O}$ includes a set of potential determinants of their time use was added in the Occupation equation, such as age, literacy, mother's educational background, family size, under 15 and above 65 dependency ratios, governorate-level lagged unemployment rate, share of agricultural work and public sector work, and the proportion of the population with at least secondary education.

\subsubsection{Data source}

This analysis uses the last wave of a longitudinal and nationally representative household survey, the ELMPS, administrated since 1998 by the Economic Research Forum in cooperation with the Central Agency for Public Mobilization and Statistics. The ELMPS is made up of four waves - 1988, 1998, 2006 and 2012 - the last three constituting a three-round panel. The ELMPS contains information on a variety of topics. Modules on labour market outcomes and time use (4-6), women's empowerment (7) and (international) return migration (10) ${ }^{33}$ are of particular interest in this chapter. This chapter uses the 2012 round as a cross-section since some variables only collected in the last wave are used. More details on data collection are available in Assaad and Kraft (2013).

The estimation sample includes married women of reproductive age, i.e. between ages 15 and

\footnotetext{
${ }^{33}$ This chapter uses this newly added module on return migration that surveys individuals aged between 15 and 59, who worked abroad for at least six months, to classify individuals as return migrants.
} 
49, whose husbands are of working age (16-64) and born before $1990 .{ }^{34}$ The sample excludes individuals who changed jobs after the January 2011 Uprising. It is also limited to those whose first destination country was an Arab country, as listed in Bertoli and Marchetta (2015) Algeria, Iraq, Jordan, Kuwait, Lebanon, Libya, Oman, Qatar, Saudi Arabia, Syria, United Arab Emirates and Yemen. This helps to focus better on the effects induced by temporary migration since (i) Egyptians emigrating to Western countries tend to stay permanently; and (ii) the majority of Egyptians emigrates to Arab countries. In equations (1) and (2), the unit of observation is married men aged 16-64, living in Egypt at the time of the survey. In equation (3), the unit of observation is married women aged 15-49, i.e. of reproductive age, whose husbands are residing in Egypt at the time of the survey. Table 4.1 presents the estimation sample, obtained after dropping observations with missing information, for the full sample 6,902 married couples.

Returnee is a binary variable taking unity if a working-age (16-64 year-old) married man (husband) $h$ has worked at least six months abroad. Self Employed is a binary variable taking unity if a working-age married man is currently self-employed. Occupation, with $j=1,2,3,4$, is alternatively a set of binary variables taking value 1 if a married woman (wife) $w$ has been engaged in paid market labour (1), unpaid market labour contributing to their family enterprise (2), subsistence work (farming for own consumption) (3) or domestic chores (4) in the last seven days. It also includes a corresponding set of continuous variables measuring the number of hours spent on each of these activities. Outcome categories are not mutually exclusive. The set of binary variables captures the decision to participate in an activity, i.e. the extensive margin, whereas the set of continuous variables captures the intensive margin.

\subsubsection{Descriptive statistics}

Table 4.1 shows that $99.1 \%$ of Egyptian women of our full estimation sample engage in domestic work; $14.2 \%$ carry out paid labour outside their household; $4.1 \%$ contribute to their family businesses as unpaid worker; and $18.1 \%$ participate in farming for their own household's consumption. These statistics are in line with the developments outlined above. Egypt is a rather traditional, conservative society, and time allocation is gender differentiated, with women more likely to engage in household chores and subsistence farming, than in paid work outside their household. Their relatively low contribution to the family enterprise might be explained by the censored nature of this variable, as slightly less than $25 \%$ of sampled men have self-employed activities. On average, women have spent 5.03 hours working outside their household in the last seven days; 1.23 hours contributing to their husbands' enterprises; 1.45 hours on subsistence farming; and, 22.8 hours on domestic chores. ${ }^{35}$

The women in the sample are on average 32 years old. $25.9 \%$ are illiterate; $54.3 \%$, literate

\footnotetext{
${ }^{34}$ No return migrants are reported in the database for individuals born after 1990. Respondents born in 1990 or after are excluded to avoid potential bias in the use of the identification strategy of this chapter.

${ }^{35}$ However, these statistics should be interpreted with caution, since they do not account for the censored nature of these variables, as suggested by relatively high standard deviations.
} 
with intermediate education or less; the rest, literate with more than intermediate education. ${ }^{36}$ $21.1 \%$ had a mother who was literate at their fifteenth birthday, a proxy for coming from a wealthier family. In contrast, $16.95 \%$ of men come from a wealthier family, $18.6 \%$ are illiterate, and $59.9 \%$ have at least high school education. Households are made of, on average, almost 5 members, the under 15 (child) dependency ratio (37.8\%), being much greater than the above 65 (elderly) (1.22). 43.7\% of interviewed households lived in urban areas at the time of the survey. $13.1 \%$ of sampled men have ever worked abroad for at least six months. Women married to return migrants, either before or after their migration, are, on average, significantly older, less educated and from poorer families than women married to men who have never migrated for work. Similarly, men who migrated are on average significantly less educated and from poorer families than men who did not. Table 4.1 suggests that women married to returnees are more likely to engage in, and to spend more time on, both paid and unpaid work outside their household, as well as farming for own consumption.

$24.5 \%$ of sampled men are self-employed (primary occupation), either as own-account workers or employers, at the time of the survey. Women whose husbands are self-employed are on average older, less educated, and come from less wealthy families than those whose husbands are not self-employed, as are self-employed men compared to wage-employed. Women living in households with family businesses appear less likely to engage in paid activities on the labour market, but more likely to contribute to the family enterprise or to engage in subsistence work, compared to women who are not.

Limiting the sample to couples in which husbands have temporarily migrated for work, women whose husbands are self-employed are significantly less educated than those married to employees. So are men who opted for self-employment upon return to Egypt compared to returnees observed as employees. Women living in households with family businesses appear less likely to engage in paid activities on the labour market, but more likely to contribute to the family enterprise or to engage in subsistence work, compared to women whose husbands are not self-employed. They tend to spend more time contributing to their family enterprises, as well as farming for their own consumption, but less on paid, outside work, or domestic chores than women whose husbands migrated but who are not self-employed.

Table 4.1 thus indicates that women's time allocation is related to their husbands' migration experience and occupational choice. That women married to return migrants or self-employed have a greater likelihood to contribute to their family work or to subsistence work suggests a distribution of task between household members. The high percentage of women engaging in domestic work - almost $100 \%$ - and the number of hours spent on average - at least 22 hours a week - whichever the status of their husbands, follow the same line and highlight the prevalence of traditional gender norms in Egypt. That women married to men who opted for self-employment upon return have a lower propensity to engage in paid labour outside their family compared to those married to employed returnees suggests that women's time might be somewhat captured by their husbands setting up firms.

\footnotetext{
${ }^{36}$ In the ELMPS, below intermediate education includes literacy without diploma, elementary and middle school; intermediate education means general and most of vocational high school; and above intermediate education refers to post-secondary and university education.
} 
Table 4.1 - Descriptive statistics of estimation sample

\begin{tabular}{|c|c|c|c|c|c|c|c|c|}
\hline & \multicolumn{2}{|c|}{ Full sample } & \multicolumn{2}{|c|}{ By migration } & \multicolumn{2}{|c|}{ By occupation } & \multicolumn{2}{|c|}{ Retu. } \\
\hline & & & Retu. & Stay. & Self. & Empl. & Self. & Empl. \\
\hline & Mean & S.D. & Mean & Mean & Mean & Mean & Mean & Mean \\
\hline Participated in paid work (W) & .142 & .349 & .175 & .137 & .076 & .164 & .084 & .220 \\
\hline Participated in unpaid work (W) & .041 & .198 & .074 & .036 & .111 & .018 & .164 & .030 \\
\hline Participated in subsistence work (W) & .181 & .385 & .259 & .169 & .257 & .1556 & .326 & .227 \\
\hline Participated in domestic work (W) & .991 & .097 & .991 & .991 & .988 & .991 & .987 & .993 \\
\hline Hours spent on paid work (W) & 5.03 & 13.0 & 5.99 & 4.88 & 2.72 & 5.78 & 2.80 & 7.57 \\
\hline Hours spent on unpaid work (W) & 1.23 & 6.69 & 2.23 & 1.08 & 3.47 & .511 & 5.01 & .866 \\
\hline Hours spent on subsistence work (W) & 1.45 & 4.70 & 11.3 & 7.60 & 8.62 & 7.90 & 2.80 & 2.01 \\
\hline Hours spent on domestic work (W) & 22.8 & 13.7 & 23.7 & 22.6 & 22.8 & 22.7 & 22.6 & 24.2 \\
\hline Hirschman-Herfindahl* (W) & .874 & .201 & .827 & .881 & .855 & .880 & .818 & .831 \\
\hline Keeble-Hauser* (W) & .927 & .117 & .900 & .931 & .916 & .931 & .893 & .903 \\
\hline Age $(W)$ & 31.7 & 8.10 & 35.6 & 31.1 & 32.9 & 31.3 & 36.2 & 35.3 \\
\hline Illiterate $(\mathrm{W})$ & .259 & .438 & .315 & .25 & .369 & .223 & .436 & .255 \\
\hline $\begin{array}{l}\text { Literate with intermediate } \\
\text { education or below }(\mathrm{W})\end{array}$ & .543 & .4982 & .549 & .543 & .498 & .558 & .473 & .586 \\
\hline $\begin{array}{l}\text { Literate with more } \\
\text { than intermediate education }(\mathrm{W})\end{array}$ & .198 & .399 & .136 & .208 & .133 & .2193 & .091 & .159 \\
\hline Literate mother $(\mathrm{W})$ & .212 & .409 & .160 & .220 & .173 & .224 & .138 & .171 \\
\hline Literate mother $(\mathrm{H})$ & .170 & .375 & .116 & .178 & .134 & .181 & .087 & .131 \\
\hline Illiterate $(\mathrm{H})$ & .186 & .389 & .211 & .182 & .298 & .150 & .339 & .1474 \\
\hline Literate (without diploma) $(\mathrm{H})$ & .050 & .218 & .062 & .048 & .065 & .045 & .067 & .060 \\
\hline Elementary school $(\mathrm{H})$ & .109 & .312 & .100 & .1105 & .141 & .100 & .131 & .084 \\
\hline Middle school $(\mathrm{H})$ & .056 & .231 & .046 & .058 & .051 & .058 & .047 & .045 \\
\hline High school $(\mathrm{H})$ & .370 & .483 & .435 & .361 & .3 & .393 & .322 & .490 \\
\hline Post-secondary, university and higher $(\mathrm{H})$ & .229 & .420 & .148 & .241 & .146 & .255 & .094 & .174 \\
\hline Returnee $(\mathrm{H})$ & .131 & .337 & 1.00 & .000 & .176 & .116 & 1.00 & 1.00 \\
\hline Self-employed $(\mathrm{H})$ & .245 & .430 & .330 & .232 & 1.00 & .000 & 1.00 & .000 \\
\hline Microenterprise $(\mathrm{H})$ & .494 & .500 & .784 & .451 & .692 & .430 & .906 & .724 \\
\hline Vocational high-school (H) & .349 & .477 & .417 & .339 & .279 & .372 & .315 & .467 \\
\hline Father was self-employed (H) & .381 & .486 & .467 & .368 & .548 & .327 & .547 & .427 \\
\hline Past self-employment $(\mathrm{H})$ & .049 & .216 & .100 & .042 & .089 & .036 & .188 & .056 \\
\hline First job was self-employed $(\mathrm{H})$ & .061 & .239 & .029 & .066 & .198 & .016 & .050 & .018 \\
\hline Years of unemployment $(\mathrm{H})$ & .552 & 1.57 & .563 & .550 & .425 & .593 & .420 & .634 \\
\hline Agriculture $(\mathrm{H})$ & .159 & .366 & .203 & .153 & .323 & .106 & .383 & .114 \\
\hline Real exchange rate MA(5) (22) (H) & 6.39 & 1.51 & 5.76 & 6.49 & 6.13 & 6.48 & 5.62 & 5.83 \\
\hline Distance $(\mathrm{H})$ & 1.684 & .0378 & 1.681 & 1.686 & 1.688 & 1.684 & 1.682 & 1.680 \\
\hline Household size & 4.60 & 1.77 & 5.06 & 4.53 & 4.92 & 4.50 & 5.31 & 4.94 \\
\hline Under 15 dependency ratio & .378 & .205 & .359 & .381 & .390 & .375 & .365 & .356 \\
\hline Above 65 dependency ratio & .012 & .048 & .017 & .011 & .013 & .012 & .014 & .018 \\
\hline 2007 Unemployment & .090 & .032 & .089 & .091 & .087 & .092 & .086 & .090 \\
\hline 2007 Agriculture & .331 & .182 & .370 & .325 & .356 & .323 & .380 & .365 \\
\hline 2007 Secondary education/higher & .371 & .080 & .359 & .373 & .362 & .374 & .354 & .362 \\
\hline 2007 Public sector & .258 & .067 & .243 & .260 & .248 & .261 & .238 & .245 \\
\hline Urban & .437 & .496 & .336 & .453 & .399 & .450 & .272 & .368 \\
\hline Observations & & & 902 & 6,000 & 1,690 & 5,212 & 298 & 604 \\
\hline
\end{tabular}

Notes: Summary statistics for variables included in the analysis. The sample consists of 6,902 married couples 6,902 working-age (16-64 year-old) men and their respective wives, aged 15-49. Means between treated (returnees, self-employed and returnee self-employed) and control groups (respectively stayers, employees and returnee employees) statistically significantly different at the 10 percent significance level are in bold. (W) describes wives' covariates; (H), husbands'. *Statistics computed for 6,850 non-missing observations. 
It is worth noting the extent of similarities between husbands and wives in terms of education and (original) family background. Women married to return migrants, to self-employed or to migrants who are self-employed upon return, are relatively less educated and come from poorer households than women who are not, as (male) returnees, self-employed and migrants who are self-employed at the time of the survey are compared to (male) stayers, wage-employed workers or returnees who are wage-employed. This is consistent with the existence of assortative mating between spouses as well as household livelihood strategies and time use gender differentiation. Lastly, it should be noted that the real exchange rate is significantly lower for return migrants compared to non-migrants, consistent with the exchange acting as a factor encouraging emigration. The average distance from governorate of birth to potential destination countries is also significantly lower for return migrants compared to migrants. This is line with the previous section suggesting that distance proxies costs to migrate - the closer the average distance to destination countries, the greater the likelihood to migrate.

\subsection{Results}

\subsubsection{Benchmark specifications}

Tables 4.2 and 4.3 present GSEM reduced-form coefficient estimates of a SUR linear probability model of husband's return migration and self-employment, and wives' time use. Table 4.2 reports coefficient estimates of the decision to engage in non mutually exclusive activities in the last seven days (extensive margin) - paid market work (column 1), unpaid market work (2), subsistence work (3) or domestic work (4). Table 4.3 reports coefficient estimates of the number of hours a woman has spent on such activities (intensive margin) in the last seven days.

Husbands' work experience in a micro-firm appears to significantly increase their propensity to be self-employed at the time of the survey, in line with Stuetzer et al. (2013). F-statistics and associated p-values testing the strength of the real exchange rate interacted with the average distance to destination countries are reported. It is strong and relevant across all model specifications, except two. While the interaction of these two variables has a significant and negative association with temporary migation, estimates from equation (1) run with only one of these variables, presented in Table $\mathrm{C} 1$, confirm that the exchange rate and the average distance to destination countries decrease the probability to migrate, in line with the assumptions made in section 3. Table $\mathrm{C} 2$ presents the average marginal effects of the real exchange rate on the probability of return migration, holding migration distance constant at different values by increment of $25 \mathrm{kms}$. These simple slopes for the real exchange rate are significant for all values of migration distance, and decrease in migration distance. Table $\mathrm{C} 2$, combined with Figure $\mathrm{C} 1$, plotting slopes for each value of migration distance, suggests that the importance of the real exchange rate as a pull factor for emigrating increases the further the average migration distance between respondents' governorates of birth and destination countries. This is as if the real exchange rate and the average migration distance compensated each other: the further a respondent is from the average destination country, i.e. the more discouraging migrating might 
be, the stronger the pulling effect of the real exchange rate to emigrate.

Tables 4.2 and 4.3 indicate that having a father who was self-employed, having been selfemployed in their first job, and having worked in a microfirm tend to increase the probability of working-age men being self-employed. Vocational training and past self-employment experiences decrease self-employment propensity, suggesting that varied, non self-employed jobs are required prior to starting a business. Family size and the need to support children tend to increase the likelihood of self-employment, maybe out of necessity. The likelihood to migrate decreases in education and wealth of the family men come from.

The marginal effects of being married to a return migrant on women's time use are displayed at the bottom of each table. Columns (1)-(4) of Table 4.2 indicate that husbands' migration significantly decreases women's likelihood to engage in paid market work, provided that men opt for self-employment upon return, by 8.92 percentage points. It increases their probability of contributing to (unpaid) family work by 10.5 percentage points, to participate in subsistence work by 13.5, and in domestic work by 1.20. Intensive margin coefficient estimates are in line with extensive margins, as Table 4.3 shows. Irrespective of their decision to participate, being married to a return migrant significantly decreases wives' time spent on paid market work over the last seven days, upon establishment of a firm upon return to Egypt, by 3.52 hours. However, it increases the number of hours spent contributing to family work, as unpaid worker (3.15 hours), to farming for own consumption (.99), and to domestic chores (1.65).

Benchmark estimates indicate a significant causal relationship between women's time allocation and husbands' migration through occupational interdependence - either in deciding to engage in, or how much time to spend on, certain activities. The lower probability of engaging in paid market labour, as self- or wage-employed, and the greater probability to contribute to family work suggests that there are few, if any, transfers of (business-related) knowledge between spouses. It also indicates that their husbands' occupation does not act as a role model, since women do not show a greater probability of following in their husbands' footsteps as selfemployed.

These estimates do not support the existence of wealth transfers between spouses. Migrationinduced wealth might not be big enough, husbands' activities might not be remunerative enough or gender norms too conservative for women to get into paid work outside their households. Traditional gender norms in Egypt - and the induced gender differentiation of its labour force - could explain the low statistical significance for domestic work. Given the increase in contributing to their family firms, it seems clear that having migrated and setting up a business upon return captures some of one's wife's time, potentially increasing the time burden placed on women. However, the existence of gender differentiated tasks combined with some degree of assortative mating in terms of education and family wealth could result in income source diversification or risk-sharing strategies within households, between spouses, as suggested by the statistically significant positive marginal effects on subsistence work.

If women's likelihood to engage in market work, either paid or unpaid, and subsistence work increases with age, literacy increases their propensity to engage in paid work outside the household, and decreases their propensity to contribute to family, unpaid, and subsistence 
work. Coming from a relatively wealthy family increases their probability of participating in paid market work, and decreases their probability of engaging in subsistence farming. This is consistent with education as 'signalling' women's abilities on the labour market.

Family size is associated with a lower likelihood to engage in paid market work, and with a higher likelihood to engage in unpaid market work and subsistence work. Moreover, a higher child dependency ratio is related to a greater likelihood to work outside their household, but a smaller likelihood to engage in subsistence farming. Only household level variables appear to significantly affect women's participation in domestic work: the more children to family size, the greater their likelihood to engage in domestic chores, accounting for household size. This may result from a greater labour burden placed on women given the existence of gender differentiation of tasks between family members.

Regional - governorate - variables show a significant and negative relationship between lagged unemployment rate and paid and unpaid market work, and a positive one, between lagged share of population working in agriculture and paid, unpaid and subsistence work. The relationship between the lagged proportion of people having at least secondary education and unpaid market work and subsistence farming is positive as well, but the one between living in an urban area and unpaid market work or subsistence farming is negative.

\subsubsection{Heterogenous effects}

The robustness of benchmark estimates is further investigated to changes in the estimation sample to understand which subgroups drive the migration effect found on wives' time use. In Table 4.4, regressions are run separately by location, by husbands' sector of occupation and by women's skill level. The effects seem to be particularly driven by women working in nonagricultural sectors, those living in urban areas, and literate women with intermediate education or less.

In spite of substantial differences between urban and rural environments, ${ }^{37}$ households implement livelihood strategies in both urban and rural areas. In rural areas, the focus is on natural assets and environmental sustainability, whereas they concentrate on housing and financial assets in urban ones, since urban economies have greater commercialisation, and most basic goods - food, accommodation - must be bought or rented through a market. Vulnerable urban households might need more cash revenue to survive compared to rural families who could rely more easily on subsistence farming or in-kind payments, and who might have a greater access to common property infrastructure (Wratten, 1995; Satterthwaite, 1997).

\footnotetext{
${ }^{37}$ These include differences in vulnerable contexts, in capital assets, in access to assets and entitlements, in policies and in desired livelihood outcomes.
} 
Table 4.2 - SUR reduced-form coefficient estimates, extensive margin

\begin{tabular}{|c|c|c|c|c|c|c|}
\hline Variables & $\begin{array}{l}\text { Paid market } \\
\text { work } \\
(1)\end{array}$ & $\begin{array}{c}\text { Unpaid market } \\
\text { work } \\
(2)\end{array}$ & $\begin{array}{c}\text { Subsistence } \\
\text { work } \\
(3)\end{array}$ & $\begin{array}{c}\text { Domestic } \\
\text { work } \\
(4)\end{array}$ & $\begin{array}{c}\text { Self- } \\
\text { employed } \\
(5)\end{array}$ & $\begin{array}{c}\text { Returnee } \\
\quad(6)\end{array}$ \\
\hline Age $(W)$ & $\begin{array}{c}0.0123^{* * *} \\
(0.0006)\end{array}$ & $\begin{array}{c}0.0010^{* * *} \\
(0.0003)\end{array}$ & $\begin{array}{c}0.0019^{* * *} \\
(0.0007)\end{array}$ & $\begin{array}{c}0.0002 \\
(0.0002)\end{array}$ & & \\
\hline At least literate $(\mathrm{W})$ & $\begin{array}{c}0.1235^{* * *} \\
(0.0092)\end{array}$ & $\begin{array}{c}-0.0437 * * * \\
(0.0070)\end{array}$ & $\begin{array}{c}-0.0772^{* * *} \\
(0.0124)\end{array}$ & $\begin{array}{c}0.0001 \\
(0.0030)\end{array}$ & & \\
\hline Literate mother $(\mathrm{W})$ & $\begin{array}{c}0.1170^{* * *} \\
(0.0124)\end{array}$ & $\begin{array}{c}0.0020 \\
(0.0040)\end{array}$ & $\begin{array}{c}-0.0216^{* *} \\
(0.0093)\end{array}$ & $\begin{array}{l}-0.0021 \\
(0.0027)\end{array}$ & & \\
\hline Household size & $\begin{array}{c}-0.0198^{* * *} \\
(0.0030)\end{array}$ & $\begin{array}{c}0.0086^{* * *} \\
(0.0023)\end{array}$ & $\begin{array}{c}0.0185^{* * *} \\
(0.0038)\end{array}$ & $\begin{array}{c}-0.0027^{* *} \\
(0.0011)\end{array}$ & $\begin{array}{c}0.0096^{* * *} \\
(0.0031)\end{array}$ & $\begin{array}{c}0.0133^{* * *} \\
(0.0029)\end{array}$ \\
\hline $\begin{array}{l}\text { Under } 15 \\
\text { dependency ratio }\end{array}$ & $\begin{array}{c}0.0754^{* * *} \\
(0.0232)\end{array}$ & $\begin{array}{l}-0.0035 \\
(0.0131)\end{array}$ & $\begin{array}{c}0.0093 \\
(0.0253)\end{array}$ & $\begin{array}{c}0.0230^{* * *} \\
(0.0075)\end{array}$ & $\begin{array}{c}0.0197 \\
(0.0241)\end{array}$ & $\begin{array}{c}-0.1061^{* * *} \\
(0.0220)\end{array}$ \\
\hline $\begin{array}{l}\text { Above } 65 \\
\text { dependency ratio }\end{array}$ & $\begin{array}{l}-0.0390 \\
(0.0829)\end{array}$ & $\begin{array}{c}0.1000 \\
(0.0614)\end{array}$ & $\begin{array}{c}0.3355^{* * *} \\
(0.1144)\end{array}$ & $\begin{array}{l}-0.0305 \\
(0.0305)\end{array}$ & & \\
\hline 2007 Agriculture & $\begin{array}{c}0.1455^{* * *} \\
(0.0480)\end{array}$ & $\begin{array}{c}0.0812^{* * *} \\
(0.0200)\end{array}$ & $\begin{array}{c}0.5471^{* * *} \\
(0.0485)\end{array}$ & $\begin{array}{c}0.0216 \\
(0.0156)\end{array}$ & & \\
\hline 2007 Secondary education & $\begin{array}{c}0.0914 \\
(0.1049)\end{array}$ & $\begin{array}{c}0.1674^{* * *} \\
(0.0509)\end{array}$ & $\begin{array}{c}1.2548^{* * *} \\
(0.1161)\end{array}$ & $\begin{array}{c}0.0514 \\
(0.0367)\end{array}$ & & \\
\hline 2007 Public sector & $\begin{array}{l}-0.0338 \\
(0.0845)\end{array}$ & $\begin{array}{c}0.0495 \\
(0.0369)\end{array}$ & $\begin{array}{c}0.0548 \\
(0.0783)\end{array}$ & $\begin{array}{c}0.0237 \\
(0.0279)\end{array}$ & $\begin{array}{c}-0.2892^{* * *} \\
(0.0840)\end{array}$ & \\
\hline 2007 Unemployment & $\begin{array}{c}-0.5869^{* * *} \\
(0.1624)\end{array}$ & $\begin{array}{c}-0.8217^{* * * *} \\
(0.0968)\end{array}$ & $\begin{array}{l}-0.1062 \\
(0.1769)\end{array}$ & $\begin{array}{l}-0.0254 \\
(0.0535)\end{array}$ & $\begin{array}{l}-0.1556 \\
(0.1784)\end{array}$ & \\
\hline Urban & $\begin{array}{c}0.0111 \\
(0.0093)\end{array}$ & $\begin{array}{c}-0.0200^{* * * *} \\
(0.0047)\end{array}$ & $\begin{array}{c}-0.1693^{* * *} \\
(0.0095)\end{array}$ & $\begin{array}{l}-0.0008 \\
(0.0023)\end{array}$ & $\begin{array}{c}0.0020 \\
(0.0095)\end{array}$ & \\
\hline Microenterprise (H) & $\begin{array}{c}-0.0351^{* * *} \\
(0.0080)\end{array}$ & $\begin{array}{c}0.0412^{* * * *} \\
(0.0043)\end{array}$ & $\begin{array}{c}0.0530 * * * \\
(0.0089)\end{array}$ & $\begin{array}{c}0.0047^{* *} \\
(0.0022)\end{array}$ & $\begin{array}{c}0.2090^{* * * *} \\
(0.0097)\end{array}$ & \\
\hline Vocational (H) & & & & & $\begin{array}{c}-0.0544^{* * *} \\
(0.0094)\end{array}$ & \\
\hline Father self-employed (H) & & & & & $\begin{array}{c}0.1127^{* * *} \\
(0.0103)\end{array}$ & \\
\hline Past self-employment (H) & & & & & $\begin{array}{c}-0.1558^{* * *} \\
(0.0326)\end{array}$ & \\
\hline First job self-employed $(\mathrm{H})$ & & & & & $\begin{array}{c}0.6631^{* * *} \\
(0.0204)\end{array}$ & \\
\hline Years unemployed $(\mathrm{H})$ & & & & & $\begin{array}{c}0.0046 \\
(0.0030)\end{array}$ & \\
\hline Exchange rate $\mathrm{X}$ Distance & & & & & $\begin{array}{c}-0.0102^{* * *} \\
(0.0020)\end{array}$ & $\begin{array}{c}-0.0191^{* * *} \\
(0.0017)\end{array}$ \\
\hline Literate mother $(\mathrm{H})$ & & & & & & $\begin{array}{c}-0.0201^{*} \\
(0.0104)\end{array}$ \\
\hline Literate (w/o diploma) $(\mathrm{H})$ & & & & & & $\begin{array}{c}0.0153 \\
(0.0217)\end{array}$ \\
\hline Elementary sch. $(\mathrm{H})$ & & & & & & $\begin{array}{l}-0.0050 \\
(0.0153)\end{array}$ \\
\hline Middle sch. (H) & & & & & & $\begin{array}{l}-0.0257 \\
(0.0185)\end{array}$ \\
\hline High sch. $(\mathrm{H})$ & & & & & & $\begin{array}{c}0.0355^{* * * *} \\
(0.0123)\end{array}$ \\
\hline Post-sec., uni. and higher $(\mathrm{H})$ & & & & & & $\begin{array}{c}-0.0320^{* *} \\
(0.0131)\end{array}$ \\
\hline Constant & $\begin{array}{c}-0.3076^{* * *} \\
(0.0581)\end{array}$ & $\begin{array}{l}-0.0365 \\
(0.0271)\end{array}$ & $\begin{array}{c}-0.5150^{* * *} \\
(0.0598)\end{array}$ & $\begin{array}{c}0.9580^{* * *} \\
(0.0221)\end{array}$ & $\begin{array}{c}0.2280^{* * *} \\
(0.0385)\end{array}$ & $\begin{array}{c}0.3142^{* * *} \\
(0.0278)\end{array}$ \\
\hline$\frac{\gamma_{2}}{\alpha_{2}} \cdot \frac{\alpha_{3}}{\delta_{2}}$ & $\begin{array}{c}-.0892^{* * *} \\
(.0281)\end{array}$ & $\begin{array}{c}.1047^{* * *} \\
(.0254)\end{array}$ & $\begin{array}{c}.1349^{* * *} \\
(.0370)\end{array}$ & $\begin{array}{l}.0120^{*} \\
(.0062)\end{array}$ & & \\
\hline Observations & 6,902 & 6,902 & 6,902 & 6,902 & 6,902 & 6,902 \\
\hline Variance of errors & $\begin{array}{c}0.1091^{* * *} \\
(0.0026)\end{array}$ & $\begin{array}{c}0.0364^{* * *} \\
(0.0019)\end{array}$ & $\begin{array}{c}0.1293^{* * *} \\
(0.0024)\end{array}$ & $\begin{array}{c}0.0093^{* * *} \\
(0.0011)\end{array}$ & $\begin{array}{c}0.1459^{* * *} \\
(0.0025)\end{array}$ & $\begin{array}{c}0.1090^{* * *} \\
(0.0028)\end{array}$ \\
\hline F-statistic (returnee) & & & & & & 127.79 \\
\hline P-value (returnee) & & & & & & .0000 \\
\hline
\end{tabular}

Notes: Outcome variables are binary variables taking value 1 if an individual has spent time on paid market work (1), unpaid market work (2), subsistence work (3) or domestic work (4) in the last seven days; 0, otherwise. Outcome categories are not mutually exclusive. In columns (1)-(4), observations are for married women in reproductive age; in columns (5)-(6), observations are for their respective husbands. Columns (1)-(4) present GSEM coefficient estimates of women's time use equations; column (5), of their husbands' self-employment propensity; and column (6), of their husbands' return migration propensity. Standard errors robust to heteroskedasticity are in parentheses. ${ }^{* * *} \mathrm{p}<0.01,{ }^{* *} \mathrm{p}<0.05,{ }^{*} \mathrm{p}<0.1$. 
Table 4.3 - SUR reduced-form coefficient estimates, intensive margin

\begin{tabular}{|c|c|c|c|c|c|c|}
\hline & $\begin{array}{l}\text { Paid market } \\
\text { work }\end{array}$ & $\begin{array}{l}\text { Unpaid market } \\
\text { work }\end{array}$ & $\begin{array}{l}\text { Subsistence } \\
\text { work }\end{array}$ & $\begin{array}{l}\text { Domestic } \\
\text { work }\end{array}$ & $\begin{array}{c}\text { Self- } \\
\text { employed }\end{array}$ & Returnee \\
\hline Variables & (1) & $(2)$ & $(3)$ & $(4)$ & $(5)$ & $(6)$ \\
\hline Age (W) & $\begin{array}{c}0.4296^{* * *} \\
(0.0234)\end{array}$ & $\begin{array}{c}0.0339^{* * *} \\
(0.0112)\end{array}$ & $\begin{array}{c}0.0132 \\
(0.0084)\end{array}$ & $\begin{array}{c}0.0778^{* * *} \\
(0.0236)\end{array}$ & & \\
\hline At least literate $(\mathrm{W})$ & $\begin{array}{c}4.1625^{* * *} \\
(0.3506)\end{array}$ & $\begin{array}{c}-1.4307^{* * *} \\
(0.2389)\end{array}$ & $\begin{array}{c}-0.7599 * * * \\
(0.1544)\end{array}$ & $\begin{array}{c}0.4753 \\
(0.4314)\end{array}$ & & \\
\hline Literate mother (W) & $\begin{array}{c}4.2042^{* * *} \\
(0.4631)\end{array}$ & $\begin{array}{l}-0.0102 \\
(0.1237)\end{array}$ & $\begin{array}{c}-0.2257^{* *} \\
(0.0992)\end{array}$ & $\begin{array}{l}-0.4461 \\
(0.4079)\end{array}$ & & \\
\hline Household size & $\begin{array}{c}-0.7461^{* * *} \\
(0.1040)\end{array}$ & $\begin{array}{c}0.2246^{* * *} \\
(0.0774)\end{array}$ & $\begin{array}{c}0.1799^{* * *} \\
(0.0524)\end{array}$ & $\begin{array}{l}-0.2186^{*} \\
(0.1212)\end{array}$ & $\begin{array}{c}0.0096^{* * *} \\
(0.0031)\end{array}$ & $\begin{array}{c}0.0133^{* * *} \\
(0.0029)\end{array}$ \\
\hline $\begin{array}{l}\text { Under } 15 \\
\text { dependency ratio }\end{array}$ & $\begin{array}{c}2.5444^{* * *} \\
(0.8392)\end{array}$ & $\begin{array}{l}-0.0320 \\
(0.4326)\end{array}$ & $\begin{array}{l}-0.0507 \\
(0.3174)\end{array}$ & $\begin{array}{c}5.6343^{* * *} \\
(0.9055)\end{array}$ & $\begin{array}{c}0.0197 \\
(0.0241)\end{array}$ & $\begin{array}{c}-0.1061^{* * *} \\
(0.0220)\end{array}$ \\
\hline $\begin{array}{l}\text { Above } 65 \\
\text { dependency ratio }\end{array}$ & $\begin{array}{l}-1.3134 \\
(2.9861)\end{array}$ & $\begin{array}{l}3.7199^{*} \\
(2.1846)\end{array}$ & $\begin{array}{l}2.4120^{*} \\
(1.3513)\end{array}$ & $\begin{array}{c}3.9218 \\
(3.3155)\end{array}$ & & \\
\hline 2007 Agriculture & $\begin{array}{c}5.3432^{* * *} \\
(1.8071)\end{array}$ & $\begin{array}{c}2.6901^{* * *} \\
(0.6743)\end{array}$ & $\begin{array}{c}4.6094^{* * *} \\
(0.6794)\end{array}$ & $\begin{array}{c}6.1844^{* * *} \\
(1.9911)\end{array}$ & & \\
\hline 2007 Secondary education & $\begin{array}{c}5.4811 \\
(3.9443)\end{array}$ & $\begin{array}{c}6.3770^{* * *} \\
(1.7242)\end{array}$ & $\begin{array}{c}11.0276^{* * *} \\
(1.5955)\end{array}$ & $\begin{array}{c}32.1458^{* * *} \\
(4.4992)\end{array}$ & & \\
\hline 2007 Public sector & $\begin{array}{l}-4.0488 \\
(3.1245)\end{array}$ & $\begin{array}{l}-0.0316 \\
(1.0896)\end{array}$ & $\begin{array}{c}-2.2422^{* * *} \\
(0.8251)\end{array}$ & $\begin{array}{c}-36.8279^{* * *} \\
(3.3831)\end{array}$ & $\begin{array}{c}-0.2892^{* * *} \\
(0.0840)\end{array}$ & \\
\hline 2007 Unemployment & $\begin{array}{c}-16.9440^{* * *} \\
(6.0832)\end{array}$ & $\begin{array}{c}-24.3983^{* * *} \\
(3.3700)\end{array}$ & $\begin{array}{l}-2.0835 \\
(2.0627)\end{array}$ & $\begin{array}{c}31.3729 * * * \\
(6.7211)\end{array}$ & $\begin{array}{l}-0.1556 \\
(0.1784)\end{array}$ & \\
\hline Urban & $\begin{array}{l}0.6737^{*} \\
(0.3477)\end{array}$ & $\begin{array}{c}-0.4568^{* * *} \\
(0.1701)\end{array}$ & $\begin{array}{c}-1.3124^{* * *} \\
(0.1135)\end{array}$ & $\begin{array}{c}1.9829 * * * \\
(0.3632)\end{array}$ & $\begin{array}{c}0.0020 \\
(0.0095)\end{array}$ & \\
\hline Microenterprise $(\mathrm{H})$ & $\begin{array}{c}-1.3829 * * * \\
(0.2991)\end{array}$ & $\begin{array}{c}1.2361^{* * *} \\
(0.1409)\end{array}$ & $\begin{array}{c}0.3883^{* * *} \\
(0.1103)\end{array}$ & $\begin{array}{l}0.6494^{*} \\
(0.3326)\end{array}$ & $\begin{array}{c}0.2090^{* * *} \\
(0.0097)\end{array}$ & \\
\hline Vocational (H) & & & & & $\begin{array}{c}-0.0544^{* * *} \\
(0.0094)\end{array}$ & \\
\hline Father self-employed $(\mathrm{H})$ & & & & & $\begin{array}{c}0.1127^{* * *} \\
(0.0103)\end{array}$ & \\
\hline Past self-employment $(\mathrm{H})$ & & & & & $\begin{array}{c}-0.1558^{* * *} \\
(0.0326)\end{array}$ & \\
\hline First job self-employed $(\mathrm{H})$ & & & & & $\begin{array}{c}0.6631^{* * *} \\
(0.0204)\end{array}$ & \\
\hline Years unemployed $(\mathrm{H})$ & & & & & $\begin{array}{c}0.0046 \\
(0.0030)\end{array}$ & \\
\hline Exchange rate $\mathrm{X}$ Distance & & & & & $\begin{array}{c}-0.0102^{* * *} \\
(0.0020)\end{array}$ & $\begin{array}{c}-0.0191^{* * * *} \\
(0.0017)\end{array}$ \\
\hline Literate mother $(\mathrm{H})$ & & & & & & $\begin{array}{l}-0.0201^{*} \\
(0.0104)\end{array}$ \\
\hline Literate (w/o diploma) (H) & & & & & & $\begin{array}{c}0.0153 \\
(0.0217)\end{array}$ \\
\hline Elementary sch. $(\mathrm{H})$ & & & & & & $\begin{array}{l}-0.0050 \\
(0.0153)\end{array}$ \\
\hline Middle sch. (H) & & & & & & $\begin{array}{l}-0.0257 \\
(0.0185)\end{array}$ \\
\hline High sch. (H) & & & & & & $\begin{array}{c}0.0355^{* * *} \\
(0.0123)\end{array}$ \\
\hline Post-sec., uni. and higher $(\mathrm{H})$ & & & & & & $\begin{array}{c}-0.0320^{* *} \\
(0.0131)\end{array}$ \\
\hline Constant & $\begin{array}{c}-10.9067^{* * *} \\
(2.1832)\end{array}$ & $\begin{array}{l}-1.3000 \\
(0.8939)\end{array}$ & $\begin{array}{c}-3.6670^{* * *} \\
(0.7859)\end{array}$ & $\begin{array}{c}10.3650 * * * \\
(2.4934)\end{array}$ & $\begin{array}{c}0.2280^{* * * *} \\
(0.0385)\end{array}$ & $\begin{array}{c}0.3142^{* * *} \\
(0.0278)\end{array}$ \\
\hline$\frac{\gamma_{2}}{\alpha_{2}} \cdot \frac{\alpha_{3}}{\delta_{2}}$ & $\begin{array}{c}-3.521^{* * *} \\
(1.077)\end{array}$ & $\begin{array}{c}3.147^{* * *} \\
(.7781)\end{array}$ & $\begin{array}{c}.9885^{* * *} \\
(.3538)\end{array}$ & $\begin{array}{l}1.653^{*} \\
(.9159)\end{array}$ & & \\
\hline Observations & 6,902 & 6,902 & 6,902 & 6,902 & 6,902 & 6,902 \\
\hline Variance of errors & $\begin{array}{c}151.5985^{* * *} \\
(4.6151)\end{array}$ & $\begin{array}{c}42.0660^{* * *} \\
(3.3187)\end{array}$ & $\begin{array}{c}20.6857^{* * *} \\
(2.3926)\end{array}$ & $\begin{array}{l}180.4451^{* * *} \\
(6.5041)\end{array}$ & $\begin{array}{c}0.1459^{* * *} \\
(0.0025)\end{array}$ & $\begin{array}{c}0.1090^{* * *} \\
(0.0028)\end{array}$ \\
\hline $\begin{array}{l}\text { F-statistic (returnee) } \\
\text { P-value (returnee) }\end{array}$ & & & & & & $\begin{array}{c}127.79 \\
.0000\end{array}$ \\
\hline
\end{tabular}

Notes: Outcome variables are continuous variables measuring hours an individual has spent on paid market work (1), unpaid market work (2), subsistence work (3) or domestic work (4) in the last seven days; 0, otherwise. Outcome categories are not mutually exclusive. In columns (1)-(4), observations are for married women in reproductive age; in columns (5)-(6), observations are for their respective husbands. Columns (1)-(4) present GSEM coefficient estimates of women's time use equations; column (5), of their husbands' self-employment propensity; and column (6), of their husbands' return migration propensity. Standard errors robust to heteroskedasticity are in parentheses. ${ }^{* * *} \mathrm{p}<0.01,{ }^{*} \mathrm{p}<0.05,{ }^{*} \mathrm{p}<0.1$. 
Although a strict distinction between rural and urban household systems might be oversimplifying, ${ }^{38}$ gender norms affecting how women and men use their time might differ between urban and rural areas. Egyptian rural households are more likely to be conservative than urban households, which could affect the degree of gender stratification of local labour markets, and therefore time allocation, across locations. In addition to location-specific assets and opportunities, the nature of household diversification strategies across family members could thus differ between rural and urban areas. Urban women could engage in domestic services or urban agriculture; rural women could work in home gardening, vending, casual labour, etc.

The signs of the coefficient estimates are similar to those of the benchmark results, but their magnitudes differ by location. Both rural and urban women show a greater likelihood to engage in subsistence work due to their husbands' migration and self-employment upon return. But rural women display a much greater probability of contributing to family work, and a weaker probability of getting out of paid market labour than urban women. Marginal effects for hours spent on each activity point to a greater time burden placed on rural women, as they contribute more to their husbands' businesses. This is in line with a location-specific gender differentiation of labour, since in rural areas, that are more conservative than urban ones, women's time allocation might be significantly more affected by their husbands' migration through the transfer of more conservative gender norms and by their occupation. In other words, women represent a cheap, if not free, labour supply for their enterprise. Estimates might also reflect the fact that rural areas are relatively less commercialised than urban ones. In rural areas, basic goods are less likely to be bought through a market, like in urban areas, but tend to be produced by households themselves.

Running regressions separately by husband's sector of occupation could help to better understand these estimates. Effects could indeed differ by husband's sector of occupation, since the Egyptian agricultural sector has kept a rather traditional structure marked by a high degree of land fragmentation. As a result, a substantial part of individual farmers work on small, lowproductivity plots, unable to benefit from economies of scale, that potentially capture the labour supply available in a household (Morsy et al., 2014). Regressions are run separately for women whose husbands work in agriculture and for those whose husbands work in non-agricultural sectors, following the International Standard Industrial Classification of all economic activities (ISIC4).

In contrast to working in non-agricultural sectors, Table 4.4 reveals that establishing agricultural ventures upon return appears to tie more of women's time to family work, with a greater likelihood of 53.7 percentage points (16.3 additional hours per week) to contribute to their husbands' farms, compared to 4.16 percentage points (1.18 additional hours) to an off-farm family business. This is consistent with a low-return type of agriculture, which is prevalent in Egypt. Women are simultaneously more likely to allocate time to farming for household consumption. Estimates might suggest that differences in results obtained by separately running the analysis for urban and rural households might be driven by the establishment of agricultural

\footnotetext{
${ }^{38}$ Indeed, urban, rural and peri-urban areas are interlinked. Many underlying causes of poverty are the same in these different settings and the spatial relationship between urban and rural areas is dynamic by nature (Farrington et al., 2002).
} 
businesses. Women married to migrants who opted for farming upon return appear more timedeprived than those whose husbands set up non-agricultural businesses. The effects of (male) return migration on women's time use thus seem to be influenced not only by their migrant husbands' employment status, but also by their industry of occupation.

Table 4.4 - Heterogenous effects

\begin{tabular}{|c|c|c|c|c|c|c|c|c|c|}
\hline & & \multicolumn{2}{|c|}{$\begin{array}{c}\text { Paid market } \\
\text { work }\end{array}$} & \multicolumn{2}{|c|}{$\begin{array}{l}\text { Unpaid market } \\
\text { work }\end{array}$} & \multicolumn{2}{|c|}{$\begin{array}{c}\text { Subsistence } \\
\text { work }\end{array}$} & \multicolumn{2}{|c|}{$\begin{array}{c}\text { Domestic } \\
\text { work }\end{array}$} \\
\hline & & $\begin{array}{l}\text { Ext. } \\
(1)\end{array}$ & $\begin{array}{r}\text { Int. } \\
(2)\end{array}$ & $\begin{array}{l}\text { Ext. } \\
(3)\end{array}$ & $\begin{array}{l}\text { Int. } \\
(4)\end{array}$ & $\begin{array}{l}\text { Ext. } \\
(5)\end{array}$ & $\begin{array}{l}\text { Int. } \\
(6)\end{array}$ & $\begin{array}{l}\text { Ext. } \\
(7)\end{array}$ & $\begin{array}{l}\text { Int. } \\
(8)\end{array}$ \\
\hline \multirow[t]{5}{*}{ Benchmark } & $\frac{\gamma_{2}}{\alpha_{2}} \cdot \frac{\alpha_{3}}{\delta_{2}}$ & $-.0892^{* * *}$ & $-3.521^{* * *}$ & $.1047^{* * *}$ & $3.147^{* * *}$ & $.1349^{* * *}$ & $.9885^{* * *}$ & $.0120^{*}$ & $1.653^{*}$ \\
\hline & & $(.0281)$ & (1.077) & $(.0254)$ & $(.7781)$ & $(.0370)$ & $(.3538)$ & $(.0062)$ & $(.9159)$ \\
\hline & F-statistic (returnee) & 127.79 & 127.79 & 127.79 & 127.79 & 127.79 & 127.79 & 127.79 & 127.79 \\
\hline & P-value (returnee) & .0000 & .0000 & .0000 & .0000 & .0000 & .0000 & .0000 & .0000 \\
\hline & $\mathrm{N}$ & 6,902 & 6,902 & 6,902 & 6,902 & 6,902 & 6,902 & 6,902 & 6,902 \\
\hline \multirow[t]{4}{*}{ Agriculture } & $\frac{\gamma_{2}}{\alpha_{2}} \cdot \frac{\alpha_{3}}{\delta_{2}}$ & $\begin{array}{l}-.0264 \\
(0543)\end{array}$ & $\begin{array}{l}-1.414 \\
(2.147)\end{array}$ & $\begin{array}{l}.5367^{* *} \\
(.2071)\end{array}$ & $\begin{array}{c}16.27^{* *} \\
(6.343)\end{array}$ & $\begin{array}{c}.4573 \\
(.1984)\end{array}$ & $\begin{array}{c}3.367 \\
(2.152)\end{array}$ & $\begin{array}{c}-.0316 \\
(.0268)\end{array}$ & $\begin{array}{c}4.222 \\
(3.819)\end{array}$ \\
\hline & F-statistic (returnee) & $\begin{array}{l}.0070) \\
12.66\end{array}$ & 12.66 & 12.66 & 12.66 & $\begin{array}{l}.1207) \\
12.66\end{array}$ & 12.66 & 12.66 & 12.66 \\
\hline & P-value (returnee) & .0004 & .0004 & .0004 & .0004 & .0004 & .0004 & .0004 & .0004 \\
\hline & $\mathrm{N}$ & 1,100 & 1,100 & 1,100 & 1,100 & 1,100 & 1,100 & 1,100 & 1,100 \\
\hline \multirow[t]{5}{*}{ Non agriculture } & $\frac{\gamma_{2}}{\alpha_{2}} \cdot \frac{\alpha_{3}}{\delta_{2}}$ & $-.0739^{* *}$ & $-2.906^{* *}$ & $.0416^{* * *}$ & $1.183^{* *}$ & $.0773^{* *}$ & $.5074^{*}$ & $.0135^{* *}$ & 1.014 \\
\hline & & $(.0307)$ & $(1.183)$ & $(.0159)$ & $(.4723)$ & $(.0315)$ & $(.2637)$ & $(.0066)$ & $(.7837)$ \\
\hline & F-statistic (returnee) & 116.15 & 116.15 & 116.15 & 116.15 & 116.15 & 116.15 & 116.15 & 116.15 \\
\hline & P-value (returnee) & .0000 & .0000 & .0000 & .0000 & .0000 & .0000 & .0000 & .0000 \\
\hline & $\mathrm{N}$ & 5,802 & 5,802 & 5,802 & 5,802 & 5,802 & 5,802 & 5,802 & 5,802 \\
\hline \multirow[t]{5}{*}{ Rural } & $\frac{\gamma_{2}}{\alpha_{2}} \cdot \frac{\alpha_{3}}{\delta_{2}}$ & -.0332 & $-1.350^{*}$ & $.1088^{* * *}$ & $3.270 * * *$ & $.1101^{* *}$ & $.6887^{*}$ & .0025 & 1.547 \\
\hline & & $(.0204)$ & $(.7656)$ & $(.0391)$ & $(1.185)$ & $(.0443)$ & $(.3880)$ & $(.0053)$ & $(.9408)$ \\
\hline & F-statistic (returnee) & 88.26 & 88.26 & 88.26 & 88.26 & 88.26 & 88.26 & 88.26 & 88.26 \\
\hline & P-value (returnee) & .0000 & .0000 & .0000 & .0000 & .0000 & .0000 & .0000 & .0000 \\
\hline & $\mathrm{N}$ & 3,883 & 3,883 & 3,883 & 3,883 & 3,883 & 3,883 & 3,883 & 3,883 \\
\hline \multirow[t]{5}{*}{ Urban } & $\frac{\gamma_{2}}{\alpha_{2}} \cdot \frac{\alpha_{3}}{\delta_{2}}$ & $-.2035^{* * *}$ & $-7.898^{* * *}$ & $.0457^{* *}$ & $1.296^{*}$ & $.1199^{* *}$ & $1.230^{* *}$ & $.0303^{* *}$ & 1.629 \\
\hline & & $(.0754)$ & $(2.920)$ & $(.0200)$ & $(.6911)$ & $(.0486)$ & $(.4940)$ & $(.0146)$ & $(1.871)$ \\
\hline & F-statistic (returnee) & 49.34 & 49.34 & 49.34 & 49.34 & 49.34 & 49.34 & 49.34 & 49.34 \\
\hline & P-value (returnee) & .0000 & .0000 & .0000 & .0000 & .0000 & .0000 & .0000 & .0000 \\
\hline & $\mathrm{N}$ & 3,019 & 3,019 & 3,019 & 3,019 & 3,019 & 3,019 & 3,019 & 3,019 \\
\hline \multirow[t]{5}{*}{ Illiterate } & $\frac{\gamma_{2}}{\alpha_{2}} \cdot \frac{\alpha_{3}}{\delta_{2}}$ & $.1067^{*}$ & 2.311 & $.3788^{* * *}$ & $12.12^{* * *}$ & $.3448^{* *}$ & 1.816 & .0022 & 2.876 \\
\hline & & $(.0583)$ & $(2.062)$ & $(.1252)$ & $(4.065)$ & $(.1392)$ & $(1.442)$ & $(.0217)$ & $(3.372)$ \\
\hline & F-statistic (returnee) & 36.68 & 36.68 & 36.68 & 36.68 & 36.68 & 36.68 & 36.68 & 36.68 \\
\hline & P-value (returnee) & .0000 & .0000 & .0000 & .0000 & .0000 & .0000 & .0000 & .0000 \\
\hline & $\mathrm{N}$ & 1,784 & 1,784 & 1,784 & 1,784 & 1,784 & 1,784 & 1,784 & 1,784 \\
\hline \multirow{5}{*}{$\begin{array}{l}\text { Intermediate } \\
\text { education } \\
\text { or below }\end{array}$} & $\frac{\gamma_{2}}{\alpha_{2}} \cdot \frac{\alpha_{3}}{\delta_{2}}$ & -.0242 & $-1.602^{*}$ & $.1534^{* * *}$ & $4.602^{* * *}$ & $.1784^{* * *}$ & $1.259^{* *}$ & .0103 & 1.550 \\
\hline & & $(.0242)$ & $(.9456)$ & $(.0351)$ & $(1.083)$ & $(.0490)$ & $(.4927)$ & $(.0081)$ & $(1.229)$ \\
\hline & F-statistic (returnee) & 117.24 & 117.24 & 117.24 & 117.24 & 117.24 & 117.24 & 117.24 & 117.24 \\
\hline & P-value (returnee) & .0000 & .0000 & .0000 & .0000 & .0000 & .0000 & .0000 & .0000 \\
\hline & $\mathrm{N}$ & 5,534 & 5,534 & 5,534 & 5,534 & 5,534 & 5,534 & 5,534 & 5,534 \\
\hline \multirow{5}{*}{$\begin{array}{l}\text { More than } \\
\text { intermediate } \\
\text { education }\end{array}$} & $\frac{\gamma_{2}}{\alpha_{2}} \cdot \frac{\alpha_{3}}{\delta_{2}}$ & .0714 & 2.168 & -.0062 & -.1414 & -.0219 & -.1336 & -.0163 & -1.517 \\
\hline & & $(.0973)$ & $(3.158)$ & $(.0094)$ & $(.2604)$ & $(.0377)$ & $(.2894)$ & $(.0218)$ & $(2.299)$ \\
\hline & F-statistic (returnee) & 5.86 & 5.86 & 5.86 & 5.86 & 5.86 & 5.86 & 5.86 & 5.86 \\
\hline & P-value (returnee) & 0.0156 & 0.0156 & 0.0156 & 0.0156 & 0.0156 & 0.0156 & 0.0156 & 0.0156 \\
\hline & $\mathrm{N}$ & 1,368 & 1,368 & 1,368 & 1,368 & 1,368 & 1,368 & 1,368 & 1,368 \\
\hline
\end{tabular}

Notes: Please, refer to Tables 2 and 3. 
Estimates could also differ by women's skill level: the higher their level of education, the higher their bargaining power within their family, either through a greater control over resources or through their competencies acting as signal of their abilities. Regressions are run separately for illiterate women, literate women with intermediate education or less, and literate women with more than intermediate education.

Illiterate women see a significant increase in their probability of participating in paid market work outside their household (10.7 percentage points), as well as in contributing to family work (37.9) and farming for their own consumption (34.5), by marrying a migrant who start up a firm upon return to Egypt. In comparison, literate women with intermediate education or below are less likely to engage in outside activities - although the estimate of -2.42 percentage points is not statistically significant - but more likely to contribute to family (14.3) and subsistence work (17.8). Literate women with more than intermediate education do not appear significantly affected by their husbands' migration experience through their occupational choice.

These estimates could result from the extent of within-couple assortative mating if illiterate, poorer women, who are married to men of a similarly low education or poorer background, have to engage in labour outside their household out of survival, in order to better spread risks attached to their husbands' main occupations. Their greater likelihood to take on work outside their households, and to contribute to their husbands' enterprises and to subsistence work compared to literate women, suggests a stronger burden placed on low-educated women. Not only the degree of assortative mating, but also spouses' backgrounds in case of assortative mating could explain couple-specific and (socio-economic) background-specific income diversification strategies. This is consistent with the fact that the more educated women are, the less likely their time allocation seems influenced by their husbands' migration through their occupation. The higher spouses' family and educational background, the less households might need to diversify out of survival - at the cost of women's time. In addition, the higher women's education level is, the greater bargaining power they might have over the use of their time, as their education signals higher productivity in outside work or through greater control over household resources. The link between husbands' return migration and the degree of specialisation and diversification of their wives' time allocation is eventually examined. Instead of a binary or continuous variable indicating the engagement in and time spent on an activity $j$ by a woman $w$, the following Hirschman-Herfindahl index (Herfindahl, 1950; Hirschman, 1964), often used to measure market concentration or economic diversity, is computed:

$$
H H_{w}=\sum_{j=1}^{4}\left(s_{w j}\right)^{2}
$$

where $s_{w j}$ represents the share of hours a woman $w$ dedicated to activity $j$ over the number of hours she spent on these four activities in total in the last seven days. An index of 1 indicates the highest level of specialisation (upper bound), meaning that a small number of activities captures a high proportion of a woman's time. Its lower bound is equal to $1 / j$, i.e. specialisation is at its lowest when a woman equally allocates her time to each of the four possible activities. To lessen the effect of too much weight given to activities capturing most of women's time, Keeble 
and Hauser's (1971) variation of the Hirschman-Herfindahl index is alternatively used:

$$
K H_{w}=\sqrt{\sum_{j=1}^{4}\left(s_{w j}\right)^{2}}
$$

By opting for an absolute measure of specialisation, the degree of differentiation is assumed to be obtained by subtracting the computed index from 1. An index of diversification as such is not used. ${ }^{39}$ Specifications are run for a sample of women who have strictly done more than zero hours of work over the last week. Benchmark estimates are presented in Table 4.4. Table 4.5 repeats the above sensitivity analysis using the Hirshman-Herfindahl index and its variation as outcome variables.

Benchmark estimates of Table 4.5, suggest that men's migration significantly decreases their wives' time specialisation, if their husbands opted for self-employment upon return to Egypt, by 2.72 (Hirschman-Herfindahl index) to 1.67 percentage points (Keeble-Hauser variation).

This holds for rural households and for women whose husbands work in agriculture. Illiterate women diversify their time significantly more than literate women with intermediate education or less (-21.1 to -12.6 against -7.75 to -4.61 percentage points). Literate women with more than intermediate education are not affected.

In the light of the previous set of results obtained by estimating specifications across main occupations independently, these results point to a greater diversification because of women's (greater) involvement in unpaid market work and subsistence work in particular, following the establishment of entrepreneurial activities upon their husbands' return to Egypt. Although the occupational choices of urban women or women whose husbands work in non-agricultural sectors are significantly affected, our measure of specialisation suggests that rural women, women whose husbands are self-employed in agriculture and women with low if any education experience a much stronger reallocation of their time. Their husbands' migration, and self-employment choice upon return, seems to push these groups of women to allocate their time to multiple activities.

\subsection{Concluding remarks}

This chapter contributes to the literature on women's time use in a developing setting with prevalent international migration. A framework of within-couple occupational interdependence was used to investigate how, and how much, husbands' migration and occupational choice upon return can alter their wives' time allocation - which activities they engage in, and how much time they spent on a certain activity. Studying women's choices of occupation is of particular importance, not only to better understand household livelihood strategies, but also because they are a key determinant of their degree of control over household resources, and therefore of their autonomy within and outside their households.

\footnotetext{
${ }^{39}$ The Hirschman-Herfindahl index has indeed been shown to perform best compared to other measures (Palan, 2010).
} 
Table 4.5 - Time specialisation estimates

\begin{tabular}{|c|c|c|c|}
\hline & & $\begin{array}{l}\text { Hirschman- } \\
\text { Herfindahl } \\
\text { (1) }\end{array}$ & $\begin{array}{c}\text { Keeble- } \\
\text { Hauser } \\
\quad(2)\end{array}$ \\
\hline \multirow[t]{4}{*}{ Benchmark } & $\frac{\gamma_{2}}{\alpha_{2}} \cdot \frac{\alpha_{3}}{\delta_{2}}$ & $\begin{array}{c}-.0272^{* *} \\
(.0133)\end{array}$ & $\begin{array}{c}-.0167^{* *} \\
(.0078)\end{array}$ \\
\hline & F-statistic (returnee) & 125.59 & 125.59 \\
\hline & P-value (returnee) & .0000 & .0000 \\
\hline & $\mathrm{N}$ & 6,850 & 6,850 \\
\hline \multirow[t]{4}{*}{ Agriculture } & $\frac{\gamma_{2}}{\alpha_{2}} \cdot \frac{\alpha_{3}}{\delta_{2}}$ & $\begin{array}{c}-.2376^{* *} \\
(.0992)\end{array}$ & $\begin{array}{c}-.1431^{* *} \\
(.0596)\end{array}$ \\
\hline & F-statistic (returnee) & 12.51 & 12.51 \\
\hline & $\mathrm{P}$-value (returnee) & .0004 & .0004 \\
\hline & $\mathrm{N}$ & 1,093 & 1,093 \\
\hline \multirow[t]{4}{*}{ Non agriculture } & $\frac{\gamma_{2}}{\alpha_{2}} \cdot \frac{\alpha_{3}}{\delta_{2}}$ & $\begin{array}{l}-.0025 \\
(.0099)\end{array}$ & $\begin{array}{l}-.0017 \\
(.0057)\end{array}$ \\
\hline & F-statistic (returnee) & 114.05 & 114.05 \\
\hline & P-value (returnee) & .0000 & .0000 \\
\hline & $\mathrm{N}$ & & \\
\hline \multirow[t]{4}{*}{ Rural } & $\frac{\gamma_{2}}{\alpha_{2}} \cdot \frac{\alpha_{3}}{\delta_{2}}$ & $\begin{array}{c}-.0440 * * \\
(.0188)\end{array}$ & $\begin{array}{c}-.0262^{* *} \\
(.0111)\end{array}$ \\
\hline & F-statistic (returnee) & 86.93 & 86.93 \\
\hline & $\mathrm{P}$-value (returnee) & .0000 & .0000 \\
\hline & $\mathrm{N}$ & 3,857 & 3,857 \\
\hline \multirow[t]{5}{*}{ Urban } & $\frac{\gamma_{2}}{\alpha_{2}} \cdot \frac{\alpha_{3}}{\delta_{2}}$ & .0383 & .0210 \\
\hline & & $(.0267)$ & $(.0153)$ \\
\hline & F-statistic (returnee) & 48.30 & 48.30 \\
\hline & $\mathrm{P}$-value (returnee) & .0000 & .0000 \\
\hline & $\mathrm{N}$ & 2,993 & 2,993 \\
\hline \multirow[t]{4}{*}{ Illiterate } & $\frac{\gamma_{2}}{\alpha_{2}} \cdot \frac{\alpha_{3}}{\delta_{2}}$ & $\begin{array}{c}-.2110^{* * *} \\
(.0772)\end{array}$ & $\begin{array}{c}-.1260^{* * *} \\
(.0459)\end{array}$ \\
\hline & F-statistic (returnee) & 35.24 & 35.24 \\
\hline & P-value (returnee) & .0000 & .0000 \\
\hline & $\mathrm{N}$ & 1,768 & 1,768 \\
\hline \multirow[t]{4}{*}{ Intermediate } & $\frac{\gamma_{2}}{\alpha_{2}} \cdot \frac{\alpha_{3}}{\delta_{2}}$ & $\begin{array}{c}-.0775^{* * *} \\
(.0226)\end{array}$ & $\begin{array}{c}-.0461^{* * *} \\
(.0133)\end{array}$ \\
\hline & F-statistic (returnee) & 114.02 & 114.02 \\
\hline & P-value (returnee) & .0000 & .0000 \\
\hline & $\mathrm{N}$ & 5,496 & 5,496 \\
\hline \multirow[t]{4}{*}{ More than } & $\frac{\gamma_{2}}{\alpha_{2}} \cdot \frac{\alpha_{3}}{\delta_{2}}$ & $\begin{array}{l}-.0172 \\
(.0298)\end{array}$ & $\begin{array}{l}-.0094 \\
(.0169)\end{array}$ \\
\hline & F-statistic (returnee) & 6.46 & 6.46 \\
\hline & $\mathrm{P}$-value (returnee) & .0112 & .0112 \\
\hline & $\mathrm{N}$ & 1,354 & 1,354 \\
\hline
\end{tabular}

Notes: Please, refer to Tables 2 and 3. Instead of wives' participation in and number of hours spent of different activities, outcome variables of equation (3) are continuous variables measuring the (absolute) degree of occupational specialisation of women, the Hirschman-Herfindahl index in column (1), and the Keeble-Hauser correction applied to the Hirschman-Herfindahl index in column (2). ${ }^{* * *} \mathrm{p}<0.01,{ }^{* *} \mathrm{p}<0.05,{ }^{*}$ $\mathrm{p}<0.1$. 
Using the 2012 ELMPS, evidence was found of statistically significant relationships between return migration of men and their wives' time use. Reduced-form estimates of a SUR model show that being married to a migrant who opted for self-employment upon return decreases a woman's likelihood to engage in and time spent on paid work, and increases her likelihood to engage in and their contribution to family work and subsistence farming, especially in rural areas. Women whose husbands are self-employed in agriculture upon return contribute relatively more to unpaid family work and to subsistence work than women whose husbands are not, stressing the traditional structure of Egyptian agriculture. Results differ by skill level as illiterate women tend to engage in outside and inside household activities, whereas how literate women with more than intermediate education allocate their time is not significantly affected. Measures of time specialisation suggest that their husbands' migration and self-employment upon return somehow pushes women in rural areas, whose husbands work in agriculture, or women with little, if any, education, to allocate their time to multiple activities.

These results are explained by the existence of occupational interdependence between spouses, most likely in order to diversify income sources, and as a result of assortative mating along time-use gender differentiation lines. Results highlight the necessity to account for the existence of interdependencies between spouses' occupational choices, beyond the existence of traditional norms or gender differentiation of labour. In this framework, return migration might affect nonmigrating wives, even once migration is complete, since spouses' occupations are interdependent in a need for intra-household income diversification and risk sharing. The transfer of conservative norms migrants immersed themselves in destination countries limits women's engagement in outside activities. However, it seems difficult to disentangle this effect from households' economic considerations.

When planning to create a favourable environment for efficient diversification and women's empowerment in Egypt, policymakers should consider the effects of migration and gender differentiated time allocation within households. This is necessary in order to give poor, vulnerable households the means to make the most out of their migration experience. A more efficient allocation of household members' time could allow households to move away from low productivity, subsistence or unpaid activities to more remunerative ones. Because the higher propensity of migrants to set up businesses upon return might disproportionately capture their wives' time, attention should be paid to buffering potentially 'enslaving', depriving migrationinduced effects on women's time use, given the existence of some degree of occupational interdependence between spouses and of gender differentiated labour options offered to women. An optimal allocation of both financial and time resources might not be ensured by men migrating and bringing back resources accumulated abroad used to start up businesses upon return as those limit women's involvement in outside activities, despite contributing to the dynamic Egyptian MSE sector.

Measures should address women's specific needs by not only providing high(er) return work opportunities to women, but also accounting for context-specific time constraints. If not, return migration might increase the time burden placed on women, which is likely to contribute to women's time poverty (Serra, 2009). Strengthening local labour markets could decrease the 
level of occupational interdependence between spouses by encouraging households to substitute women's family work with hired external labour, whereby freeing up women's time. Women would be offered viable outside options, potentially enhancing their autonomy, for a more inclusive growth.

In this analysis, conclusions on women's empowerment were drawn from estimates based on the existing literature. The link between return migration, spouses' occupations and intrahousehold bargaining power has not been formally tested. The induced time diversification that women living in rural areas and illiterate women experience could lead to a decrease in their autonomy, since greater contribution to their husbands' businesses or to subsistence work might not be linked to a greater control over household resources, and could decrease in household efficiency. For instance, Sadania (2017) finds that working outside their households has a stronger empowering effect than working at home on Egyptian women, but that working at home increases their power in investment decisions jointly taken with their spouses. However, Sadania (2017) does not formally test household decision-making, bargaining power and efficiency implications of within-household task allocation and family enterprises. This might be an interesting direction for future research, moreover that returnees have been found to transfer (sometimes conservative) destination country norms (Bertoli and Marchetta, 2015; Tuccio and Wahba, 2015).

Finally, this chapter highlights the importance of occupational interdependence between spouses over other existing channels to explain how migration can affect non-migrating wives in a static setting. Future research could investigate alternative explanations and study dynamics. It could indeed be that family enterprises capture women's time in their start-up phase, but release it in later stages - return migration of husbands would have only transitory effects on their wives' occupational choices in this case. Linking return migration, performance and family participation is also an interesting avenue for research, since the literature has found that dynamics of entry into an occupation differ from those of success. Return migrants' entrepreneurial success, survival or profitability could be related to their wives' occupations in a longer run. 


\subsection{Appendix}

Table C1 - Sensitivity to instrument definition

\begin{tabular}{|c|c|c|c|}
\hline & Returnee & Returnee & Returnee \\
\hline Variables & $(1)$ & $(2)$ & $(3)$ \\
\hline Literate (without diploma) & $\begin{array}{c}0.0162 \\
(0.0217)\end{array}$ & $\begin{array}{c}0.0182 \\
(0.0218)\end{array}$ & $\begin{array}{c}0.0153 \\
(0.0217)\end{array}$ \\
\hline Elementary school & $\begin{array}{l}-0.0044 \\
(0.0153)\end{array}$ & $\begin{array}{l}-0.0157 \\
(0.0155)\end{array}$ & $\begin{array}{l}-0.0050 \\
(0.0153)\end{array}$ \\
\hline Middle school & $\begin{array}{l}-0.0251 \\
(0.0185)\end{array}$ & $\begin{array}{c}-0.0314^{*} \\
(0.0184)\end{array}$ & $\begin{array}{c}-0.0257 \\
(0.0185)\end{array}$ \\
\hline High school & $\begin{array}{c}0.0356^{* * *} \\
(0.0123)\end{array}$ & $\begin{array}{c}0.0267^{* *} \\
(0.0123)\end{array}$ & $\begin{array}{c}0.0355^{* * *} \\
(0.0123)\end{array}$ \\
\hline Post-secondary, university and higher & $\begin{array}{c}-0.0315^{* *} \\
(0.0131)\end{array}$ & $\begin{array}{c}-0.0339^{* * *} \\
(0.0131)\end{array}$ & $\begin{array}{c}-0.0320^{* *} \\
(0.0131)\end{array}$ \\
\hline Literate mother & $\begin{array}{c}-0.0195^{*} \\
(0.0104)\end{array}$ & $\begin{array}{c}-0.0232^{* *} \\
(0.0105)\end{array}$ & $\begin{array}{c}-0.0201^{*} \\
(0.0104)\end{array}$ \\
\hline Household size & $\begin{array}{c}0.0132^{* * *} \\
(0.0029)\end{array}$ & $\begin{array}{c}0.0253^{* * *} \\
(0.0028)\end{array}$ & $\begin{array}{c}0.0133^{* * *} \\
(0.0029)\end{array}$ \\
\hline Under 15 dependency ratio & $\begin{array}{c}-0.1063^{* * *} \\
(0.0221)\end{array}$ & $\begin{array}{c}-0.1413^{* * *} \\
(0.0223)\end{array}$ & $\begin{array}{c}-0.1061^{\text {*** }} \\
(0.0220)\end{array}$ \\
\hline Exchange rate & $\begin{array}{c}-0.0313^{* * *} \\
(0.0029)\end{array}$ & & \\
\hline Distance & & $\begin{array}{c}-0.5540^{* * *} \\
(0.0985)\end{array}$ & \\
\hline Exchange rate $\mathrm{X}$ Distance & & & $\begin{array}{c}-0.0191^{\text {*** }} \\
(0.0017)\end{array}$ \\
\hline Constant & $\begin{array}{c}0.3087^{* * *} \\
(0.0279)\end{array}$ & $\begin{array}{c}1.0053^{* * *} \\
(0.1669)\end{array}$ & $\begin{array}{c}0.3142^{* * *} \\
(0.0278)\end{array}$ \\
\hline Observations & 6,902 & 6,902 & 6,902 \\
\hline R-squared & 0.0397 & 0.0266 & 0.0408 \\
\hline F-statistic (instrument) & 119.86 & 31.63 & 127.79 \\
\hline p-value (instrument) & .0000 & .0000 & .0000 \\
\hline
\end{tabular}

Notes: Please, refer to Tables 4.2 and 4.3. 
Table C2 - Average marginal effects of real exchange rate on the probability of return migration, holding migration distance constant at different values

\begin{tabular}{|c|c|c|c|c|c|c|c|}
\hline & & $\begin{array}{l}\mathrm{dy} / \mathrm{dx} \\
(1)\end{array}$ & $\begin{array}{l}\text { SE } \\
(2)\end{array}$ & $\begin{array}{c}\mathrm{t} \\
(3)\end{array}$ & $\begin{array}{c}\mathrm{p} \text {-value } \\
(4)\end{array}$ & \multicolumn{2}{|c|}{$\begin{array}{l}95 \% \text { Conf. interval } \\
\text { (5) }\end{array}$} \\
\hline \multicolumn{8}{|c|}{ Real exchange rate MA(5) 22} \\
\hline \multirow[t]{10}{*}{ At } & 1.596667 & -.0304703 & .0026955 & -11.30 & 0.000 & -.0357542 & -.0251863 \\
\hline & 1.621667 & -.0309474 & .0027377 & -11.30 & 0.000 & -.036314 & -.0255807 \\
\hline & 1.646667 & -.0314244 & .0027799 & -11.30 & 0.000 & -.0368738 & -.025975 \\
\hline & 1.671667 & -.0319015 & .0028221 & -11.30 & 0.000 & -.0374337 & -.0263694 \\
\hline & 1.696667 & -.0323786 & .0028643 & -11.30 & 0.000 & -.0379935 & -.0267638 \\
\hline & 1.721667 & -.0328557 & .0029065 & -11.30 & 0.000 & -.0385533 & -.0271581 \\
\hline & 1.746667 & -.0333328 & .0029487 & -11.30 & 0.000 & -.0391132 & -.0275525 \\
\hline & 1.771667 & -.0338099 & .0029909 & -11.30 & 0.000 & -.039673 & -.0279468 \\
\hline & 1.796667 & -.034287 & .0030331 & -11.30 & 0.000 & -.0402328 & -.0283412 \\
\hline & 1.821667 & -.0347641 & .0030753 & -11.30 & 0.000 & -.0407926 & -.0287356 \\
\hline
\end{tabular}

Notes: Average marginal effects of the real exchange rate on the probability of return migration, holding the average migration distance (in 1,000 kms) constant at different values by increment of $25\left(0.025^{*} 1,000\right) \mathrm{kms}$. Estimates of column (1) give the amount of change in the probability to be a return migrant with a one unit change in the real exchange rate while holding migration distance constant at different values.

Figure C1 - Slopes for the probability of return migration on real exchange rate, holding the value of migration distance constant

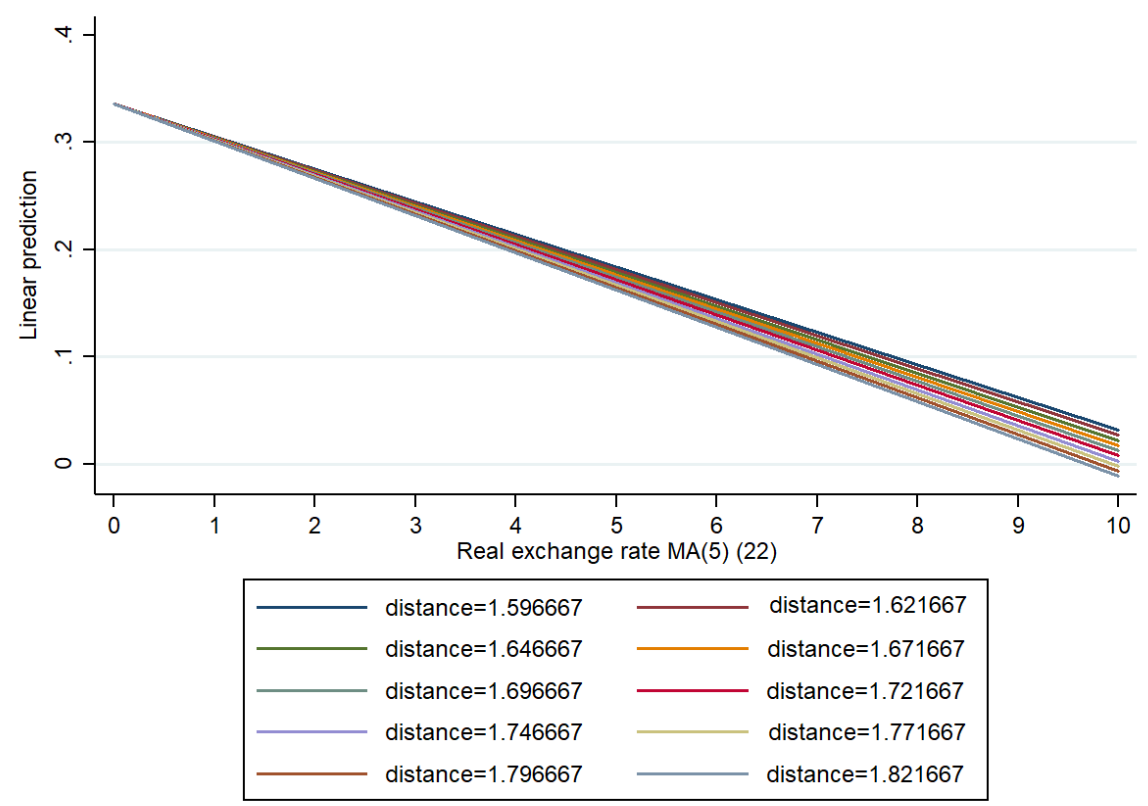





\section{Chapter 5}

\section{Does publicly provided healthcare affect migration?}

\subsection{Introduction}

Publicly provided healthcare has received growing attention in the academic and policy debate. Extending public healthcare is claimed to be one of the most effective ways of reaching universal health coverage (Jamison et al., 2013). Positive impacts on health and poverty are more and more acknowledged (Finkelstein and McKnight, 2008; Limwattananon et al., 2015). Still, concerns about adverse labour market effects, such as disincentives to work or switching from formal to informal work, have been raised (Cutler et al., 1996; Gruber and Simon, 2008; Levy and Schady, 2013). Overall, empirical evidence on labour market outcomes remains mixed. ${ }^{1}$

By providing (near-)poor households with the means to deal with risk, not only might noncontributory health insurance affects labour market behaviours, it might simultaneously alter household livelihood strategies. However, relationships between social health protection ${ }^{2}$ and livelihood strategies have not attracted much scrutiny. Since Stark and Bloom's (1985) New Economics of Labour Migration (NELM), one of these, migrating, has been seen as a coping strategy - a means for households to respond to shocks (Sabates-Wheeler and Waite, 2003). In this sense, accessing different sources of living, in kind or in cash, through publicly provided

This chapter is based on Mahé, C. (2017). Does publicly provided healthcare affect migration? Evidence from Mexico. UNU-MERIT Working Paper 2017-049, Maastricht: United Nations University Maastricht Economic and Social Research Institute on Innovation and Technology. I would like to thank Raymundo Miguel Campos-Vázquez for sharing data on Seguro Popular beneficiaries. I am furthermore grateful to Carlo Alcaraz, Wim Naudé, Sergio Parra-Cely, Isabel Ruiz, Melissa Siegel and Judit Vall Castelló, who provided comments, suggestions and encouragements.

${ }^{1}$ For a review, see Ravallion (2003); for evidence from the United States (US), Baicker et al. (2014), Dave et al. (2015) or Garthwaite et al. (2014); for evidence from Mexico, Azuara and Marinescu (2013), Bosch and Campos-Vázquez (2014) or del Valle (2016).

${ }^{2}$ Social health protection refers to policy initiatives that aim at protecting individuals from health risks through good quality of care and financial protection from health and care shocks. In this regard, non-contributory health insurance is a means to ensure financial protection in the healthcare sector (Arsenijevic et al., 2015). 
healthcare could affect the need to migrate (Hagen-Zanker and Leon-Himmelstine, 2013). Providing healthcare for free could directly affect migration by relaxing financial constraints, reducing the occurrence and duration of health shocks, and therefore enabling (healthier) working-age household members to migrate. It could indirectly influence migration through its effects on local labour markets by inducing them to reallocate time from care giving to working outside their households, for instance prompting their entry into the labour market, which might involve migrating.

In analysing the dynamics between publicly provided healthcare and labour force attachment of working-age members in affiliated households, this chapter aims at shedding light on the mixed evidence on the links between publicly provided healthcare and labour market behaviours often found in the literature. Because of their very focus on recipients and household members who live with them, considering spatial mobility by looking at implications for migration, that is including non-resident household members and household members who (might have) migrated in the analysis, could explain the heterogeneity in existing results. Household affiliation to healthcare might enable working-age beneficiaries to migrate, who would then 'disappear' from estimation samples. Not accounting for the potential effects of social (health) protection programmes on the likelihood to migrate might question the reliability of results obtained for labour market outcomes.

Moreover, in studying specifically whether publicly provided healthcare helps surmount financial and care constraints, this chapter clarifies the migration decision-making process as well as livelihood strategies. Given the documented effects of migration on development, ${ }^{3}$ adding evidence on whether migration complements or substitutes for social (health) policies could give insights into what prevents migration. This is necessary to improve the design and target of policies seeking to remove impediments to mobility for those who could benefit from welfare gains, and to leverage the contribution of migration to the development of origin communities (Cazzuffi and Modrego, 2017).

To assess how migration relates to publicly provided healthcare, this analysis exploits the random expansion of the programme Sistema de Protección Social en Salud, introduced in Mexico in 2003, that aims at improving economic resilience through access to health services (almost) for free. Offered to some 50 million Mexicans without social security, it institutionalised a pilot programme, Seguro Popular de Salud, running from October 2002 to December 2003, that has gradually expanded across Mexico. I take advantage of the timing of the Mexican Life Satisfaction Survey (MxFLS), a three-wave household panel conducted from 2002, before the start of Seguro Popular pilot phase, to 2009. A difference-in-differences specification is used to compare changes in migration between individuals living in municipalities where this programme was introduced earlier and individuals living in municipalities where it was implemented later. The panel structure of the MxFLS allows controlling for endogenous migration by assigning changes in coverage to individuals based on their municipality of residence at the beginning of each time period. This chapter focuses on short-run effects on internal and international

\footnotetext{
${ }^{3}$ On the positive development impacts of migration, see for instance Adams and Page (2005); on its negative effects, see Portes (2006) or Vullnerati and King (2008).
} 
migration. Effects on health status, time use, health-related shocks and credit worthiness are also taken into account.

Exposure to a change in coverage is found to raise internal migration, but to have a statistically insignificant effect on international migration. Estimates suggest that access to publicly provided healthcare might play a role in reducing credit and care constraints, enabling workingage household members to migrate in families vulnerable to adverse shocks. It appears to free up caregivers' time and strengthen household economic resilience in the face of health-related shocks. In contrast to contributory healthcare that tends to crowd out migration by tying affiliates to formal employment and so a specific location, non-contributory healthcare seems to complement, rather than substitute for, alternative livelihood strategies. Placebo tests confirm the validity of the identification strategy against threats of time-trending unobservables, and suggest that changes in migration propensity prior to the programme were negatively correlated with its expansion.

The rest of this chapter is structured as follows. Section 5.2 describes how access to free healthcare could affect migration, section 5.3, Mexico's health insurance system and section 5.4, data and estimation strategy. Section 5.5 presents results. Section 5.6 concludes.

\subsection{Publicly provided healthcare and migration}

Departing from neo-classical models, ${ }^{4}$ later theoretical approaches, such as the NELM, consider migration as a decision made within a household to maximise wealth, diversify income sources between household members and across space, and minimise risks (Stark and Bloom, 1985). In this regard, migrating can be viewed as an informal livelihood coping strategy (Sabates-Wheeler and Waite, 2003). Whether and which household members migrate is decided jointly by those likely to migrate and those likely to stay behind, to support migrants or benefit from their migration, through the receipt of remittances for instance. The decision to migrate depends on opportunities inside and outside households' places of residency, costs induced by moving and being absent, number and share of household dependants, and credit constraints - deciding to migrate is determined by financial and care (time) constraints.

Assuming that household members share their resources, accessing alternative sources of livelihoods thanks to safety nets, such as healthcare, could influence the decision to migrate directly or indirectly through effects on labour market behaviours. Figure 5.1 depicts these dynamics. By reducing the occurrence and duration of health shocks and health-related expenditures, publicly provided healthcare is expected to improve beneficiaries' health statuses, increase their disposable income and limit working-age members' time dedicated to caring for (potentially sick) dependants.

On one hand, by minimising health-related shocks and expenditures, publicly provided healthcare might reduce the need to diversify income sources, i.e. working outside one's household and relocating its labour force. In a cost-benefit analysis, labour, migration and safety nets would be substitutes in this case. Accessing healthcare would crowd out work and

\footnotetext{
${ }^{4}$ See, for instance, Harris and Todaro's (1970) model of rural-urban wage differences.
} 
migration, since households and individuals would not have to rely on the labour market and migration to minimise risks. In addition, the opportunity costs of migrating would increase, if it implies losing health insurance coverage. The alleviation of financial constraints would induce working-age members to work less or not to work, and hence, not to migrate.

On the other hand, non-contributory healthcare could support affiliated households and their working-age members in looking for work, locally or outside their communities of origin. This could be effected by improving health and enabling the relocation of their labour force and financial resources, previously used to tackle household (dependant) and individual health shocks, towards remunerative activities outside their households. Healthcare, labour and migration would be complements. This might be particularly relevant in a context of imperfect labour markets where it is difficult and costly to hire non-household members to care for dependants.

Indeed, by specifically targeting the incidence and dissemination of communicable diseases (Knaul et al., 2006), Sosa-Rubi et al. (2009), Pfutze (2015) and Conti and Ginja (2016) showed that the introduction of Seguro Popular has led to significant improvements in healthcare use and health status in Mexico. ${ }^{5}$ Evidence from a randomized experiment in Kenya also reveals that health insurance limits stress and cortisol levels (Haushofer et al., 2017). After investigating several channels, the authors conclude that, akin to a 'peace of mind' effect, the simple fact of having coverage improves sleep, in particular among more vulnerable people. That affiliation to healthcare improves physical and mental health is likely to enhance the productivity of workingage affiliates, which could strengthen their ability to migrate, consistent with a 'healthy emigrant effect'. 6

Second, if financial constraints hinder the capacity of households to send migrants away, access to healthcare, i.e. a punctual but exogenous source of income, could relieve such constraints and alter the degree of labour attachment of working-age members in affiliated households (Hagen-Zanker and Leon-Himmelstine, 2013). By limiting daily and catastrophic health expenditures, and thus increasing disposable income, non-contributory healthcare could not only boost consumption, but also be used to directly finance migration. Bryan et al. (2014) show that, when households were randomly assigned a financial incentive in rural Bangladesh, $22 \%$ of recipient families sent a member away during the pre-harvest lean season. By limiting risks induced by migration, this cash incentive contributed to diversify income sources through migration.

Non-contributory healthcare could also be used to finance migration indirectly. Programme entitlement has been shown to relax binding financial constraints. For instance, Angelucci (2015) shows that poor households' entitlement to an exogenous source of income through Oportunidades ${ }^{7}$ increased emigration to the United States (US). Although cash transfers were

\footnotetext{
${ }^{5}$ For further evidence on the effect of health insurance on healthcare use, see for instance Kondo and Shigeoka (2013) for Japan, Limwattananon et al. (2015) for Thailand or Bernal et al. (2017) for Peru.

${ }^{6}$ Migrating often involves many obstacles. The literature suggests that only the fittest, and hence healthiest, would successfully emigrate. The harder such obstacles, the stronger the positive health selection (Jasso et al., 2004).

${ }^{7} \mathrm{~A}$ Mexican conditional cash transfer (CCT) programme giving cash to households with children, conditional on children regularly attending school, visiting health clinics and looking after their diet.
} 
mainly consumed, families who could not previously afford to migrate, used entitlement to Oportunidades as collateral to ask for loans and finance migration.

By enabling households to overcome financial constraints, access to healthcare could thus directly or indirectly help households by supporting working-age members in looking for work, which might involve migrating. This is in line with evidence on other non-contributory programmes such as the Old Age Grant, a pension scheme targeting the elderly in South Africa. Inder and Maitra (2004), Posel et al. (2006), Sienaert (2008) and Ardington et al. (2009) have indeed found that non-contributory pension programmes induced migration within multi-generational households by alleviating budget constraints, whereby enabling working-age members to search for (and eventually find) work in urban areas.

If there is any effect, effects might differ depending on household composition. Because women tend to bear the greatest care giving burden in Mexican households, Seguro Popular might have differential impacts across gender. Affiliation might affect women's entry into the labour market in source communities rather than - or before - their propensity to migrate. Since women are more likely to take care of dependants than men, accessing health coverage might push women to enter the (informal) labour market, as shown by del Valle (2016), now freed from caring for their dependants.

Since access to public healthcare is conditional on not working in the formal sector, Seguro Popular could affect the decision to work in the informal sector by increasing the non-monetary benefits of informal work (Bosch and Campos-Vázquez, 2014; Azuara and Marinescu, 2013) and the relative price of formal (health) insurance (Gruber and Madrian, 1994). Moreover, this could encourage formal workers with employer-based health insurance to become informal with publicly provided, cheaper if not free, health insurance, and dissuade informal workers from becoming formal. The associated increase in disposable income and decrease in time constraints might not be significant enough to prompt women to migrate. In contrast, men, less likely to take care of dependants compared to women, might show greater labour attachment flexibility. Upon affiliation to healthcare coverage, they might be more likely to leave source households in order to further diversify household income sources. Gender-differentiated evidence from South Africa for instance shows that, when women are those affiliated, other family members, in particular men, tend to migrate (Sienaert, 2008). Women would simultaneously work (parttime) outside of their households and take care of household dependants, as del Valle (2016) points out.

Moreover, since international migration tends to be more costly than internal migration, and as the entitlement to Seguro Popular does not represent an exogenous stream of income as such, but rather an increase in disposable income due to a reduction in health expenditures, this insurance might be more likely to affect internal than international migration. Existing empirical findings suggest that safety nets have different, often opposite effects on domestic and global migration. While Chau et al. (2012), Inder and Maitra (2004), Posel et al. (2006), Sienaert (2008) and Ardington et al. (2009) have confirmed a positive effect of safety nets on internal migration via its funding channel, Angelucci (2015) does not find a consistent effect of Oportunidades on internal migration. Internal and international migration bear different costs. 
Internal migration is less expensive and less risky, since conditions to migrate internally are easier to meet (Stecklov et al., 2005). International migration might only be affected when it is not more costly than internal migration, which is unlikely to be the case.

Figure 5.1 - Linkages between publicly provided healthcare and migration

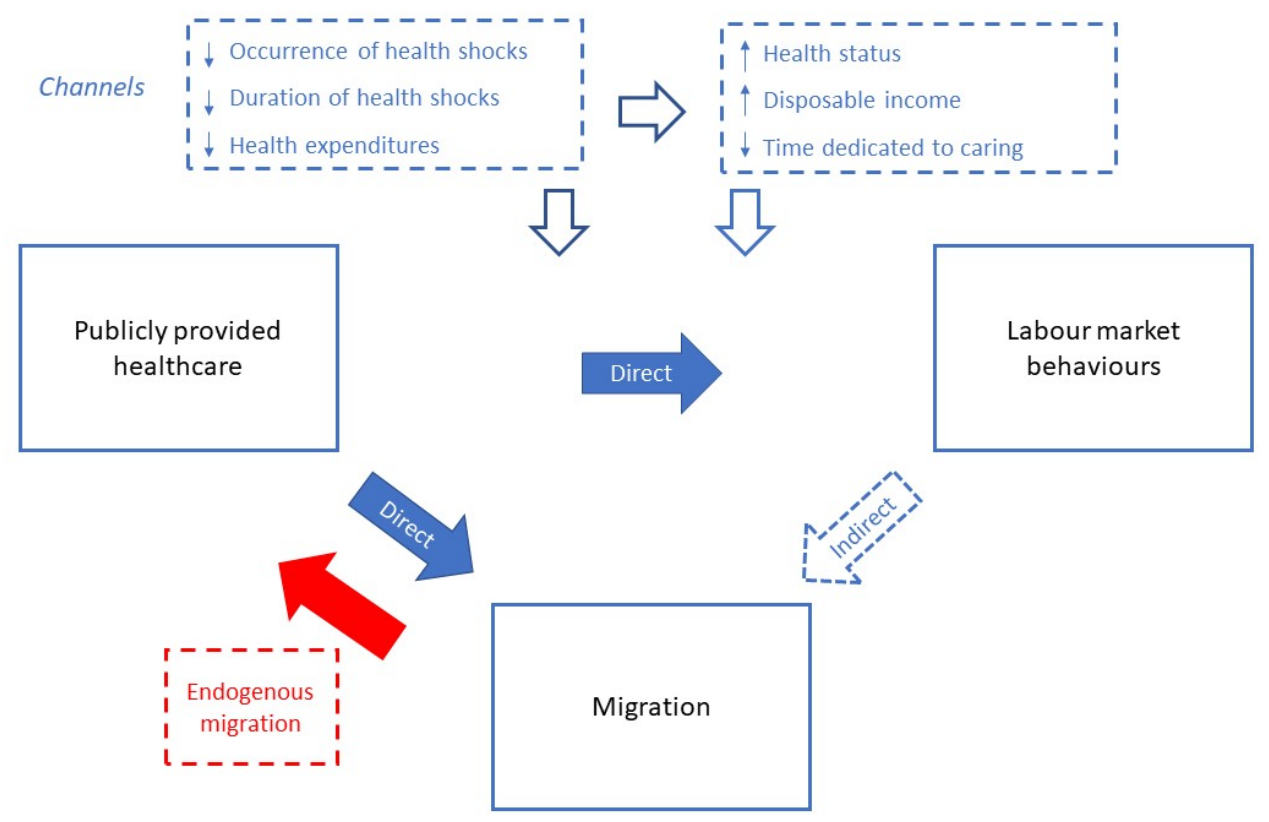

\subsection{Mexico's health insurance system}

Mexico's health system is divided into two sectors. Health services are provided upon contributions to social security institutions run by the government - mainly the Instituto Mexicano del Seguro Social (IMSS, Mexican Social Security Institute) in the private sector and the Instituto de Seguridad y Servicios Sociales de los Trabajadores del Estado (ISSSTE, Social Security and Services Institute for Public Workers) in the public sector. They are accessed through formally registered employers. Those out of the labour force or working in the informal sector - about half the population - access a small number of underfunded services through the Secretaria de Salud (SS, Ministry of Health). As a result, there have been major gaps in resource allocation and inequalities between beneficiaries of these two healthcare systems (Frenk et al., 2009).

For this reason, the Sistema de Protección Social en Salud was introduced in 2003 to improve financial strength through health services. Offered to some 50 million individuals without social security, it guarantees subsidised, publicly provided basic universal healthcare services - essential primary and secondary services and high-complexity healthcare interventions, medication, laboratory and cabinet analyses. Affiliates have access to medical-surgical, pharmaceutical and hospital services to meet their health needs. It currently offers coverage to 275 medical interventions, as well as services that support people who do not have access to 
formal social security, and who suffer from high-cost diseases that can put their lives and family assets at risk. This programme has eliminated fees for services and drugs, removed access to health services and extended the supply of health services through medical infrastructure.

Healthcare is provided almost for free, ${ }^{8}$ only to those not covered by any social security institution. To be affiliated, individuals must reside in Mexico and may not benefit from any other social security institutions. They can apply for (nuclear) family affiliation on a voluntary basis, ${ }^{9}$, after providing the necessary information for a socio-economic evaluation of the family. ${ }^{10}$ If an affiliate happens to be outside her place of residence, she is covered, for medical emergencies and in case of patients in transit, as long as her policy is in force and she can refer to her entity of origin. ${ }^{11}$

Seguro Popular was introduced in October 2002 with a pilot phase in five states and then expanded in stages. 14 additional states adopted it until December 2003. As shown by Figure 5.2, expansion was relatively fast, with almost full coverage reached in 2011 (Pfutze, 2015). Although the roll-out of the programme in principle gave priority to the poorest areas with sufficient healthcare infrastructure, political and logistical considerations might have played a role (Barros, 2008; Díaz-Cayeros et al., 2006). Governors decided when to participate, and had some degree of autonomy in choosing when the programme would be implemented in eligible municipalities. However, others have concluded that its introduction was close to random with regard to ex-ante (2000) covariates at the municipality and state levels such as income, number of uninsured, industrial structure, informality and labour market outcomes (Aterido et al., 2010; Azuara and Marinescu, 2013; Bosch and Campos-Vázquez, 2014; del Valle, 2016).

Following these studies, the analysis exploits the random expansion of Seguro Popular at the municipality level to examine its effect on migration propensity, as in del Valle (2016). It is argued that random variation in roll-out can be identified by focusing on municipalities where Seguro Popular was introduced in its expansion phase - in the middle of its roll-out - from 2004 onwards. Municipalities that experienced a significant change in coverage from 2002 to 2004, i.e. in its pilot phase, are excluded. Following Alcaraz et al. (2016), treated municipalities are defined as municipalities where the change in coverage from the last quarter of 2004 to 2008 was at least $10 \%$ or greater. Control municipalities are those where the change in coverage was strictly less than $10 \%$ in both the 2002-2004 and 2004-2008 periods. Municipalities where the change in coverage was at least $10 \%$, but strictly less than $20 \%$, are excluded. This is done to ensure estimates are not biased by treatment contagion (Alcaraz et al., 2016). This would

\footnotetext{
${ }^{8}$ For a detailed review of this initiative, see Bosch et al. (2012).

${ }^{9}$ That is (i) spouses or cohabiting partners, (ii) parents who are not married, (iii) children younger than 18 years old, (iv) minors who are part of the household and are related to spouses by blood, partners or parents, (v) single children up to 25 years old who can prove to be students, (vi) dependant disabled children, (vii) straight-line direct ancestors over 64 years of age, who are economic dependants and live in the same household, and (viii) persons not related to spouses, partners or parents, but who live in the same house and depend economically on it and are under 18 or disabled dependant of any age.

${ }^{10} \mathrm{Such}$ as proof of address, a unique code of population registry, birth certificate, official identification with photograph of the person who acts as family head, receipt of payment for the corresponding family fee, except in the case of households that enter the non-contributory regime due to their socio-economic status.

${ }^{11}$ To receive the services offered by Seguro Popular in a hospital or health centre in another state, an affiliate must submit either a voting card, a Mexican passport or a military service primer.
} 
be the case if control municipalities were similar to treated municipalities that experienced a relatively small increase in coverage that was big enough to be defined as treated.

Figure 5.2 - Seguro Popular beneficiaries and implementation phases

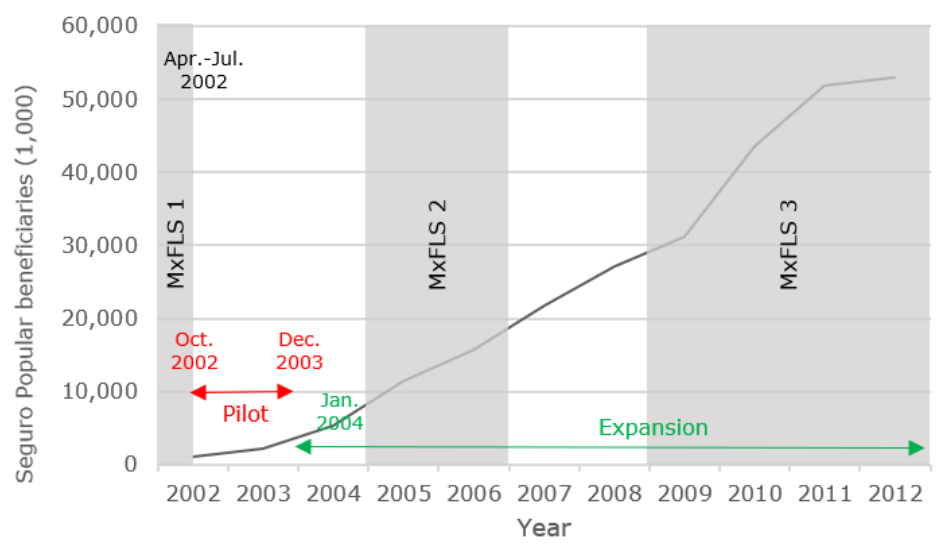

\subsection{Data and empirical strategy}

\subsubsection{Empirical strategy}

To estimate the effect of healthcare provision on migration, this analysis estimates a differencein-differences specification, by comparing the difference in migration propensity between treated and control municipalities, before and after the expansion of Seguro Popular. It is assumed that the difference in migration propensity would have remained the same had Seguro Popular not been introduced. Moreover, municipality fixed effects take into account unobserved characteristics at the treatment (municipality) level. Any unobserved variable that might be related to migration is assumed to be uncorrelated with Seguro Popular expansion, conditional on observed covariates. Estimate robustness to this assumption is assessed later. Treated municipalities with a change in coverage of at least $10 \%$ and strictly less than $20 \%$ are excluded to avoid treatment contagion, as explained in the previous sections.

Regression (1) estimates the impact of living in a municipality $m$ at time $t$ on the propensity to have migrated in the subsequent wave of the survey. A linear probability model with municipality fixed effects is run as shown below:

$$
\begin{aligned}
Y_{\text {imt }}=\alpha & +\beta_{1} \text { Treated }_{m}+\beta_{2} \text { Post }_{t}+\beta_{3}\left(\text { Treated } * \text { Post }_{m t}+\delta^{\prime} X_{i m t}\right. \\
& +\gamma \text { Municipality }_{m}+u_{i m t}
\end{aligned}
$$

where $Y$ represents the outcome variable of interest, between wave migration, of a 21-65 yearold individual successfully interviewed in at least two consecutive waves, living in municipality $m$ at the beginning of time period $t$. Treated is a binary variable taking value 1 if changes in Seguro Popular coverage in a municipality $m$ in which respondent $i$ lived at the beginning of each time period were strictly smaller than $10 \%$ between the last quarter of 2002 and the last quarter of 2004, and of at least $10 \%$ between the last quarter of 2004 and the last quarter of 
2008 (treated municipalities); 0, if changes in coverage in a municipality were strictly less than $10 \%$ in both periods (control municipalities). Post and Municipality are respectively time and municipality fixed effects. $\beta_{3}$ is the difference-in-differences estimator.

$X$ is a vector of individual, household and municipality characteristics. It includes gender, age, years of schooling of respondents; household heads' gender, age, years of schooling and indigenous origins; household dependency ratios for 0-7, 8-14, 15-20 and 66 years old and more; whether a household has experienced any economic shock in the preceding five years; household wealth (asset) index, excluding farm-related assets; and lagged indices of marginalization at the municipality level, ${ }^{12}$ which should control for the presence of welfare programmes like Oportunidades as their introductions are based on such marginalization indices. $u_{i m t}$ is the error term. Standard errors are robust to heteroscedasticity.

Variations in cross-municipality (-state) health insurance coverage could incite low-income families to migrate, if they were not provided with similar benefits in their current places of residence. Existing findings point to an increase in mobility from low- to high-benefit areas (Moffitt, 1992). If individuals might (have) migrate(d) to municipalities where Seguro Popular was introduced to access healthcare, any migration observed between waves might be the result of individuals pulled to migrate to benefit from the programme, rather than Seguro Popular affiliation enabling them to migrate.

As Moffitt (1992) explains, the literature on migration effects, rather scarce, is limited by econometric and methodological issues, in particular in the use of a truly random source of variation in welfare schemes. This chapter takes advantage of the timing and the panel dimension of the MxFLS to control for this potential source of endogeneity - reverse causality. Changes in Seguro Popular coverage are assigned to respondents based on their municipality of residence at the beginning of each period - their 2002 municipality of residence when looking at the relation between changes in coverage and migration between MxFLS wave 1 (2002) and 2 (2005), and their 2005 municipality of residence when looking at the relation between changes in coverage and migration between MxFLS wave 2 (2005) and 3 (2009).

\subsubsection{Data}

\section{Data source}

The analysis exploits the timing of the MxFLS, a three-wave household panel conducted from April to July 2002, before the start of Seguro Popular pilot phase, in 2005-2006 and in 2009-2012 (cf. Figure 5.2). The MxFLS specifically identifies all migrants, internal or international, even those who permanently moved to the US. This avoids potential biases of other data sets used in the literature, such as the undercount of Mexican migrants to the US as in Chiquiar and Hanson (2005), or migration information based on recall as in Orrenius and Zavodny (2005) (Kaestner and Malamud, 2014). In addition, the MxFLS provides individual and household level details

\footnotetext{
${ }^{12}$ Compiled by Consejo Nacional de Población (CONAPO), marginalization indices are based on several indicators of education, dwelling and income, collected every five years, to inform about the degree of poverty, inequality and exclusion at some administrative level. The higher marginalization indices are, the poorer localities are.
} 
on demographic and socio-economic characteristics.

Information on individual and household administrative records of Seguro Popular by municipality by quarter comes from Bosch and Campos-Vázquez (2014). Of the number of affiliates to Seguro Popular in each quarter from 2002 to 2009, municipalities that experienced a significant change in coverage, at least 10\%, from the last quarter of 2002 to the last quarter of 2004 are excluded to simultaneously take advantage of the timing of the MxFLS and the random variation in the middle of Seguro Popular implementation, from 2004 onwards. As explained previously, this analysis follows Alcaraz et al. (2016) in defining treated municipalities as municipalities where the change in coverage was at least $10 \%$ or greater from the last quarter of 2004 to the last quarter of 2008. Control municipalities are those where changes in coverage were less than $10 \%$ in both the 2002-2004 and 2004-2008 periods. ${ }^{13}$ Individuals living in municipalities where the change in coverage was at least $10 \%$ but less than $20 \%$ are excluded, not to bias estimates because of treatment contagion (Alcaraz et al., 2016).

Figure 5.3 shows Mexican municipalities by changes in Seguro Popular coverage rate up to the last quarter of 2004 (pre-treatment period) on the left, and from the last quarter of 2004 to the last quarter of 2008 (treatment period) on the right. ${ }^{14}$ Figure 5.4 represents municipalities by treatment status.

\section{Descriptive statistics}

As in Kaestner and Malamud (2014), the estimation sample is limited to 21-65 year-old men and women, successfully interviewed in at least two waves of the survey. After dropping observations with missing variables, a sample of 5,872 unique respondents interviewed across two time periods is obtained, forming an unbalanced panel of 9,431 observations. The dependant variable is a binary variable taking value 1 if an individual has migrated between two subsequent waves, between MxFLS wave 1 (2002) and 2 (2005), and/or between MxFLS wave 2 (2005) and 3 (2009); 0, otherwise.

Descriptive statistics provided in Tables 5.1-5.3 reveal differences across treatment and control groups. Individuals living in treated municipalities are relatively older, and have a lower level of education than individuals living in control areas. Their household heads are also more likely to be men, with lower education, and more likely to be from an ethnic minority background. They come from households with a greater share of dependants; poorer households that are more likely to have reported an economic shock in the previous 12 months, but less likely to have reported a health-related shock. Lagged marginalization indices of treated municipalities are higher than in control municipalities. These differences are observed in both periods, except regarding respondents' age, the reporting of household economic shocks. The analysis takes into account such differences and unobserved heterogeneity by including time fixed effects, alternatively municipality and individual fixed effects, and time-varying characteristics.

\footnotetext{
${ }^{13}$ The last quarters of 2004 and 2008 are selected because individuals are not expected to change their behaviour instantaneously to changes in coverage.

${ }^{14}$ On this part of Figure 5.3, municipalities that experienced a significant change in coverage rate by the last quarter of 2004 are coloured in dark green regardless of their change in coverage rate in the second time period.
} 
Figure 5.3 - Municipalities by change in coverage rate in the last quarter of 2004 (l) and 2008 (r)
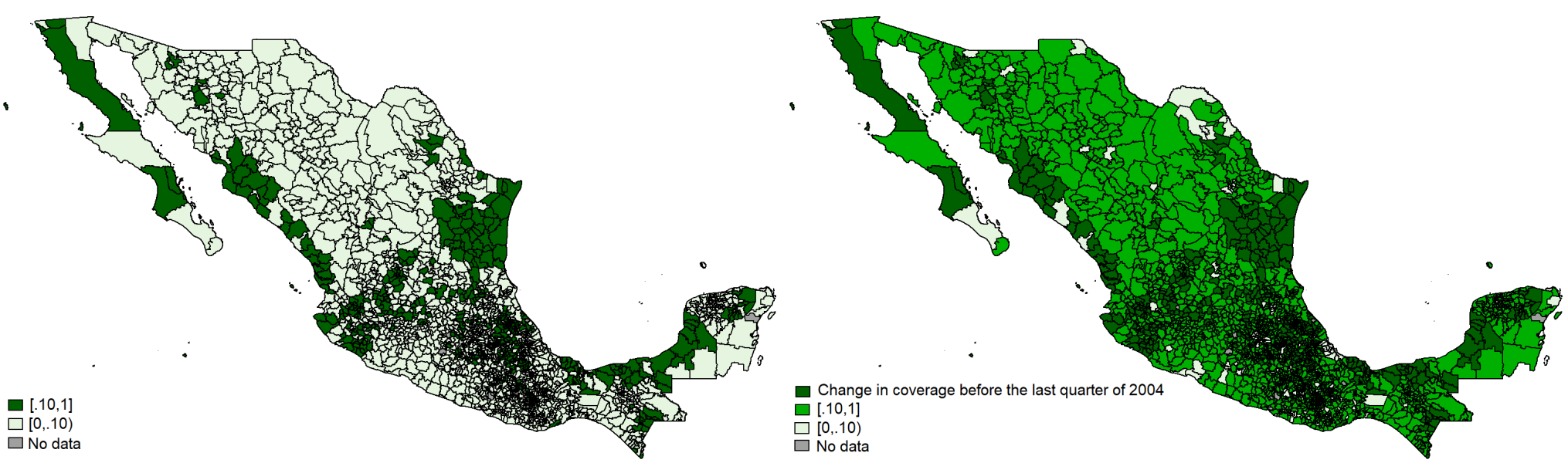
Figure 5.4 - Municipalities by treatment status

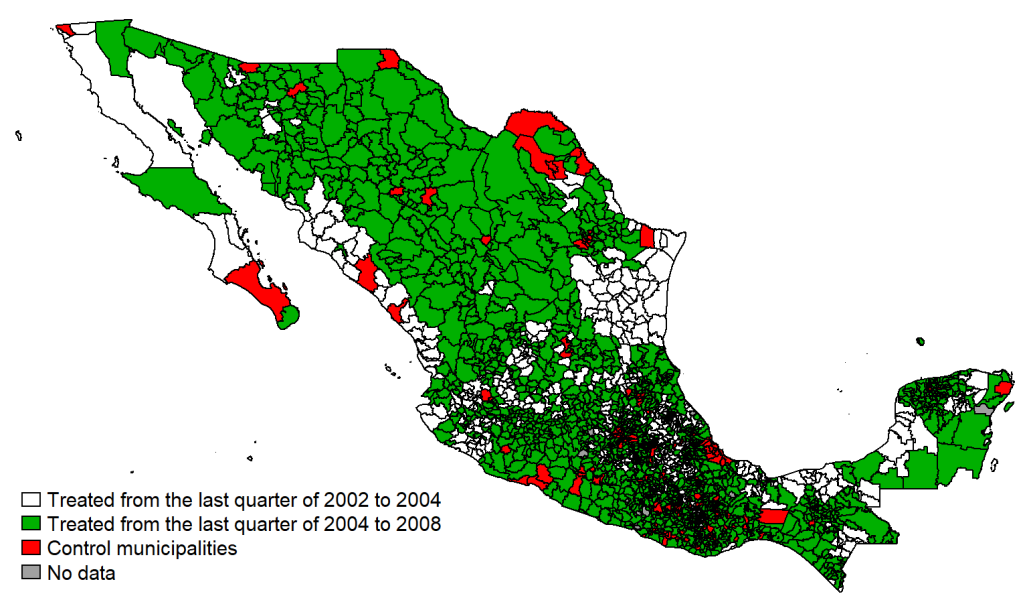

While individuals in treated municipalities have, on average, a lower probability to migrate between waves than individuals in control municipalities (cf. Table 5.1), Table 5.2 indicates that individuals living in treated municipalities display a significantly lower propensity to migrate in the pre-treatment period, between 2002 (wave 1) and 2005 (wave 2), but not any significant difference in the post-treatment period, between 2005 (wave 2) and 2009 (wave 3). Migration propensity before the introduction of the programme was lower in treated areas than in control areas, and migration propensity in control areas slightly decreased between the two periods. Looking at respondents' migration propensity since 12 years old, it appears that those living in control areas are significantly more likely to have permanently migrated - for 12 months or more - since the age of 12 (row (1)). It is worth noting that individuals residing in treated and control municipalities in 2002 do not show any statistically significant difference in temporarily migrating (row (2)) - for at least one month but less than 12 months.

This downward shift in control municipalities is consistent with migration trends in Mexico. While the proportion of the Mexican population who lived in a state different from their state of birth increased from $10.6 \%$ in 1940 (2,081,000 people) to $19.2 \%$ in $2000(18,752,000)$, it remained almost constant in relative terms in 2010 (19.3\%, 13,976,000 people) (PimientaLastra et al., 2012). These downward trends are confirmed for internal migration between functional territories (Cazzuffi and Pereira-López, 2016). ${ }^{15}$ International migration has also been decreasing, likely because of a labour-foreign direct investment (FDI) effect in receiving Mexican states (Aroca and Maloney, 2005), combined with increasing costs involved in international migration (Orrenius, 2001). Descriptive statistics of the estimation sample thus suggest that the expansion of healthcare coverage might have offset an ex-ante downward trend in migration in Mexico. ${ }^{16}$

\footnotetext{
${ }^{15}$ Functional territories are based on commuting flows between municipalities, using cluster analysis. These units help to avoid problems common with administrative units, e.g. commuting, as people could travel back and forth without migrating (Cazzuffi and Pereira-López, 2016).

${ }^{16}$ Of the information gathered, migration seems to be largely intra-state and undertaken for job purposes. Unfortunately, data on migration variables could not give consistent information. They are available on request.
} 
Table 5.4 presents descriptive statistics by migration status. On average, migrants are younger, more likely to be men and more educated than non-migrants. They are more likely to have spent time caring for their dependants, and to have borrowed money in the last 12 months. The heads of their households tend to be younger, more educated and less likely to be of indigenous origins. They come from households with a greater share of 0-7-year-old dependants, but with a lower share of 8-14-year-old, 15-20-year-old or 66+ dependants. Their households are more likely to have experienced economic shocks in the last 12 months, to have spent on health expenditures, and to reside in less wealthy areas.

Disaggregating statistics by treatment status, Table 5.4 further shows that, on average, migrants in treated areas are less educated than migrants in control areas. They come from poorer, more vulnerable families with a slightly higher share of below 15-year-old dependants, and are located in more marginalized areas, compared to households with migrants living in control municipalities. These statistics seem to point to affiliation to Seguro Popular increasing the probability of those less educated, who might have (more) limited job opportunities, with greater time constraints and coming from poorer, more vulnerable households, to migrate. This is as if publicly provided healthcare enabled families vulnerable to adverse shocks, and who could not afford otherwise - families, individuals on the edge of poverty for who a small amount can make a difference - to send members away by relaxing their financial and care constraints.

Following Angelucci (2015), Figure 5.5 depicts pre-programme distributions of years of schooling (left), dependency ratios (right) and household wealth (bottom) for non-migrants in control municipalities, migrants in control municipalities and migrants in treated municipalities. The migrant skill distribution in control municipalities has more density in its middle (dashed grey line) than non-migrants (solid grey line), but it is shifted to the right compared to that of migrants in treated municipalities.

As in the case of Oportunidades and international migration in Angelucci (2015) or in Greenwood and McDowell (2011), the figure on the left indicates that, while migrants in control municipalities are positively selected into migration, migrants in treated municipalities are negatively selected into migration with regard to education, which is consistent with Table 5.4. By alleviating financial constraints on those who are the most likely to be affected by health shocks, significant changes in health insurance coverage might worsen migrants' skill profiles, since, if skill set is a proxy for labour market opportunities, unskilled migrants are those facing the greatest difficulties in funding migration. Accessing health insurance might thus enable those with a relatively bad skill set to expand their work opportunities across space. While the figure at the bottom suggests that migrants in treated municipalities are poorer than migrants in control municipalities, the statistical relationship between either dependency ratios or wealth is not confirmed by Mann-Whitney tests. ${ }^{17}$

\footnotetext{
${ }^{17}$ Estimates are available on request.
} 
Table 5.1 - Descriptive statistics of estimation sample

\begin{tabular}{|c|c|c|c|c|c|}
\hline & \multicolumn{2}{|c|}{ Full sample } & \multirow{2}{*}{$\begin{array}{c}\text { Treated } \\
\text { Mean }\end{array}$} & \multirow{2}{*}{$\begin{array}{c}\text { Control } \\
\text { Mean }\end{array}$} & \multirow[b]{2}{*}{ t-test } \\
\hline & Mean & $\mathrm{SD}$ & & & \\
\hline \multicolumn{6}{|l|}{ Outcome variables (period end) } \\
\hline Migrated between waves & .063 & .244 & .053 & .080 & $-5.18^{* * *}$ \\
\hline Internal & .058 & .233 & .046 & .076 & $-5.96^{* * *}$ \\
\hline International & .008 & .086 & .009 & .006 & 1.57 \\
\hline \multicolumn{6}{|l|}{ Control variables (period start) } \\
\hline Age & 39.991 & 11.5149 & 40.229 & 39.613 & $2.53^{* *}$ \\
\hline Male & .468 & .499 & .473 & .459 & 1.31 \\
\hline Years of schooling & 6.894 & 4.073 & 6.356 & 7.750 & $-16.41^{* * *}$ \\
\hline \multicolumn{6}{|l|}{ Household head } \\
\hline Age & 47.739 & 13.105 & 47.794 & 47.652 & 0.51 \\
\hline Male & .832 & .374 & .848 & .806 & $5.36 * * *$ \\
\hline Years of schooling & 6.175 & 4.199 & 5.716 & 6.907 & $-13.53^{* * *}$ \\
\hline Indigenous & .1465 & .354 & .187 & .083 & $13.98^{* * *}$ \\
\hline \multicolumn{6}{|l|}{ Household dependency ratio } \\
\hline $0-7$ & .131 & .164 & .130 & .131 & -0.35 \\
\hline $8-14$ & .142 & .166 & .149 & .131 & $4.87^{* * *}$ \\
\hline $15-20$ & .109 & .148 & .113 & .104 & $2.79 * * *$ \\
\hline 66 and more & .036 & .105 & .038 & .033 & $1.97^{* *}$ \\
\hline Has spent time caring & .223 & .416 & .225 & .220 & 0.56 \\
\hline Hours spent caring & 5.833 & 15.304 & 5.708 & 6.033 & -1.00 \\
\hline Health status ${ }^{\mathrm{a}}$ & .947 & .224 & .945 & .950 & -0.85 \\
\hline Household economic shock & .290 & .454 & .295 & .283 & 1.26 \\
\hline Household health shock & .1225 & .328 & .114 & .136 & $-3.18^{* * *}$ \\
\hline Household wealth index & .140 & 1.425 & -.016 & .388 & $-13.55^{* * *}$ \\
\hline Has borrowed & .100 & .300 & .095 & .108 & $-2.03^{* *}$ \\
\hline Health expenditures $(b)^{b}$ & .991 & .095 & .993 & .987 & $2.89 * * *$ \\
\hline Health expenditures $(c)^{c}$ & 349.011 & 1701.176 & 338.94 & 365.33 & -0.72 \\
\hline Health expenditures $(c, \log )^{c}$ & 1.903 & 2.933 & 1.872 & 1.955 & -1.32 \\
\hline Lagged marginalization index & -.983 & .889 & -.687 & -1.454 & $44.95^{* * *}$ \\
\hline Observations & \multicolumn{2}{|c|}{9,431} & 5,791 & 3,640 & \\
\hline
\end{tabular}

Notes: Means and standard deviations (SD) of variables of interest of the estimation sample, 5,872 unique individuals aged 21-65 years old, forming an unbalanced panel of 9,431 respondents interviewed across $2002-2009$. ${ }^{* * *} \mathrm{p}<0.01,{ }^{* *} \mathrm{p}<0.05,{ }^{*} \mathrm{p}<0.1$.

a Means of 'Health status' are based on 8,860 observations.

b Means of 'Health expenditures (b)' are based on 9,183 observations.

c Means of 'Health expenditures (c)' and 'Health expenditures (c, log)' are based on 9,099 observations. 
Table 5.2 - Migration by year

\begin{tabular}{lccc}
\hline \hline & Treated & Control & t-test \\
\cline { 2 - 4 } & & & \\
(1) pre-2002 migration since 12 years old & .2787 & .3540 & $-5.66^{* * *}$ \\
(2) pre-2002 migration in the last two years & .0367 & .0375 & -0.18 \\
(1) $+(2)$ & .3033 & .3731 & $-5.15^{* * *}$ \\
(3) 2002-2005 migration & .0531 & .0947 & $-5.76^{* * *}$ \\
(4) 2005-2009 migration & .0530 & .0612 & -1.14 \\
\hline Observations & 5,791 & 3,640 & \\
\hline \hline
\end{tabular}

Notes: Please, refer to Table 5.1.

Table 5.3 - Covariates of estimation sample by year (period start)

\begin{tabular}{|c|c|c|c|c|c|c|}
\hline & \multicolumn{3}{|c|}{2002} & \multicolumn{3}{|c|}{2005} \\
\hline & Treated & Control & t-test & Treated & Control & t-test \\
\hline Age & 38.257 & 37.535 & $2.24^{* *}$ & 42.607 & 42.167 & 1.24 \\
\hline Male & .479 & .466 & 0.85 & .467 & .451 & 1.02 \\
\hline Years of schooling & 6.496 & 7.840 & $-11.78^{* * *}$ & 6.188 & 7.641 & $-11.42^{* * *}$ \\
\hline \multicolumn{7}{|l|}{ Household head } \\
\hline Age & 46.552 & 46.36 & 0.51 & 49.291 & 49.239 & 0.13 \\
\hline Male & .853 & .810 & $4.15^{* * *}$ & .842 & .802 & $3.41^{* * *}$ \\
\hline Years of schooling & 5.814 & 6.874 & $-8.95^{* * *}$ & 5.598 & 6.946 & $-10.27 * * *$ \\
\hline Indigenous & .186 & .073 & $11.54^{* * *}$ & .187 & .096 & $8.12^{* * *}$ \\
\hline \multicolumn{7}{|l|}{ Household dependency ratio } \\
\hline $0-7$ & .138 & .138 & 0.01 & .120 & .123 & -0.52 \\
\hline $8-14$ & .154 & .135 & $3.88^{* * *}$ & .142 & .127 & $2.98^{* * *}$ \\
\hline $15-20$ & .110 & .100 & $2.21^{* *}$ & .116 & .108 & $1.70^{*}$ \\
\hline 66 and more & .035 & .032 & 1.03 & .041 & .035 & $1.76^{*}$ \\
\hline Has spent time caring & .217 & .211 & 0.46 & .235 & .231 & 0.31 \\
\hline Hours spent caring & 5.552 & 5.934 & -0.89 & 5.896 & 6.154 & -0.52 \\
\hline Health status & .951 & .953 & -0.39 & .939 & .945 & -0.80 \\
\hline Household economic shock & .344 & .281 & $4.76^{* * *}$ & .235 & .285 & $-3.63^{* * *}$ \\
\hline Health shock & .090 & .134 & $-4.99 * * *$ & .143 & .139 & 0.38 \\
\hline Household wealth index & -.024 & .339 & $-9.02^{* * *}$ & -.007 & .450 & $-10.24^{* * *}$ \\
\hline Has borrowed & .070 & .087 & $-2.23^{* *}$ & .126 & .135 & -0.82 \\
\hline Health expenditures (b) & .990 & .989 & 0.18 & .997 & .985 & $4.53^{* * *}$ \\
\hline Health expenditures (c) & 309.37 & 360.79 & -1.25 & 374.5 & 370.93 & 0.06 \\
\hline Health expenditures $(\mathrm{c}, \mathrm{log})$ & 1.815 & 1.976 & $-1.90^{*}$ & 1.940 & 1.929 & 0.11 \\
\hline Lagged marginalization index & -.666 & -1.342 & $28.87^{* * *}$ & -.712 & -1.591 & $35.73^{* * *}$ \\
\hline Observations & 3,166 & 2,007 & & 2,625 & 1,633 & \\
\hline
\end{tabular}

Notes: Please, refer to Table 5.1. 
Table 5.4 - Descriptive statistics of estimation sample by migration status

\begin{tabular}{|c|c|c|c|c|c|c|c|c|c|}
\hline & \multirow{2}{*}{$\begin{array}{c}\text { Migrants } \\
\text { Mean }\end{array}$} & \multicolumn{2}{|l|}{ Stayers } & \multicolumn{3}{|c|}{ Migrants } & \multicolumn{3}{|c|}{ Stayers } \\
\hline & & Mean & t-test & $\begin{array}{c}\text { Treated } \\
\text { Mean }\end{array}$ & $\begin{array}{c}\text { Control } \\
\text { Mean }\end{array}$ & t-test & $\begin{array}{c}\text { Treated } \\
\text { Mean }\end{array}$ & $\begin{array}{c}\text { Control } \\
\text { Mean }\end{array}$ & t-test \\
\hline Age & 35.089 & 40.322 & $-10.81 * * *$ & 35.752 & 34.386 & 1.57 & 40.479 & 40.065 & 1.64 \\
\hline Male & .541 & .463 & $3.71^{* * *}$ & .567 & .514 & 1.30 & .468 & .455 & 1.21 \\
\hline Years of schooling & 8.054 & 6.816 & $7.21^{* * *}$ & 7.329 & 8.821 & $-4.67 * * *$ & 6.302 & 7.658 & $-15.40 * * *$ \\
\hline \multicolumn{10}{|l|}{ Household head } \\
\hline Age & 44.253 & 47.975 & $-6.73^{* * *}$ & 44.303 & 44.2 & 0.09 & 47.989 & 47.951 & 0.14 \\
\hline Male & .839 & .832 & 0.48 & .857 & .821 & 1.20 & .848 & .805 & $5.26^{* * *}$ \\
\hline Years of schooling & 6.898 & 6.127 & $4.35^{* * *}$ & 6.407 & 7.417 & $-2.95^{* * *}$ & 5.677 & 6.862 & $-13.01^{* * *}$ \\
\hline Indigenous & .099 & .150 & $-3.41^{* * *}$ & .147 & .048 & $4.07^{* * *}$ & .189 & .086 & $13.26^{* * *}$ \\
\hline \multicolumn{10}{|l|}{ Household dep. ratio } \\
\hline $0-7$ & .170 & .128 & $6.10 * * *$ & .162 & .179 & -1.08 & .128 & .127 & 0.30 \\
\hline $8-14$ & .123 & .143 & $-2.90 * * *$ & .136 & .109 & $2.03^{* *}$ & .149 & .133 & $4.35^{* * *}$ \\
\hline $15-20$ & .078 & .111 & $-5.39 * * *$ & .083 & .072 & 1.10 & .114 & .107 & $2.33^{* *}$ \\
\hline 66 and more & .027 & .036 & $-2.18^{* *}$ & .027 & .027 & 0.02 & .038 & .034 & $1.90^{*}$ \\
\hline Caring time (b) & .286 & .219 & $3.84^{* * *}$ & .296 & .276 & 0.55 & .221 & .215 & 0.64 \\
\hline Caring time (c) & 7.811 & 5.700 & $3.26^{* * *}$ & 8.121 & 7.483 & 0.45 & 5.573 & 5.908 & -1.01 \\
\hline Health status & .954 & .946 & 0.84 & .948 & .962 & 0.421 & .945 & .948 & 0.532 \\
\hline Household shock & .343 & .287 & $2.96^{* * *}$ & .355 & .331 & 0.62 & .291 & .279 & 1.30 \\
\hline Health shock & .124 & .122 & 0.11 & .104 & .145 & -1.50 & .115 & .135 & $-2.88^{* * *}$ \\
\hline Household wealth & .175 & .138 & 0.61 & -.126 & .493 & $-5.47 * * *$ & -.010 & .379 & $-12.56^{* * *}$ \\
\hline Has borrowed & .161 & .096 & $5.09 * * *$ & .169 & .152 & 0.59 & .091 & .105 & $-2.06 * *$ \\
\hline Health expenditures (b) & .988 & .991 & -0.79 & .997 & .979 & $1.94^{*}$ & .993 & .988 & $2.38^{* *}$ \\
\hline Health expenditures (c) & 521.95 & 337.52 & $2.50 * *$ & 478.22 & 567.73 & -0.51 & 331.37 & 347.79 & -0.44 \\
\hline Health expenditures $(c, l o g)$ & 2.397 & 1.871 & $4.14^{* * *}$ & 2.446 & 2.345 & 0.38 & 1.841 & 1.921 & -1.24 \\
\hline Lagged marginalization & -1.113 & -.974 & $-3.69 * * *$ & -.735 & -1.513 & $13.64^{* * *}$ & -.684 & -1.449 & $42.85^{* * *}$ \\
\hline Observations & 597 & 8,834 & & 307 & 290 & & 5,484 & 3,350 & \\
\hline
\end{tabular}

Notes: Please, refer to Table 5.1. 
Figure 5.5 - Years of schooling (1), dependency ratio (r) and wealth index (b) by treatment status
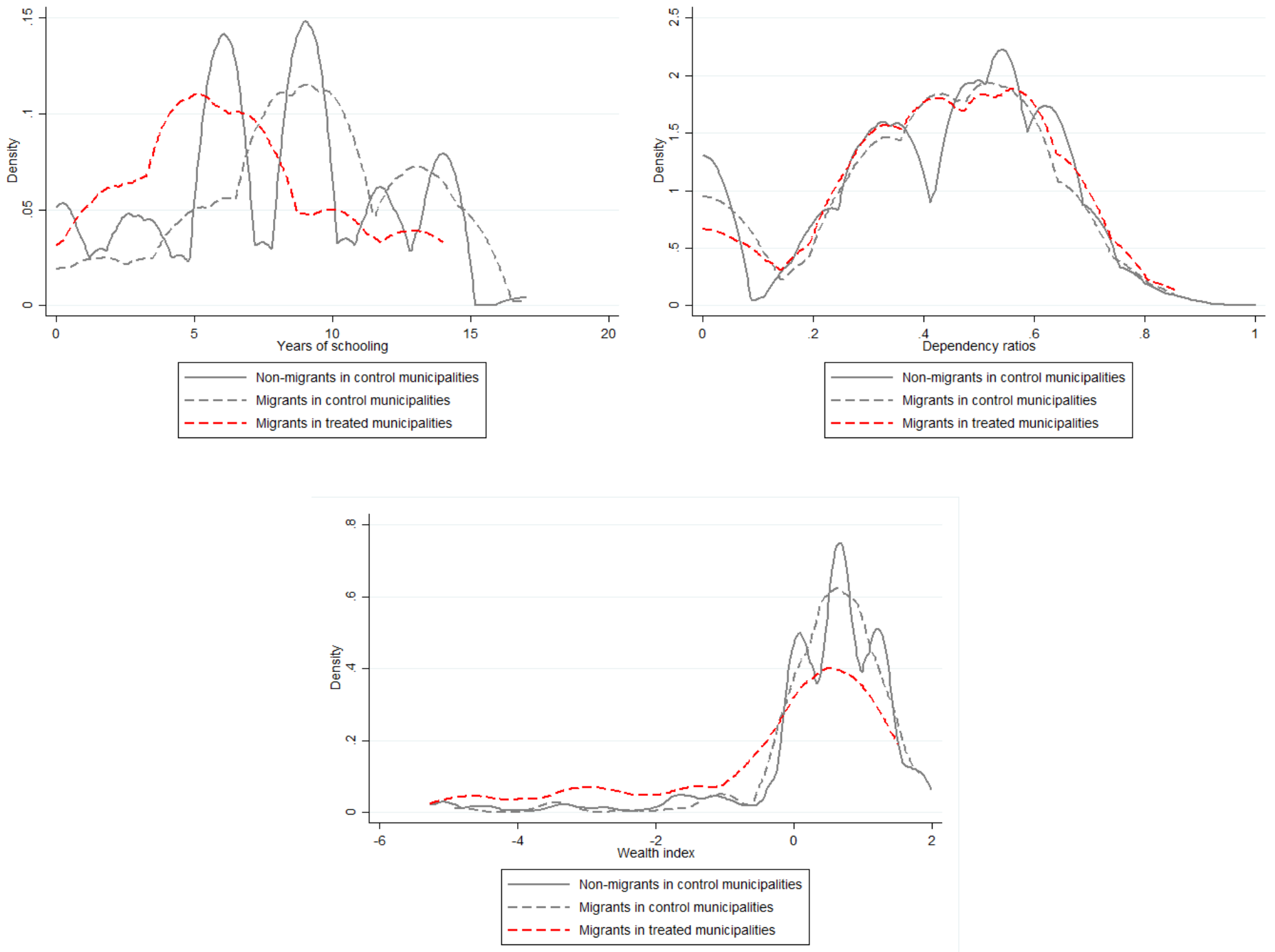


\subsection{Results}

\subsubsection{Benchmark results}

Estimates of equation (1) on an unbalanced panel of 21-65-year-olds are presented in Table 5.5. Column (1) indicates that the probability of migrating between waves increased by 3.69 percentage points for respondents in municipalities that experienced a significant change in Seguro Popular coverage compared to municipalities that did not. This estimate is robust to the inclusion of individual instead of municipality fixed effects, with a slight decrease in estimate magnitude and significance, which could be explained by the reduction in sample size. With municipality fixed effects and controlling for individual and household time-invariant and timevarying variables, from columns (3) to (4), and municipality time-varying variables, in column (5), the estimates similarly give an effect between 3.40 to 3.78 percentage points.

Table 5.5 clearly points to the expansion of Seguro Popular increasing the likelihood to migrate. Looking across all benchmark specifications, the introduction of non-contributory healthcare appears to increase migration by an average of about 3 percentage points. Compared with an average propensity to migrate of about 7.967 percentage points in control municipalities, point estimates of column (5) suggest, for instance, an increase in migration of about 42.660 per cent of the level in control municipalities. In addition, age and the proportion of dependants in a household decrease the likelihood of a prime-aged member to migrate. Being a man and the occurrence of an economic shock increase the propensity to migrate.

Benchmark results suggest that the expansion of Seguro Popular is different from contributory schemes that might be tying affiliates to formal employment, and hence to a specific location. By linking social health protection to formal employment, Mexico's contributory health insurance system has been shown to increase beneficiaries' security, and thus to reduce the need to migrate, since formal employment increases income stability, which might decrease the necessity to diversify income sources. In contrast, Seguro Popular might act as an unconditional cash transfer programme, such as the South Africa Old Age Grant, by which the reduced occurrence and duration of health shocks, and the alleviation of budget constraints, might free caregivers' time. This could enable them to relocate and diversify income sources, while ensuring coverage of household dependants.

The relatively small magnitude of these coefficient estimates might be expected because access to non-contributory healthcare does not induce a stable source of income, but rather punctual transfers to compensate out-of-pocket health expenditures. In this sense, the effect of publicly provided healthcare might be close to the impact of small monetary incentives on internal migration in rural Bangladesh, as found in Bryan et al. (2014). 
Table 5.5 - Coefficient estimates of benchmark specifications

\begin{tabular}{|c|c|c|c|c|c|}
\hline \multirow[b]{2}{*}{ Variables } & \multicolumn{5}{|c|}{ Has migrated } \\
\hline & (1) & (2) & $(3)$ & (4) & (5) \\
\hline Treated X 2005 & $\begin{array}{c}0.0369 * * * \\
(0.0114)\end{array}$ & $\begin{array}{c}0.0267^{* *} \\
(0.0122)\end{array}$ & $\begin{array}{c}0.0361^{* * *} \\
(0.0114)\end{array}$ & $\begin{array}{c}0.0378^{* * *} \\
(0.0114)\end{array}$ & $\begin{array}{c}0.0340^{* * *} \\
(0.0122)\end{array}$ \\
\hline 2005 & $\begin{array}{c}-0.0327^{* * *} * \\
(0.0088)\end{array}$ & $\begin{array}{c}-0.0220^{* *} \\
(0.0098)\end{array}$ & $\begin{array}{c}-0.0239 * * * \\
(0.0088)\end{array}$ & $\begin{array}{c}-0.0238^{* * *} \\
(0.0088)\end{array}$ & $\begin{array}{c}-0.0191^{*} \\
(0.0099)\end{array}$ \\
\hline Treated & - & - & - & - & - \\
\hline Age & & & $\begin{array}{c}-0.0018^{* * *} \\
(0.0003)\end{array}$ & $\begin{array}{c}-0.0016^{* * *} \\
(0.0004)\end{array}$ & $\begin{array}{c}-0.0016^{* * *} \\
(0.0004)\end{array}$ \\
\hline Male & & & $\begin{array}{c}0.0148^{* *} \\
(0.0059)\end{array}$ & $\begin{array}{c}0.0130^{* *} \\
(0.0060)\end{array}$ & $\begin{array}{c}0.0130^{* *} \\
(0.0060)\end{array}$ \\
\hline Years of schooling & & & $\begin{array}{c}0.0014 \\
(0.0010)\end{array}$ & $\begin{array}{c}0.0017 \\
(0.0013)\end{array}$ & $\begin{array}{c}0.0017 \\
(0.0013)\end{array}$ \\
\hline Age of head & & & & $\begin{array}{c}-0.0002 \\
(0.0004)\end{array}$ & $\begin{array}{l}-0.0002 \\
(0.0004)\end{array}$ \\
\hline Head is male & & & & $\begin{array}{c}-0.0030 \\
(0.0083)\end{array}$ & $\begin{array}{c}-0.0029 \\
(0.0083)\end{array}$ \\
\hline Years of schooling of head & & & & $\begin{array}{l}-0.0007 \\
(0.0012)\end{array}$ & $\begin{array}{l}-0.0007 \\
(0.0012)\end{array}$ \\
\hline Head is indigenous & & & & $\begin{array}{c}-0.0078 \\
(0.0118)\end{array}$ & $\begin{array}{c}-0.0082 \\
(0.0118)\end{array}$ \\
\hline 0-7 dependency ratio & & & & $\begin{array}{c}0.0055 \\
(0.0244)\end{array}$ & $\begin{array}{c}0.0051 \\
(0.0244)\end{array}$ \\
\hline 8-14 dependency ratio & & & & $\begin{array}{c}-0.0803^{* * *} \\
(0.0196)\end{array}$ & $\begin{array}{c}-0.0802^{* * *} \\
(0.0196)\end{array}$ \\
\hline 15-20 dependency ratio & & & & $\begin{array}{c}-0.0708^{* * *} \\
(0.0201)\end{array}$ & $\begin{array}{c}-0.0705^{* * *} \\
(0.0201)\end{array}$ \\
\hline 66 and more dependency ratio & & & & $\begin{array}{l}-0.0551^{*} \\
(0.0329)\end{array}$ & $\begin{array}{c}-0.0548^{*} \\
(0.0329)\end{array}$ \\
\hline Household economic shock & & & & $\begin{array}{c}0.0257^{* * *} \\
(0.0069)\end{array}$ & $\begin{array}{c}0.0257^{* * *} \\
(0.0069)\end{array}$ \\
\hline Household wealth index & & & & $\begin{array}{l}-0.0016 \\
(0.0025)\end{array}$ & $\begin{array}{l}-0.0018 \\
(0.0025)\end{array}$ \\
\hline Lagged marginalization index & & & & & $\begin{array}{c}0.0184 \\
(0.0148)\end{array}$ \\
\hline Municipality FE & Yes & No & Yes & Yes & Yes \\
\hline Individual FE & No & Yes & No & No & No \\
\hline Mean of dependent variable & $\begin{array}{l}.0658 \\
(.2480)\end{array}$ & $\begin{array}{c}.0595 \\
(.2366)\end{array}$ & $\begin{array}{l}.0658 \\
(.2480)\end{array}$ & $\begin{array}{l}.0658 \\
(.2480)\end{array}$ & $\begin{array}{l}.0658 \\
(.2480)\end{array}$ \\
\hline Observations & 7,231 & 5,528 & 7,231 & 7,231 & 7,231 \\
\hline R-squared & 0.0245 & 0.5631 & 0.0341 & 0.0404 & 0.0405 \\
\hline
\end{tabular}

Notes: Estimates are for 21-65-year-old individuals, interviewed in at least two consecutives waves. Respondents exposed to a change in coverage of at least $10 \%$ and strictly lower than $20 \%$ are excluded. The dependent variable is a binary variable taking unity if an individual migrated between wave 1 (2002) and wave 2 (2005) and/or between wave 2 and wave 3 (2009). Columns (1)-(5) present coefficient estimates of linear probability models. Standard errors robust to heteroscedasticity are reported in parentheses. ${ }^{* * *} \mathrm{p}<0.01,{ }^{* *} \mathrm{p}<0.05,{ }^{*} \mathrm{p}<0.1$. 


\subsubsection{Robustness checks}

Several tests are conducted to assess the validity of the identifying assumptions. An important threat to identification would be a significant relationship between municipality-specific timing of Seguro Popular roll-out and migration trends - differential time trends between treated and control municipalities correlated with its expansion. This would bias the estimated average treatment effects. Because there are only two time periods (2002-2005 and 2005-2009), municipality-specific trends cannot be controlled for. In addition to controlling for time-varying characteristics at the municipality level by including lagged marginalization indices, placebo tests are performed. As in Alcaraz et al. (2016) and de Janvry et al. (2015), a first placebo test is run by estimating equation (1) on first-period data with treatment status as variable of interest. The change in migration between wave 1 and wave 2 is regressed on treatment status, controlling for individual, household and municipality characteristics, as in:

$$
Y_{i m 02 / 05}=\alpha+\beta_{1} \text { Treated }_{m 05}+\delta^{\prime} X_{i m t}+u_{i m t}
$$

Column (1) of Table 5.6 indicates that the propensity to migrate was significantly but negatively related with a major expansion of Seguro Popular in the next period. Although migration propensities between treated and control municipalities before programme expansion significantly differ as highlighted in the previous section, the fact that the sign on treatment status is opposite to difference-in-differences estimates of Table 5.5 supports the identification strategy.

A second placebo test is performed by randomly assigning the treatment to control municipalities. Specifically, (i) the estimation sample is restricted to control municipalities; (ii) a 'fake' treatment is randomly assigned to half of the control municipalities; (iii) equation (1) is estimated; and (iv) this procedure is repeated (bootstrapped) 1,000 times. As shown in column (2) of Table 5.6, the difference-in-differences estimator is statistically significant and negative, suggesting that the difference-in-differences estimates of benchmark specifications do not reflect the existence of any positive selection into the treatment or pre-programme positive trend in treated municipalities. Its negative sign indicates that benchmark difference-in-differences estimates represent the lower bound of the true effect of the expansion of Seguro Popular on migration. ${ }^{18}$

Another threat to identification would be that the timing of Seguro Popular expansion is associated with significant changes in the probability to migrate before its introduction. For instance, if Seguro Popular was expanded to react to (pre-programme) downward trends in migration, estimates could mirror what was intended, i.e. changes to average migration rates. Individuals and households could also have anticipated that they would benefit from a greater coverage and lowered their propensity to migrate before its expansion. In this case, estimated effects would reflect returns to 'normal' migration rates. Since there are only two time periods, the robustness of the estimates to a potential pre-treatment 'trend' specific to treated observations - an Ashenfelter dip effect (Ashenfelter, 1978) - cannot be assessed. However,

\footnotetext{
${ }^{18}$ In a context of non-decreasing or increasing migration trends, publicly providing healthcare could then be expected to have a stonger effect on migration.
} 
it is reasonable to assume that increasing migration rates have not driven the expansion of Seguro Popular, as policies tend to fight rather than encourage migration, in particular internal migration, fearing unwieldy, unsustainable urbanisation. Migration has been decreasing both internally and globally in Mexico, and respondents in treated areas display a significantly lower propensity to migrate than those residing in control areas before the introduction of the programme (cf. Table 5.2). Moreover, focusing on municipalities that experienced changes in coverage in its expansion phase, not in its pilot phase, is assumed to rule out the existence of households' or individuals' anticipatory migration behaviours.

A last threat to identification is the attrition of households and individuals from the MxFLS. Around $51 \%$ of estimation sample observations were not successfully interviewed in all three waves. Estimates would be biased if there were selection into attrition (retention) due to the expansion of Seguro Popular. The probability of estimation sample respondents not to be interviewed in all three waves of the survey is first regressed. As column (3) of Table 5.6 shows, the effect of a change in coverage is negative but statistically insignificant. This is potential evidence of negative (positive) selection into attrition (or retention). Those living in municipalities that experienced a significant change in coverage might be more likely to be successfully interviewed in all three waves. Equation (1) is then run on a balanced panel. The difference-in-differences estimate in column (4) of Table 5.6 is of a similar magnitude, but slightly loses in statistical significance compared to difference-in-differences estimates with the unbalanced panel. This suggests that, despite potential selection, panel attrition might not substantially affect the estimated effect of Seguro Popular on respondents' propensity to migrate.

Equation (1) is next run with treatment variables defined differently, from a change in Seguro Popular coverage of at least $10 \%$ to $90 \%$ between the two time periods. Table 5.7 shows that accessing non-contributory healthcare significantly increases the propensity to migrate overall (column (11)) as well as up to (and including) a 50\% change in coverage (columns (1)-(6)). Beyond, this effect is negative and statistically insignificant. ${ }^{19}$

\subsubsection{Heterogenous effects}

The full estimation sample is decomposed by gender to account for some degree of genderdifferentiated time and task distribution. In Mexico, women tend to spend more time caring for dependants than men (del Valle, 2016). Columns (1) and (2) of Table 5.8 confirm this hypothesis: men are significantly more likely to migrate than women following a change in coverage (respectively 3.87 and 2.90 percentage points). Estimates hold robustness checks. This is consistent with evidence from South Africa and India showing that, when women are those affiliated, other family members, in particular men, tend to migrate (e.g. Sienaert, 2008). Treated households might simultaneously follow different livelihood strategies. Some household members, women, would stay home to benefit from local labour market opportunities and

\footnotetext{
${ }^{19}$ Estimates hold robustness checks, only their statistical significance is (sometimes) slightly reduced. Robustness checks are available on request. Overall, estimates of Table 5.7 from column (7) to (10) might be affected by a reduced sample size of treated.
} 
affiliation to Seguro Popular, while taking care of dependants when they do not work outside their households. Men, now financially 'enabled' to leave, with less time tied to dependants and not socially expected to care for them, would migrate (Hagen-Zanker and Leon-Himmelstine, 2013).

Table 5.6 - Robustness checks

\begin{tabular}{|c|c|c|c|c|}
\hline Variables & $\begin{array}{c}\text { Has migrated } \\
\text { (1) }\end{array}$ & $\begin{array}{c}\text { Has migrated } \\
(2)\end{array}$ & $\begin{array}{l}\text { Attrition } \\
\quad(3)\end{array}$ & $\begin{array}{c}\text { Has migrated } \\
\text { (4) }\end{array}$ \\
\hline Treated X 2005 & & & $\begin{array}{c}-0.0144 \\
(0.0198)\end{array}$ & $\begin{array}{c}0.0311^{* *} \\
(0.0143)\end{array}$ \\
\hline 2005 & & $\begin{array}{c}.0336^{* * *} \\
(.0000)\end{array}$ & $\begin{array}{c}-0.1073^{* * *} \\
(0.0154)\end{array}$ & $\begin{array}{l}-0.0118 \\
(0.0133)\end{array}$ \\
\hline Treated & $\begin{array}{c}-0.0333^{* * *} \\
(0.0094)\end{array}$ & & & \\
\hline Fake treatment X 2005 & & $\begin{array}{c}-.0143^{* * *} \\
(.0009)\end{array}$ & & \\
\hline Time FE & No & Yes & Yes & Yes \\
\hline Municipality FE & No & Yes & Yes & Yes \\
\hline Control variables & Yes & Yes & Yes & Yes \\
\hline Mean of dependent variable & $\begin{array}{c}.0732 \\
(.2606)\end{array}$ & $\begin{array}{l}.0815 \\
(.0002)\end{array}$ & $\begin{array}{l}.3876 \\
(.4872)\end{array}$ & $\begin{array}{l}.0540 \\
(.2260)\end{array}$ \\
\hline Observations & 3,919 & 3,508 & 7,231 & 7,074 \\
\hline R-squared & 0.0285 & .0359 & 0.3190 & 0.0489 \\
\hline
\end{tabular}

Notes: Estimates are for 21-65-year-old individuals, interviewed in at least two consecutive waves in columns (1)-(3); in three consecutives waves in column (4) (balanced panel). Respondents exposed to a change in coverage of at least $10 \%$ and strictly lower than $20 \%$ are excluded. In column (1), the estimation sample is limited to the first time period. In column (2), observations are limited to never treated that were assigned a fake treatment. In columns (1), (2) and (4), the dependent variable is a binary variable taking unity if an individual migrated between wave 1 (2002) and wave 2 (2005) and/or between wave 2 and wave 3 (2009). In column (3), the dependent variable is a binary variable that takes value 1 if a respondent with non-missing information was not successfully interviewed in three consecutive waves. Columns (1)-(4) present coefficient estimates of linear probability models. Column (1) presents estimates of a placebo test; column (2), of a falsification test; columns (3)-(4) investigates panel attrition. Standard errors robust to heteroscedasticity are in parentheses. In column (2), random assignment of fake treatment and regressions were bootstrapped (1,000 repetitions) (standard errors reported in parentheses in column (2) are bootstrapped). $* * * \mathrm{p}<0.01, * * \mathrm{p}<0.05, * \mathrm{p}<0.1$. 
Table 5.7 - Non-linearities

\begin{tabular}{|c|c|c|c|c|c|c|c|c|c|c|c|}
\hline Variables & (1) & (2) & (3) & (4) & (5) & (6) & (7) & (8) & (9) & $(10)$ & (11) \\
\hline $10 \%$ coverage change X 2005 & $\begin{array}{c}0.0340^{* * *} \\
(0.0122)\end{array}$ & $\begin{array}{c}0.0311^{* * *} \\
(0.0111)\end{array}$ & & & & & & & & & \\
\hline $20 \%$ coverage change X 2005 & & & $\begin{array}{c}0.0214^{* *} \\
(0.0103)\end{array}$ & & & & & & & & \\
\hline $30 \%$ coverage change X 2005 & & & & $\begin{array}{c}0.0166 \\
(0.0116)\end{array}$ & & & & & & & \\
\hline $40 \%$ coverage change X 2005 & & & & & $\begin{array}{c}0.0174 \\
(0.0125)\end{array}$ & & & & & & \\
\hline $50 \%$ coverage change X 2005 & & & & & & $\begin{array}{c}0.0362^{*} \\
(0.0194)\end{array}$ & & & & & \\
\hline $60 \%$ coverage change X 2005 & & & & & & & $\begin{array}{l}-0.0092 \\
(0.0105)\end{array}$ & & & & \\
\hline $70 \%$ coverage change X 2005 & & & & & & & & $\begin{array}{l}-0.0092 \\
(0.0105)\end{array}$ & & & \\
\hline $80 \%$ coverage change X 2005 & & & & & & & & & $\begin{array}{c}0.0000 \\
(0.0000)\end{array}$ & & \\
\hline $90 \%$ coverage change X 2005 & & & & & & & & & & $\begin{array}{c}0.0000 \\
(0.0000)\end{array}$ & \\
\hline Coverage change X 2005 & & & & & & & & & & & $\begin{array}{c}0.0736^{* *} \\
(0.0296)\end{array}$ \\
\hline 2005 & $\begin{array}{c}-0.0191^{*} \\
(0.0099)\end{array}$ & $\begin{array}{c}-0.0164^{*} \\
(0.0098)\end{array}$ & $\begin{array}{l}-0.0049 \\
(0.0074)\end{array}$ & $\begin{array}{c}0.0011 \\
(0.0063)\end{array}$ & $\begin{array}{c}0.0018 \\
(0.0062)\end{array}$ & $\begin{array}{c}0.0030 \\
(0.0056)\end{array}$ & $\begin{array}{c}0.0051 \\
(0.0056)\end{array}$ & $\begin{array}{c}0.0051 \\
(0.0056)\end{array}$ & $\begin{array}{c}0.0048 \\
(0.0053)\end{array}$ & $\begin{array}{c}0.0048 \\
(0.0053)\end{array}$ & $\begin{array}{l}-0.0103 \\
(0.0089)\end{array}$ \\
\hline Time FE & Yes & Yes & Yes & Yes & Yes & Yes & Yes & Yes & Yes & Yes & Yes \\
\hline Municipality FE & Yes & Yes & Yes & Yes & Yes & Yes & Yes & Yes & Yes & Yes & Yes \\
\hline Control variables & Yes & Yes & Yes & Yes & Yes & Yes & Yes & Yes & Yes & Yes & Yes \\
\hline Mean of dependent variable & $\begin{array}{l}.0658 \\
(.2480)\end{array}$ & $\begin{array}{l}.0633 \\
(.2435)\end{array}$ & $\begin{array}{l}.0633 \\
(.2435)\end{array}$ & $\begin{array}{l}.0633 \\
(.2435)\end{array}$ & $\begin{array}{l}.0633 \\
(.2435)\end{array}$ & $\begin{array}{l}.0633 \\
(.2435)\end{array}$ & $\begin{array}{l}.0633 \\
(.2435)\end{array}$ & $\begin{array}{l}.0633 \\
(.2435)\end{array}$ & $\begin{array}{l}.0633 \\
(.2435)\end{array}$ & $\begin{array}{l}.0633 \\
(.2435)\end{array}$ & $\begin{array}{l}.0633 \\
(.2435)\end{array}$ \\
\hline Observations & 7,231 & 9,431 & 9,431 & 9,431 & 9,431 & 9,431 & 9,431 & 9,431 & 9,431 & 9,431 & 9,431 \\
\hline R-squared & 0.0405 & 0.0408 & 0.0403 & 0.0401 & 0.0401 & 0.0401 & 0.0399 & 0.0399 & 0.0399 & 0.0399 & 0.0404 \\
\hline
\end{tabular}

Notes: Estimates are for 21-65-year-old individuals, interviewed in at least two consecutive waves In column (1), respondents exposed to a change in coverage of at least $10 \%$ and strictly lower than $20 \%$ are excluded. Columns (1)-(11) present coefficient estimates of linear probability models. In columns (1)-(2), the treatment variable is a binary variable taking value one if respondents were exposed to a change in coverage of at least $10 \%$; in column (3), of at least 20\%; in column (4), of at least 30\%; in column (5), of at least 40\%; in column (6), of at least $50 \%$; in column (7), of at least $60 \%$; in column (8), of at least $70 \%$; in column (9), of at least $80 \%$; in column (10), of at least $90 \%$; in column (11), it is a continuous variable measuring the change in coverage exposure between time periods. Standard errors robust to heteroscedasticity are in parentheses. ${ }^{* * *} \mathrm{p}<0.01,{ }^{* *} \mathrm{p}<0.05,{ }^{*} \mathrm{p}<0.1$. 
The probability to migrate internally and internationally are then separately regressed on the full estimation sample. As columns (3) and (4) of Table 5.8 show, difference-in-differences estimates only hold for internal migration, with a statistically significant increase of 3.48 percentage points. The effect on international migration is null but statistically insignificant. Estimates hold robustness checks. The fact that the insignificance of the expansion of Seguro Popular on international migration is explained by the very low average international migration in the estimation sample $(0.8 \%)$ cannot be ruled out. However, it can be the case that access to healthcare has a significant effect on internal migration but insignificant on international migration, in particular if difficult access to financial capital and budget constraints have been limiting migration. This might be because internal migration tends to be less expensive, less risky than international migration, and because affiliation to Seguro Popular does not directly provide cash, but increases disposable income by limiting health expenditures.

Table 5.8 - Heterogeneous effects

\begin{tabular}{lccccc}
\hline \hline & \multicolumn{4}{c}{ Has migrated } \\
\cline { 2 - 3 } Variables & Female & Male & & Internal & International \\
& $(1)$ & $(2)$ & & $(3)$ & $(4)$ \\
\cline { 2 - 3 } \cline { 5 - 6 } Treated X 2005 & $0.0290^{*}$ & $0.0387^{* *}$ & & $0.0348^{* * *}$ & 0.0001 \\
& $(0.0154)$ & $(0.0195)$ & & $(0.0118)$ & $(0.0044)$ \\
2005 & $-0.0225^{*}$ & -0.0129 & & -0.0137 & -0.0017 \\
& $(0.0124)$ & $(0.0160)$ & & $(0.0097)$ & $(0.0031)$ \\
Time FE & Yes & Yes & & Yes & Yes \\
Municipality FE & Yes & Yes & & Yes & Yes \\
Control variables & Yes & Yes & & Yes & Yes \\
Mean of dependent variable & .0582 & .0746 & & .0595 & .0086 \\
& $(.2342)$ & $(.2628)$ & & $(.2365)$ & $(.0922)$ \\
Observations & 3,865 & 3,364 & & 7,231 & 7,231 \\
R-squared & 0.0520 & 0.0399 & 0.0403 & 0.0472 \\
\hline \hline
\end{tabular}

Notes: Estimates are for 21-65-year-old individuals, interviewed in at least two consecutive waves. In columns (1)-(4), the dependent variable is a binary variable taking unity if an individual migrated between wave 1 (2002) and wave 2 (2005) and/or between wave 2 and wave 3 (2009). In columns (1), the estimation sample is limited to women; in column (2), to men. In column (3), the dependent variable takes value 1 if migration was internal; 0, otherwise. In column (4), it takes value 1 if migration was international; 0, otherwise. Columns (1)-(4) present coefficient estimates of linear probability models. Standard errors robust to heteroscedasticity are in parentheses. ${ }^{* * *} \mathrm{p}<0.01,{ }^{* *} \mathrm{p}<0.05,{ }^{*} \mathrm{p}<0.1$.

\subsubsection{Investigating potential mechanisms}

This subsection further sheds light on mechanisms that might be at stake by running equation (1) on a different set of outcomes. Column (1) of Table 5.9 suggests that a change in healthcare coverage has an almost null, insignificant effect on subjective health reported at the end of each time period. Columns (2) and (3) look at the relationship between change in coverage and time dedicated to caring for dependants. Column (2) shows that a major increase in publicly 
provided healthcare decreases the propensity to spend time caring. The coefficient estimate on the number of hours in column (3) is negative but statistically insignificant.

Column (4) indicates that changes in coverage are associated with a greater propensity to report health-related economic shocks in a household. This increase in risk of health shocks is in line with the fact that, to benefit from non-contributory healthcare, health-related shocks have to be reported. Health insurance might encourage affiliates to look for care when sick, as evidenced by Wagstaff and Lindelow (2008). Estimates from columns (1)-(4) taken together suggest that healthcare expansion has improved households' resilience to health-related shocks, and enabled caregivers to reallocate time from caring to work outside their household, thus expanding their work opportunities across space.

The increase in disposable income following affiliation to Seguro Popular could not only limit financial constraints, but also, if used as collateral, increase beneficiaries' credit worthiness. Loans could then fund migration. Equation (1) is run with a dependent variable that takes value 1 if respondents have asked for a loan in the 12 months preceding the end of the time period of each wave. ${ }^{20}$ Although this is an imperfect measure of borrowing behaviours, ${ }^{21}$ column (5) of Table 5.9 shows a positive but statistically insignificant relationship between changes in healthcare coverage and likelihood to borrow in the previous 12 months. While the fact that this insignificance is due to the relatively high variance of the outcome variable cannot be ruled out, it does not clearly support the hypothesis.

In columns (6) and (7) of Table 5.9, equation (1) is run with a dependent variable that takes value 1 if respondents' households have made health expenditures in the three months preceding the end of each time period (6), and how much they spent on health in natural logarithm (plus 1) (7). Column (6) and (7) suggest a positive and statistically significant relationship between changes in healthcare coverage and likelihood to spend on health and the amount spent on health expenditures. Albeit counterintuitive, this last set of results could be interpreted as the access to non-contributory healthcare enabling affiliated households to spend on non-covered health items, and so fostering greater consumption of health goods and services.

In interpreting these results, it should however be kept in mind that only estimates for the propensity to borrow and to spend on health expenditures hold robustness checks. Taken together, estimates thus suggest that changes in Seguro Popular affiliation affected migration by relaxing financial constraints through borrowing or health expenditures. Accessing Seguro Popular might have further freed up working-age members in affiliated households from care constraints, a decreasing trend that might have affected respondents in both treated and control municipalities at the time of the survey.

\footnotetext{
${ }^{20}$ That is up to a year from 2005 for the first time period, and up to a year from 2009 for the second time period.

${ }^{21} \mathrm{~A}$ household member might ask for a loan for another relative. Loans that were used to fund migration that took place more than 12 months before MxFLS 2 and MxFLS 3 are not reported.
} 
Table 5.9 - Potential mechanisms

\begin{tabular}{|c|c|c|c|c|c|c|c|}
\hline & $\begin{array}{l}\text { Health } \\
\text { status }\end{array}$ & $\begin{array}{c}\text { Spent } \\
\text { time } \\
\text { caring }\end{array}$ & $\begin{array}{l}\text { Hours } \\
\text { spent } \\
\text { caring }\end{array}$ & $\begin{array}{c}\text { Health } \\
\text { shock }\end{array}$ & $\begin{array}{c}\text { Borrowed } \\
\text { money }\end{array}$ & $\begin{array}{c}\text { Spent } \\
\text { money } \\
\text { on health }\end{array}$ & $\begin{array}{c}\text { Health } \\
\text { expenditures }\end{array}$ \\
\hline Variables & (1) & $(2)$ & (3) & (4) & (5) & (6) & (7) \\
\hline Treated X 2005 & $\begin{array}{l}-0.0046 \\
(0.0117)\end{array}$ & $\begin{array}{c}-0.0379^{* *} \\
(0.0193)\end{array}$ & $\begin{array}{c}-0.6992 \\
(0.7318)\end{array}$ & $\begin{array}{c}0.0556^{* * *} \\
(0.0168)\end{array}$ & $\begin{array}{c}0.0216 \\
(0.0154)\end{array}$ & $\begin{array}{c}0.0155^{* * *} \\
(0.0051)\end{array}$ & $\begin{array}{c}0.2427^{*} \\
(0.1449)\end{array}$ \\
\hline 2005 & $\begin{array}{c}-0.0005 \\
(0.0087)\end{array}$ & $\begin{array}{c}0.0450^{* * *} \\
(0.0152)\end{array}$ & $\begin{array}{l}1.0890^{*} \\
(0.5865)\end{array}$ & $\begin{array}{c}0.0024 \\
(0.0135)\end{array}$ & $\begin{array}{c}0.0531^{* * *} \\
(0.0125)\end{array}$ & $\begin{array}{c}-0.0106^{* *} \\
(0.0043)\end{array}$ & $\begin{array}{c}-0.2292^{* *} \\
(0.1163)\end{array}$ \\
\hline Time FE & Yes & Yes & Yes & Yes & Yes & Yes & Yes \\
\hline Municipality FE & Yes & Yes & Yes & Yes & Yes & Yes & Yes \\
\hline Control variables & Yes & Yes & Yes & Yes & Yes & Yes & Yes \\
\hline Mean of dependent variable & $\begin{array}{c}.9422 \\
(.2335)\end{array}$ & $\begin{array}{l}.2228 \\
(.4161)\end{array}$ & $\begin{array}{c}5.9508 \\
(15.5124)\end{array}$ & $\begin{array}{l}.1230 \\
(.3319)\end{array}$ & $\begin{array}{l}.1026 \\
(.3035)\end{array}$ & $\begin{array}{l}.9908 \\
(.0954)\end{array}$ & $\begin{array}{c}1.8468 \\
(2.9177)\end{array}$ \\
\hline Observations & 6,811 & 7,231 & 7,231 & 7,231 & 7,231 & 7,070 & 7,005 \\
\hline R-squared & 0.0411 & 0.1565 & 0.1341 & 0.0422 & 0.0492 & 0.0214 & 0.0758 \\
\hline
\end{tabular}

Notes: Estimates are for 21-65-year-old individuals, interviewed in at least two consecutive waves. In column (1), the dependent variable is a binary variable taking unity if an individual reported to have regular, good or very good health at the end of the time period; 0 , if s/he reported bad or very bad health. In column (2), it is a binary variable taking unity if an individual dedicated time to caring for dependants over the previous week at the end of the time period. In column (3), it is a continuous variable measuring the number of hours an individual dedicated to caring for dependants over the previous week at the end of the time period. In column (4), it is a binary variable taking value 1 if an individual belongs to a household that experienced at least one health-related economic shock in the five years preceding the end of the time period. In column (5), it is a binary variable that takes value 1 if an individual has borrowed in the 12 months preceding the end of the time period. In column (6), it is a binary variable that takes value 1 if the household of respondents has had health expenditures in the 3 months preceding the end of the time period. In column (7), it is a continuous variable of the natural logarithm of how much respondents' households have spent on health expenditures in the 3 months preceding the end of the time period plus 1. Columns (1)-(7) present coefficient estimates of linear probability models. Standard errors robust to heteroscedasticity are in parentheses. ${ }^{* * *} \mathrm{p}<0.01,{ }^{* *} \mathrm{p}<0.05,{ }^{*} \mathrm{p}<0.1$.

\subsection{Conclusion}

While the academic and political debate has emphasised adverse labour market incentives, the positive effects of safety nets on health and poverty are increasingly recognised. A growing literature has been studying how social health protection programmes relate to household livelihood strategies, in particular the decision to migrate within recipient households. A contribution of this analysis is to exploit the expansion of a publicly provided healthcare programme initiated in 2002 in Mexico to obtain causal estimates on this relationship.

This analysis takes advantage of the timing and the panel structure of the MxFLS and uses a difference-in-differences specification to estimate a non-negligible migration effect in municipalities that experienced a major change in coverage rate in the middle of Seguro Popular roll-out. Individuals living in treated municipalities were more likely to migrate following a change in exposure to the treatment, compared to respondents living in municipalities that did not experience a significant change in coverage rate. Examining estimate heterogeneity suggests that associated increases in disposable income were not substantial enough to fund international migration, in contrast to other non-contributory health insurance schemes, e.g. conditional cash transfer programmes. The increase in the probability to migrate is only statistically significant for men, supporting the idea that, in a context of gender-differentiated task distribution and income source diversification like in Mexico, men are those more likely 
to migrate compared to women. Robustness checks confirm the validity of the identification strategy against threats of time-trending unobservables that might vary significantly between treated and control municipalities. They reveal that changes in migration propensity prior to the programme were negatively correlated with its expansion, consistent with current migration trends within and from Mexico.

In showing that (non-contributory) safety nets can increase the propensity to migrate, these results shed light on some (unattended) effects of publicly provided healthcare. They suggest that migrating might be a channel through which labour market behaviours and livelihood strategies are affected. Building financial strength and freeing up caregivers' time through reduced occurrence and duration of health shocks can encourage labour force detachment of working-age members in households vulnerable to adverse shocks. By enabling the relocation of labour available within a household, having coverage furthers the diversification of household income sources, which is likely to help families break out of poverty traps.

While findings are obtained for the case of Mexico, with about 9,000 observations from household survey data that are not representative at the municipality level (treatment unit), which might threaten the external validity of this study, they have interesting implications. Given the importance publicly provided healthcare has been receiving as a means to reduce poverty, while potentially distorting labour markets, analysing dynamics between access to healthcare and migration is likely to be at the centre of the social policy debate. This chapter contributes to this discussion by providing causal estimates of the impacts of a significant change in publicly provided healthcare on the propensity to migrate. It also suggests that it is necessary to include both recipients and household members living with them or who have migrated in this analysis. Results emphasise the importance of including household members who do not reside with recipients. Not accounting for the effects of social (health) protection programmes on migration might question the reliability of results obtained in other literatures, such as labour market behaviours.

This analysis only focused on short-run effects. However, healthcare coverage has been found to have positive effects on the health and educational outcomes of dependants, in particular children of affiliates (Alcaraz et al., 2016). For this reason, these dependants could be expected to display a greater propensity to migrate in the longer run if, while they are equipped with better health and higher education, local labour markets did not offer them adequate opportunities. Investigating the implications of non-contributory healthcare expansion on the likelihood to migrate in the long term is thus an interesting direction for research. 



\section{Chapter 6}

\section{Conclusion}

Motivated by the growing interest in migration as an economic and social phenomenon, this thesis has explored several aspects of the relationship between migration and occupational choice, using data from Egypt, Kyrgyzstan and Mexico. Chapters 2 to 4 consider the effects of migration on occupational choice; and Chapter 5 , the determinants of migration. Chapter 2 analyses how migration shapes entrepreneurial abilities. Chapter 3 examines whether migration affects dynamics in and out of self-employment in a consistent and integrated fashion. Chapter 4 exploits the documented effect of migration on occupational choice upon migrants' return to their origin countries to establish a link between return migration of men and their wives' time allocation through within-couple occupational interdependence. Chapter 5 uses a natural experiment, the introduction of a publicly provided healthcare programme, to understand the links between social health protection and migration, and document the migration decision process.

\subsection{Main findings}

In the introduction of this thesis, four questions relating migration to occupational choice were asked. Here, I first restate and answer each question. Then, I draw policy implications and suggest directions for future research.

1. Can migrating develop entrepreneurial abilities? (Chapter 2) Migration increases the likelihood of being and surviving as self-employed through the development of entrepreneurial abilities - the exposure to varied occupations or industries. Beyond migration-induced wealth effects, the work experience gained abroad per se is found to affect migrants' occupational choice upon return. Migration appears to contribute to the formation of a balanced skill profile conducive to entrepreneurship by facilitating the accumulation of skills across sectors and occupations. In this sense, migrating can be seen as a process shaping entrepreneurial abilities.

2. Does migration disrupt self-employment trajectories? (Chapter 3) While return migration is found to increase the probability to enter into self-employment, returnees' motives 
to do so are based on necessity rather than opportunity. As a result, self-employment tends to be more of a temporary choice, akin to a 'parking lot'. If migrants were selfemployed before leaving, they are found to be less likely to be self-employed upon return to their origin countries, at least as soon as they return. They are more likely to exit from self-employment in subsequent periods than non-migrants, and to move to employed occupations. Temporary migration seems more disruptive of self-employment trajectories than is often thought. The potential for return migration to stimulate entrepreneurship should not be overestimated, as it might not necessarily lead to sustaining a career in self-employment.

3. Does living with return migrants affect time use? (Chapter 4) Being married to migrants who opted for self-employment upon return decreases women's likelihood to engage in paid work, and increases their likelihood to engage in family business, subsistence farming and domestic chores, at both the extensive and intensive margins. Results question the idea that the return of migrant household members does not alter time allocation and task distribution within a household, nor the occupations of non-migrating household members. They emphasise (possibly) time depriving migration-induced effects on women, even once migration is complete.

4. Does publicly provided healthcare influence migration? (Chapter 5) Financial and care constraints are found to prevent households from sending migrants. By freeing up working-age household members' time and strengthening household (economic) resilience in the face of health shocks, accessing publicly provided healthcare alleviates financial and time constraints. Non-contributory health insurance can enable labour force detachment of working-age members in affiliated households.

\subsection{Policy implications}

Several policy lessons based on the findings of these Essays can be of interest to policymakers. I have presented them in the introductory chapter and each corresponding analytical chapter. To summarise,

1. Chapter 2 informs entrepreneurship (education) policies in a low middle-income country context with high youth unemployment, a dynamic micro- and small enterprise (MSE) sector and significant (temporary) international migration. In showing how migration can offer learning opportunities, it confirms that entrepreneurship can be learnt, and that learning-by-doing and experiential learning matter for entering into and persisting in selfemployment. This is of particular relevance since the MSE sector is often thought of as a solution to (youth) unemployment, characteristic of developing and emerging economies. Entrepreneurship support policies should focus on widening the work experience of potential entrepreneurs, except maybe in agriculture, a sector for which results of Chapter 2 do not hold. In countries like Egypt, the agricultural sector might be facing institutional and geography-specific challenges. Entrepreneurial success in agriculture might require 
easier access to land as well as skill specialisation rather than diversification. Better access to land, land consolidation and modernisation of the farming sector could allow moving away from subsistence farming towards higher efficiency and economies of scale.

2. Chapter 3 suggests that migration can disrupt self-employment trajectories in a low middle-income country setting in transition from planned to market economy. That migrants who were self-employed before leaving would be less likely to be self-employed upon return can be seen in a positive light as this 'disruption' enables career development by offering an escape from necessity-driven self-employment. It thus reduces the number of low-ability self-employed. In this case, the appropriate policy response is to support swift occupational transitions to returnees' preferred options and their reintegration in origin country labour markets to avoid low-productivity entrepreneurship. However, if migrants gained resources abroad, that self-employment is a rather temporary occupational choice suggests that the 'disruption' caused by migration may prevent an economy from benefiting from return migrants' experience as entrepreneurs. In this case, the appropriate policy response is to improve the conditions for doing business in source countries. In transition economies like Kyrgyzstan, temporary migration might substitute for an imperfect legal framework and weak financial markets, legacies of the Soviet era. Support for formal market-supporting institutions is advised if countries are to harness the entrepreneurial acumen migrants might have developed.

3. The results of Chapter 4 are explained by the existence of occupational interdependence between spouses, most likely to diversify activities and as a result of assortative mating, along time-use gender differentiation lines. They indicate that, when planning to create a favourable environment for efficient income source diversification and women's empowerment in Egypt, policymakers should consider the effects of migration, withincouple occupational interdependence and gender-differentiated time allocation within households. Given the higher propensity of migrants to set up businesses upon return, return migrants might dispose over their wives' time for their own business purposes either directly, as unpaid workers, or indirectly, by working outside their households or in subsistence farming. As a result, they might disproportionately capture their wives' time. Attention should be paid to buffering possibly time-depriving migration-induced effects on women. If not, return migration might increase the time burden placed on women, and contribute to women's time poverty. Strengthening local labour markets could decrease the level of occupational interdependence between spouses by encouraging households to substitute women's family work with hired external labour, freeing up women's time. Women would then be offered viable outside options, enhancing their autonomy, for a more inclusive growth.

4. Given the interest the expansion of publicly provided healthcare has recently received, analysing dynamics between access to healthcare and migration as a mechanism contributing to occupational mobility is likely to be at the centre of the social policy and development debate. Chapter 5 contributes to this discussion by providing causal 
estimates of the impacts of a significant change in publicly provided healthcare on the propensity to migrate in an upper middle-income country with decreasing migration. First, the significant relationship between non-contributory healthcare and migration could explain the heterogeneity in existing evidence on the impacts of social health policies on labour market behaviours. Household affiliation to healthcare might enable working-age beneficiaries to migrate, which would make them 'disappear' from estimation samples. Chapter 5 highlights the importance of taking into account their effects on within-household labour attachment, i.e. of including non-resident household members and household members who (might have) migrated in such analyses. Not accounting for the potential effects of social (health) protection programmes on the likelihood to migrate might question the reliability of results obtained for labour market outcomes. Second, the provision of non-contributory health insurance was found to complement alternative livelihood strategies. By limiting the number and the length of health shocks, accessing healthcare (almost) for free increases disposable income and frees up (working-age) caregivers' time, enabling them to spatially reallocate their labour force, and hence further diversify income sources. Non-contributory healthcare could thus have multiplier effects on economic development and welfare through migration by helping surmount financial and care constraints. Chapter 5 gives insights into what prevents migration, which is necessary to improve the design and target of policies seeking to remove impediments to mobility, and to leverage the contribution of migration to the development of origin communities.

\subsection{Suggestions for future research}

There are certainly still several questions regarding migration and occupational choice that can be explored. One of them is whether the general findings of these Essays hold for who migrates men or women, parents or children - and where individuals migrate. Since labour markets tend to be segregated along gender lines, and task distribution gender-stratified, that women migrate might have different implications for source households than the out-migration of men. Analyses account for gender-specific implications when possible, as in Chapters 4 and 5. In Chapters 2 and 3 , the nature of migration trends and the data at hand do not allow investigating these dynamics. Similarly, migration distance and location are exploited when feasible, as in Chapters 2, 4 and, to some extent, 5, but data are not detailed enough to do so in a consistent manner. Where migrants relocate is likely to condition the resources they accumulate while away. The more destination country economies are open to newcomers, the more they can gain from their experience of migration, which determines what and how productive their activities are upon return to their origin communities.

Moreover, while Chapters 2 and 3 study the relationship between migration and selfemployment, other labour market outcomes - wage employment, unemployment or inactivity might be of interest, in particular since Chapter 3 reveals that returnees do not sustain a career in self-employment, but are more likely to exit from self-employment if they were self-employed 
before leaving their origin countries.

Another question concerns general equilibrium implications. The share of return migrants in a household and in a community could simultaneously affect the supply and demand of labour from non-migrating members, including their self-employed activities, and the supply of labour and inputs or the demand for goods and services in their communities of origin.

Furthermore, in Chapter 3, data limit the analysis to occupational choice dynamics, as individuals' businesses were not tracked. However, even if individuals were observed as selfemployed in year $t$ and year $t+1$, they might have shut down, and started up a new venture in that same year or in the following year. Exploring the links between migration and business creation and failure, as well as implications for local labour market equilibria, are thus interesting directions for future research.

In Chapter 4, the links between return migration, spouses' occupations and intra-household cooperation is not formally tested. Examining implications for household cooperation bargaining power, domestic violence - and household efficiency might be an interesting avenue for future research, moreover since returnees have been found to transfer (sometimes conservative) destination country norms.

The importance of occupational interdependence between spouses has been emphasised through other channels to explain how migration can affect non-migrating wives in a static setting. Further research could investigate alternative explanations and study dynamics. It could indeed be that family enterprises capture women's time in their start-up phase, but release it in later stages. The migration experience of husbands would then have only transitory effects on their wives' occupational choices. Linking return migration, business performance and family participation over a longer run constitutes an interesting avenue of research.

Finally, Chapter 5 only focuses on short-run effects. Because healthcare coverage has been found to have positive effects on the health and educational outcomes of dependants, children of affiliates, they could be expected to display a greater propensity to migrate in the longer term if, equipped with better health and higher education, local labour markets do not offer them adequate opportunities. Investigating the long-run implications of non-contributory healthcare expansion on the likelihood to migrate and their welfare impacts will be an interesting direction for future research.

These Essays on Migration and Occupational Choice have sought to refine existing thinking on migration by showing that migration can contribute to a lifetime continuum of occupations, and that social policies condition migration through effects on the labour force. Implications informing gender-sensitive and inclusive labour, entrepreneurship and social protection policies were inferred. To conclude, these Essays are a first attempt at disentangling the dynamics between migration and occupational choice, and have set an original agenda for future research. 



\section{Bibliography}

Abadie, A. and Imbens, G. (2006). Large sample properties of matching estimators for average treatment effects. Econometrica, 74(1):235-267.

Adams, R. and Page, J. (2005). Do international migration and remittances reduce poverty in developing countries? World Development, 33(10):1645-1669.

Alcaraz, C., Chiquiar, D., Orraca, M., and Salcedo, A. (2016). The Effect of publicly provided health insurance on education outcomes in Mexico. World Bank Econmic Review, 30(Supplement):S145-S156.

Alden, L., Hammarstedt, M., and Neuman, E. (2017). All about balance? A Test of the Jack-of-all-Trades theory using military enlistment data. Labour Economics, 49(C):1-13.

Amuedo-Dorantes, C. and Pozo, S. (2006). Remittance receipt and business ownership in the Dominican Republic. The World Economy, 29(7):939-956.

Anderson, S. and Eswaran, M. (2009). What determines female autonomy? Evidence from Bangladesh. Journal of Development Economics, 90(2):179-191.

Angelucci, M. (2015). Migration and financial constraints: Evidence from Mexico. Review of Economics and Statistics, 97(1):224-228.

Antman, F. (2011). International migration and gender discrimination among children leftbehind. American Economic Review, 101(3):645-649.

Antman, F. (2012). Gender, educational attainment and the impact of parental migration on children left behind. Journal of Population Economics, 25(4):1187-1214.

Antman, F. (2015). Gender discrimination in the allocation of migrant household resources. Journal of Population Economics, 28(3):565-592.

Ardington, C., Case, A., and Hosegood, V. (2009). Labor supply responses to large social transfers: Longitudinal evidence from South Africa. American Economic Journal: Applied Economics, 1(1):22-48.

Aroca, P. and Maloney, W. (2005). Migration, trade, and foreign direct investment in Mexico. World Bank Economic Review, 19(3):449-472.

Arsenijevic, J., Pavlova, M., and Groot, W. (2015). Social protection in health care and vulnerable population groups in Serbia. Frontiers in Public Health, 3(194):1-4.

Ashenfelter, O. (1978). Estimating the effect of training programs on earnings. Review of Economics and Statistics, 6(1):47-57.

Assaad, R. and El-Hamidi, F. (2009). Women in the Egyptian labor market: An Analysis of developments, 1988-2006. In Assaad, R., editor, The Egyptian Labor Market Revisited, chapter 7, pages 259-284. Cairo: The American University Cairo Press.

Assaad, R. and Kraft, C. (2013). The Egypt Labor Market Panel Survey: Introducing the 2012 round. ERF Working Paper No. 758. Giza: Economic Research Forum.

Astebro, T. and Thompson, P. (2011). Entrepreneurs: Jacks of all trades or hobos? Research Policy, 40(5):637-649.

Atamanov, A. and van den Berg, M. (2012). Heterogeneous effects of international migration and remittances on crop income: Evidence from the Kyrgyz Republic. World Development, 40(3):620-630. 
Aterido, R., Hallward-Driemeier, M., and Pages, C. (2010). Does expanding health insurance beyond formal-sector workers encourage informality? Measuring the impact of Mexico's Seguro Popular. Mimeo.

Atinc, T., Banerjee, A., Ferreira, F., Lanjouw, P., Menendez, M., Ozler, B., Prennushi, G., Rao, V., Robinson, J., Walton, M., and Woolcock, M. (2005). World development report 2006: Equity and development. Washington, D.C.: World Bank Group.

Audretsch, D. B. and Thurik, A. R. (2001). What is new about the new economy: Sources of growth in the managed and entrepreneurial economies. Industrial and Corporate Change, 10(1):267-315.

Azuara, O. and Marinescu, I. (2013). Informality and the expansion of social protection programs: Evidence from Mexico. Journal of Health Economics, 32(5):938-950.

Baicker, K., Finkelstein, A., Song, J., and Taubman, S. (2014). The Impact of Medicaid on labor market activity and program participation: Evidence from the Oregon health insurance experiment. American Economic Review, 104(5):322-28.

Barros, R. (2008). Wealthier but not much healthier: Effects of a health insurance program for the poor in Mexico. SIEPR Discussion Papers No. 09-002. Stanford: Stanford Institute for Economic Policy Research.

Batista, C., McIndoe-Calder, T., and Vicente, P. (2017). Return migration, self-selection and entrepreneurship. Oxford Bulletin of Economics and Statistics, 79(5):797-821.

Becker, G. (1973). A Theory of marriage: Part I. Journal of Political Economy, 81(4):813-846.

Becker, G. (1981). A Treatise on the Family. Cambridge, MA: Harvard University Press.

Beegle, K., de Weerdt, J., and Dercon, S. (2011). Migration and economic mobility in Tanzania: Evidence from a tracking survey. Review of Economics and Statistics, 93(3):1010-1033.

Bernal, N., Carpio, M., and Klein, T. (2017). The Effects of access to health insurance: Evidence from a regression discontinuity design in Peru. Journal of Public Economics, 154(C):122-136.

Bertoli, S. and Marchetta, F. (2015). Bringing it all back home - Return migration and fertility choices. World Development, 65:27-40.

Binzel, C. and Assaad, R. (2011). Egyptian men working abroad: Labor supply responses by the women left behind. Labour Economics, 18(S1):S98-S114.

Black, R. and Castaldo, A. (2009). Return migration and entrepreneurship in Ghana and Cote d'Ivoire: The Role of capital transfers. Tijdschrift voor Economische en Sociale Geografie, 100(1):44-58.

Bleaney, M. and Dimico, A. (2011). How different are the correlates of onset and continuation of civil wars? Journal of Peace Research, 48(2):145-155.

Bosch, M. and Campos-Vázquez, R. (2014). The Trade-offs of welfare policies in labor markets with informal jobs: The Case of the 'Seguro Popular' program in Mexico. American Economic Journal: Economic Policy, 6(4):71-99.

Bosch, M., Cobacho, M., and Pages, C. (2012). Taking stock of eight years of implementation of Seguro Popular in Mexico. Mimeo.

Browning, M., Bourguignon, F., Chiappori, P., and Lechene, V. (1994). Income and outcomes: A Structural model of intrahousehold allocation. Journal of Political Economy, 102(6):10671096.

Brück, T., Esenaliev, D., Kroeger, A., Kudebayeva, A., Mirkasimov, B., and Steiner, S. (2014). Household survey data for research on well-being and behavior in Central Asia. Journal of Comparative Economics, 42(3):819-835.

Bryan, G., Chowdhury, S., and Mobarak, A. (2014). Underinvestment in a profitable technology: TheCase of seasonal migration in Bangladesh. Econometrica, 82(5):1671-1748.

Cameron, A. and Trivedi, P. (2009). Microeconometrics using Stata. College station, tx: Stata press edition.

Cazzuffi, C. and Modrego, F. (2017). Place of origin and internal migration decisions in Mexico. 
Spatial Economic Analysis, 0(0):1-19.

Cazzuffi, C. and Pereira-López, M. (2016). Internal migration and convergence in Mexico 20002010. Rimisp Working Paper series No. 199. Santiago: Centro Latinoamericano para el Desarollo Rural.

Chakraborty, T., Mirkasimov, B., and Steiner, S. (2015). Transfer behaviour in migrant sending communities. Journal of Comparative Economics, 43(3):690-705.

Chau, N., Kanbur, R., and Qin, Y. (2012). Do public work schemes deter or encourage outmigration? Empirical evidence from China. CEPR Discussion Paper No. DP8778. London: Centre for Economic Policy Research.

Chen, Y. and Feng, H. (2012). Are Entrepreneurs Jacks-of-all-trades? Evidence from a return migration survey in rural China. Mimeo.

Chiquiar, D. and Hanson, G. (2005). International migration, self-selection, and the distribution of wages: Evidence from Mexico and the United States. Journal of Political Economy, 113(2):239-281.

Christiaensen, L. and Todo, Y. (2014). Poverty reduction during the rural-urban transformation - The Role of the missing middle. World Development, 63(C):43-58. Elsevier.

Clemens, M. and Pritchett, L. (2016). The New economic case for migration restrictions: An Assessment. CGD Working Paper No. 423. Washington, D.C.: Center for Global Development.

Conti, G. and Ginja, R. (2016). Health insurance and child health: Evidence from Mexico. IZA Discussion Paper Series No. 10122. Bonn: Institute for the Study of Labor.

Cutler, D., J., and Gruber (1996). Does public insurance crowd out private insurance? Quarterly Journal of Economics, 111(2):391-430.

Dave, D., Decker, S., Kaestner, R., and Simon, K. (2015). The Effect of Medicaid expansions in the late 1980s and early 1990s on the labor supply of pregnant women. American Journal of Health Economics, 1(2):165-193.

de Janvry, A., Emerick, K., Gonzalez-Navarro, M., and Sadoulet, E. (2015). Delinking land rights from land use: Certification and migration in Mexico. American Economic Review, 105(10):3125-3149.

de Ree, J. and Nillesen, E. (2009). Aiding violence or peace? The Impact of foreign aid on the risk of civil conflict in sub-Saharan Africa. Journal of Development Economics, 88(2):301-313.

del Valle, A. (2016). From caring to work: The Labor market effects of public health insurance. Mimeo.

Démurger, S. and Xu, H. (2011). Return migrants: The Rise of new entrepreneurs in rural China. World Development, 39(10):1847-1861.

Díaz-Cayeros, A., Estévez, F., and Magaloni, B. (2006). Buying-off the poor: Effects of targeted benefits in the 2006 presidential race. Presented at the Mexico 2006 Panel Study Conference, Harvard University, Boston, USA.

Dillon, E. and Stanton, C. (2017). Self-employment dynamics and the returns to entrepreneurship. NBER Working Paper No. 23168. Cambridge, M.A.: National Bureau of Economic Research.

Dunn, T. and Holtz-Eakin, D. (2000). Financial capital, human capital and the transition to self-employment: Evidence from intergenerational links. Journal of Labor Economics, 18(2):282-305.

Dustmann, C. and Gorlach, J.-S. (2016). The Economics of temporary migrations. Journal of Economic Literature, 54(1):98-136.

Dustmann, C. and Kirchkamp, O. (2002). The Optimal migration duration and activity choice after re-migration. Journal of Development Economics, 67(2):351-372.

Economic Research Forum and Central Agency for Public Mobilization and Statistics (2013). Egypt Labor Market Panel Survey, ELMPS (2012), Version 2.1 of the 
licensed data files. Provided by the Economic Research Forum, available at http://www.erfdataportal.com/index.php/catalog [Accessed in May 2015].

Egger, H., Egger, P., and Greenaway, D. (2008). The Trade structure effects of endogenous regional trade agreements. Journal of International Economics, 74(2):278-298.

El-Mallakh, N. and Wahba, J. (2016). Upward or downward: Occupational mobility and return migration. ERF Working Paper Series No. 1010. Giza: Economic Research Forum.

Falvey, R. and Foster-McGregor, N. (2015). North-South FDI and bilateral investment treaties. UNU-MERIT Working Paper No. 2015-010. Maastricht: United Nations University Maastricht Economic and Social Research Institute on Innovation and Technology.

Farrington, J., Ramasut, T., and Walker, J. (2002). Sustainable livelihoods approaches in urban areas: General lessons, with illustrations from Indian cases. ODI Working Paper No. 162. London: Overseas Development Institute.

Finkelstein, A. and McKnight, R. (2008). What did Medicare do? The Initial impact of Medicare on mortality and out of pocket medical spending. Journal of Public Economics, 92(7):1644-1668.

Frenk, J., Gómez-Dantés, O., and Knaul, F. (2009). The Democratization of health in Mexico: Financial innovations for universal coverage. Bulletin of the World Health Organization, 87(7):542-548.

Gallego, J. and Mendola, M. (2013). Labour migration and social networks participation in southern Mozambique. Economica, 80(320):721-759.

Gardner, A. (2011). Gulf migration and the family. Journal of Arabian Studies, 1(1):3-25.

Garthwaite, C., Gross, T., and Notowidigdo, M. (2014). Public health insurance, labor supply, and employment lock. Quarterly Journal of Economics, 129(2):653-696.

Ghanem, H. (2013). The Role of micro and small enterprises in Egypt's economic transition. Global Economy \& Development Working Paper No. 55.

Gibson, J. and McKenzie, D. (2012). The Economic consequences of brain drain of the best and brightest: Microeconomic evidence from five countries. Economic Journal, 122(560):339-375.

Gibson, J., McKenzie, D., and Stillman, S. (2011). The Impacts of international migration on remaining household members: Omnibus results from a migration lottery program. Review of Economics and Statistics, 93(4):1297-1318.

Giulietti, C., Wahba, J., and Zimmermann, K. (2013). Entrepreneurship of the left behind. Research in Labor Economics, 37:65-92.

Greenwood, M. and McDowell, J. (2011). USA immigration policy, source-country social programs, and the skill composition of legal USA immigration. Journal of Population Economics, 24(2):521-539.

Gruber, J. and Madrian, B. (1994). Health insurance and job mobility: The Effects of public policy on job-lock. Industrial and Labor Relations Review, 48(1):86-102.

Gruber, J. and Simon, K. (2008). Crowd-out 10 years later: Have recent public insurance expansions crowded out private health insurance? Journal of Health Economics, 27(2):201217.

Gubert, F. and Nordman, C. (2011). Return migration and small enterprise development in the Maghreb. In Plaza, S. and Ratha, D., editors, Diaspora for Development in Africa, pages 103-126. Washington, D.C.: World Bank Group.

Hagen-Zanker, J. and Leon-Himmelstine, C. (2013). What do we know about the impact of social protection programmes on the decision to migrate? Migration and Development, 2(1):117-131.

Harris, J. and Todaro, M. (1970). Migration, unemployment and development: A Two-sector analysis. American Economic Review, 60(1):126-142.

Haushofer, J., Chemin, M., Jang, C., and Abraham, J. (2017). Peace of Mind: Health insurance reduces stress and cortisol levels. Evidence from a randomized experiment in Kenya. Mimeo. 
Herfindahl, O. (1950). Concentration in the U.S. steel industry. Unpublished doctoral dissertation. Columbia University.

Hessels, J., Brixy, U., Naudé, W., and Gries, T. (2014). Skill variety, innovation and new business formation. IZA Working Paper No. 7889. Bonn: Institute for the Study of Labor.

Hirschman, A. (1964). The Paternity of an index. American Economic Review, 54(5):761-762.

Inder, B. and Maitra, P. (2004). Social pensions, migration and household composition: Evidence from South Africa. In Sheen, J., editor, Program and Abstract Book: Proceedings of the Economic Society of Autralia's 33rd Conference of Economists 2004, pages 1-42. www.ecosoc.ord.au/ace2004: The Economic Society of Australia.

International Bank for Reconstruction and Development and World Bank (2014). Kyrgyzstan country profile 2013: Enterprise survey. Washington, D.C.: World Bank Group.

Jamison, D., Summers, L., Alleyne, G., Arrow, K., Berkley, S., Binagwaho, A., Bustreo, F., Evans, D., Feachem, R., and Frenk, J. (2013). Global health 2035: A World converging within a generation. The Lancet, 382(9908):1898-1955.

Jasso, G., Massey, D. S., Rosenzweig, M. R., and Smith, J. P. (2004). Immigrant health: Selectivity and acculturation. In Anderson, N. B., Bulatao, R. A., and Cohen, B., editors, Critical Perspectives on Racial and Ethnic Differences in Health in Late Life, chapter 7, pages 227-266. Washington, D.C.: National Academy Press.

Jovanovic, B. (1979). Job matching and the theory of turnover. Journal of Political Economy, 87(5):972-990.

Kaestner, R. and Malamud, O. (2014). Self-selection and international migration: New evidence from Mexico. Review of Economics and Statistics, 96(1):78-91.

Karymshakov, K. and Sulaimanova, B. (2017). Migration impact on left-behind women's labour participation and time-use: Evidence from Kyrgyzstan. UNU-WIDER Working Paper Series No. 119. Helsinki: United Nations University World Institute for Development Economic Research.

Keeble, D. and Hauser, D. (1971). Spatial analysis of manufacturing growth in outer South-East England 1960-1967. Regional Studies, 5(4):229-262.

Kilic, T., Calogero, C., Davis, B., and Zezza, A. (2009). Investing back home: Return migration and business ownership in Albania. Economics of Transition, 17(3):587-623.

King, R. (2012). Theories and typologies of migration: An Overview and a primer. Willy Brandt Series of Working Papers in International Migration and Ethnic Relations No. 3/12. Malmo: Malmo Institute for Studies of Migration Diversity and Welfare.

Knaul, F., Frenk, J., Gonzalez-Pier, E., Gomez-Dantes, O., and Lezana, M. (2006). Comprehensive reform to improve health system performance in Mexico. The Lancet, 9546(368):1524-1934.

Koelle, M. (2016). Firm dynamics and occupational choice. Number E20-V2 in Beiträge zur Jahrestagung des Vereins für Socialpolitik 2016: Demographischer Wandel - Session: Labor Economics: Theory, Kiel und Hamburg. ZBW - Deutsche Zentralbibliothek für Wirtschaftswissenschaften, Leibniz-Informationszentrum Wirtschaft.

Koellinger, P. and Thurik, A. (2012). Entrepreneurship and the business cycle. Review of Economics and Statistics, 94(4):1143-1156.

Kondo, A. and Shigeoka, H. (2013). Effects of universal health insurance on health care utilization, and supply-side responses: Evidence from Japan. Journal of Public Economics, 99(C):1-23.

Laband, D. and Lentz, B. (1983). Like father, like son: Toward an economic theory of occupational following. Southern Economic Journal, 50(2):474-493.

Lazear, E. P. (2005). Entrepreneurship. Journal of Labor Economics, 24(4):649-680.

Lazear, E. P. and Gibbs, M. (2010). Personnel Economics in Practice, 2nd Edition. Hoboken, N.J.: John Wiley And Sons Limited. 
Lechmann, D. and Schnabel, C. (2014). Are the self-employed really jacks-of-all-trades? Testing the assumptions and implications of Lazear's theory of entrepreneurship with German data. Small Business Economics, 42(1):59-76.

Levy, S. and Schady, N. (2013). Latin America's social policy challenge: Education, social insurance, redistribution. Journal of Economic Perspectives, 27(2):193-218.

Lewis, W. (1954). Economic development with unlimited supplies of labour. Manchester School of Economic and Social Studies, 22(2):139-191.

Limwattananon, S., Neelsen, S., O'Donnell, O., Prakongsai, P., Tangcharoensathien, V., van Doorslaer, E., and Vongmongkol, V. (2015). Universal coverage with supply-side reform: The Impact on medical expenditure risk and utilization in Thailand. Journal of Public Economics, 121(C):79-94.

Lucas, R. (2008). International migration and economic development: Lessons from low-income countries. London, U.K.: Edward Elgar Publishing Edward Elgar Publishing Limited.

Mafukidze, J. (2006). A Discussion of migration and migration patterns and flows in Africa. In Views on Migration in Sub-Saharan Africa: Proceedings of An African Migration Alliance Workshop, pages 103-29. C. cross, and d. gelderblom, n. roux, and j. mafukidze edition.

Mansuri, G. (2007). Does work migration spur investment in origin communities? Entrepreneurship, schooling and child health in rural Pakistan. In Özden, C. and Schiff, M., editors, International migration, economic development and policy, pages 99-140. Washington, D.C.: World Bank Group.

Marchetta, F. (2012). Return migration and the survival of entrepreneurial activities in Egypt. World Development, 40(10):1999-2013.

McCormick, B. and Wahba, J. (2001). Overseas work experience, savings and entrepreneurship amamong return migrants to LDCs. Scottish Journal of Political Economy, 48(2):164-78.

McMillan, J. and Woodruff, C. (2002). The Central role of entrepreneurs in transition economies. Journal of Economic Perspectives, 16(3):153-170.

Mesnard, A. (2004). Temporary migration and capital market imperfections. Oxford Economic Papers, 56(2):242-262.

Moffitt, R. (1992). Incentive effects of the U.S. welfare system: A Review. Journal of Economic Literature, 30(1):1-61.

Morsy, H., Levy, A., and Sanchez, C. (2014). Growing without changing: A Tale of Egypt's weak productivity growth. EBRD Working Paper No. 172. London, U.K.: European Bank for Reconstruction and Development.

Morten, M. (2016). Temporary migration and endogenous risk sharing in village India. NBER Working Paper No. 22159. Cambridge, M.A.: National Bureau of Economic Research.

Nagler, P. (2015). Occupational Choice in the Developing World. PhD thesis, Maastricht University and United Nations University. Maastricht: Boekenplan.

Naudé, W., Siegel, S., and Marchand, K. (2017). Migration, entrepreneurship and development: Critical questions. IZA Journal of Migration, 6(5).

Nelson, P. (1970). Information and consumer behavior. Journal of Political Economy, 78(2):311329.

Obukhova, E., Wang, Y., and Li, J. (2012). The Power of local networks: Returnee entrepreneurs, school ties, and firm performance. Mimeo.

Organisation for Economic Co-operation and Development (2010). Entrepreneurship and migrants. Report by the OECD Working Party on SMEs and Entrepreneurship. Paris: Organisation for Economic Co-operation and Development.

Orrenius, P. (2001). Illegal immigration and enforcement along the U.S.-Mexico border: An Overview. Federal Reserve Bank of Dallas Economic and Financial Review, pages 2-11.

Orrenius, P. and Zavodny, M. (2005). Self-selection among undocumented immigrants from Mexico. Journal of Development Economic, 78(1):215-240. 
Palan, N. (2010). Measurement of specialization: The Choice of indices. FIW Working Paper No. 62. Vienna: Forschungsschwerpunkt Internationale Wirtschaft.

Parker, S. (2008). Entrepreneurship among married couples in the United States: A Simultaneous probit approach. Labour Economics, 15(3):459-481.

Paxson, C. and Schady, N. (2004). Child health and economic crisis in Peru. World Bank Policy Research Working Paper Series No. 3260. Washington, D.C.: World Bank Group.

Paxson, C. and Schady, N. (2007). Cognitive development among young children in Ecuador: The Roles of wealth, health and parenting. Journal of Human Resources, 42(1):49-84.

Pfutze, T. (2015). Does access to health insurance reduce the risk of miscarriages? Evidence from Mexico's Seguro Popular. Latin American Economic Review, 24(8).

Pimienta-Lastra, R., Vera-Bolaos, M., Shea, M., and Gutiérrez-Cárdenas, E. (2012). Internal migration in Mexico in the year 2000. Perspectivas Sociales, 13(2).

Piore, M. (1979). Birds of passage: Migrant labour and industrial societies. Cambridge, U.K.: Cambridge University Press.

Piracha, M. and Vadean, F. (2010). Return migration and occupational choice: Evidence from Albania. World Development, 38(8):1141-1155.

Portes, A. (2006). Migration and development: A Conceptual review of the evidence. Center for Migration and Development Working Paper No. 6-\%. Princeton, N.J.: Princeton University.

Posel, D., Fairburn, J., and Lund, F. (2006). Labour migration and households: A Reconsideration of the effects of the social pension on labour supply in South Africa. Economic Modelling, 23(5):836-853.

Ranis, G. and Fei, J. (1961). A Theory of economic development. American Economic Review, 51(4):533-565.

Rapoport, H. and Docquier, F. (2006). The Economics of migrants' remittances. In Kolm, S. and Ythier, J., editors, Handbook on the Economics of Giving, Reciprocity and Altruism, volume 2, chapter 17, pages 1135-1198. Amsterdam, Netherlands: Elsevier.

Ravallion, M. (2003). Targeted transfers in poor countries: Revisiting the trade-offs and policy options. Social Protection Discussion Paper series No. 0314. Washington, D.C.: World Bank Group.

Reardon, T., Berdegu, J., Barrett, C., and Stamoulis, K. (2006). Household income diversification into rural nonfarm activities. In Haggblade, S., Hazell, P., and Reardon, T., editors, Transforming the Rural Nonfarm Economy, chapter 8. Baltimore, M.D.: John Hopkins University Press.

Rudaz, P. (2017). The State of MSME development in Kyrgyzstan. UNCTAD Working Paper Series on Informal Markets and Trade No. 3. Geneva: United Nations Conference on Trade and Development.

Sabates-Wheeler, R. and Waite, M. (2003). Migration and social protection: A Concept paper. Development Research Centre on Migration, Globalisation and Poverty Working Paper No. T2. Falmer: University of Sussex.

Sadania, C. (2017). Working and women's empowerment in the Egyptian household: The Type of work and location matter. AMSE Working Paper 2017 No. 22. Marseille: Aix-Marseille School of Economics.

Satterthwaite, D. (1997). Urban poverty: Reconsidering its scale and nature. IDS Bulletin, $28(2): 923$.

Serra, R. (2009). Gender and occupational choices in Africa: The Role of time poverty and associated risks. Paper presented at the FAO-IFAD-ILO Workshop on Gaps, trends and current research in gender dimensions of agricultural and rural employment: Differentiated pathways out of poverty, Rome, 31 March - 2 April.

Sienaert, A. (2008). The Labour supply effects of the South African state old age pension: Theory, evidence and implication. SALDRU Working Paper series No. 20. Cape Town: 
University of Cape Town.

Silva, O. (2007). The Jack-of-all-trades entrepreneur: Innate talent or acquired skill? Economics letters, 97(2):118-123.

Sosa-Rubi, S., Galarraga, O., and Harris, J. (2009). Heterogeneous impact of the 'Seguro Popular' program on the utilization of obstetrical services in Mexico, 2001-2006: A Multinomial probit model with a discrete endogenous variable. Journal of Health Economics, $28(1): 20-34$.

Stark, O. (2009). Reasons for remitting. World Economics, 10(3):147-158.

Stark, O. and Bloom, D. (1985). The New Economics of Labour Migration. American Economic Review, 75:173-178.

Stecklov, G., Winters, P., Stampini, M., and Davis, B. (2005). Do conditional cash transfers influence migration? A Study using experimental data from the Mexican PROGRESA program. Demography, 42:769-790.

Steinmayr, A. (2015). When a random sample is not random. Bounds on the effect of migration on household members left behind. Mimeo.

Storey, D. (1994). Understanding the Small Business Sector. Thomson Learning.

Stuetzer, M., Obschonka, M., E., and Schmitt-Rodermund (2013). Balanced skills among nascent entrepreneurs. Small Business Economics, 41(1):93-114.

Taylor, E. (1984). Egyptian migration and peasant wives. MERIP Reports, 124:3-10. Richmond, V.A.: Middle East Research and Information Project.

Taylor, J. and Lopez-Feldman, A. (2010). Does Migration Make Rural Households More Productive? Evidence from Mexico. Journal of Development Studies, 46(1):68-90.

The Diplomat (2015). Central Asia feels effects of Russian economic slowdown. [Accessed on 19/10/2017].

Thieme, S. (2014). Coming home? Patterns and characteristics of return migration in Kyrgyzstan. International Migration, 52(5):127-143.

Tuccio, M. and Wahba, J. (2015). Can I have permission to leave the house? Return migration and the transfer of gender norms. IZA Discussion Paper No. 9216. Bonn: Institute for the Study of Labor.

Valerio, A., Parton, B., and Robb, A. (2014). Entrepreneurship education and training pprogram around the world: Dimensions for success. Washington, D.C.: World Bank Group.

Vullnerati, J. and King, R. (2008). Does your granny eat grass? On mass migration, care drain and the fate of older people in rural Albania. Global Networks, 8(2):139-171.

Wagstaff, A. and Lindelow, M. (2008). Can insurance increase financial risk? The Curious case of health insurance in China. Journal of Health Economics, 27(4):990-1005.

Wahba, J. (2009). An Overview of internal and international migration in Egypt. In Assaad, R., editor, Egypt's labor market revisited, chapter 5. Cairo: The American University in Cairo Press.

Wahba, J. (2014). Through the keyhole: International migration in Egypt. ERF Working Paper No. 830. Giza: Economic Research Forum.

Wahba, J. (2015). Selection, selection, selection: The Impact of return migration. Journal of Population Economics, 28(3):535-563.

Wahba, J. and Zenou, Y. (2012). Out of sight, out of mind: Migration, entrepreneurship and social capital. Regional Science and Urban Economics, 42:890-903.

White, N. and Wolaver, A. (2003). Occupation choice, information, and migration. Review of Regional Studies, 33(2):142-163.

Wooldridge, J. (2005). Simple solutions to the initial conditions problem in dynamic, nonlinear panel data models with unobserved heterogeneity. Journal of Applied Econometrics, 20(1):3954 . 
World Bank (2012). World Development Report 2012: Gender equality and development. Washington, D.C.: World Bank Group.

World Bank (2017). World Bank Gender Database. Available at http://data.worldbank.org/topic/gender [Accessed on 16/03/2017].

Wratten, E. (1995). Conceptualising urban poverty. Environment and Urbanisation, 7(1):11-38.

Zohry, A. (2009). The Development impact of internal migration: findings from Egypt. Paper presented at the 26th International Conference on Population, IUSSP, Marrakech, 27 Sep.-2 Oct. 



\section{Addendum on valorization}

This addendum on valorization is added in accordance with article 23.5 of the 'Regulation governing the attainment of doctoral degrees at Maastricht University' decreed by the 2013 resolution of the Board of Deans.

These Essays on Migration and Occupational Choice explore several aspects of the relationship between migration and occupational choice. Given the growing interest in migration as an economic and social phenomenon, its findings could be of interest to development, policymaking and research communities, in particular in low- and middle-income economies.

First, by showing that, beyond migration-induced wealth effects, the work experience gained abroad increases the likelihood of being self-employed through the development of entrepreneurial abilities, Chapter 2 informs entrepreneurship (education) policies in a low middle-income country context with high youth unemployment, a dynamic micro- and small enterprise (MSE) sector and significant (temporary) international migration. Chapter 2 finds that learning-by-doing and experiential learning matter for entering into and persisting in selfemployment. This is of relevance since the MSE sector is often thought of as a solution to (youth) unemployment, characteristic of developing and emerging economies. From Chapter 2 , it can be inferred that entrepreneurship support policies should focus on widening the work experience of potential entrepreneurs.

In contrast, by finding that, if migrants were self-employed before leaving, they are less likely to be self-employed upon return to their origin countries, and more likely to move to employed occupations, at least as soon as they return, Chapter 3 stresses that temporary migration might be more disruptive of self-employment trajectories than is often thought in a setting of transition from planned to market economy that lacks market-supporting institutions. The potential for return migration to stimulate entrepreneurship should thus not be overestimated, as it might not necessarily lead to sustaining a career in self-employment. This can however be seen in a positive light as this 'disruption' enables career development by offering an escape from necessity-driven self-employment; it reduces the number of low-ability self-employed. In this case, the appropriate policy response is to support swift occupational transitions to returnees' preferred options and their reintegration in origin country labour markets to avoid low-productivity entrepreneurship.

On the other hand, if migrants gained resources abroad, that self-employment is a rather temporary occupational choice suggests that the 'disruption' caused by migration may prevent an economy from benefiting from return migrants' experience as entrepreneurs. In this case, 
the appropriate policy response derived from Chapter 3 is to improve the conditions for doing business in source countries. In transition economies like Kyrgyzstan, temporary migration might substitute for an imperfect legal framework and weak financial markets, legacies of the Soviet era. Chapter 3 indicates that support for formal market-supporting institutions should be advised if countries are to harness the entrepreneurial acumen migrants might have developed abroad.

Third, Chapter 4 emphasises the occupational interdependence between spouses. Given the higher propensity of migrants to set up businesses upon return, return migrants might dispose over their wives' time for their own business purposes either directly, as unpaid workers, or indirectly, by working outside their households or in subsistence farming. As a result, they might disproportionately capture their wives' time. Attention should be paid to buffering possibly time-depriving effects on women induced by men's migration. If not, return migration might increase the time burden placed on women, and contribute to women's time poverty. Strengthening local labour markets could decrease the level of occupational interdependence between spouses by encouraging households to substitute women's family work with hired external labour, freeing up women's time.

Chapter 4 implies that, when planning to create a favourable environment for efficient income source diversification and women's empowerment in middle-income countries with strong segregation along gender lines, the effects of migration, within-couple occupational interdependence and gender-differentiated time allocation within households should be considered to offer women viable outside options, enhancing their autonomy, and for a more inclusive growth.

Fourth, financial and care constraints were found to prevent households from sending migrants. By freeing up working-age household members' time and strengthening household (economic) resilience in the face of health shocks, Chapter 5 suggests that accessing publicly provided healthcare alleviates financial and time constraints. As a result, non-contributory health insurance could enable labour force detachment of working-age members in affiliated households. Given the interest publicly provided healthcare has received as a means to alleviate poverty, these results are likely to be at the centre of the social policy and development debate. Chapter 5 contributes to this discussion by providing causal estimates of the impacts of a significant change in publicly provided healthcare on the propensity to migrate in an upper middle-income country with decreasing migration. The importance of taking into account effects on withinhousehold labour attachment, i.e. of including non-resident household members and household members who (might have) migrated in such analyses, has been highlighted; not accounting for the potential effects of social protection programmes on the likelihood to migrate might question the reliability of results obtained for labour market outcomes.

Moreover, by limiting the number and the length of health shocks, accessing healthcare (almost) for free increases disposable income and frees up (working-age) caregivers' time, enabling them to spatially reallocate their labour force, complementing alternative livelihood strategies, and further diversifying income sources. Non-contributory healthcare could thus have multiplier effects on economic development and welfare through migration by helping surmount financial 
and care constraints. Chapter 5 gives insights into what prevents migration, which is necessary to improve the design and target of migration policies, and to leverage the contribution of migration to the development of origin communities.

These Essays have offered original insights by questioning and refining existing thinking in the fields of economic development, labour, migration and social (health) protection. They have been published as working papers, freely available to the public. Analytical chapters are currently being reshaped to be submitted to academic journals. They have been presented in internal and external conferences, seminars and workshops attended by both academics and policy makers. These were fruitful opportunities to disseminate results and receive comments and suggestions. For instance, Chapter 2 has been presented at the first Workshop on Migration and the Labour Markets (2018, UK) and at the 29th European Association of Labour Economists (EALE) Conference (2017, Switzerland); Chapter 3 at the first IZA/World Bank/NJD Conference on Jobs and Development (2018, Colombia), the Inaugural Asian and Australasian Society of Labour Economists (AASLE) Conference (2017, Australia), the third IZA/DFID GLM-LIC Research Conference (2017, USA), the third Life in Kyrgyzstan (LiK) Conference (2017, Kyrgyzstan) and at the final TRANSMIC Conference (2017, Italy); Chapter 4 at the UNU-WIDER Development Conference on Migration and Mobility (2017, Ghana) and at the first UNU-MERIT Internal Conference (2017, Netherlands); and Chapter 5 at the 2018 Association for Public Policy Analysis \& Management (APPAM) International Conference (2018, Mexico), at Banco de México (2008, Mexico) and at the 32nd European Society for Population Economics (ESPE) Conference (2018, Belgium). 



\section{About the author}

Clotilde Mahé was born on June 3, 1990, in Colombes, France. After a childhood spent in francophone Africa and the Caribbean, she moved to Ermont, France, at the age of 16, where she completed high-school. Clotilde obtained a Bachelor's degree in Economics from Université Paris-Dauphine, France, and a Master's degree in Economic Development and Policy Analysis from the University of Nottingham, United Kingdom. Before joining Maastricht University as a PhD candidate funded under the European Union Marie Curie Initial Training Network 'Transnational Migration, Citizenship and the Circulation of Rights and Responsibilities' (TRANSMIC) in December 2014, she worked at Enda Tiers-Monde, a non-governmental organisation based in Dakar, Senegal, and at the Regional Office for Asia and the Pacific of the International Labour Organization (ILO) in Bangkok, Thailand. Clotilde's research has been presented in various conferences, seminars and workshops in West Africa, Central Asia, Europe, Latin America, North America and Oceania. 



\section{UNU-MERIT/MGSoG Dissertation Series}

2018

Clotilde Mahé

Essays on Migration and Occupational Choice UNU-MERIT/MGSoG Dissertation Series No. 206

\section{Simone Sasso}

Talent on the move. Essays on Human Capital, Graduate Mobility and Economic Development

UNU-MERIT/MGSoG Dissertation Series No. 205

\section{Khaled Walid Rajab}

Strategic Planning under Fragility UNU-MERIT/MGSoG Dissertation Series No. 204

Mutinta Hambayi Nseluke

A Tall Order: Improving Child Linear Growth UNU-MERIT/MGSoG Dissertation Series No. 203

\section{Elvis Korku Avenyo}

Innovations and Firm Performance in subSaharan Africa: Empirical Analyses UNU-MERIT/MGSoG Dissertation Series No. 202

\section{Ni Zhen}

Employment Dynamics, Firm Performance and Innovation Persistence in the Context of Differentiated Innovation Types: Evidence from Luxembourg UNU-MERIT/MGSoG Dissertation Series No. 201

\section{Caroline Wehner}

Too Scared to Achieve: The Relation

Between Neuroticism, Conscientiousness and Socioeconomic Outcomes UNU-MERIT/MGSoG Dissertation Series No. 200

\section{Stefania Innocenti}

On Institutional Persistence UNU-MERIT/MGSoG Dissertation Series No. 199

\section{Hassen Abda Wako}

Economic Globalization, Institutions and Development: Essays on Aid, Foreign Direct Investment and Trade

UNU-MERIT/MGSoG Dissertation Series No. 198

\section{7}

\section{Hans-Erik Edsand}

Winds of Change

UNU-MERIT/MGSoG Dissertation Series

No. 197

Ana Patricia Silva Vara Redressing the Gender Gap UNU-MERIT/MGSoG Dissertation Series No. 196

\section{Andrés Iván Mideros Mora}

Essays on the Economic Effects of Noncontributory Social Protection UNU-MERIT/MGSoG Dissertation Series No. 195 


\section{Tobias Broich}

New Actors in the Global Economy

UNU-MERIT/MGSoG Dissertation Series

No. 194

\section{Bernard Nikaj}

From No-government to E-government UNU-MERIT/MGSoG Dissertation Series No. 193

\section{Ali Safarnejad}

Prioritizing the HIV Response

UNU-MERIT/MGSoG Dissertation Series

No. 192

\section{Clovis Freire}

Diversification and Structural Economic

Dynamics

UNU-MERIT/MGSoG Dissertation Series

No. 191

\section{Michael Verba}

Innovation and Knowledge Dynamics: Essays on the Knowledge Economy

UNU-MERIT/MGSoG Dissertation Series

No. 190

\section{Pui Hang Wong}

The Hearts and Minds in Conflict and Peace:

The Economics of Counterinsurgency and the

Psychology of Reconstruction

UNU-MERIT/MGSoG Dissertation Series

No. 189

\section{Brenda Yamba}

Schooling Despite All Odds: Evidence from

Lesotho on Female Child Carers who Stayed in School

UNU-MERIT/MGSoG Dissertation Series

No. 188

\section{Sheng Zhong}

Moving towards An Energy Efficient Future:

Essays on Energy Efficiency, Technology and

Development

UNU-MERIT/MGSoG Dissertation Series

No. 187

\section{Julieta Marotta}

Access to Justice and Legal Empowerment of
Victims of Domestic Violence through Legal

Organizations in the City of Buenos Aires: A Qualitative Empirical Legal Study

UNU-MERIT/MGSoG Dissertation Series

No. 186

\section{Andrea Franco-Correa}

On the Measurement of Multidimensional

Poverty as a Policy Tool: Empirical

Applications to Chile, Colombia, Ecuador and

Peru

UNU-MERIT/MGSoG Dissertation Series

No. 185

2016

\section{Yesuf Awel}

Insurance for Growth: Empirical Essays on Insurance Demand and Impacts in Africa UNU-MERIT Dissertation Series No. 108

\section{Tigist Mekonnen Melesse}

Grow More Food using Fewer Resources:

Agricultural Technology Adoption and

Innovation Practices for Inclusive and

Sustainable Development

UNU-MERIT Dissertation Series No. 107

\section{Eleni Yitbarek}

Getting Ahead or left Behind? Essays on Poverty Dynamics and Social Mobility in Africa

UNU-MERIT Dissertation Series No. 106

\section{Thuy Dieu Nguyen}

Firm-Level Theory and Evidence of

Corruption

UNU-MERIT Dissertation Series No. 105

\section{Raquel Tsukada Lehman}

Essays on Household Production with Labor-

Saving Technology

UNU-MERIT Dissertation Series No. 104

\section{Eva Barteková}

Multi-Problem Challenges for a Renewable

Future: Empirical Studies on Competitive

Disadvantages from Electricity Price

Differentials and Mineral Supply Risk in an

Open Economy

UNU-MERIT Dissertation Series No. 103 


\section{Jocelyn Olivari}

Entrepreneurial Traits and Innovation:

Evidence from Chile

UNU-MERIT Dissertation Series No. 102

\section{Muhammad Shafique}

Essays on the role of knowledge, RED, and

Technology-based Firms in the Evolution of

Socio-techno-economic System

UNU-MERIT Dissertation Series No. 101

\section{Serdar Türkeli}

Governance of Innovation Policy: Empirical

Studies on Applied Political Economy by Multi-

Methods Analysis

UNU-MERIT Dissertation Series No. 100

\section{Ayokunu Adedokun}

Pathways to Sustainable Peace building in

Divided Societies: Lessons and Experiences

from Mozambique

MGSoG Dissertation Series No. 75

\section{Luiz Rothier Bautzer}

Organizing Concurrent Engineering through

ICT Platforms - Blueprinting Product

Lifecycle Management Platforms across

Disciplinary Agencies

MGSoG Dissertation Series No. 74

\section{Natalia Popova}

Migration in the Periphery of the European Union: Determinants of Successful and Sustainable Labour Market Integration of Return Migrants in Albania, Egypt, Moldova and Tunisia

MGSoG Dissertations Series No. 73

\section{Richard A. Martina}

Uncertainty and Resource Constraint in the

Small Island Developing States: Essays in

Entrepreneurial Cognition

MGSoG Dissertations Series No. 72

\section{Cécile Cherrier}

The Expansion of Basic Social Protection in Low-income Countries: An Analysis of Foreign Aid Actors' Role in the Emergence of Social Transfers in sub-Saharan Africa

MGSoG Dissertations Series No. 71

\section{Paul Caldron}

The Tacit Bargain in Short-Term Medical

Missions: Why U.S. physicians go and what it costs

MGSoG Dissertation Series No. 70

\section{Mahmut Kobal}

Customs \& Excellence: A Comparative

Approach on Administrative and Regulatory

Compliance Perspectives of the EU-Turkey

Customs Union

MGSoG Dissertation Series No. 69

\section{Craig Loschmann}

Essays on Conflict-related Migration and Development in the Case of Afghanistan

MGSoG Dissertations Series No. 68

\section{Andrea Milan}

Rural Livelihoods, Location and Vulnerable Environments: Approaches to Migration in Mountain areas of Latin America

MGSoG Dissertation Series No. 67

\section{Farida Lada}

On Guarding the Welfare of Clinical Trial Subjects While Promoting Novel Drug Innovation - A Game Theoretical Approach MGSoG Dissertation Series No. 66

2015

\section{Hibret Belete Maemir}

Dissecting Aggregate Productivity: International Integration and Growth with Heterogeneous Firms

UNU-MERIT Dissertation Series No. 96

\section{Giorgio Triulzi}

Looking for the Right Path: Technology

Dynamics, Inventive Strategies and Catchingup in the Semiconductor Industry UNU-MERIT Dissertation Series No. 95

\section{Abdul Baseer Qazi}

Knowledge flows and networks in the ICT sector: The case of Pakistan

UNU-MERIT Dissertation Series No. 94

\section{Ajay Thutupalli}


Technology Paradigm Shifts in Agriculture: Drivers of Sustainability and Catch up UNU-MERIT Dissertation Series No. 93

\section{Eduardo Urias}

Improving access to HIV/AIDS treatment in Brazil: When are Compulsory Licenses effective in Price Negotiations?

UNU-MERIT Dissertation Series No. 92

\section{Francesca Guadagno}

Why have so few Countries Industrialised? UNU-MERIT Dissertation Series No. 91

\section{Daniel Opolot}

The Evolution of Beliefs and Strategic Behaviour

UNU-MERIT Dissertation Series No. 90

\section{Alejandro Lavopa}

Structural Transformation and Economic Development: Can Development Traps be Avoided UNU-MERIT Dissertation Series No. 89

\section{Jinjin Zhao}

Urban water management reform: The Case of China

UNU-MERIT Dissertation Series No. 88

\section{Simona Vezzoli}

Borders, Independence and Post-colonial Ties: the Role of the State in Caribbean Migration

MGSoG Dissertation Series No. 65

\section{Silvia Consuelo Gómez Soler}

Civil Conflict and Education: How Does Exposure to Civil Conflict Affect Human Capital Accumulation? Evidence from Standardized Exit Exams in Colombia MGSoG Dissertation Series No. 64

\section{Paula Nagler}

Occupational Choice in the Developing World MGSoG Dissertation Series No. 63

\section{Jasmin Kientzel}

Determinants of Professional Commitment to Environmental Sustainability

MGSoG Dissertation Series No. 62

\section{Mehmet Güney Celbiş}

Regional Policies: Convergence, Trade, and the Allocation of Public Capital

MGSoG Dissertation Series No. 61

\section{Florian Henning}

Living Up to Standard: Interoperability

Governance and Standards Adoption in

Government Information Networks

MGSoG Dissertation Series No. 60

\section{Niels P. Groen}

The Never-Ending Project - Understanding EGovernment Project Escalation

MGSoG Dissertation Series No. 59

\section{Derek Copp}

Teacher-Based Reactivity to Provincial Largescale Assessment in Canada

MGSoG Dissertation Series No. 58

\section{Michaella Vanore}

Family-Member Migration and the Psychosocial Health Outcomes of Children in Moldova and Georgia

MGSoG Dissertation Series No. 57

\section{Sonja Fransen}

The Economic and Social Effects of Remittances and Return Migration in ConflictAffected Areas: The Case of Burundi

MGSoG Dissertation Series No. 56

\section{Ibrahim Khalil Conteh}

The Impact of Floods on Primary School

Education in Zambia

MGSoG Dissertation Series No. 55

\section{Richard Bluhm}

Growth Dynamics and Development -

Essays in Applied Econometrics and Political Economy

MGSoG Dissertation Series No. 54

\section{Nevena P. Zhelyazkova}

Work-Family Reconciliation and Use of Parental Leave in Luxembourg: Empirical Analysis of Administrative Records MGSoG Dissertation Series No. 53 


\section{Dirk Crass}

The Impact of Brands on Innovation and Firm Performance: Empirical Evidence from Germany

UNU-MERIT Dissertation Series No. 87

\section{Samyukta Bhupatiraju}

The Geographic Dimensions of Growth and Development

UNU-MERIT Dissertation Series No. 86

\section{François Lafond}

The Evolution of Knowledge Systems

UNU-MERIT Dissertation Series No. 85

\section{Annalisa Primi}

Promoting Innovation in Latin America: What Countries Have Learned (and What They Have Not) in Designing and Implementing Innovation and Intellectual Property Policies UNU-MERIT Dissertation Series No. 84

\section{Fatoumata Lamarana Diallo}

Evaluation of Meal and Deworming Programs for Primary Schools in Rural Senegal UNU-MERIT Dissertation Series No. 83

\section{Sachin Kumar Badkas}

Metachoice and Metadata: Innovating with Environmental Policy Analysis in Europe MGSoG Dissertation Series No. 52

\section{Irina S. Burlacu}

An Evaluation of Tax-Benefit Systems Impact on the Welfare of Frontier Worker: The Case of Luxembourg and Belgium

MGSoG Dissertation Series No. 51

\section{Özge Bilgili}

Simultaneity in Transnational Migration

Research: Links Between Migrants' Host and

Home Country Orientation

MGSoG Dissertation Series No. 50

\section{Yulia Privalova Krieger}

Reshaping the Big Agenda: Transnational Politics and Domestic Resistance Financial crisis and social protection reform in Bosnia and Herzegovina

\section{Marieke van Houte}

Moving Back or Moving Forward? Return migration after Conflict

MGSoG Dissertation Series No. 48

\section{Oxana Slobozhan}

Global Governance in the Management of Natural Resources: The Case of the Extractive Industries Transparency Initiative (EITI)

MGSoG Dissertation Series No. 47

\section{Luis Bernardo Mejia Guinand}

The Changing Role of the Central Planning Offices in Latin America: A Comparative Historical Analysis Perspective (1950-2013) MGSoG Dissertation Series No. 46

\section{Cheng Boon Ong}

Ethnic Segregation in Housing, Schools and

Neighbourhoods in the Netherlands

MGSoG Dissertation Series No. 45

Luciana V. Cingolani

Bureaucracies for Development: Oxymoron or Reality? Studies on State Capacity in Challenging Governance Contexts MGSoG Dissertation Series No. 44

\section{Carlos Cadena Gaitán}

Green Politics in Latin American Cities Sustainable Transport Agendas

MGSoG Dissertation Series No. 43

\section{Katie Kuschminder}

Female Return Migration and Reintegration Strategies in Ethiopia

MGSoG Dissertation Series No. 42

Metka Hercog

Highly-Skilled Migration and New Destination

Countries

MGSoG Dissertation Series No. 41

\section{Margaret Agaba Rugadya}

Can Remittances Influence the Tenure and Quality of Housing in Uganda?

MGSoG Dissertation Series No. 40 


\section{Ilire Agimi}

New Governance Under Limited Statehood: The Case of Local Government Reform in Kosovo

MGSoG Dissertation Series No. 39

\section{3}

\section{Anant Kamath}

Information Sharing through Informal Interaction in Low-Tech Clusters

UNU-MERIT Dissertation Series No. 82

\section{Flavia Pereira de Carvalho}

What we talk about when we talk about Brazilian Multinationals: An Investigation on Brazilian FDI, Economic Structure, Innovation and the Relationship between them UNU-MERIT Dissertation Series No. 81

\section{Jun Hou}

Complementarity in Innovation and Development: A Cross-country Comparison UNU-MERIT Dissertation Series No. 80

\section{Rufin Baghana}

Impacts of Government Incentives to RED, Innovation and Productivity: A Microeconometric Analysis of the Québec Case UNU-MERIT Dissertation Series No. 79

\section{Lilia I. Stubrin}

High-Tech Activities in Emerging Countries: A Network perspective on the Argentinean Biotech Activity UNU-MERIT/MGSoG Dissertation Series No. 78

\section{Kristine Farla}

Empirical Studies on Institutions, Policies and Economic Development MGSoG Dissertation Series No. 38

\section{Marina Petrovic}

Social Assistance and Activation in the Pursuit of Happiness: Shedding New Light on Old Policy Solutions to Social Exclusion MGSoG Dissertation Series No. 37

\section{Laura Torvinen}

Assessing Governance Assessments: The Case of Mozambique: Governance Assessments in the Context of Aid Effectiveness Discourse MGSoG Dissertation Series No. 36

\section{Biniam Egu Bedasso}

Institutional Change in the Long Shadow of Elite: Essays on Institutions, Human Capital and Ethnicity in Developing Countries MGSoG Dissertation Series No. 35

\section{Sepideh Yousefzadeh Faal Deghati} Childhoods Embargoed: Constructing and Reconstructing Multidimensional Child Poverty in Iran 1984-2009

MGSoG Dissertation Series No. 34

\section{Robert Bauchmüller}

Investing in Early Childhood Care and Education: The Impact of Quality on Inequality MGSoG Dissertation Series No. 33

\section{Martin Rehm}

Unified Yet Separated: Empirical Study on the Impact of Hierarchical Positions within Communities of Learning

MGSoG Dissertation Series No. 32

\section{2}

\section{Abdul Waheed}

Innovation Determinants and Innovation as a Determinant: Evidence from Developing Countries UNU-MERIT Dissertation Series No. 77

\section{Bilal Mirza}

Energy Poverty and Rural Energy Markets in Pakistan

UNU-MERIT Dissertation Series No. 76

Benjamin Engelstätter

Enterprise Software and Video Games: An Empirical Analysis

UNU-MERIT Dissertation Series No. 75

\section{Fulvia Farinelli}

Natural Resources, Innovation and Export Growth: The Wine Industry in Chili and Argentina UNU-MERIT Dissertation Series 


\section{Rodolfo Lauterbach}

Innovation in Manufacturing: From Product

Variety and Labor Productivity Growth to

Economic Development in Chile

UNU-MERIT Dissertation Series

\section{Kirsten Wiebe}

Quantitative Assessment of Sustainable

Development and Growth in sub-Saharan

Africa

UNU-MERIT Dissertation Series No. 74

\section{Julio Miguel Rosa}

Organizational Strategies, Firms' Performance and Spatial Spillovers: The Canadian Case in Research and Development

UNU-MERIT Dissertation Series No. 73

Johannes Wilhelmus Marie Boels

Joseph Schumpeter, Honderd Jaar

Economische Ontwikkeling: Een Historisch-

theoretische Beschouwing.

UNU-MERIT Dissertation Series

\section{Dorcas Mbuvi}

Utility Reforms and Performance of the Urban

Water Sector in Africa

MGSoG Dissertation Series No. 31

\section{Lina Salanauskaite}

Distributional Impacts of Public Policies:

Essays in Ex-Ante and Ex-Post Evaluation

MGSoG Dissertation Series No. 30

\section{Esther Schüring}

To Condition or not - is that the Question? $A n$

Analysis of the Effectiveness of Ex-Ante and

Ex-Post Conditionality in Social Cash Transfer

Programs

MGSoG Dissertation Series No. 29

Joe Abah

Strong Organisations in Weak States: Atypical

Public Sector Performance in Dysfunctional

Environments

MGSoG Dissertation Series No. 28

Zina Samih Nimeh

Social Citizenship Rights: Inequality and
Exclusion

MGSoG Dissertation Series No. 27

\section{1}

\section{Daniel Vertesy}

Interrupted Innovation: Emerging Economies in the Structure of the Global Aerospace

Industry

UNU-MERIT Dissertation Series No. 72

\section{Tina Saebi}

Successfully Managing Alliance Portfolios:

An Alliance Capability View

UNU-MERIT Dissertation Series No. 71

\section{Nora Engel}

Tuberculosis in India: A Case of Innovation and Control

UNU-MERIT/MGSoG Dissertation Series No. 70

\section{Evans Mupela}

Connectivity and growth in sub-Saharan

Africa: The Role of Communication Satellites

UNU-MERIT Dissertation Series No. 69

\section{Nantawan Kwanjai}

Cross Cultural Intelligence amid Intricate

Cultural Webs: A Tale of the UnDutchables

in the Land of 1002 Smiles

UNU-MERIT Dissertation Series No. 68

\section{Lina Sonne}

Innovation in Finance to Finance Innovation: Supporting Pro-poor Entrepreneur-based

Innovation

UNU-MERIT Dissertation Series No. 67

\section{Lenka Eisenhamerová}

Legitimacy of 'Humanitarian Military

Intervention'

MGSoG Dissertation Series No. 26

\section{Sonila Tomini}

Informal Payments for Health Care Services in Albania

MGSoG Dissertation Series No. 25

\section{Jinjing Li}

Dynamic Microsimulation in Public Policy 
Evaluation

MGSoG Dissertation Series No. 24

\section{Aziz Atamanov}

Rural Nonfarm Employment and International Migration as Alternatives to Agricultural Employment: The Case of Kyrgyzstan MGSoG Dissertation Series No. 23

Frieda Vandeninden

Poverty Alleviation: Aid and Social Pensions

MGSoG Dissertation Series No. 22

\section{Juliana Nyasha Tirivayi}

The Welfare Effects of Integrating AIDS

Treatment with Food Transfers: Evidence from Zambia

MGSoG Dissertation Series No. 21

\section{Agnieska Ewa Sowa}

Who's Left Behind? Social Dimensions of Health Transition and Utilization of Medical Care in Poland

MGSoG Dissertation Series No. 20

\section{Emmanaouil Sfakianakis}

The Role of Private Actors in the Provision of Public Goods with Applications to Infrastructure and Financial Stability MGSoG Dissertation Series No. 19

\section{Siu Hing Lo}

White Collars Green Sleeves: An Interorganizational Comparison of Determinants of Energy-Related Behaviors among Office Workers

MGSoG Dissertation Series No. 18

\section{Treena $\mathbf{W u}$}

Constraints to Human Capital Investment in Developing Countries: Using the Asian Financial Crisis in Indonesia as a Natural Experiment

MGSoG Dissertation Series No. 17

\section{Henry Espinoza Pena}

Impact Evaluation of a Job-Training

Programme for Disadvantaged Youths: The Case of Projoven

MGSoG Dissertation Series No. 16

\section{0}

\section{Fernando Santiago}

Human Resources Management Practices

and Learning for Innovation in Developing

Countries: Pharmaceutical Firms in Mexico

UNU-MERIT Dissertation Series No. 66

\section{Zakaria Babutsidze}

Essays on Economies with Heterogeneous

Interacting Consumers

UNU-MERIT Dissertation Series No. 65

\section{Bertha Vallejo}

Learning and Innovation Under Changing

Market Conditions: The Auto Parts Industry in Mexico

UNU-MERIT Dissertation Series No. 64

\section{Donatus Ayitey}

Technical Change, Competitiveness and

Poverty Reduction: A Study of the Ghanaian

Apparel Industry

UNU-MERIT Dissertation Series No. 63

\section{Sergey Filippov}

Multinational subsidiary Evolution: Corporate Change in New EU Member States

UNU-MERIT Dissertation Series No. 62

\section{Asel Doranova}

Technology Transfer and Learning under the Kyoto Regime: Exploring the Technological Impact of CDM Projects in Developing Countries

UNU-MERIT Dissertation Series No. 61

\section{Florian Tomini}

Between Family and Friend: Understanding the Interdependency of Private Transfers MGSoG Dissertation Series No. 15

\section{Michał Polalowski}

The Institutional Transformation of Social Policy in East Central Europe: Poland and Hungary in Comparative and Historical Perspective

MGSoG Dissertation Series No. 14

Maha Ahmed

Defining, Measuring and Addressing 
Vulnerability: The Case of Post Conflict

Environments

MGSoG Dissertation Series No. 13

\section{Pascal Beckers}

Local Space and Economic Success: The Role of Spatial Segregation of Migrants in the

Netherlands

MGSoG Dissertation Series No. 12

\section{Victor Cebotari}

Conflicting Demands in Ethnically Diverse

Societies: Ethno-political Contention and

Identity Values in Europe

MGSoG Dissertation Series No. 11

\section{Dennis Gyllensporre}

Competing and Complementary Perspectives on the EU as a Crisis Management Actor:

An Examination of the Common Security and Defence Policy through the Lenses of Idealism and Realism

MGSoG Dissertation Series No. 10

\section{Judit Vall Castello}

Business Cycle and Policy Effects on Labour Market Transitions of Older and Disabled Workers in Spain

MGSoG Dissertation Series No. 9

\section{Keetie Roelen}

False Positives or Hidden Dimensions: The Definition and Measurement of Child Poverty MGSoG Dissertation Series No. 8

\section{Denisa Maria Sologon}

Earning Dynamics in Europe

MGSoG Dissertation Series No. 7

\section{Melissa Siegel}

Money and Mobility: Migration and

Remittances

MGSoG Dissertation Series No. 6

\section{Jessica S. Hagen-Zanker}

Modest Expectations: Causes and Effects of Migration on Migrant Households in Source Countries

MGSoG Dissertation Series No. 5
2009

\author{
Alexis Habiyaremye \\ From Primary Commodity Dependence to \\ Diversification and Growth: Absorptive \\ Capacity and Technological Catch Up in \\ Botswana and Mauritius. \\ UNU-MERIT Dissertation Series No. 60
}

\section{Yoseph Getachew}

The Role of Public Capital in Economic Development

UNU-MERIT Dissertation Series No. 59

\section{Sandra Leitner}

Embodied Technological Change and Patterns of Investment in Austrian Manufacturing UNU-MERIT Dissertation Series No. 58

\section{Semih Akçomak}

The Impact of Social Capital on Economic and Social Outcomes UNU-MERIT Dissertation Series No. 57

\section{Abraham Garcia \\ The Role of Demand in Technical Change UNU-MERIT Dissertation Series No. 56}

\section{Saurabh Arora}

Coherence in Socio-technical Systems: A Network Perspective on the Innovation Process UNU-MERIT Dissertation Series No. 55

\section{Mirtha R. Muniz Castillo}

Human Development and Autonomy in Project Aid: Experiences from four bilateral projects in Nicaragua and El Salvador

MGSoG Dissertation Series No. 4

\section{Christiane Arndt}

Governance Indicators

MGSoG Dissertation Series No. 3

\section{Britta Augsburg}

Microfinance: Greater Good or Lesser Evil?

MGSoG Dissertation Series No. 2

\section{8}

\section{Rutger Daems}

Medicines for the Developing World 
UNU-MERIT Dissertation Series No. 54

\section{Johannes Hanel}

Assessing Induced Technology: Sombart's Understanding of Technical Change in the History of Economics

UNU-MERIT Dissertation Series No. 53

\section{Rifka Weehuizen}

Mental Capital: the Economic Significance of Mental Health

UNU-MERIT Dissertation Series No. 52

\section{Danielle Cloodt}

The Relationship between RED Partnership Formation, Social Embeddedness and Innovative Performance

UNU-MERIT Dissertation Series No. 51

\section{Sabine Fuss}

Sustainable Energy Development under

Uncertainty

UNU-MERIT Dissertation Series No. 50

\section{Geranda Notten}

Measuring and Managing Poverty Risks

MGSoG Dissertation Series No. 1

\section{7}

\section{Tobias Kronenberg}

Reconciling Environmental Conservation with Economic Prosperity: The Feasibility of Double Dividends in the Short and Long Run UNU-MERIT Dissertation Series No. 49

\section{Viktoria Kravtsova}

Assessing the Impact of Foreign Direct Investment in Transition Economies UNU-MERIT Dissertation Series No. 48

\section{Suhail Sultan}

The Competitive Advantage of Small and Medium Sized Enterprises: The Case of Jordan's Natural Stone Industry UNU-MERIT Dissertation Series No. 47

\section{6}

\section{Bulat Sanditov}

Essays on Social Learning and Imitation
UNU-MERIT Dissertation Series No. 46

\section{Mamata Parhi}

Dynamics of New Technology Diffusion: A

Study of the Indian Automotive Industry

UNU-MERIT Dissertation Series No. 45

\section{Andreas Reinstaller}

Social Structures and the Innovation Process:

Their Role in the Demand of Firms and Consumers

UNU-MERIT Dissertation Series No. 44

\section{Rose Kiggundu}

Innovation systems and Development: The Journey of a Beleaguered Nile Perch Fishery in Uganda

UNU-MERIT Dissertation Series No. 43

\section{Thomas Pogue}

The Evolution of Research Collaboration in South African Gold Mining: 1886-1933

UNU-MERIT Dissertation Series No. 42

\section{Geoffrey Gachino}

Foreign Direct Investment, Spillovers and Innovation: The Case of Kenyan Manufacturing Industry UNU-MERIT Dissertation Series No. 41

\section{Önder Nomaler}

Technological Change, International Trade and Growth: An Evolutionary, Multi-Agents-Based Modeling Approach

UNU-MERIT Dissertation Series No. 40

\section{5}

\section{Samia Satti Osman Mohamed-Nour \\ Change and Skill Development in the Arab Gulf Countries \\ UNU-MERIT Dissertation Series No. 39}

\section{Elad Harison}

Intellectual Property Rights: Economics and Policy Analysis

UNU-MERIT Dissertation Series No. 38

\section{Daniel Dalohoun}

The Relationship between R\&D Partnership Formation, Social Embeddedness and 
Innovative Performance: a Multi-level Approach of Social Embeddedness

UNU-MERIT Dissertation Series No. 37

\section{Müge Ozman}

Networks, Organizations and Knowledge

UNU-MERIT Dissertation Series No. 36

\section{Bas Straathof}

Product Variety and Economic Growth:

The Counteracting Effects of Scale and

Idiosyncrasy

UNU-MERIT Dissertation Series No. 35

\section{Wilfred Schoenmakers}

Knowledge Flows between Multinational Companies: A Patent Data Analysis

UNU-MERIT Dissertation Series No. 34

\section{Myriam Cloodt}

Mergers and Acquisitions ( $M$ and As) in High-

Tech Industries: Measuring the Post- $M$ and $A$

Innovative Performance of Companies

UNU-MERIT Dissertation Series No. 33

\section{4}

\section{Paola Criscuolo}

RED Internationalisation and Knowledge

Transfer: Impact on MNEs and their Home Countries

UNU-MERIT Dissertation Series No. 32

\section{Maarten Verkerk}

Trust and Power on the Shop Floor

UNU-MERIT Dissertation Series No. 31

\section{Gottfried Leibbrandt}

Adoption, Harmonization and Succession of

Network Technologies across Countries

UNU-MERIT Dissertation Series No. 30

\section{Mark Sanders}

Skill Biased Technical change: Its Origins, the Interaction with the Labour Market and Policy Implications

UNU-MERIT Dissertation Series No. 29

2003

Nadine Roijakkers
Inter-firm Cooperation in High-tech

Industries: a Study of RED Partnerships in

Pharmaceutical Biotechnology

UNU-MERIT Dissertation Series No. 28

\section{Viki Sonntag}

Speed, Scale and Sustainability

UNU-MERIT Dissertation Series No. 27

Masaru Yarime

From End-of-Pipe Technology to Clean

Technology

UNU-MERIT Dissertation Series No. 26

\section{Stéphane Malo}

The Combinatorial Chemistry Revolution: Sustaining a Superior Performance Position through Technological Learning

UNU-MERIT Dissertation Series No. 25

\section{2}

\section{Annelies Hogenbirk}

Determinants of Inward Foreign Direct

Investment: the Case of the Netherlands

UNU-MERIT Dissertation Series No. 24

Bastiaan Johan terWeel

The Computerization of the Labour Market

UNU-MERIT Dissertation Series

2001

\section{John Adeoti}

Technology Investment in Pollution Control in sub-Saharan Africa: The Case of the Nigerian Manufacturing Industry

UNU-MERIT Dissertation Series No. 23

\section{Edward Huizenga}

Innovation Management: How Frontrunners

Stay Ahead: An Empirical Study on Key

Success Factors in the ICT sector

UNU-MERIT Dissertation Series No. 22

2000

\section{Machiel van Dijk}

Technological Change and the Dynamics of Industries: Theoretical Issues and Empirical Evidence from Dutch Manufacturing 
UNU-MERIT Dissertation Series No. 21

1999

\section{Jan Cobbenhagen}

Managing Innovation at the Company Level: A

Study on Non-Sector-Specific Success Factors

UNU-MERIT Dissertation Series No. 20

\section{Marjolein Caniëls}

Regional Growth Differentials: The Impact of Locally Bounded Knowledge Spillovers

UNU-MERIT Dissertation Series No. 19

1998

\section{Aldo Geuna}

Resource Allocation and Knowledge

Production: Studies in the Economics of

University Research

UNU-MERIT Dissertation Series No. 18

\section{6}

\section{Reinoud Joosten}

Dynamics, Equilibria, and Values

UNU-MERIT Dissertation Series No. 17

\section{Hugo Kruiniger}

Investment, REDD, and the Financing

Decisions of the Firm

UNU-MERIT Dissertation Series No. 16

1995

\section{Hans van Meijl}

Endogenous Technological Change: The

Case of Information Technology, Theoretical

Considerations and Empirical Results

UNU-MERIT Dissertation Series No. 15

\section{René Kemp}

Environmental Policy and Technical Change:

A Comparison of the Technological Impact of

Policy Instruments

UNU-MERIT Dissertation Series No. 14

\section{Rohini Acharya}

The Impact of New Technologies on Economic Growth and Trade: A Case Study of
Biotechnology

UNU-MERIT Dissertation Series No. 13

\section{Geert Duysters}

The Evolution of Complex Industrial Systems:

The Dynamics of Major IT Sectors

UNU-MERIT Dissertation Series No. 12

\section{Marjan Groen}

Technology, Work and Organisation: A Study of the Nursing Process in Intensive Care Units UNU-MERIT Dissertation Series No. 11

\section{4}

\section{Huub Meijers}

On the Diffusion of Technologies in a Vintage Framework: Theoretical Considerations and Empirical Results UNU-MERIT Dissertation Series No. 10

\section{Theon van Dijk}

The Limits of Patent Protection: Essays on the Economics of Intellectual Property Rights UNU-MERIT Dissertation Series No. 9

\section{Hans Voordijk}

Naar Integrale Logistiek in Bedrijfsketens:

Ontwikkelingen in de Bouw

UNU-MERIT Dissertation Series No. 8

\section{3}

\section{Paul Diederen}

Technological Progress in Enterprises and Diffusion of Innovation: Theoretical Reflections and Empirical Evidence UNU-MERIT Dissertation Series No. 7

\section{Ben Dankbaar}

Economic Crisis and Institutional Change:

The Crisis of Fordism from the Perspective of the Automobile Industry

UNU-MERIT Dissertation Series No. 6

\section{Hanno Roberts}

Accountability and Responsibility: The Influence of Organisation Design on Management Accounting

UNU-MERIT Dissertation Series No. 5 
1992

\section{Bart Verspagen}

Uneven Growth between Interdependent

Economies: An Evolutionary View on

Technology Gaps, Trade and Growth

UNU-MERIT Dissertation Series No. 4

\section{Sjoerd Romme}

A Self-organization Perspective on Strategy

Formation

UNU-MERIT Dissertation Series No. 3
John Spangenberg

Economies of Scale, and Atmosphere in Research Organisations

UNU-MERIT Dissertation Series No. 2

\section{8}

\section{John Hagedoorn}

Evolutionary and Heterodox Innovation Analysis: A Study of Industrial and Technological Development in Process Control and Information Technology

UNU-MERIT Dissertation Series No. 1

1989 
